\title{
Máximazing the quality of perioperative patient counselling
}

Citation for published version (APA):

Leclercq, W. K. G. (2021). Máximazing the quality of perioperative patient counselling: Surgical informed consent and postoperative e-health in present day surgical care. [Doctoral Thesis, Maastricht University]. Maastricht University. https://doi.org/10.26481/dis.20210924wl

Document status and date:

Published: 01/01/2021

DOI:

10.26481/dis.20210924wl

Document Version:

Publisher's PDF, also known as Version of record

\section{Please check the document version of this publication:}

- A submitted manuscript is the version of the article upon submission and before peer-review. There can be important differences between the submitted version and the official published version of record.

People interested in the research are advised to contact the author for the final version of the publication, or visit the DOI to the publisher's website.

- The final author version and the galley proof are versions of the publication after peer review.

- The final published version features the final layout of the paper including the volume, issue and page numbers.

Link to publication

\footnotetext{
General rights rights.

- You may freely distribute the URL identifying the publication in the public portal. please follow below link for the End User Agreement:

www.umlib.nl/taverne-license

Take down policy

If you believe that this document breaches copyright please contact us at:

repository@maastrichtuniversity.nl

providing details and we will investigate your claim.
}

Copyright and moral rights for the publications made accessible in the public portal are retained by the authors and/or other copyright owners and it is a condition of accessing publications that users recognise and abide by the legal requirements associated with these

- Users may download and print one copy of any publication from the public portal for the purpose of private study or research.

- You may not further distribute the material or use it for any profit-making activity or commercial gain

If the publication is distributed under the terms of Article $25 \mathrm{fa}$ of the Dutch Copyright Act, indicated by the "Taverne" license above, 

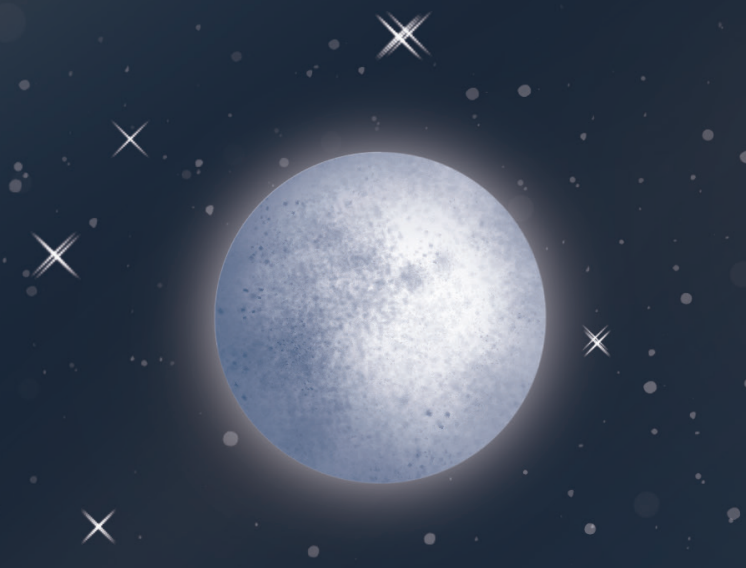

$\because$

\section{X}

\section{Máximizing the quality of}

\section{perioperative patient counselling}

$x$

Surgical informed consent and postoperative e-health in present day surgical care

\section{Woute̊r K.G. Leclèrcq}

\section{$x$}
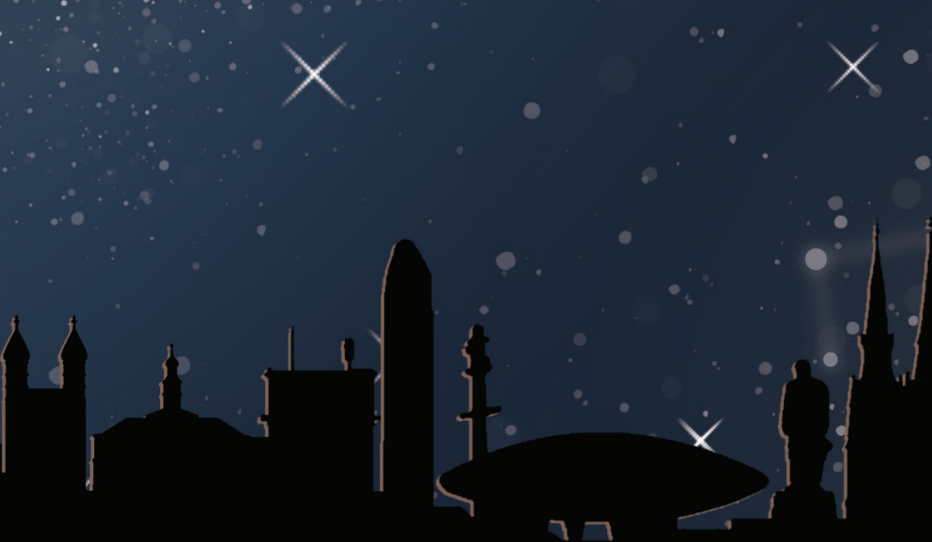



\section{Máximizing the quality of}

perioperative patient counselling

Surgical informed consent and

postoperative e-health in present day surgical care

Wouter K.G. Leclercq 


\section{Colofon}

Copyright Wouter K.G. Leclercq, Maastricht 2021

All rights reserved. No part of this thesis may be reproduced or transmitted in any form or by any means, without prior permission in writing by the author, or when appropriate, by the publishers of the publications.

ISBN: 978-94-6416-722-1

Cover design and layout: (c) evelienjagtman.com

Printed by: Ridderprint | www.ridderprint.nl

Editing: Tiny Wouters 


\section{Máximizing the quality of \\ perioperative patient counselling \\ Surgical informed consent and \\ postoperative e-health in present day surgical care}

Proefschrift

Ter verkrijging van de graad van doctor aan de Universiteit Maastricht,

Op gezag van Rector Magnificus, Prof. dr. Rianne M. Letschert

Volgens het besluit van het College van Decanen,

in het openbaar te verdedigen op

vrijdag 24 september 2021 om 10.00 uur

door

Wouter Karel Gerard Leclercq

Geboren op 13 oktober 1978

te Gouda 


\section{Promotores}

Prof. dr. L.P.S. Stassen

Prof. mr. J. Legemaate

\section{Copromotor}

Dr. M.R.M. Scheltinga

\section{Beoordelingscommissie}

Prof. dr. I.H.J.T. de Hingh

Prof. dr. C.H.C. Dejong

Dr. J.H. Zwaveling

Dr. mr. E. Pans, Vrije Universiteit Amsterdam 
In herinnering aan Wim Zwiers

Uroloog Máxima MC, gezondheidsrecht advocaat èn mentor

Voor mijn patiënten èn collega's 



\section{TABLE OF CONTENTS}

Chapter 1 General Introduction and outline of thesis 9

Part I Preoperative counselling and surgical informed consent

Chapter 2 A review of surgical informed consent: Past, present, and future. 19

A quest to help patients make better decisions

Chapter 3 A survey of the current practice of the informed consent process

in general surgery in the Netherlands

Chapter 4 Challenging the knowledge base and skillset for providing surgical consent by orthopedic and plastic surgeons in the Netherlands: An identified area of improvement in patient safety

Chapter 5 Preoperative education and informed consent in young adults undergoing bariatric surgery: Patient perspectives on current practice

Chapter 6 Insight in information provision prior to obtaining surgical informed consent by audiotaping outpatient consultations

Chapter 7 Shared decision making and surgical informed consent in general surgery: A pilot study on differences in perspectives of physicians and patients

Chapter 8 A decade of litigation regarding surgical informed consent in the Netherlands

Chapter 9 Preoperative medical record-keeping can be improved: New informed consent form assists both physicians and patients

\section{Part II Postoperative counselling and e-health}

Chapter 10 Personalised perioperative care by e-health after intermediategrade abdominal surgery: A multicentre, single-blind, randomised, placebo-controlled trial

Chapter 11 Summarizing discussion and conclusions

Chapter 12 Future perspectives

Chapter 13 Samenvatting

Chapter 14 Impact paragraph

\section{Appendix}

Dankwoord

List of publications 
$x$ 

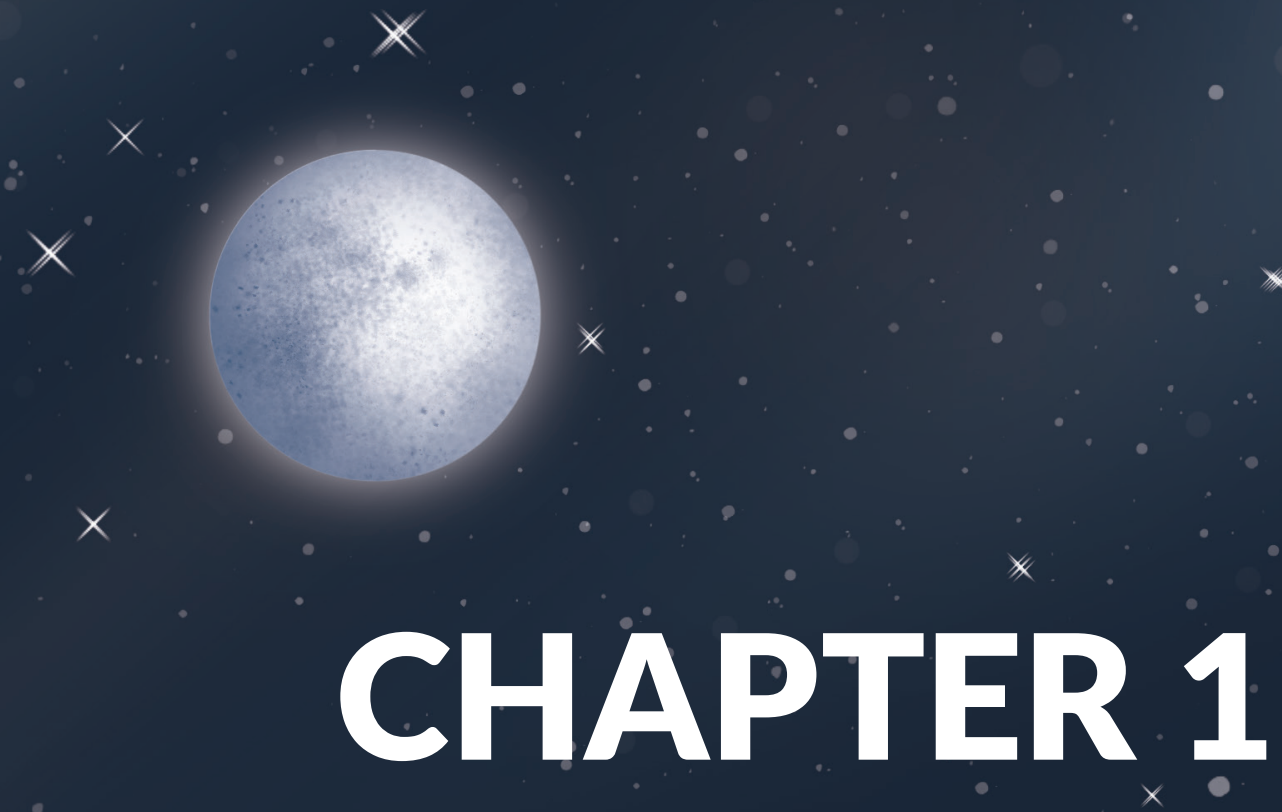

General întroduction

$x$

$x$

$x$

$x$
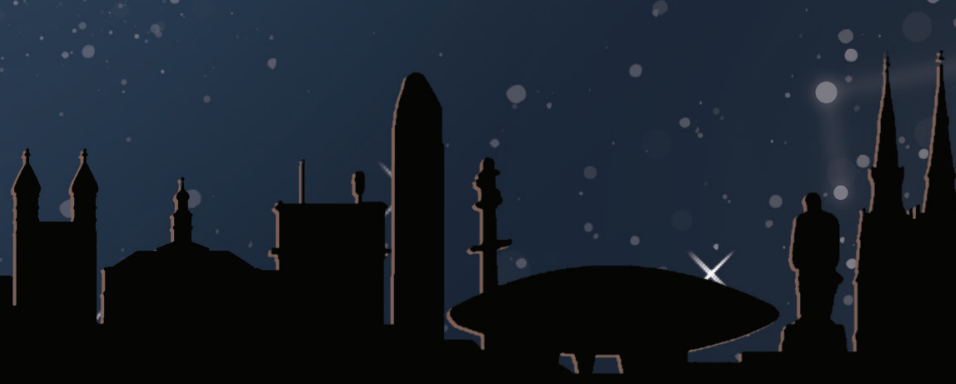

$\times$ 



\section{GENERAL INTRODUCTION}

Oh, do not fear the darkness, it is the home of light.

Had we no dark skies over us, ne'er we'd see stars so bright. ${ }^{1}$

Nobody chooses to be born; nobody chooses to become ill. Illness happens unexpectedly and violates your normal daily routine. Being diagnosed with a disease may feel that you're losing your grip on life. The realisation of how vulnerable you are as a human being may suggest that you are falling into a black hole as in dreams may occur. Insecurities, anxiety and health symptoms can hinder rational thinking and influence emotions, at a time when extraordinary circumstances potentially diminish a patient's ability to listen, judge and make choices.

For centuries, options for treatment were limited. ${ }^{2}$ One chose either prayer or resignation, and often not much else. Like small stars shining a tiny light in a dark universe, there were ointments, leeches, or herbal potions, but often a more powerful treatment, acting as a beacon in the darkness, was lacking. In the past, surgical procedures were performed, but only in precarious situations with obvious consequences such as an amputation, ranging from a finger to a limb, or the removal of abscesses or tumours. ${ }^{3}$

As a result of advances in science and safer operating conditions, surgical alternatives have also greatly increased. While there was often no surgical option 150 years ago, nowadays there are many possibilities. People are faced with a wide range of treatments that they can hardly grasp, or have even heard of. In their fall into the black hole of their diagnosis, these options now appear as stars that bring light into the darkness. ${ }^{4}$ However, there are so many that it is not easy to decide which option suits the patient best: 'confusion by superabundance'.

For decades, physicians have guided their patients through this forest with the paternalistic idea that they always know best what is good for their patients. Gradually, the position of a physician has changed to an advisor of options. ${ }^{5}$ The physician sums up possibilities and impossibilities and advises his patient, but the patient ultimately chooses what is or feels best in their situation. What is good for one patient may not be optimal for the other. What one patient likes, another considers a burden. ${ }^{6}$ The patient's personal preference has become the focal point of the medical treatment..$^{-9}$

For a previous healthy person, any disease comes unexpectedly, and the speed makes a well-considered choice rather difficult. Unfortunately, there is often little time to make a choice when a disease is diagnosed and your physician suggests surgery as an option. 
The severity of the symptoms or possible progression of the disease will put pressure on the patient, who is expected to make choices about things he/she has never had to think about before. Because of these many options, a patient can quickly lose sight of things. The physician tries to lead the patient in the right direction, enabling him to make the right choice, by providing coordinated information and advice. Patients often don't know who and what they can rely on; they look for security that is often not available. In these circumstances, it can be difficult to feel 'connected' to a physician you have known only briefly, and to trust his advice. This can lead to feelings of doubt about the selected option. These uncertainties, the multitude of options and the advice do not stop once the surgical procedure is over. ${ }^{10-15}$

Until a few years ago it was customary for patients to remain in the hospital while recovering. These extended hospital stays provided physicians and nurses with ample time to instruct and advise patients. However, modern medicine has fully embraced the practice of Enhanced Recovery After Surgery (ERAS). Faster mobilisation and maintenance of fitness are paramount for postoperative treatment nowadays. Rarely do patients stay in the hospital longer than one week, and day care is common practise. ${ }^{16-17}$ The downside of this clinically optimised care is a loss of time to adequately communicate all knowledge about the postoperative process to our patients. The patient arrives at home and is considered 'self-reliant', but is once again searching for answers: what can I do, what am I allowed to do, what can I expect? Any untoward events such as infection or pain can lead to dissatisfaction and ultimately to a loss of confidence in the physician. A medical claim or complaint may be the sum of these events. ${ }^{18-25}$

Improved preoperative counselling may be part of the solution as patients know beforehand better what to expect. They may be well-informed before, during and after surgery and recovery. Moreover, an appropriate preoperative counselling ensures that patients possibly recognise negative events more quickly, will seek and receive help, or can consider disappointing results in a broader perspective than just themselves. These patients, regardless of a beneficial outcome, are generally more satisfied. In the end, an important parameter is the way a patient and their loved ones look back on the treatment process? Only by optimally preparing and guiding patients using modern resources are we able to provide a patient with a solid basis to rely on during the SIC process. Endless space, initially representing the vast variety of options, then becomes a blanket of support, attention and advice that the patient can fall back on in times of uncertainty. ${ }^{26-30}$ 


\section{OBJECTIVE OF THE THESIS}

The general aim of this thesis is to study methods of improving patient counselling before and after an operation.

More specifically, in order to reach this aim, the following aspects of the process of patient counselling will be studied:

1. To study history as well as the current and future status of the surgical informed consent (SIC) process.

2. To evaluate various characteristics of SIC in general, orthopedic and plastic surgical practice.

3. To report on perceptions and experiences of young adults undergoing bariatric surgery regarding the SIC process.

4. To assess the relation between SIC and Shared Decision Making (SDM) in general surgery.

5. To analyse characteristics of malpractice claims and Medical Disciplinary Board (MDB) decisions regarding SIC in the Netherlands.

6. To evaluate currently used SIC forms in general surgery in the Netherlands and to provide a best-practice SIC form for surgeon and patient.

7. To evaluate the effect of a personalised e-health-care programme on 'return to normal activities' after surgery. 


\section{OUTLINE OF THESIS}

This thesis presents studies that focus on surgical patient counselling using methods of preoperative surgical informed consent (SIC) and postoperative e-health counselling.

Part I Preoperative counselling and surgical informed consent

In chapter $\mathbf{2}$ the aspects of SIC are reviewed. A general introduction of issues related to consent in the medical arena including historical background, evolution and present dilemmas is provided. A number of suggestions possibly improving the SIC process in daily practice are discussed.

The current knowledge base, skillset and practice regarding SIC of Dutch general surgeons, orthopaedic surgeons and plastic surgeons are discussed in chapter $\mathbf{3}$ and $\mathbf{4}$. Improvement on all aspects may seem possible, feasible and necessary to improve daily healthcare.

Chapter $\mathbf{5}$ focuses on the patient's perspective of preoperative education and informed consent in young adults undergoing bariatric surgery. The goal of this study was to improve the SIC process and to develop an informed consent process for adolescents undergoing bariatric surgery.

In chapter 6 the quality of the SIC process is analysed after audiotaping consultations. In chapter 7 patient and surgeon questionnaires for Shared Decision Making (SDM) are compared to the medical notes in the electronic patient dossier (EPD).

An inadequate SIC process may result in malpractice claims or medical disciplinary board (MDB) complaints. Aim of the study in chapter $\mathbf{8}$ was to analyse characteristics of a decade of malpractice claims and MDB decisions regarding SIC in the Netherlands.

In chapter $\mathbf{9}$ the currently used SIC forms that are used in Dutch hospitals were analysed for legal adequacy and readability in order to design a best practice SIC form that may aid surgeons and patients in the SIC process.

Part II Postoperative counselling and e-health

Substitution of usual perioperative care by e-health as a means to enhance postoperative recovery in patients undergoing day care surgery for general surgical or gynaecological procedures is the subject of chapter 10.

Chapter 11-14 provide a summarizing discussion and conclusions, future perspectives, impact paragraph and Dutch summary. 


\section{REFERENCES}

1. Erik Blomberg. Jorden. Stockholm: Dahlberg. 1920.

2. Ajlouni KM. History of informed medical consent. Lancet 1995;346(8980):980.

3. Katz J. Reflections on informed consent: 40 years after its birth. J Am Coll Surg 1998;186(4):466-474.

4. World Health Organization Staff. Promotion of the Rights of Patients in Europe. In: Proceedings of a WHO Consultation. 1995.

5. Ende J, Kazis L, Ash A, et al. Measuring patients' desire for autonomy: decision making and information-seeking preferences among medical patients, J. Gen. Intern. Med. 1989;4:23-30.

6. Fink AS, Prochazka AV, Henderson WG, Bartenfeld D, Nyirenda C, Webb A, Berger DH, Itani K, Whitehill T, Edwards J, et al: Enhancement of surgical informed consent by addition of repeat back: a multicenter, randomized controlled clinical trial. Ann Surg 2010;252:27-36.

7. Keulers BJ, Scheltinga MR, Houterman S, et al. Surgeons underestimate their patients' desire for preoperative information. World J Surg 2008;32(6):964-970.

8. Pleat JM, Dunkin CS, Davies CE et al. Prospective survey of factors affecting risk discussion during consent in a surgical specialty. Br J Surg 2004;91(10):1377-1380.

9. Scholl I, Kriston L, Dirmaier J, Buchholz A, Harter M. Development and psychometric properties of the Shared Decision Making Questionnaire--physician version (SDM-Q-Doc). Patient Educ Couns 2012;88(2):284-290.

10. Royal Dutch Medical Association (KNMG): [Guidebook Informed Consent]. 2001.

11. Dutch Institute for Healthcare Improvement (Centraal Beleids Orgaan C: [Guideline the preoperative route]. 2009. http://www.cbo.nl/Downloads/934/rl_preop_traject_10.pdf.

12. Appelbaum PS. Clinical practice. Assessment of patients' competence to consent to treatment. N Engl J Med 2007;357(18):1834-1840.

13. Anderson OA, Wearne IM. Informed consent for elective surgery--what is best practice? J R Soc Med. 2007;100:97-100.

14. Baum N. Informed consent-more than a form. J Med Pract Manag 2006;22(3):145-148.

15. Falagas ME, Korbila IP, Giannopolou KP, Kondilis BK, Peppas G. Informed consent: how much and what do patients understand? Am. J. Surg. 2009;198(3):420-435.

16. Dutch Institute for Healthcare Improvement (Centraal Beleids Orgaan C: [Guideline the peroperative route]. 2010.

17. Spanjersberg WR, Reurings J, Keus F, van Laarhoven CJ. Fast track surgery versus conventional recovery strategies for colorectal surgery. Cochrane Database Syst Rev 2011;2:CD007635.

18. Leenen HJJ, Geevers JKM, Legemaate J. Handboek Gezondheidsrecht Deel 1 - Rechten van mensen in de gezondheidszorg. The Hague: Boom Legal Publishers; 2011:189-209.

19. Bulstra G, Wiggers T, Hubben H. Chirurg en tuchtrecht 1996-2007. The Hague: Sdu Uitgevers BV; 2008.

20. Curran WJ, Hall MA, Kaye DH (1990) Health care law, forensic science, and public policy, 4th edn. Little, Brown and Company, Boston

21. Verbogt S (2003) Hoofdstukken over gezondheidsrecht (chapters in health law), 9th edn. WoltersNoordhoff, Groningen, The Netherlands. ISBN:9068905759

22. Beckman HB, Markakis KM, Suchman AL, Frankel RM. The doctor-patient relationship and malpractice. Lessons from plaintiff depositions, Arch. Intern. Med. 1994;154:1365-1370. 
23. Gogos AJ, Clark RB, Bismark MM, Gruen RL, Studdert DM. When informed consent goes poorly: a descriptive study of medical negligence claims and patient complaints, Med. J. Aust. 2011;195(6): 340-344.

24. Kastelein WR (1998) [Informed consent and medical liability: jurisprudence 1994-1998. Tijdschr Gezondhd 22:134-146 [in Dutch]

25. Vincent C, Young M, Phillips A. Why do people sue doctors? A study of patients and relatives taking legal action, Lancet 1994;343:1609-1613.

26. Kinnersley P, Phillips K, Savage K, Kelly MJ, Farrell E, Morgan B, et al. Interventions to promote informed consent for patients undergoing surgical and other invasive healthcare procedures. Cochrane Database Syst Rev. 2013;7:CD009445.

27. Schenker $Y$, Fernandez A, Sudore R, Schillinger D: Interventions to improve patient comprehension in informed consent for medical and surgical procedures: a systematic review. Med Decis Making 2011;31:151-173.

28. Farrell EH, Whistance RN, Phillips K, Morgan B, Savage K, Lewis V, et al. Systematic review and metaanalysis of audio-visual information aids for informed consent for invasive healthcare procedures in clinical practice. Patient Educ Couns. 2014;94:20-32.

29. Bollschweiler E, Apitzsch J, Obliers R, et al. Improving informed consent of surgical patients using a multimedia-based program? Results of a prospective randomized multicenter study of patients before cholecystectomy. Ann Surg 2008;248(2):205-211.

30. Keulers BJ, Welters CF, Spauwen PH, et al. Can face-to-face patient education be replaced by computer-based patient education? A randomised trial. Patient Educ Couns 2007;67(1-2):176-182. 

$x$ 


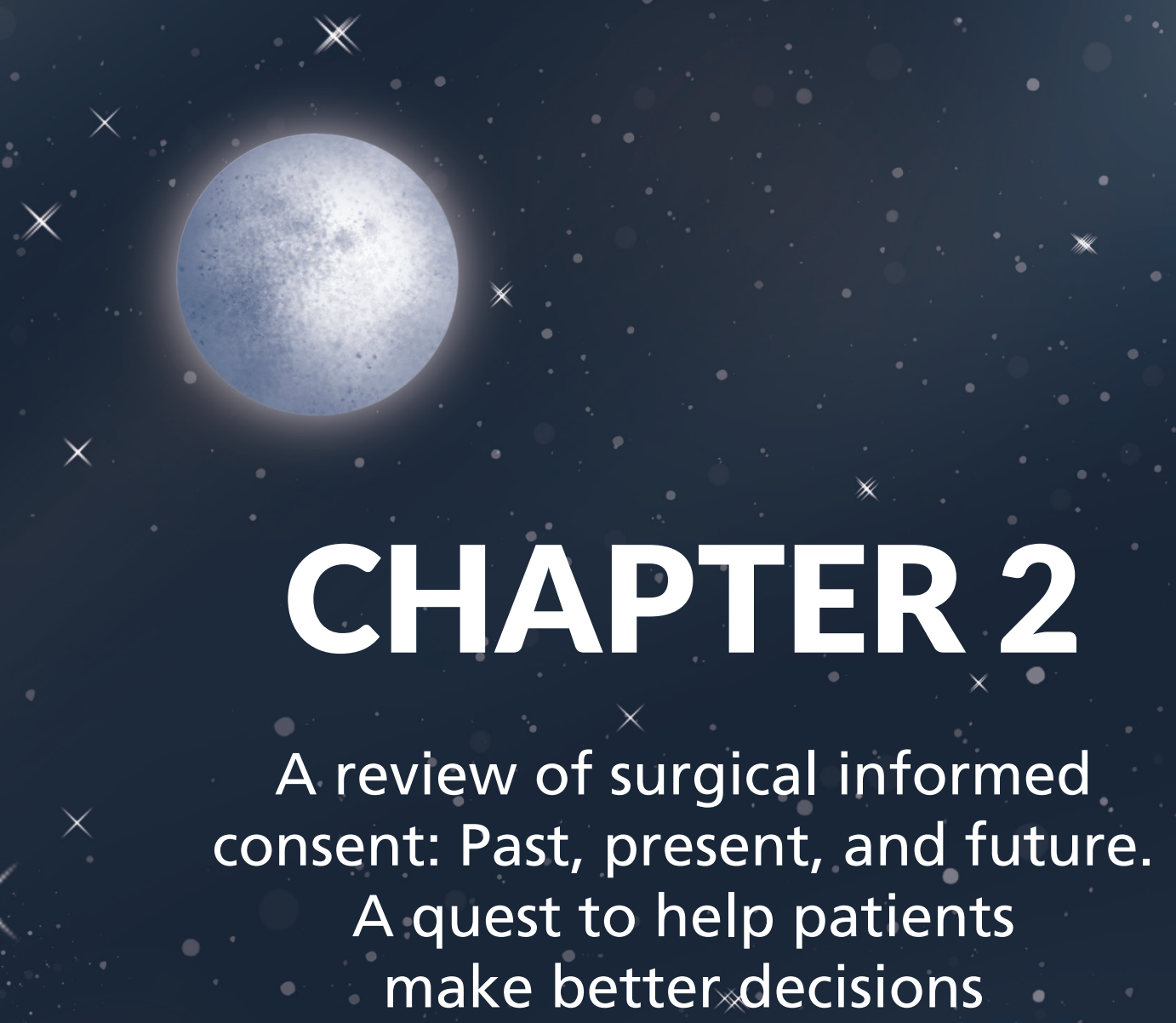

Wouter K.G. Leclercq, Bram J. Keulers, Marc R.M. Scheltinga, Paul H.M. Spauwen, Gert-Jan van der Wilt. World J Surg 2010;34:1406-1415.

X
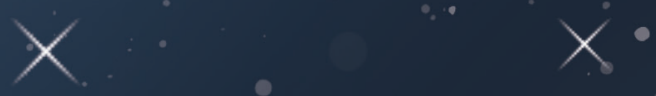


\section{ABSTRACT}

\section{Background}

Informed consent (IC) is a process requiring a competent doctor, adequate transfer of information, and consent of the patient. It is not just a signature on a piece of paper. Current consent processes in surgery are probably outdated and may require major changes to adjust them to modern day legislation. A literature search may provide an opportunity for enhancing the quality of the surgical IC (SIC) process.

\section{Methods}

Relevant English literature obtained from Pub-Med, Picarta, PsycINFO, and Google between 1993 and 2009 was reviewed.

\section{Results}

The body of literature with respect to SIC is slim and of moderate quality. The SIC process is an underestimated part of surgery and neither surgeons nor patients sufficiently realize its importance. Surgeons are not specifically trained and lack the competence to guide patients through a legally correct SIC process. Computerized programs can support the SIC process significantly but are rarely used for this purpose.

\section{Conclusions}

IC should be integrated into our surgical practice. Unfortunately, a big gap exists between the theoretical/legal best practice and the daily practice of IC. An optimally informed patient will have more realistic expectations regarding a surgical procedure and its associated risks. Well-informed patients will be more satisfied and file fewer legal claims. The use of interactive computer-based programs provides opportunities to improve the SIC process. 


\section{INTRODUCTION}

Daily surgical practice is characterized by an increased complexity of the operative procedures while time pressure on the outpatient staff continues to increase. Moreover, a patient today tends to demand more extensive information from his/her doctors. Execution of these complicated processes must be legally sound. One way to cope with these developments is to optimize patient education in daily practice through computerbased techniques. A next step is to expand the focus from patient education to surgical informed consent (SIC). This overview provides a descriptive study of this challenging field of surgical practice.

Informed consent (IC) is a legal term that is supported by jurisdiction and international laws and is described as "voluntary authorization, by a patient or research subject, with full comprehension of the risks involved, for diagnostic or investigative procedures, and for medical and surgical treatment" (year introduced: 1973 (1971), http://www. ncbi. nlm.nih.gov/mesh/68007258? ordinalpos=1 \&itool= Entrez System2.PEntrez.Mesh.Mesh_ ResultsPanel.Mesh_RVDoc Sum). Basic elements of IC are "preconditions," "information," and "consent." Preconditions for proper IC include the patient's competence and voluntariness. The information provided must be adequate and comprehensible. The consent of a patient authorizes the (surgical) procedure that will be performed.

The system of the patient giving consent for an invasive procedure or operation (surgical IC or SIC) has been common practice for many years. Providing appropriate preoperative information to a surgical patient is dictated by law and may prevent litigation. In spite of major developments in the law, information technology, and patients wishes, procedural aspects of SIC have not changed sufficiently over the last few decades in most hospitals. Surgeons prepare their patients randomly, and the quality of information will probably differ extensively. Patients are supposed to give SIC with (or without) written information.

Currently, patient education and patient-oriented care are important topics. Nevertheless, the literature on the quality of SIC is scarce. The initial concepts and laws on SIC are outdated and have been replaced by up-to-date legislation. Our hypothesis is that daily practice is still based on old habits and therefore is not as good as necessary to meet current needs. The aim of this review was to describe the pertinent literature concerning $\mathrm{SIC}$ and to provide suggestions to improve the SIC process in daily practice. 


\section{METHODS}

We were interested in identifying hard data in the literature that could be used to enhance the quality of the SIC process. Our objectives were to answer the following questions: (1) What are the fundamental elements of an adequate SIC process? (2) What is the current state of the SIC process? (3) How can we improve the quality of the SIC process in the future?

\section{Search strategy}

Relevant literature was identified in PubMed, Picarta, PsycINFO, and Google using the keywords/Mesh terms "informed consent," "surgical procedures," "operative," "patient education," "mental competency," and "history." Searches were performed by two surgical trainees (WL and BK) independently. All selected articles were scanned for relevant references or "related articles" (PubMed). Selection criteria included language (English publications or abstracts) and time period (January 1993-January 2009, with the exception of the legal cases). 


\section{MAIN RESULTS}

A total of 2,952 articles was identified using the Mesh terms "surgical procedures" and "informed consent," of which 2,567 were in English. Most of these articles were not related to the present study questions listed above, as operative procedures were tested which required an IC. Only a limited number of articles focused on the SIC process itself. Eventually, 175 articles were selected directly, through references, or a related article search. Of this body of literature, 71 articles met our inclusion criteria. Meta-analysis of these articles was not possible because the studies differed in study design, tests used, and outcome measurement.

History of surgical informed consent

In medieval times doctors asked for a "hold harmless document" aimed at releasing them from any future responsibility to the patient or family in the event anything adverse happened following therapy. This pro corpore mortuoto can be found in Italian, French, and Middle East archives as early as the 14th century and is considered an early precursor of IC, although its purpose was to protect the doctor and not the patient. ${ }^{1-3}$ The initial concept of current IC legislation developed in later centuries from case-related litigation into a standard practice (Figure 2.1). Some bizarre landmark cases may be identified and are worth mentioning in the present overview. In the 18th century, a patient sued his doctor for refracturing his leg and experimenting with a novel external fixating mechanism without informing the patient or obtaining approval. This 1767 Slater vs. Baker and Stapleton trial was the first example of an IC case. ${ }^{4,5}$ The concept of IC was used in an 1845 novel by Edgar Allen Poe. A patient was asked for permission for an experimental therapy just before his death (Figure 2.2).6,7

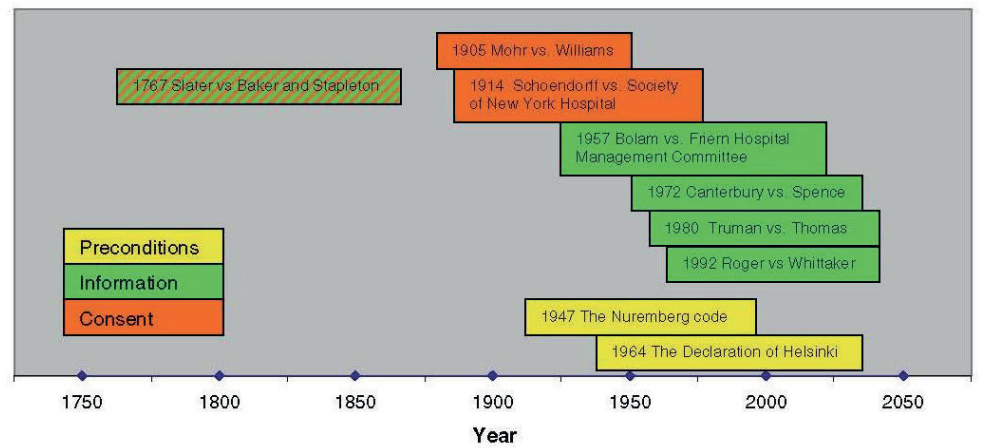

Figure 2.1 Landmarks in the history of the IC process: a timetable. 
The fundamentals of today's practice of SIC gained more structure at the beginning of 20th century, especially after the development of anesthesia and more invasive surgery (Figure 2.1). In Mohr vs. Williams in 1905, a woman agreed to an operation on her right ear. ${ }^{8}$ However, during the operation the surgeon found her left ear in the need of a repair. He was subsequently sued and convicted because he had not proceeded according to the preoperative agreement. The judge called this agreement a contract that authorizes the physician to operate only to the extent of the consent given. ${ }^{9}$ In Schoendorff vs. Society of New York Hospital in 1914, Justice Benjamin Cardozo (Figure 2.3) became famous for his judgment in the following case. A woman had consented to an abdominal examination under anesthesia but not to an operation. ${ }^{10}$ Nevertheless, the surgeon removed a tumor that eventually led the patient to file a law suit. Cardozo's opinion has become one of the most basic elements in the concept of SIC development: "Every human being of adult years and sound mind has a right to determine what shall be done with his own body, and a surgeon who performs an operation without the patient's consent commits an assault for which he is liable in damages". ${ }^{11-13} \mathrm{~A}$ patient should be viewed as a person who has the right of bodily self-determination..$^{5,12}$

After the Second World War, there was a strong public reaction to the cruelties committed by Nazi concentration camp "doctors" who performed horrible tests on "patients" without prior information or approval. A code was written as a direct result of the Nuremberg trials (U.S.A. vs. Karl Brandt et al.). This "Nuremberg Code" was an important step in the development of the IC process in trials (Figure 2.4). It consisted of ten preconditions any human research study had to fulfill. Interestingly, the first governmental instruction for IC in trials originated in Germany and was written in 1900. ${ }^{14}$ Later on in 1964, The World Health Organization set the Declaration of Helsinki with 22 preconditions for human research. The 1957 case Salgo vs. Leland Stanford, Jr. University Board of Trustees introduced the term "informed consent," and this term was accepted in Natanson vs. Kline in $1960 .^{12,15,16}$

At the same time, a development occurred in the domain of "information." The 1957 UK case Bolam vs. Friern Hospital Management Committee focused on which risks should be discussed with a surgical patient. ${ }^{17}$ This doctor-centered view resulted in a reasonable standard: Any surgeon should tell what other surgeons also tell their patients, a principle known as the Bolam principle. ${ }^{11}$ However, the 1972 Canterbury vs. Spence case determined that all risks and alternatives of a procedure have to be explained. ${ }^{18}$ This trial clearly demonstrated a shift from the doctors' point of view toward the patients' point of view as the standard of IC: the "reasonable patient standard". 11,12,19,20 Subsequently, the Australian High Court overruled the Bolam principle in the 1992 Roger vs. Whittaker case of a woman losing sight in her good eye after being operated on her diseased eye. ${ }^{21}$ Although 
the risk of this happening was a mere 1:14,000, the court ruled that the surgeon should have informed the woman of the risk as she had apparently asked for this information. On the other hand, the doctor had considered this low risk not relevant. ${ }^{11,20}$ Although not totally abandoned, the "reasonable doctor standard" has become a secondary standard next to the "reasonable patient standard" in most countries. ${ }^{21}$ Since the 1980 Truman vs. Thomas case, information provided in an IC process must also include the risks of "not acting or postponing". ${ }^{22}$ In this case, a Pap smear was refused by a woman who claimed not to know the associated risks, i.e., not detecting cancer in time for curative treatment. ${ }^{7}$

Dutch legislators as well as governments from various other Western countries have realized that their legislation was out of date. Based on cases such as those mentioned above, several adjustments have led to the 1995 Dutch Medical Treatment Contract Act in which all elements of IC are present, including preconditions, information, and consent. Although legislation differs widely between countries, these "basic elements" are consistent in the Western world. 
THE FACTS OF M. VALDEMAR'S CASE.

$$
\text { BX EDGA A. POE. }
$$

Or course I shall not pretend to consider it any matter for wonder, that the extraordinary case of $\mathrm{M}$. Valdemar has excited discussion. It would have been a miracle had it not-especially under the circumstances. Throngh the desire of all parties concerned to keep the attair from the public, at least for the present, or until we had farther opportunities for investigation - through our endeavons to effect this-a garbled or exaggerated account made its way into society, and became the source of many unpleasant misrepresentations, and, very naturally, of a great deal of disbelief.

It is now rendered necessary that give the facts-as far as I comprehend them myself. They are, succinctly, these :

My attention, for the last three years, had been repeatedly drawn to the subject of Mesmerism; and, about nine months ago, it occurred to me, quite suddenly, that in the series of experiments made hitherto, there had been a very remarkable and most unaccountable omission:-no person had as yet been mesmerized in articulo mortis. It remained to be seen, first, whether, in such condition, there existed in the patient any susceptibility to the magnetic influence; secondly, whether, if any existed, it was impaired or increased by the condition; thirdly, to what extent, or for how long a peried, the encroachments of Death might be arrested by the process. There were other points to be ascertained, but these most excited my curiosity - the last in especial, from the immensely important character of its consequences.

In looking around me for some subject by whose means 1 might test these parti. culars, I was brought to think of my friend, M. Ernest Valdemar, the well-known compiler of the "Bibliotheca Forensica," and author (under the nom de plume of Issachar Marx) of the Polish versions of "Wallenstein" and "Gargantua." M. Valdemar, who has resided principally at Harlaem, N. Y., since the year 1839 , is (or was) particularly noticeable for the extreme spareness of his person-his lower limbs much resembling those of John Randolph; and, also, for the whitevol. H. $\rightarrow$ No. vi. ness of his whiskers, in violent contrast to the blackness of his hair-the latter, in consequence, being very generally mistaken for a wig. . His temperament was markedly nervous, and rendered him a good subject for mesmeric experiment. On two or three occasions I bad put him to sleep with little difficulty, but was disappointed in other results which his peculiar constitution had naturally led me to anticipate. His will was at no period positively, or thoroughly, under my control, and in regard to clairvoyance, I could accomplish with him nothing to be relied upon. I always attributed my failure at these points to the disordered state of his health. For some months previous to my becoming acquainted with him, his physicians had declared him in a confirmed phthisis. It was his custom, indeed, to speak calmly of his approaching dissolution, as of a matter neither to be avoided nor regretted.

When the ideas to which I have alluded first occurred to me, it was of course very natural that 1 should think of M. Valdemar. I knew the steady philosophy of the man too well to apprehend any scruples from him; and he had no relatives in America who would be likely to interfere. I spoke to him frankly upon the subject; and, to my surprise, his interest seemed vividly excited. I say to my surprise; for, although he had always yielded his person freely to my experiments, he had never before given me any tokens of sympathy with what I did. His disease was of that character which would admit of exact calculation in respect to the epoch of its termination in death; and it was finally arranged between us that he would send for me about twenty-four hours before the period announced by his physicians as that of his decease.

It is now rather more than seven months since I received from M. Valdemar, himself, the subjoined note :

\section{"MY dear P-,}

"You may as well come noto. Dand $\mathrm{F}-$ are agreed that I cannot bold out beyond to-morrow midnight; and I think they have hit the time very nearly.

Figure 2.2 American Review: A Whig Journal of Politics, Literature, Art, and Science (December 1845); publication of Edgar Allen Poe's "The fact in the case of M. Valdemar." Available at http://digital.library. cornell.edu/cgi/t/text/text-idx?c=amwh;idno= amwh0002-6. 


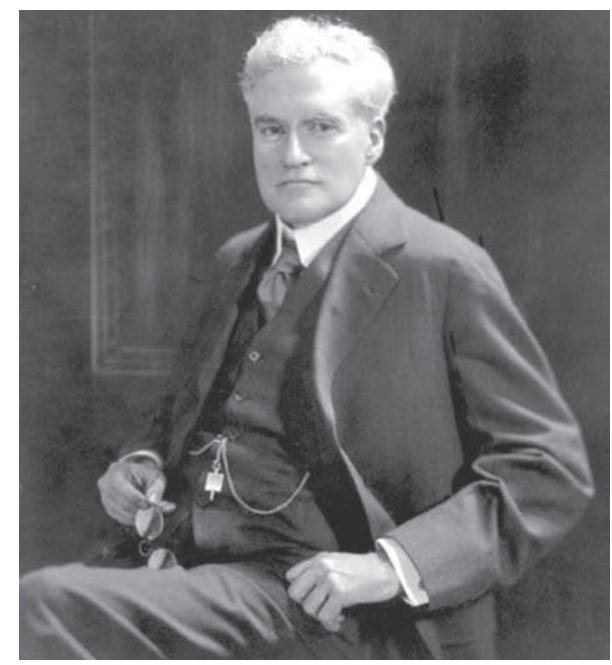

Figure 2.3 Cardozo, Benjamin Nathan. Online photograph from the Encyclopædia Britannica. Available at http://www.britannica.com/eb/art-96738

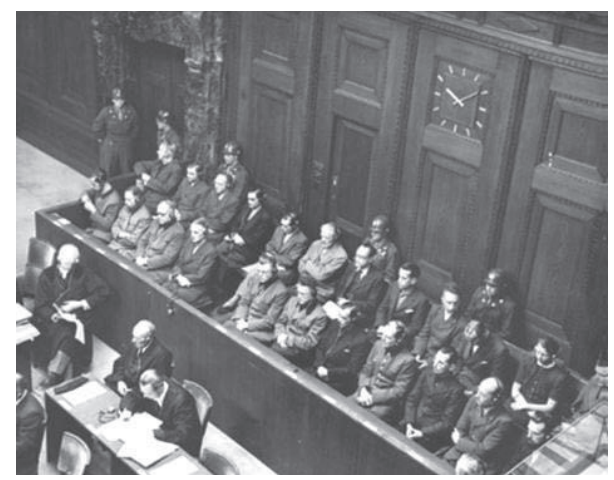

Figure 2.4 Nuremberg Trial: the 23 defendants in dock during the doctors' trial. Available at http://www. law.umkc.edu/faculty/projects/ftrials/nuremberg/docdef.jpg 


\section{PRESENT PRACTICE OF SURGICAL INFORMED CONSENT}

\section{Current elements of SIC}

Based on historical cases and legislation, IC is supported by three cornerstones: "preconditions," "information," and "consent" (Figure 2.5).

Preconditions include competence and voluntariness. A patient is a person who has a right of self-determination. He/she must be able to make decisions about his/her own body and must be able to decide freely without being influenced by others.

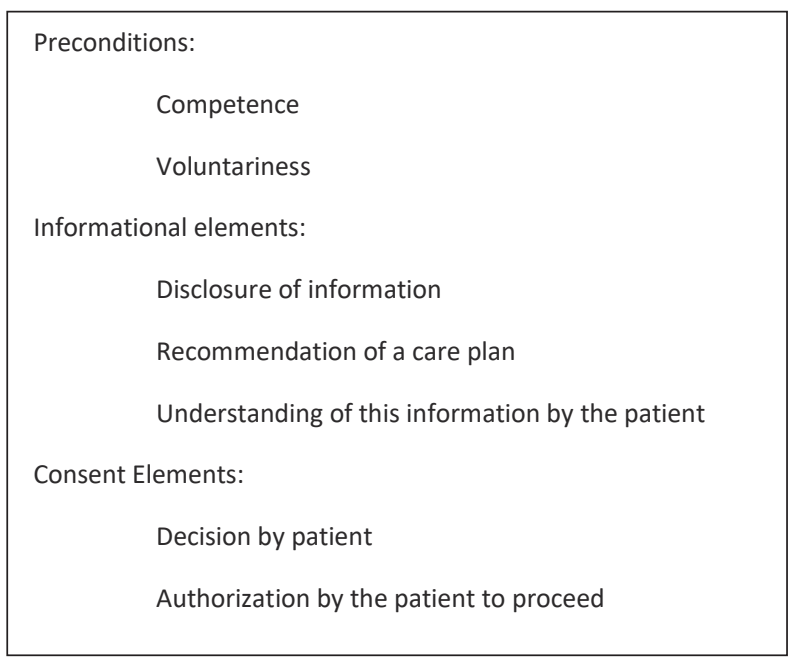

Figure 2.5 The elements of IC.

The second cornerstone is information. According to the 1995 WHO declaration on the promotion of patients rights, patients have the right to be fully informed about their health status, including the medical facts about their condition; about the proposed medical procedures, together with the potential risks and benefits of each procedure; about alternatives to the proposed procedures, including the effect of nontreatment; and about the diagnosis, prognosis, and progress of treatment. ${ }^{23}$ All this information must be disclosed by the surgeon to enable the patient his/her right of self-determination. A welldefined care plan incorporating the surgeon's advice should be discussed and it must be verified that the patient understands this information. The third cornerstone is consent: registration of the patient's decision and (written) consent. ${ }^{11,24,25}$ 
Informed consent is often given by the patient during a preoperative consult with a consultant, a resident, or a specialized nurse. The information associated with a surgical procedure can be exchanged verbally, in writing, by video, or by computer technology. In this respect, large differences exist between countries. The US demands a patient signature, whereas a note in the patient chart is sufficient in the UK. In the Netherlands, doctors are not strictly required to obtain written consent. ${ }^{26}$

\section{Preconditions}

As a routine, the patient's competence is only "checked" in a general sense and deemed appropriate if communication with a patient is "normal". ${ }^{27}$ Only if the patient is officially "incompetent" will a legally appointed surrogate decision maker or an other representative in accordance with the law be allowed to decide for the patient. ${ }^{27}$ However, a normal intelligence per se does not necessarily mean that a patient is really competent. Recently, Appelbaum ${ }^{28}$ reviewed the literature on patient competence. A group of patients with known cognitive disease and patients with cancer demonstrated variable outcomes on competence tests. Lower scores were found in people of older age and limited education. The number of "incompetent" patients was higher than expected. Surprisingly, the doctor's ability to differentiate between competent and incompetent was not better than throwing a dice. ${ }^{28}$

On the other hand, even patients who are objectively deemed competent may be ignorant. They frequently do not know the process of SIC and do not know their rights, which results in wrong beliefs. ${ }^{29,30}$ Only $40 \%$ of the patients think that the IC paper confirms their wishes. ${ }^{29}$ Interestingly, they usually do not feel the need for more information and their actual knowledge of the benefits and risks involved remains poor. ${ }^{31-35}$ In contrast, when asked what information they would like to have, they indicate that they would like more information than they actually receive. ${ }^{36}$

Several misconceptions also exist with respect to voluntariness. One study reveals that $46 \%$ of patients in the study were under the impression that the major goal of an IC is to protect the hospital from litigation. In addition, $68 \%$ of the patients were convinced that the IC process gives the doctor control of what is going to happen. ${ }^{29}$

Information elements

Literature on patient education is extensive and is usually focused on informing patients in a general sense. On the other hand, studies on information in relation to the IC process are scarce. Results consistently demonstrate that neither doctors nor patients are well prepared for all elements of the IC process. ${ }^{19,20,30,37-42}$ Residents are frequently "in charge" of the IC process but do not know what to tell a patient and do not perform well in 
tests on IC and medical law. ${ }^{25,37,43}$ In contrast, they are more capable in informing the patient of benefits of the surgical procedure than they are giving information about risks or alternatives. ${ }^{37}$ Interestingly, $21 \%$ of patients in one study reported that they received most information from sources outside the hospital. ${ }^{44}$

The way information is presented greatly influences what a patient remembers. Oral information is retained very poorly, and patients tend to forget crucial parts of information such as alternative treatment options. ${ }^{41,45}$ This will lead to false-negative feelings, particularly in patients with a IQ below average, age over 60, a tendency to somatization, or a poor perceived control. ${ }^{44}$ On the other hand, betterinformed patients will have more realistic expectations, higher satisfaction, and demonstrate more treatment cooperation. ${ }^{46} \mathrm{~A}$ recent study reveals that a great difference exists between the points of view of surgeons and patients regarding relevance of information and what should be told or not told. ${ }^{36}$ Another study demonstrates that patients are not interested in the IC form that is used, and two thirds of the patients do not read it carefully. ${ }^{44}$

Studies on the patient's comprehension of information are rare. Analyses of tapes of IC indicate that various elements of the surgical procedure are discussed in $71 \%$ of the cases. The assessment of whether the patients actually understand this information is performed in only $1.5 \%$ of the cases! $!^{41,47}$

\section{Consent elements}

Studies focusing on the consent element indicate that consent forms are not composed very well. ${ }^{48,49}$ Readability is poor, and only a minority are written on a 12-year-old reading level, which is best practice. ${ }^{48-50}$ More than half of all IC forms are filled out incorrectly. ${ }^{19,51}$ One retrospective study shows that the consent forms cannot be retrieved in $7.7 \%$ of the cases. ${ }^{19}$ 


\section{FUTURE IMPROVEMENTS OF SURGICAL INFORMED CONSENT}

Substantial weaknesses and omissions of SIC are evident and the current elements of the SIC process are largely neglected in daily practice. ${ }^{19,20,27-35,37-39,41,44,45,47,48}$ Preconditions are ignored, information is incomplete, and the consent itself is not an accurate reflection of the patient's authorization. SIC apparently is not a popular part of the doctor-patient relationship, and presumably both parties are guilty. In the media surgeons are blamed for making mistakes and people are encouraged to "sue for every fault their surgeons make," leading to an increase in medicolegal claims. ${ }^{35}$ However, it should be realized that most legal cases are not due to failures in treatment but due to failure in communication. ${ }^{11,35}$ Discrepancies between expected and achieved results (55\%) and faulty information (30\%) are the main reasons for patients to file claims. In contrast to what one would expect, most complaints are generated after minor elective operations (70\%). ${ }^{52}$

Articles analyzing the quality of the SIC forms and their performances in court were not identified in the present overview. Circumstantial evidence, however, supports the view that ample opportunities are available to improve not only these forms but the whole SIC process. An IC form is inadequate if it deals only with the IC form itself while omitting the incorporation of the information process or the quality of the total process. Several cases based on faulty forms resulted in successful claims: no documented alternatives, risks, or IC form at all. ${ }^{53}$ Hence, a nonstandardized way of informing a patient of the risks of complications inherently results in a vulnerable position for the surgeon. ${ }^{25}$ Both surgeons and their patients must realize that an improved and standardized IC process leads to more realistic expectations. Better-informed patients are more satisfied, have a higher commitment to their treatment, and demonstrate less tendency toward filing legal claims. ${ }^{53}$ Both groups obviously have a lot to gain from an optimized SIC process.

Strengthening the surgeon's education on SIC might look like an easy way to optimize the SIC process. However, training doctors, or specialised nurses, aimed at improving their skills in the SIC process is not very successful and this approach is very time consuming. ${ }^{38,54-56}$

A computer may aid the doctor help his patient receive high-quality SIC for elective procedures. It should be realized that computer programs do not undermine the doctorpatient relationship but are potentially valuable. ${ }^{40,42}$ The SIC should therefore ideally be performed using an integrated interactive computer program. ${ }^{40,42,56}$ As most surgeons prefer to spend their time on surgery itself, they must consider introducing computer technology as an aid in the SIC process in daily surgical practice. 
A number of validated tests have been developed to check the patient's competence. A recent study demonstrates that the outcome of such a test is almost as consistent as an expert opinion. ${ }^{28}$ Examples of such validated tests are the Mini-Mental State Examination, the MacArthur Competence Assessment Tool, the Decision Evaluation Scales (DES), and the MacCaT-T.23,28,57 All these tests are suitable for computer-based programs.

An effective way of informing patients about their surgical procedure might be by using computer-based information. 23,51,58 The more interactive information is provided, the more a patient remembers (Table 2.1). ${ }^{11,13,24,34,40,42,58-76}$ Nonetheless, the amount of information that is transferred during a preoperative consultation in an outpatient environment can be overwhelming. ${ }^{41}$ If transfer of information is adjusted to the patient's own speed and wishes in an interactive setting, he/she tends to comprehend more and will have better recapitulation. ${ }^{40-42,66}$ Surprisingly, patients with limited computer experience, a low educational level, or of old age appear to benefit.40,52,77,78 Validated tests have been developed to check if the patient actually understands the information. ${ }^{28,57}$ Using this approach, doctors buy time that can be used for discussing specific procedural details, personal questions, or emotions.

Recording the SIC process is of growing importance in medicolegal cases. Computer-based interactive IC programs have the advantage of recording every step a patient takes in gaining information. ${ }^{35}$ In various empirical studies the consent form is replaced by a recorded patient authorization through a computer-based interface. ${ }^{40,42,79}$ This approach focuses on only the consent part of the process; it does not check whether a patient is competent or understands the information sufficiently. Basically, it is nothing more than a digitized IC form. ${ }^{40,42}$

More research is necessary to improve the SIC process in daily practice. We have recently developed a SIC program based on the best available practice as described in this review. This program uses an online interface that can be used at home or at the hospital for patients needing more guidance. In this program, patients are first screened for their competence. Then basic information on their specific surgical procedure is provided through text, audio information, and flash movies. Many words are highlighted (hyperlinked) and can be selected for extra information. Patients can also select other options for extra information on logistic, medical, or legal items. The patient's level of knowledge is checked at the end of this information part. If insufficient information is retained, these items are repeated because basic information must be trustworthy before the consent part starts. The consent part of SIC provides an overview of the surgical procedure, its risks, and alternatives. The patient or the surgeon can print out the form and both can sign it after all remaining questions are answered. This program will be evaluated on a national level in an upcoming trial and may ideally be integrated into our future practice. 
Table 1 Overview of randomized controlled trials focused on IC

\begin{tabular}{|c|c|c|c|c|c|c|c|}
\hline Author & Journal & $\begin{array}{l}\text { Year of } \\
\text { publication }\end{array}$ & Specialism & Country & $N$ & Study groups & $\begin{array}{l}\text { Outcome in favor of } \\
\text { study group }(s)\end{array}$ \\
\hline $\begin{array}{l}\text { Armstrong } \\
\text { et al. [11] }\end{array}$ & Br J Plast Surg & 1997 & Plast Surg & UK & 269 & Oral vs. oral and written information & Oral and written \\
\hline $\begin{array}{l}\text { Deyo et al. } \\
\text { [64] }\end{array}$ & Med Care & 2000 & Neuro/Ort & USA & 393 & $\begin{array}{l}\text { Oral and written information vs. pc- } \\
\text { based video }\end{array}$ & pc-based video \\
\hline $\begin{array}{l}\text { Chan et al. } \\
{[61]}\end{array}$ & $\begin{array}{l}\text { Arch Otolaryngol } \\
\text { Head Neck Surg }\end{array}$ & 2002 & $\begin{array}{l}\text { Ent/Gen } \\
\text { surg }\end{array}$ & Canada & 125 & $\begin{array}{l}\text { Oral vs. oral and written information } \\
\text { with figures }\end{array}$ & $\begin{array}{l}\text { Oral and written with } \\
\text { figures }\end{array}$ \\
\hline $\begin{array}{l}\text { Mason et al. } \\
\text { [69] }\end{array}$ & $B J O G$ & 2003 & Gyn & UK & 31 & Oral vs. oral and video information & Oral and video \\
\hline $\begin{array}{l}\text { Rossi et al. } \\
\text { [73] }\end{array}$ & Arthroscopy & 2005 & Ort & USA & 150 & Oral vs. oral and video information & Oral and video \\
\hline $\begin{array}{l}\text { Danino et al. } \\
\text { [62] }\end{array}$ & $\begin{array}{l}\text { Plast Reconstr } \\
\quad \text { Surg }\end{array}$ & 2006 & Plast Surg & France & 60 & Oral vs. oral and video information & Oral and video \\
\hline $\begin{array}{l}\text { Moseley et al. } \\
\text { [71] }\end{array}$ & Br J Ophthalmol & 2006 & Oph & USA & 90 & $\begin{array}{l}\text { Oral vs. oral and dia or video } \\
\text { information }\end{array}$ & Oral and dia or video \\
\hline $\begin{array}{l}\text { Keulers et al. } \\
\text { [66] }\end{array}$ & $\begin{array}{l}\text { Patient Educ } \\
\text { Couns }\end{array}$ & 2007 & Plast Surg & Netherlands & 113 & $\begin{array}{l}\text { Oral and written vs. pc-based } \\
\text { information }\end{array}$ & pc-based \\
\hline $\begin{array}{l}\text { Masood et al. } \\
{[70]}\end{array}$ & BJU Int & 2007 & Uro & UK & 45 & Oral vs. oral and written information & Oral only \\
\hline $\begin{array}{l}\text { Eggers et al. } \\
\text { [42] }\end{array}$ & Obesity & 2007 & Gen surg & Germany & 40 & $\begin{array}{l}\text { Oral and written information vs. Oral, } \\
\text { written and pc-based information }\end{array}$ & $\begin{array}{l}\text { Oral, written, and pc- } \\
\text { based information }\end{array}$ \\
\hline $\begin{array}{l}\text { Bollschweiler } \\
\text { et al. [43] }\end{array}$ & Ann Surg & 2008 & Gen surg & Germany & 76 & $\begin{array}{l}\text { Oral and written information vs. Oral, } \\
\text { written and pc-based information }\end{array}$ & $\begin{array}{l}\text { Oral, written, and pc- } \\
\text { based information }\end{array}$ \\
\hline
\end{tabular}




\section{PRACTICE IMPLICATION FOR AN ADEQUATE IC PROCESS}

\section{General}

1. Professionalize and structure your SIC and do not rely on good intent.

2. Focus on all operations, not just on the major operations.

3. Make patients and doctors aware of the importance of an adequate SIC.

4. Teach your patient what IC is.

5. Make sure the patient realizes he/she is in control and not the doctor.

6. Do not be afraid to use an interactive computer to help you, the doctor, and the patient.

\section{Competence}

Check your patient's competence and do not count on your clinical insight.

Information

1. Provide locally adapted information and try not to use general information.

2. Check if your patient understands your plan of operation, e.g., ask the patient to repeat the information.

3. Check if your patient understands the risks and the alternatives.

\section{Consent}

Register the SIC process in detail using an adequate IC form, and check that it is filled in correctly and store it in a safe place.

\section{Research}

Check for more research to be published as SIC is not a fixed format but a developing area of medicine. 


\section{REFERENCES}

1. Ajlouni KM. History of informed medical consent. Lancet 1995;346(8980):980.

2. Baron JH. History of informed medical consent. Lancet 1996;347(8998):410.

3. Rothman DJ. History of informed medical consent. Lancet 1995;346(8990):1633.

4. Eng Rep. Slater vs. Baker and Stapleton, 1767 (Slater vs. Baker and Stapleton 95 Eng Rep. 860 (k.b. 1767)).

5. Curran WJ, Hall MA, Kaye DH. Health care law, forensic science, and public policy, 4th edn. Little, Brown and Company, Boston 1990.

6. Altschuler EL. Informed consent in an Edgar Allen Poetale. Lancet 2003;362(9394):1504.

7. Poe EA. The fact in the case of M. Valdemar. Am Rev: Whig J Polit Lit Art Sci II(VI) 1845. http://digital. library.cornell.edu/cgi/t/text/text-idx?c=amwh;idno=amwh0002-6

8. Supreme Court of Minnesota. Mohr v. Williams (104 N.W. 12 Supreme Court of Minnesota) 1905.

9. Recent Decisions: Tort. assault and battery. Unauthorized surgical operation constitutes "assault and battery." Virginia Law Rev 1927;13(6):505. http://www.jstor.org/pss/1064659

10. N.E. Schoendorff v. Society of New York Hospital, 1914 (106N.E. 93 (N.Y. 1914))

11. Armstrong AP, Cole AA, Page RE. Informed consent: are we doing enough? Br J Plast Surg 1997;50(8):637-640

12. Katz J. Reflections on informed consent: 40 years after its birth. J Am Coll Surg 1998;186(4):466-474.

13. Langdon IJ, Hardin R, Learmonth ID. Informed consent for total hip arthroplasty: does a written information sheet improve recall by patients? Ann R Coll Surg Engl 2002;84(6): 404-408.

14. Vollmann J, Winau R. Informed consent in human experimentation before the Nuremberg code. BMJ 1996;313(7070):1445-1449.

15. P. Salgo v. Leland Stanford Jr. University Board of Trustees, 1957 (317 P.2d 170).

16. P. Natanson vs. Kline, 1960 (350 P.2d 1093).

17. WLR Bolam vs. Friern Hospital Management Committee, 1957 (1 WLR 583).

18. F. Canterbury vs. Spence, 1972 (464 F.2d 772 (d.c. 1972)).

19. Issa MM, Setzer $E, C$ Charaf $C$, et al. Informed versus uninformed consent for prostate surgery: the value of electronic consents. J Urol 2006;176(2):694-699.

20. Skene L, Smallwood R. Informed consent: lessons from Australia. BMJ 2002;324(7328): 39-41.

21. Kastelein WR. [Informed consent and medical liability: jurisprudence 1994-1998. Tijdschr Gezondhd 1998;22:134-146 [in Dutch].

22. P. Truman vs. Thomas, 1980 (611 P.2d 902 (Cal 1980))

23. World Health Organization Staff. Promotion of the Rights of Patients in Europe. In: Proceedings of a WHO Consultation 1995

24. Ashraff S, Malawa G, Dolan T, et al. Prospective randomised controlled trial on the role of patient information leaflets in obtaining informed consent. ANZ J Surg 2006;76(3):139-141

25. Pleat JM, Dunkin CS, Davies CE, et al. Prospective survey of factors affecting risk discussion during consent in a surgical specialty. Br J Surg 2004;91(10):1377-1380

26. Verbogt $\mathrm{S}$. Hoofdstukken over gezondheidsrecht (chapters in health law), 9th edn. Wolters-Noordhoff, Groningen, The Netherlands 2003. ISBN:9068905759.

27. Bernat JL, Peterson LM. Patient-centered informed consent in surgical practice. Arch Surg 2006;141(1):86-92.

28. Appelbaum PS. Clinical practice. Assessment of patients' competence to consent to treatment. N Engl J Med 2007357(18):1834-1840. 
29. Akkad A, Jackson C, Kenyon S, et al. Patients' perceptions of written consent: questionnaire study. BMJ 2006;333(7567):528.

30. Schouten B, Hoogstraten J, Eijkman M. Dutch dental patients on informed consent: knowledge, attitudes, self-efficacy and behaviour. Patient Educ Couns 2002;46(1):47-54.

31. Ghulam AT, Kessler M, Bachmann LM, et al. Patients' satisfaction with the preoperative informed consent procedure: a multicenter questionnaire survey in Switzerland. Mayo Clin Proc 2006;81(3):307312.

32. Godwin Y. Do they listen? A review of information retained by patients following consent for reduction mammoplasty. Br J Plast Surg 2000;53(2):121-125.

33. Kriwanek $S$, Armbruster $C$, Beckerhinn $P$, et al. Patients' assessment and recall of surgical information after laparoscopic cholecystectomy. Dig Surg 1998;15(6):669-673.

34. Pesudovs K, Luscombe CK, Coster DJ. Recall from informed consent counselling for cataract surgery. J Law Med 2006;13(4):496-504.

35. Shamsian N, Southern SJ, Wilkinson S, et al. What is the medicolegal implication of a Web-based threedimensional interactive virtual reality plastic surgery package? Plast Reconstr Surg 2005;116(6):1839_ 1840.

36. Keulers BJ, Scheltinga MR, Houterman S, et al. Surgeons underestimate their patients' desire for preoperative information. World J Surg 2008;32(6):964-970.

37. Angelos $P$, Darosa DA, Bentram D, et al. Residents seeking informed consent: are they adequately knowledgeable? Curr Surg 2002;59(1):115-118.

38. Leeper-Majors K, Veale JR, Westbrook TS, et al. The effect of standardized patient feedback in teaching surgical residents informed consent: results of a pilot study. Curr Surg 2003;60(6):615-622.

39. Soin B, Smellie WA, Thomson HJ. Informed consent: a case for more education of the surgical team. Ann R Coll Surg Engl 1993;75(1):62-65.

40. Bollschweiler E, Apitzsch J, Obliers R, et al. Improving informed consent of surgical patients using a multimedia-based program? Results of a prospective randomized multicenter study of patients before cholecystectomy. Ann Surg 2008;248(2):205-211.

41. Brezis $M$, Israel $S$, Weinstein-Birenshtock $A$, et al. Quality of informed consent for invasive procedures. Int J Qual Health Care 2008;20(5):352-357.

42. Eggers $C$, Obliers R, Koerfer A, et al. A multimedia tool for the informed consent of patients prior to gastric banding. Obesity (Silver Spring) 2007;15(11):2866-2873.

43. McGaughey I. Informed consent and knee arthroscopies: an evaluation of patient understanding and satisfaction. Knee 2004;11(3):237-242.

44. Lavelle-Jones $C$, Byrne DJ, Rice $P$, et al. Factors affecting quality of informed consent. BMJ 1993;306(6882):885-890.

45. Keating NL, Weeks JC, Borbas C, et al. Treatment of early stage breast cancer: do surgeons and patients agree regarding whether treatment alternatives were discussed? Breast Cancer Res Treat 2003; 79(2):225-231.

46. Kessler TM, Nachbur BH, Kessler W. Patients' perception.of preoperative information by interactive computer program—exemplified by cholecystectomy. Patient Educ Couns 2005;59(2):135-140.

47. Braddock $\mathrm{CH}$ III, Edwards KA, Hasenberg NM, et al. Informed decision making in outpatient practice: time to get back to basics. JAMA 1999;282(24):2313-2320.

48. Bottrell MM, Alpert $H$, Fischbach RL, et al. Hospital informed consent for procedure forms: facilitating quality patient-physician interaction. Arch Surg 2000;135(1):26-33.

49. Hopper KD, TenHave TR, Tully DA, et al. The readability of currently used surgical/procedure consent forms in the United States. Surgery 1998;123(5):496-503. 
50. Paasche-Orlow MK, Taylor HA, Brancati FL. Readability standards for informed-consent forms as compared with actual readability. N Engl J Med 2003;348(8):721-726.

51. Edwards AG, Weale AR, Morgan JD. Informed consent in renal transplantation. Postgrad Med J 2005;81(953):188-190.

52. Krause HR, Bremerich A, Rustemeyer J. Reasons for patients' discontent and litigation. J Craniomaxillofac Surg 2001;29(3):181-183.

53. Baum N. Informed consent—more than a form. J Med Pract Manag 2006;22(3):145-148.

54. Guadagnoli E, Soumerai SB, Gurwitz JH, et al. Improving discussion of surgical treatment options for patients with breast cancer: local medical opinion leaders versus audit and performance feedback. Breast Cancer Res Treat 2000;61(2):171-175.

55. Steinemann $S$, Furoy $D$, Yost $F$, et al. Marriage of professional and technical tasks: a strategy to improve obtaining informed consent. Am J Surg 2006;191(5):696-700.

56. Dimond B. Legal aspects of consent 22: nurses' position when obtaining consent. Br J Nurs 2002;11(4):281-283.

57. Stalmeier PF, Roosmalen MS, Verhoef LC, et al. The decision evaluation scales. Patient Educ Couns 2005; 57(3):286-293.

58. Edwards MH. Satisfying patients' needs for surgical information. Br J Surg 1990;77(4): 463-465.

59. Askew G, Pearson KW, Cryer D. Informed consent: can we educate patients? J R Coll Surg Edinb 1990;35(5):308-310.

60. Brown TF, Massoud E, Bance M. Informed consent in otologic surgery: prospective study of risk recall by patients and impact of written summaries of risk. J Otolaryngol 2003;32(6):368-372.

61. Chan Y, Irish JC, Wood SJ, et al. Patient education and informed consent in head and neck surgery. Arch Otolaryngol Head Neck Surg 2002;128(11):1269-1274.

62. Danino AM, Lile A, Moutel G, et al. Visual documentation of oral consent: a new method of informed consent before major gigantomastia reduction for an illiterate population. Plast Reconstr Surg 2006;117(4):1370-1371.

63. Dawes PJ, O'Keefe L, Adcock S. Informed consent: using a structured interview changes patients' attitudes towards informed consent. J Laryngol Otol 1993;107(9):775-779.

64. Deyo RA, Cherkin DC, Weinstein J, et al. Involving patients in clinical decisions: impact of an interactive video program on use of back surgery. Med Care 2000;38(9):959-969.

65. Hermann M. 3-dimensional computer animation-a new medium for supporting patient education before surgery. Acceptance and assessment of patients based on a prospective randomized studypicture versus text. Chirurg 2002;73(5):500-507.

66. Keulers BJ, Welters CF, Spauwen PH, et al. Can face-to-face patient education be replaced by computer-based patient education? A randomised trial. Patient Educ Couns 2007; 67(1-2):176-182.

67. Layton S, Korsen J. Informed consent in oral and maxillofacial surgery: a study of the value of written warnings. Br J Oral Maxillofac Surg 1994;32(1):34-36.

68. Makdessian AS, Ellis DA, Irish JC. Informed consent in facial plastic surgery: effectiveness of a simple educational intervention. Arch Facial Plast Surg 2004;6(1):26-30.

69. Mason V, McEwan A, Walker D, et al. The use of video information in obtaining consent for female sterilisation: a randomised study. BJOG 2003;110(12):1062-1071.

70. Masood J, Hafeez A, Wiseman O, et al. Informed consent: are we deluding ourselves? A randomized controlled study. BJU Int 2007;99(1):4-5.

71. Moseley TH, Wiggins MN, O'Sullivan P. Effects of presentation method on the understanding of informed consent. Br J Ophthalmol 2996;90(8):990-993. 
72. O'Neill P, Humphris GM, Field EA. The use of an information leaflet for patients undergoing wisdom tooth removal. Br J Oral Maxillofac Surg 1996;34(4):331-334.

73. Rossi MJ, Guttmann D, MacLennan MJ, et al. Video informed consent improves knee arthroscopy patient comprehension. Arthroscopy 2005;21(6):739-743.

74. Shurnas PS, Coughlin MJ. Recall of the risks of forefoot surgery after informed consent. Foot Ankle Int 2003;24(12):904-908.

75. Stanley BM, Walters DJ, Maddern GJ. Informed consent: how much information is enough? AustNZ J Surg 1998;68(11):788-791.

76. Wadey $\mathrm{V}$, Frank $C$. The effectiveness of patient verbalization on informed consent. Can J Surg 1997;40(2):124-128.

77. Hopper KD, Zajdel M, Hulse SF, et al. Interactive method of informing patients of the risks of intravenous contrast media. Radiology 1994;192(1):67-71.

78. Jimison HB, Sher PP, Appleyard R, et al. The use of multimedia in the informed consent process. J Am Med Inform Assoc 1998;5(3):245-256.

79. Klima S, Hein W, Hube A, et al. Multimedia preoperative patient information. Chirurg 2005; 76(4):398-403. 




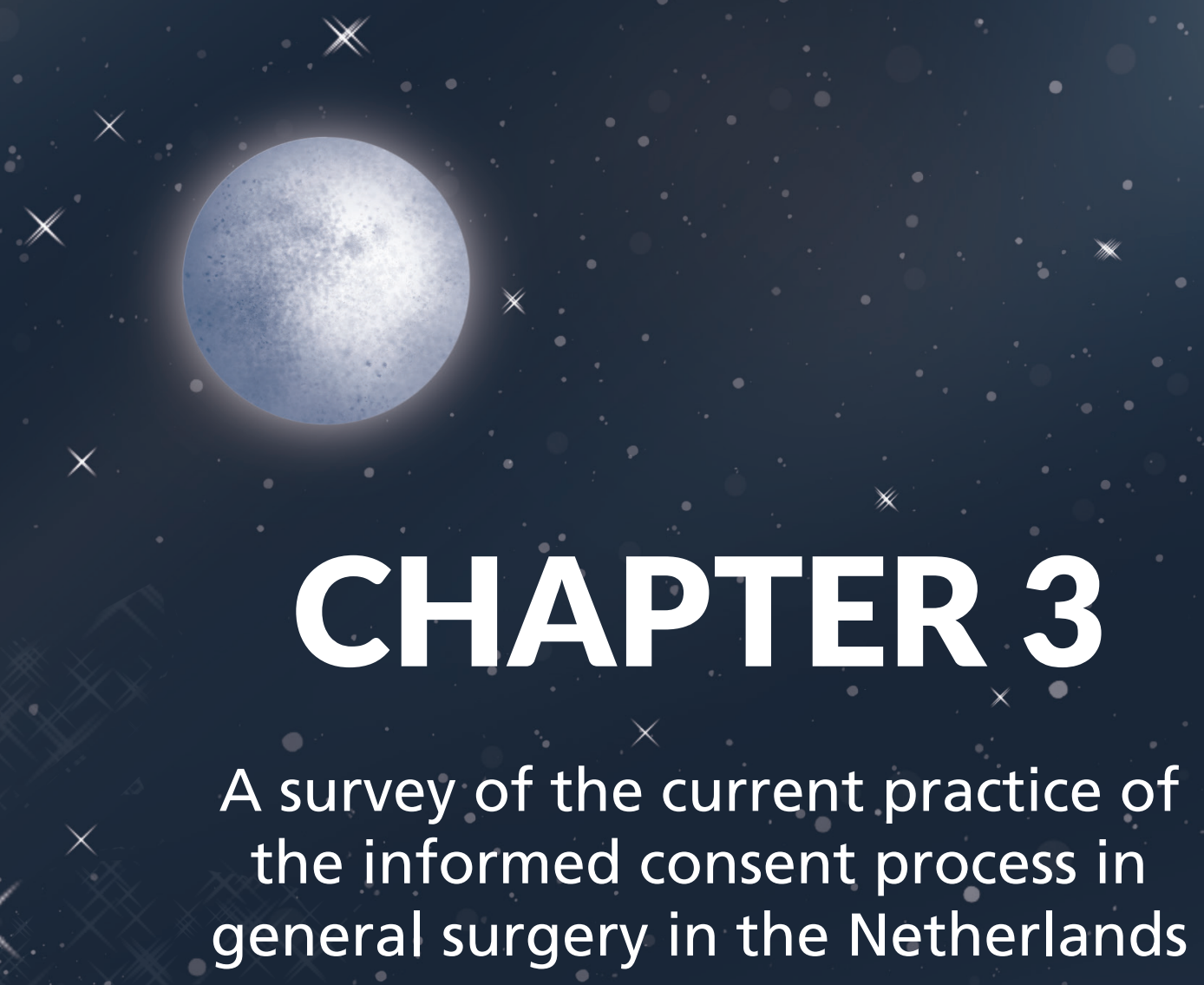

\section{CHAPTER 3}

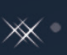

Wouter K.G. Leclercq, Bram J. Keulers, Saskia Houterman, Margot Veerman, Johan Legemaate, Marc R. Scheltinga

Patient Safety in Surgery 2013;7(1):4

\section{x}

$x$ 


\section{ABSTRACT}

\section{Background}

A properly conducted surgical informed consent process (SIC) allows patients to authorize an invasive procedure with full comprehension of relevant information including involved risks. Current practice of SIC may differ from the ideal situation. The aim of this study is to evaluate whether SIC practiced by Dutch general surgeons and residents is adequate with involvement of all required elements.

\section{Methods}

All members of the Dutch Society of Surgery received an online multiple choice questionnaire evaluating various aspects of SIC.

\section{Results}

A total of 453 questionnaires obtained from surgeons and residents representing $>95 \%$ of all Dutch hospitals were eligible for analysis (response rate 30\%). Knowledge on SIC was limited as only 55\% was familiar with all three basic elements ('assessment of preconditions', 'provision of information' and 'stage of consent'). Residents performance was inferior compared to surgeons regarding most aspects of daily practice of SIC. One in 6 surgeons (17\%) had faced a SIC-related complaint in the previous five years possibly illustrating suboptimal SIC implementation in daily surgical practice.

\section{Conclusions}

The quality of the current SIC process is far from optimal in the Netherlands. Surgical residents require training aimed at improving awareness and skills. The SIC process is ideally supported using modern tools including web-based interactive programs. Improvement of the SIC process may enhance patient satisfaction and may possibly reduce the number of complaints. 


\section{BACKGROUND}

It is common surgical practice to provide patients with the opportunity to consent to an operative procedure. Moreover, a surgical informed consent process (SIC) is considered a conditional element of standard surgical patient care. The basic elements presupposed by the Nuremberg and Helsinki code, the U.S. National Institute of Health and the World Health Organization are 'assessment of preconditions', 'provision of information' and the 'stage of consent' (Figure 3.1). ${ }^{1-4} \mathrm{~A}$ properly conducted SIC process is an interactive and structured process resulting in fully informed patients who are truly able to make an informed decision on risks and benefits of a treatment, alternative treatment options or postponing surgery. ${ }^{1,5-7}$ Past, present and future aspects of SIC were discussed in a previous contribution. ${ }^{1}$ Conversely, an inadequate SIC compromises patient autonomy, creates potential risks, diminishes patient satisfaction and trust in their surgeon and thereby jeopardizes the patient-physician relationship. Moreover, SIC violation may lead to a disciplinary tribunal, assault or battery action..$^{8,9}$

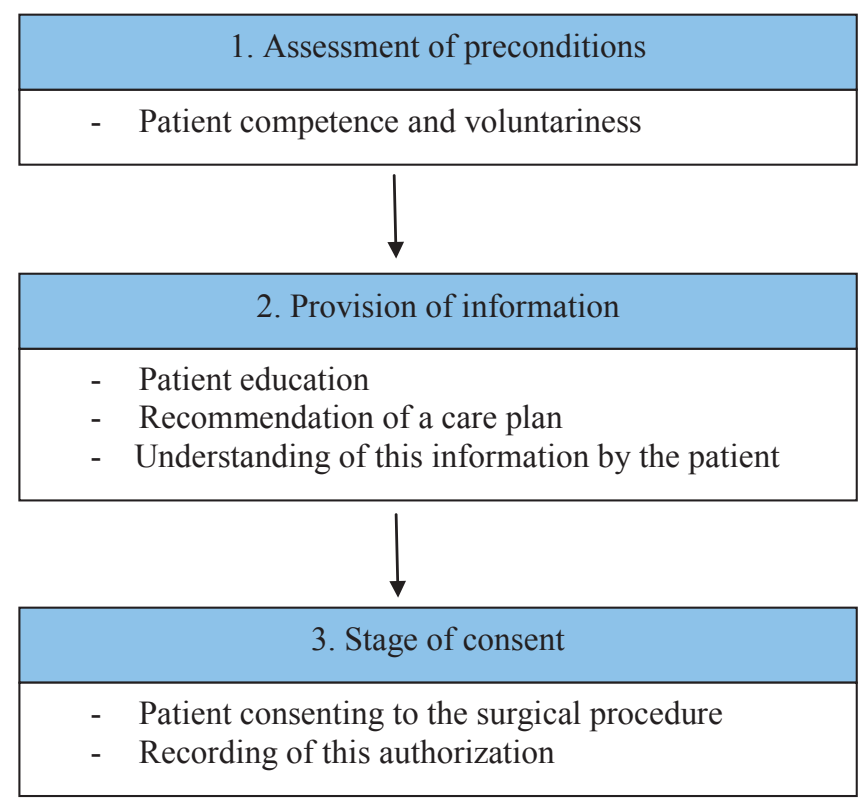

Figure 3.1 Three elements of informed consent.

In the Netherlands, surgical patients are predominantly treated in 94 public hospitals around the country (8 university, 26 large teaching and 60 general hospitals). A limited number of private clinics (10\%) provide a restricted volume of outpatient surgical care. 
All doctors including senior and junior staff are legally allowed to execute SIC. Specifics of SIC are anchored in the 1995 Dutch Medical Treatment Contract Act (Wet Geneeskundige Behandelings Overeenkomst, WGBO). More recently, the Royal Dutch Medical Association (Koninklijke Nederlandse Maatschappij ter bevordering van de Geneeskunst, KNMG) published a specific guideline in a 'Handbook of Informed Consent'. ${ }^{10}$ In 2009 a guideline for 'the preoperative route' initiated by the Dutch Institute for Healthcare Improvement (Centraal Beleids Orgaan, CBO) was published with even more strict guidelines. ${ }^{11}$ In 2010, the Dutch Society of Surgery (Nederlandse Vereniging voor Heelkunde, NVvH) and the Dutch Society of Anaesthesia (Nederlandse Vereniging voor Anesthesie, NVA) implemented this guideline as the gold standard. ${ }^{12}$ Although written consent is strongly recommended, a signature of the patient or medical representative is not legally required. ${ }^{12}$

Even though improvements in SIC were attained in recent years, other studies suggest that the implementation of SIC is still suboptimal in surgical practice. ${ }^{1,3}$ Surgical staff may overestimate patient's competence to make well informed decisions whereas patients are often unaware or misinformed on the role of SIC. 1,3,13,14 Surgeons may also underestimate the extent of information that is expected by their patients. ${ }^{15}$ Some aspects of the information may not be understood. Moreover, patients understanding is not routinely checked. ${ }^{3,5,16-20}$ Organisation and recording of the SIC process is often poor. ${ }^{21-23}$ Training of residents may vary as considerable geographical differences in knowledge were found. ${ }^{14,23}$ Whether these shortcomings are also present in the Netherlands is unknown.

The aim of this study is to evaluate the reported daily practice of Dutch surgeons and residents regarding characteristics of the SIC process. We hypothesized that levels of knowledge and skills are suboptimal and may differ between Dutch surgeons and residents. 


\section{METHODS}

\section{Questionnaire}

The study was initiated by the Department of Surgery of Máxima Medical Centre (MMC) in Veldhoven, the Netherlands. MMC is a teaching hospital serving a population of 350,000 patients in a semi-rural area in the southeastern part of the country. Ethical approval was obtained from the hospital's Institutional Review Board. A primordial version of a self designed questionnaire was tested on a limited number of staff members and residents $(n=3)$. Criticisms and suggestions led to an improved version that was again tested on a different portion of the surgical senior and junior staff $(n=5)$ as an online pilot questionnaire. After a final check for ambiguities and linguistic errors, the online questionnaire contained 23 multiple choice questions concerning general characteristics of the respondent, knowledge of SIC and various other aspects of daily practice on SIC (Appendix 3.1).

Endorsed and facilitated by the Dutch Society of Surgery, an e-mail linked to the online questionnaire was sent to all actively practicing surgeons and surgical residents throughout the Netherlands in the month of May 2010. This population consisted of 1,065 surgeons $(90 \%$ practicing, $10 \%$ retired) and 453 other members practising in all Dutch public hospitals and private clinics (90\% residents, 10\% researchers, other MD's interested in surgery). Surgeons $(S)$ and residents $(R)$ were the focus of the current study as both groups are regularly involved in the SIC process. ${ }^{23,24} \mathrm{~A}$ reminder was sent to all non-responders one month later, shortly followed by an official study closure one month thereafter.

Statistical analysis

All data were collected in an online database, checked for duplicates and immediately rendered anonymous. Statistical analyses were performed using version 18 SPSS, Chicago, Illinois, USA. Descriptive statistics were used to analyse the data. $X^{2}$ and Fisher's Exact tests were used to compare data obtained from surgeons with data from residents. A $P<0.05$ was considered significant.

Results

Representativeness

Questionnaires were received from 96\% (90/94) of all public hospitals and from four private ones. Incomplete or duplicate questionnaires were excluded from the study as well as questionnaires from researchers and other members $(n=10)$. A total of 453 questionnaires were eligible for processing, representing a 30\% response rate (453/1518; 296 surgeons (S), 157 residents ( $R$, Figure 3.2). Almost one third (32\%) of the respondents were experienced surgeons ( $>10$ years), one third (33\%) was $0-10$ years active as a surgeon and the remaining $35 \%$ consisted of residents. Distribution over type of hospital was almost even (university $29 \%$, teaching 36\%, general 35\%). 


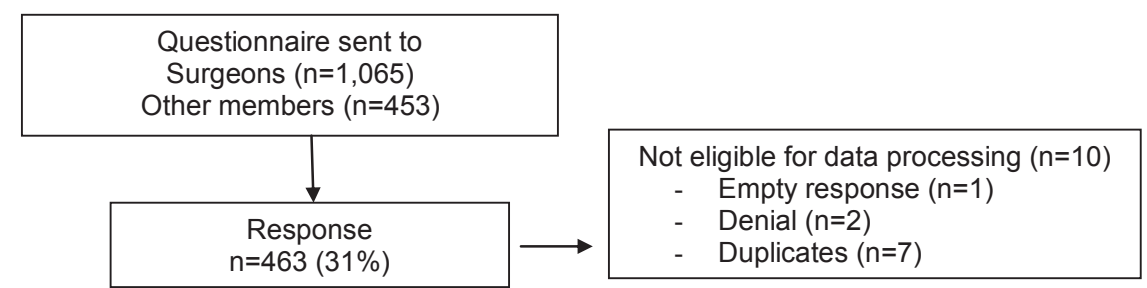

Eligible for data processing $\mathrm{n}=453(30 \%)$

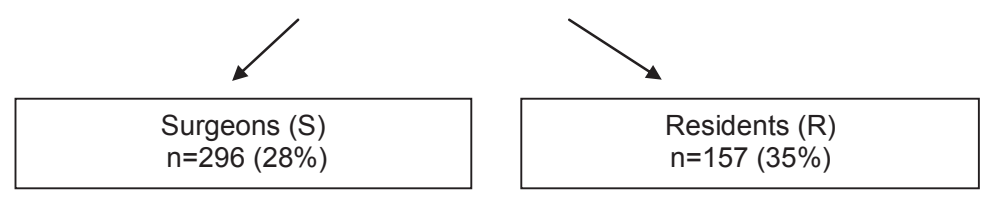

Figure 3.2 Response to surgical informed consent questionnaire.

Knowledge of SIC elements

SIC consists of three elements (Figure 3.1). When asked to point these out, almost all respondents (92\%) were familiar with the element of 'provision of information' (Table 3.1). However, 'assessment of preconditions' and 'stage of consent' were less known by surgeons compared to residents (competence: S 55\% vs. R 73\%, P<0.001; consent: S $86 \%$ vs. R 92\%, $P=0.041$; Table 3.1). One-third of both groups were wrongly convinced that a signature of either surgeon or patient was necessary for a legally sound consent procedure.

Table 3.1 Which elements form an informed consent process.

\begin{tabular}{|c|c|c|c|c|c|c|}
\hline Q-Nr & Element of SIC & $\begin{array}{l}\text { Question: Is the following } \\
\text { item required in SIC }\end{array}$ & $\begin{array}{c}\text { Total } \\
\text { Y/N \% } \\
(n=453)\end{array}$ & $\begin{array}{l}\text { Surgeons } \\
\text { Y/N \% } \\
(n=296)\end{array}$ & $\begin{array}{c}\text { Residents } \\
\text { Y/N \% } \\
(n=157)\end{array}$ & P-value \\
\hline \multirow[t]{5}{*}{18} & $\begin{array}{l}\text { Assessment of } \\
\text { preconditions }\end{array}$ & Evaluation of competence & $62 / 38 \%$ & $55 / 45 \%$ & $73 / 27 \%$ & $<0.001$ \\
\hline & $\begin{array}{l}\text { Provision of } \\
\text { information }\end{array}$ & Patient education & $92 / 8 \%$ & $91 / 9 \%$ & $94 / 6 \%$ & 0.37 \\
\hline & Stage of consent & Recording of consent & $88 / 12 \%$ & $86 / 14 \%$ & $92 / 8 \%$ & 0.041 \\
\hline & & Patients' signature & $31 / 69 \%$ & $29 / 71 \%$ & $34 / 66 \%$ & 0.30 \\
\hline & & Surgeons' signature & $36 / 64 \%$ & $34 / 66 \%$ & $41 / 59 \%$ & 0.16 \\
\hline
\end{tabular}

Q-NR = Question number as reported in Appendix 3.1. SIC = Surgical informed consent. Y/N\% = Percentage of persons in this category who answers positive / negative. 
SIC in daily practice

More than two-thirds (68\%) of all respondents did not realize that they are obliged to inform their patients on SIC and patient rights (Question 14). Responses varied widely regarding who is in charge of providing patients with this information (Question 15). Some judged the surgeon responsible (S $42 \%$ vs. R 29\%, $P=0.01$ ), whereas others thought the resident (S 24\% vs. R 36\%, P=0.004) or the nursing staff (S 9\% vs. R 3\%, $P=0.01$ ) were responsible. Some were convinced leaflets would suffice (S $12 \%$ vs. R 5\%, P=0.01).

By Dutch law, a SIC is required for elective and emergency surgical procedures. Almost half (49\%) of the respondents indeed followed this regimen, whereas the other half ignored this requirement (Table 3.2). The latter half obtained SIC only for elective procedures $(28 \%)$ or decided whether a SIC was necessary on an individual basis (23\%).

\section{Elements of SIC}

\section{Assessment of preconditions}

The first step in the SIC process is checking the patient's competence on making an informed decision regarding his/her own body and whether this decision is made freely. The respondents almost always (98\%) judged these issues on the basis of a personal impression. In contrast, questionnaires or other validated tools were hardly used (1\%; Table 3.2).

\section{Provision of information}

The vast majority (98\%) provided various specifics on diagnosis and surgical procedure. Surgeons performed better on discussing alternative treatment options compared to residents (S 89\% vs. R 80\%, P=0.017). Surprisingly, 39\% claimed that there was no institutional standard on quality and quantity of information that was deemed necessary to communicate to a patient in the preoperative stage (Table 3.2).

Another important issue is the disclosure of potential risks and complications. Surgeons were more often aware of the department's general agreement on complication rates to be used compared to residents ( $58 \%, \mathrm{R} 40 \%, \mathrm{P}<0.001$, Table 3.2). Most respondents used a $1 \%$ or $5 \%$ complication incidence cut-off point for informing patients (34\% or $51 \%$, respectively, Question 13). If a complication was considered serious, respondents were more willing to discuss this untoward event with their patients (S 81\%, R 74\%, $P=0.062$, Question 13). Overall, surgeons used specific complication rates more frequently compared to residents. Sources were literature based (S 73\%, R 56\%, P<0.001), department-specific (S 35\%, R 17\%, P<0.001) or based on individual results (S 23\%, R $3 \%, \mathrm{P}<0.001$ ) (Table 3.2). 
In case of complex interventions, the surgeon is legally expected to check whether the patient comprehended the information. The repeat back method (RB) is considered gold standard. ${ }^{16}$ However, this method was only used by $14 \%$ of the respondents whereas the vast majority ( $86 \%$ ) relied on less reliable methods including asking 'if everything was understood' or 'are there any questions', or judged on the basis of their own intuition (Table 3.2).

\section{Stage of consent}

The use of IC forms is not obligatory in the Netherlands. However, a minority (26\%) of the respondents used these forms whereas $65 \%$ made notes in the surgical record; $9 \%$ made no report of SIC at all (Question 6). Nearly half (46\%) routinely checked if a SIC was obtained before starting a surgical procedure (Table 3.2).

\section{SIC support tools}

Tools to support patient education were used more frequently by surgeons compared to residents (Table 3.3). Leaflets (97\%) were popular in contrast to websites (S 37\%, R 24\%, $\mathrm{P}=0.008$ ) or movies (S 16\%, R 8\%, $\mathrm{P}=0.019$ ). Almost half of all respondents also relied on other staff members for patient information (48\%). 76\% were interested in using SIC software (S 79\%, R 71\%, P=0.038).

Medicolegal consequence of SIC

The majority of the respondents (94\%) judged a proper SIC important for themselves (Question 19). Interestingly, just 73\% thought that their patients also considered a sound SIC important (Question 20). Some 17\% of the surgeons faced an officially filed complaint regarding improper SIC in the previous five years compared to $3 \%$ of the residents $(P<0.001$, Question 21). Non-university hospital surgeons were significantly more at risk for these complaints compared to university hospitals colleagues ( $21 \%$ vs. $7 \%, P=0.004$ ). 


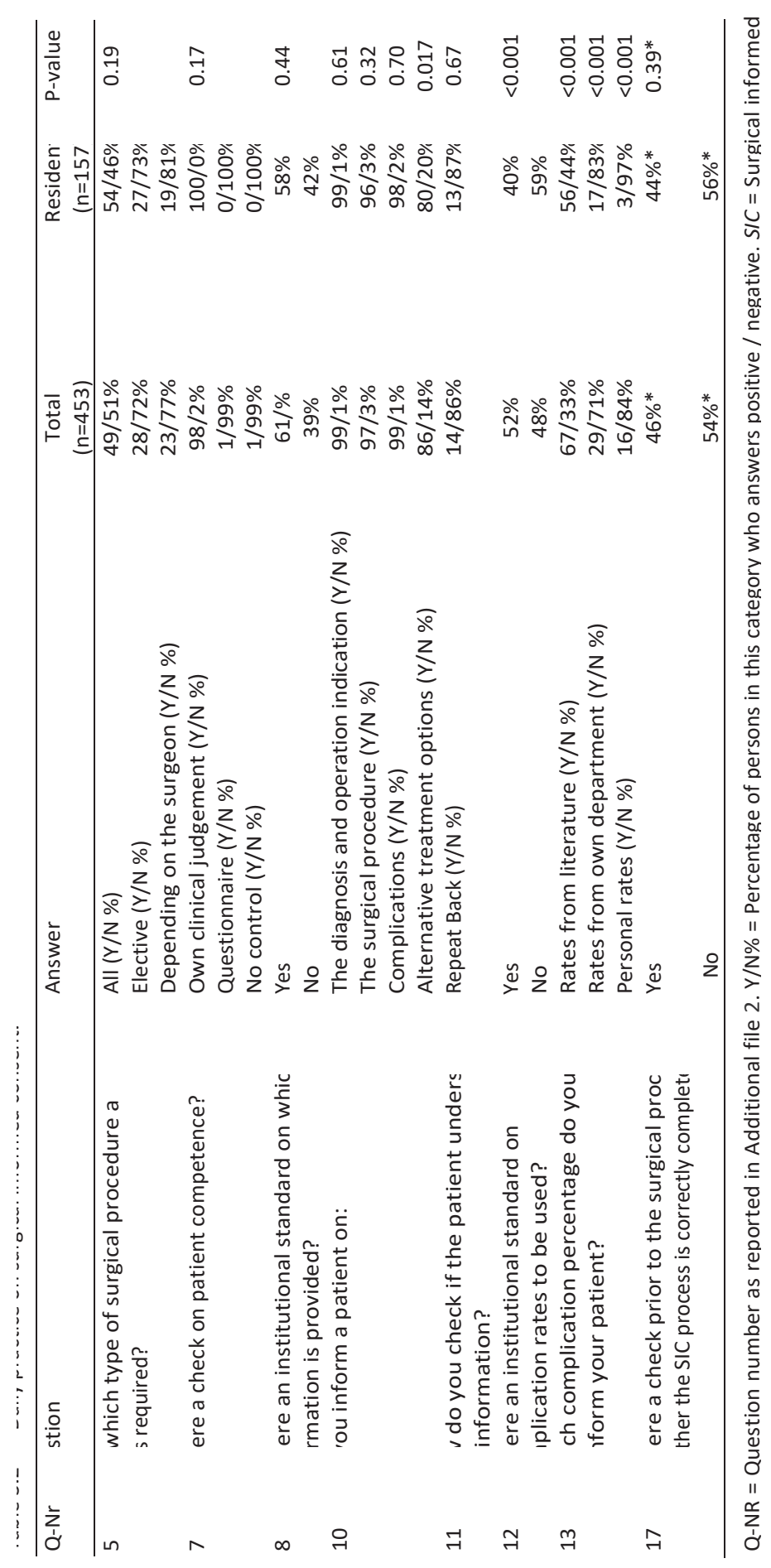




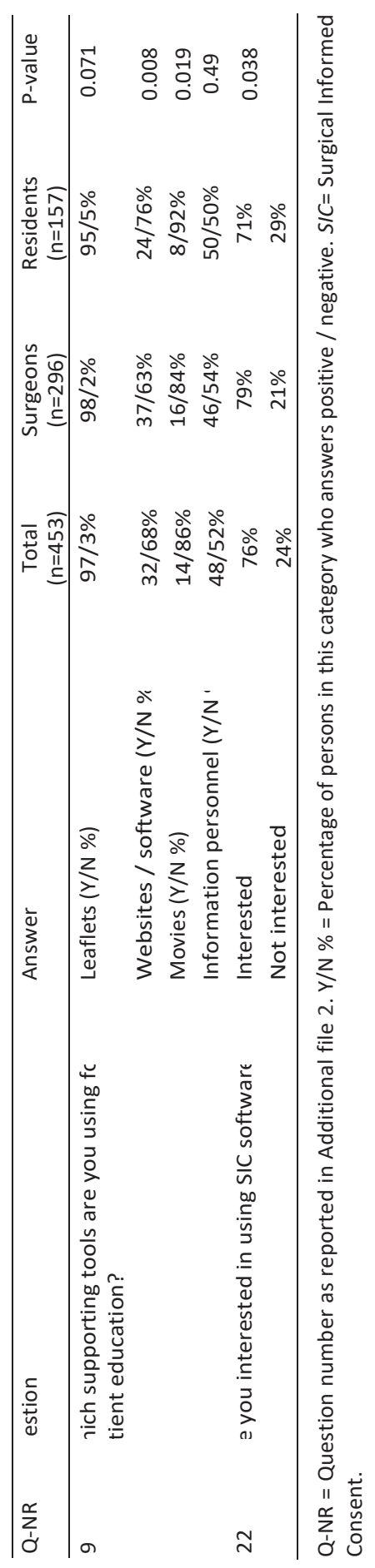




\section{DISCUSSION}

The aim of this study was to investigate the daily practice of the SIC process by general surgeons and residents in the Netherlands. It was assumed that level of knowledge and skills were suboptimal. Results of the present study indeed confirmed this hypothesis. Interestingly, considerable differences between knowledge levels of surgeons and residents regarding various elements of SIC were identified. It may be assumed that lack of knowledge, training and structure in the SIC process may result in a suboptimal implementation in daily practice. Conversely, an optimized SIC process may enhance patient compliance, safety, satisfaction and trust, leading to an improved physician-patient relationship.

The present study is the first of its kind in the Netherlands. However, a lack of knowledge on most aspects of SIC is consistently found in various other studies investigating surgical staffs in Europe, USA and New Zealand. . $5,14,25-27$ Residents performed worse compared to surgeons in Ireland, Germany, UK and USA.23-25,28 They do not feel confident due to a lack of training $5,13,23,24,26,29$, and up to $60 \%$ of residents in the USA claimed that they never received any feedback on these issues during their residency. ${ }^{29,30}$ In recent years, informed consent was topic of debate in the USA and the UK and improvements in care followed. However, this debate was not so intense in the Netherlands. Dutch surgeons judge the process of SIC important but they are faced with uncertainties in daily practice. Which aspects of SIC are obligatory and which are accessory? Residents were familiar with some elements of SIC but evidently lacked practical knowledge and practice on other aspects of SIC. The recently updated curriculum for Dutch surgical residents referred to SIC only twice and just in general terms. ${ }^{31}$ Moreover, training for surgical residents is only starting to be implemented. It may well be that surgeons still improve their knowledge the hard way, that is through complaints and legal actions. Future surgical residents require optimized training in SIC using specific courses supported by supervision in daily practice. An option would be to incorporate an educational SIC programme in the early phase (year 1-2) of the surgical residency.

Structuring a SIC process will improve its quality, completeness and legal solidity. Moreover, it will improve patient satisfaction, safety and prevent high impact malpractice claims. ${ }^{1,32-35}$ In recent years, preoperative safety programs (SURPASS) have structured and improved patient safety significant, but there was little interest in the aspects of $\mathrm{SIC} .{ }^{33} \mathrm{~A}$ standard SIC form was introduced and successfully implemented in daily practice in various countries including Australia and the UK. ${ }^{23}$ According to the present study, the SIC process in the Netherlands is highly dependent on local and personal circumstances. Therefore this process requires standardization and implementation in preoperative safety programs. A substantial number of respondents would like to receive specific forms that are designed to guide doctors and patients through the steps of the SIC process. ${ }^{23}$ 
Is proper introduction and implementation of SIC in daily practice considered a nuisance by surgical staffs? All steps of the process require substantial amounts of precious consultation time. Theoretically, modern tools including computer based techniques may be used to facilitate SIC. Computers provide structure, improve quality, diminish consultation time and stimulate patient commitment. ${ }^{1}$ At present, surgeons and residents are not using these tools for SIC on a large scale but the majority claim an open mind regarding the use of interactive software in the future. ${ }^{23,24}$ Unfortunately, development of these programs in Europe nowadays is at the level of small pilot studies. ${ }^{1}$ In the US however, the iMed program is fully implemented. ${ }^{16,36}$ Further studies are necessary to explore and introduce these web-based interactive programs on a larger scale in Europe. ${ }^{8}$

The present study may suffer from several shortcomings, as it reports on the daily practice using multiple-choice questions. Reporting bias may therefore be of influence although completing the questionnaire was voluntary and results were made anonymous. Although a $30 \%$ response rate is comparable to results obtained from other studies, the topic of the present study and e-mailing rather than post mailing may have negatively influenced this response rate. 5,28,37-42 Selection bias may have been of influence even though the response rate of surgeons and residents (65\% vs. 35\%) closely reflects the present Dutch surgical population (70\% vs. 30\%). Moreover, a response was received from $96 \%$ of all hospitals whereas the existing types of hospitals were equally distributed. ${ }^{41}$ We therefore feel that this study is representative for the current practice of surgeons and surgical residents in the Netherlands. However, the lack of validated questionnaires and few comparable studies render interpretation of our results somewhat hazardous. It is obvious that more studies are needed to confirm these results. Strengths of this study include the voluntary setting of this survey with a response of a substantial amount $(n>450)$ of individuals and the support of the Dutch Society of Surgery. The comparison between surgeons and residents incidentally, showed large differences in knowledge and practice. Interestingly, several respondents declared that the questionnaire itself was very instructive and opened discussions within their departments potentially suggesting an improved awareness and a more solid role of SIC in future surgical practice.

In conclusion, the quality of the current SIC process is suboptimal in the Netherlands. Surgical residents require training aimed at improving awareness and skills. The SIC process is ideally supported using modern tools including web-based interactive programs. Improvement of the SIC process may enhance patient satisfaction and may possibly reduce the number of complaints. 


\section{REFERENCES}

1. Leclercq WK, Keulers BJ, Scheltinga MR, Spauwen PH, van der Wilt GJ: A review of surgical informed consent: past, present, and future. A quest to help patients make better decisions. World J Surg 2010;34:1406-1415.

2. Legemate DA, Legemaate J: [The preoperative informed consent procedure]. Ned Tijdschr Geneeskd 2010;154:A2492.

3. Schenker $Y$, Meisel A: Informed consent in clinical care: practical considerations in the effort to achieve ethical goals. JAMA 2011;305:1130-1131.

4. Jefford M, Moore R: Improvement of informed consent and the quality of consent documents. Lancet Oncol 2008;9:485-493.

5. Abed H, Rogers R, Helitzer D, Warner TD: Informed consent in gynecologic surgery. Am J Obstet Gynecol 2007;197:674-675.

6. Kenton K, Pham T, Mueller E, Brubaker L: Patient preparedness: an important predictor of surgical outcome. Am J Obstet Gynecol 2007;197:654-656.

7. McKneally MF, Martin DK, Ignagni E, D'Cruz J: Responding to trust: surgeons' perspective on informed consent. World J Surg 2009;33:1341-1347.

8. Schenker $Y$, Fernandez A, Sudore R, Schillinger D: Interventions to improve patient comprehension in informed consent for medical and surgical procedures: a systematic review. Med Decis Making 2011;31:151-173.

9. Chassin MR, Becher EC: The wrong patient. Ann Intern Med 2002;136:826-833.

10. Royal Dutch Medical Association (KNMG): [Guidebook Informed Consent]. 2001. http:// www. kiesbeter.nl/object_binary/o798_vademecum\%20informed \%20consent\%20knmg.pdf.

11. Dutch Institute for Healthcare Improvement (Centraal Beleids Orgaan C: [Guideline the preoperative route]. 2009. http://www.cbo.nl/Downloads/934/rl_preop_traject_10.pdf.

12. Dutch Institute for Healthcare Improvement (Centraal Beleids Orgaan C: [Guideline the peroperative route]. 2010. http://wWW.nvpc.nl/stand/70NVPC111103DOC-MW-Richtlijn\%20Het\%20 Peroperatieve\%20 Traject\%20def.pdf.

13. Jukic M, Kozina S, Kardum G, Hogg R, Kvolik S: Physicians overestimate patient's knowledge of the process of informed consent: a cross-sectional study. Med Glas Ljek komore Zenicko -doboj kantona 2011;8:39-45.

14. Jukic M, Kvolik S, Kardum G, Kozina S, Tomic JA: Knowledge and practices of obtaining informed consent for medical procedures among specialist physicians: questionnaire study in 6 Croatian hospitals. Croat Med J 2009;50:567-574.

15. Timmermans D, Molewijk B, Stiggelbout A, Kievit J: Different formats for communicating surgical risks to patients and the effect on choice of treatment. Patient Educ Couns 2004; 54:255-263.

16. Fink AS, Prochazka AV, Henderson WG, Bartenfeld D, Nyirenda C, Webb A, Berger DH, Itani K, Whitehill T, Edwards J, et al: Enhancement of surgical informed consent by addition of repeat back: a multicenter, randomized controlled clinical trial. Ann Surg 2010;252:27-36.

17. Falagas ME, Akrivos PD, Alexiou VG, Saridakis V, Moutos T, Peppas G, Kondilis BK: Patients' perception of quality of pre-operative informed consent in athens Greece: a pilot study. PLoS One 2009;4:e8073.

18. Knops AM, Ubbink DT, Legemate DA, de Haes JC, Goossens A: Information communicated with patients in decision making about their abdominal aortic aneurysm. Eur J Vasc Endovasc Surg 2010;39:708-713. 
19. Berman L, Dardik A, Bradley EH, Gusberg RJ, Fraenkel L: Informed consent for abdominal aortic aneurysm repair: assessing variations in surgeon opinion through a national survey. J Vasc Surg 2008;47:287-295.

20. Rajab TK, Wallwiener M, Talukdar S, Kraemer B: Adhesion-related complications are common, but rarely discussed in preoperative consent: a multicenter study. World J Surg 2009;33:748-750.

21. Bottrell MM, Alpert H, Fischbach RL, Emanuel LL: Hospital informed consent for procedure forms: facilitating quality patient-physician interaction. Arch Surg 2000;135:26-33.

22. Paasche-Orlow MK, Taylor HA, Brancati FL: Readability standards for informed-consent forms as compared with actual readability. N Engl J Med 2003;348:721-726.

23. Chen AM, Leff DR, Simpson J, Chadwick SJ, McDonald PJ: Variations in consenting practice for laparoscopic cholecystectomy. Ann R Coll Surg Engl 2006;88:482-485.

24. Schildmann J, Cushing A, Doyal L, Vollmann J: Informed consent in clinical practice: pre-registration house officers' knowledge, difficulties and the need for postgraduate training. Med Teach 2005;27:649-651.

25. Wenger NS, Lieberman JR: An assessment of orthopaedic surgeons' knowledge of medical ethics. J Bone Joint Surg Am 1998;80:198-206.

26. Peters $C$ : Consenting to medical treatment: legal requirements vs medical practice. Are healthcare providers exposing themselves to potential legal action? N Z Med J 2009;122: 50-59.

27. Fisher-Jeffes L, Barton C, Finlay F: Clinicians' knowledge of informed consent. J Med Ethics 2007;33:181-184.

28. O'Dwyer HM, Lyon SM, Fotheringham T, Lee MJ: Informed consent for interventional radiology procedures: a survey detailing current European practice. Cardiovasc Intervent Radiol 2003;26: 428-433.

29. Gaeta T, Torres R, Kotamraju R, Seidman C, Yarmush J: The need for emergency medicine resident training in informed consent for procedures. Acad Emerg Med 2007;14:785-789.

30. Hutul OA, Carpenter RO, Tarpley JL, Lomis KD: Missed opportunities: a descriptive assessment of teaching and attitudes regarding communication skills in a surgical residency. Curr Surg 2006;63: 401-409.

31. Hamming J, Borel Rinkes I, Heineman E: Curriculum for surgical residents in the Netherlands (Scherp Structuur Curriculum Heelkunde voor Reflectieve Professionals. Opleidingsplan Heelkunde). 2008.

32. Keulers BJ, Scheltinga MR, Houterman S, van der Wilt GJ, Spauwen PH: Surgeons underestimate their patients' desire for preoperative information. World J Surg 2008;32: 964-970.

33. de Vries EN, Eikens-Jansen MP, Hamersma AM, Smorenburg SM, Gouma DJ, Boermeester MA: Prevention of surgical malpractice claims by use of a surgical safety checklist. Ann Surg 2011;253: 624-628.

34. Krause HR, Bremerich A, Rustemeyer J: Reasons for patients' discontent and litigation. J Craniomaxillofac Surg 2001;29:181-183.

35. Betti S, Sironi A, Saino G, Ricci C, Bonavina L: Effect of the informed consent process on anxiety and comprehension of patients undergoing esophageal and gastrointestinal surgery. J Gastrointest Surg 2011;15:922-927.

36. Fink AS, Prochazka AV, Henderson WG, Bartenfeld D, Nyirenda C, Webb A, Berger DH, Itani K, Whitehill T, Edwards J, et al: Predictors of comprehension during surgical informed consent. J Am Coll Surg 2010;210:919-926.

37. Wauben LS, van Veelen MA, Gossot D, Goossens RH: Application of ergonomic guidelines during minimally invasive surgery: a questionnaire survey of 284 surgeons. Surg Endosc 2006;20:1268-1274. 
38. Manthous CA, DeGirolamo A, Haddad C, Moateng-Adjepong Y: Informed consent for medical procedures: local and national practices. Chest 2003;124:1978-1984.

39. Pleat JM, Dunkin CS, Davies CE, Ripley RM, Tyler MP: Prospective survey of factors affecting risk discussion during consent in a surgical specialty. Br J Surg 2004;91:1377-1380.

40. Dawes PJ, Kitcher E: Informed consent: British otolaryngologists surveyed. Clin Otolaryngol Allied Sci 1999;24:198-207.

41. Buddingh KT, Hofker HS, ten Cate Hoedemaker HO, van Dam GM, Ploeg RJ, Nieuwenhuijs VB: Safety measures during cholecystectomy: results of a nationwide survey. World J Surg 2011;35(6):1235-41.

42. Barton $A$, Williams $D$, Beveridge $M$ : A survey of Canadian general surgery residents' interest in international surgery. Can J Surg 2008;51:125-129. 


\section{APPENDIX 3.1. THE QUESTIONNAIRE}

1. Name

2. Type of surgical staff

3. Type of hospital

4. Does your department have a standard procedure describing the informed consent process?

5. For which surgical procedures is the informed consent process held?

6. In which way is the informed consent process recorded?

7. How do you verify if a patient is competent to make an informed consent about his / her surgical procedure?

8. Does your department have a standard, what information is being told to a patient in a pre-operative consult?

9. Are the following support tools used in informing your patients at your outpatient clinic?

10. Which of the following points are discussed with the patient in a pre-operative consult?

11. How do you verify if the patient has understood the information?

12. Which complications do you always discuss with your patient?

13. Which complication percentage do you use to inform your patient?

14. Is the patient being educated in what informed consent consists of?

15. If so, who is educating the patient?

16. Where is the informed consent form being stored?

17. Is there a check just before the surgical procedure if the informed consent process is being held correctly?

18. Of what elements consists the informed consent process according to you?

19. How important is the informed consent process in total patient care according to you?

20. How important is the informed consent process in total patient care according to the patient in your opinion?

21. Have you had any legal cases in which informed consent was part of the complaint?

22. Are you interested in software helping to inform patients about their surgical procedure and to fulfil the informed consent process?

23. Do you have any remarks? 

X

0

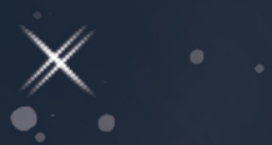

0

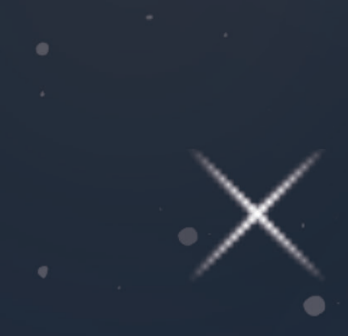

$x$

。

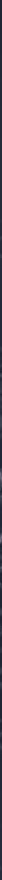

$$
\bullet
$$

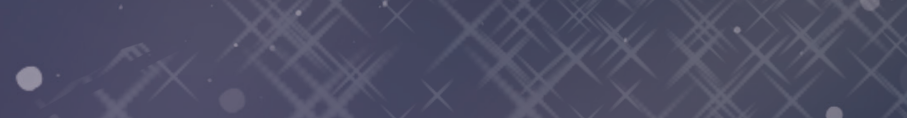

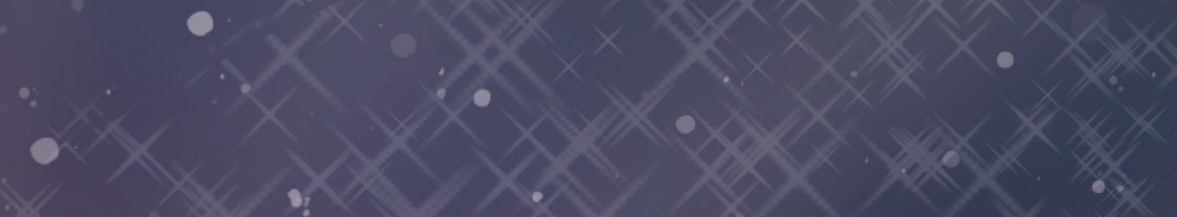

\section{\% $20 \div$}

$10.0 \times$

$\therefore \quad 0 \times 200$

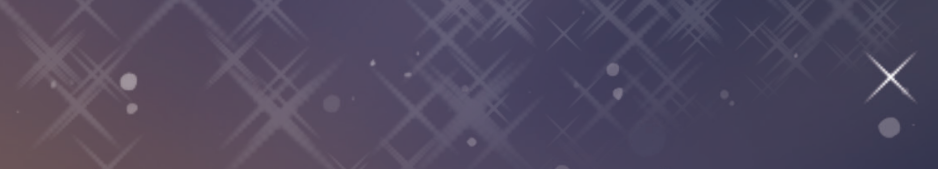

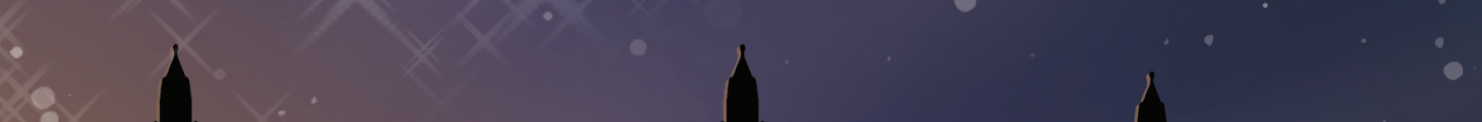

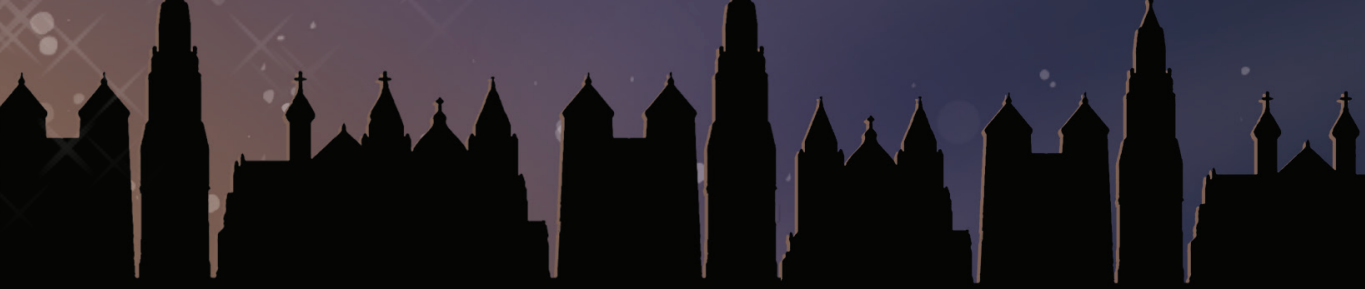




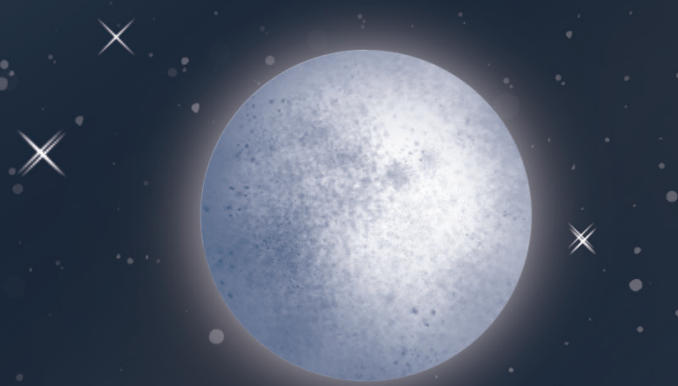

$$
\text { CHAPTER } 4
$$

Challenging the knowledge base and skillset for providing surgical consent by orthopaedic and plastic surgeons in the Netherlands: an identified area of improvement in patient safety

Wouter K.G. Leclercq, Sarah Slọot, Bram J. Keulers, Saskia Houterman, Johan Legemaate, Margot Veerman, Leslie Thomas, Marc R. Scheltinga

Patient Safety in Surgery (2016) 10:21

x 


\section{ABSTRACT}

\section{Background}

Successfully completing a surgical informed consent process is an important element of the preoperative consult. A previous study of Dutch general surgeons demonstrated that the implementation of SIC did not meet acceptable standards. However, the quality of the SIC process in the orthopaedic surgical or plastic surgical arena is unknown.

\section{Methods}

Following ethical approval, an online survey investigating specifics of surgical informed consent was performed among members of the Dutch Scientific Association of Orthopaedic Surgeons and the Dutch Society for Plastic Surgery.

\section{Results}

A total of 335 responses from a majority of departments of orthopaedic (86\%) and plastic surgery $(78 \%)$ were eligible for analysis. Scores on knowledge were poor as only $50 \%$ recognized the three basic elements of surgical informed consent (competence, exchange of information and consent). The orthopaedic group used more tools in the surgical informed consent process, such as instruction movies and websites or specialized nursing staff, compared to plastic surgery (orthopaedic: $31-50 \%$ vs. plastic: $6-30 \%, P=0.05-$ $<0.001)$. In contrast, surgical informed consent forms were used more frequently by the plastic surgical group (orthopaedic $21 \%$ vs. plastic:42\% $\mathrm{P}<0.001$ ). Control of the efficacy of the surgical informed consent process was low, $36 \%$ in both groups. One in every seven orthopaedic or plastic surgeons was faced with an official surgical informed consent-related complaint in the previous five years.

\section{Conclusions}

Similar to general surgeons, Dutch orthopaedic and plastic surgeons demonstrate poor knowledge and skills regarding surgical informed consent. Increased awareness, better training and use of modern tools including standard forms and online software programs will improve the SIC process and will optimize patient care. 


\section{BACKGROUND}

Each patient is entitled to detailed information prior to an invasive or a surgical procedure. Once properly educated by a surgeon, a shared decision is made whether or not to perform the proposed operation. These basic rights and obligations are incorporated into the surgical informed consent (SIC) process. ${ }^{1-4}$ However, daily practice is troublesome as just a minority of patients are offered the opportunity to complete all stages of this SIC process. ${ }^{3,5,6}$ General goals of SIC are to anchor the patient's authority and to enhance safety, satisfaction and compliance. 3,5,6 If the quality of the SIC process is high, patients are better informed and more compliant while results after surgery may be optimized. , $^{3,6}$ Moreover, patient expectations are more realistic, resulting in more trust in their surgeon and/or surgical procedure and eliciting fewer complaints. $3,5,6$

Since 1995, the Dutch Medical Treatment Contract Act (WGBO) has provided legal requirements on informed consent in the Netherlands. This act describes the legal boundaries of SIC in a civil law approach - in other words, in a contract that is made between a healthcare provider and a patient. ${ }^{7}$ In contrast, other countries may have explored alternative views. For instance, legislation in Scandinavia is based upon a public approach formulating 'obligations imposed on physicians and other healthcare providers'. Therefore, a private contract between one doctor and one patient is not required in these countries. $^{7}$

Although details of legislation differ per country, the three elements of SIC are equal in western countries. Features of consecutive steps of a correctly executed SIC process were previously reported (Figure 4.1).3,8 Firstly, it should be checked whether patients are competent and free (without pressure) to decide. Secondly, information on diagnosis, prognosis, procedures, benefits, risks and alternative strategies including postponing surgery should be provided. A check on whether the information is understood is also required. The final stage includes adequate recording. Written consent for invasive procedures is strongly recommended, although a patient's (or representative's) signature is not obliged in many European countries, including the Netherlands. ${ }^{7}$

A recent survey investigating daily practice regarding SIC demonstrated that knowledge of general surgeons (GS) in the Netherlands was inadequate and guidelines were often not followed. ${ }^{9}$ Only $55 \%$ of surgeons were familiar with the three basic elements of SIC. Daily practice varied widely between surgeons and residents. This practice resulted in $17 \%$ of the surgeons facing an SIC-related complaint in the previous five years. Several other Dutch surgical organizations, including the Scientific Association of Orthopaedic 
Surgeons and the Dutch Society for Plastic Surgery, have also adopted guidelines on SIC. ${ }^{10,11}$ However, it is unknown whether these Dutch specialists perform any better regarding these issues compared to their fellow general surgeons.

The general aim of this study was to analyze knowledge and daily practice concerning SIC in orthopaedic surgeons (OS) and plastic surgeons (PS). As OS and PS procedures are mainly elective and frequently based upon functional or cosmetic complaints, it was hypothesized that both of these subspecialists would score comparably regarding knowledge and skills in SIC. Moreover, both groups were expected to have more knowledge and a better implementation in daily practice when compared with general surgeons. Possible differences between surgeons and their residents were also studied.

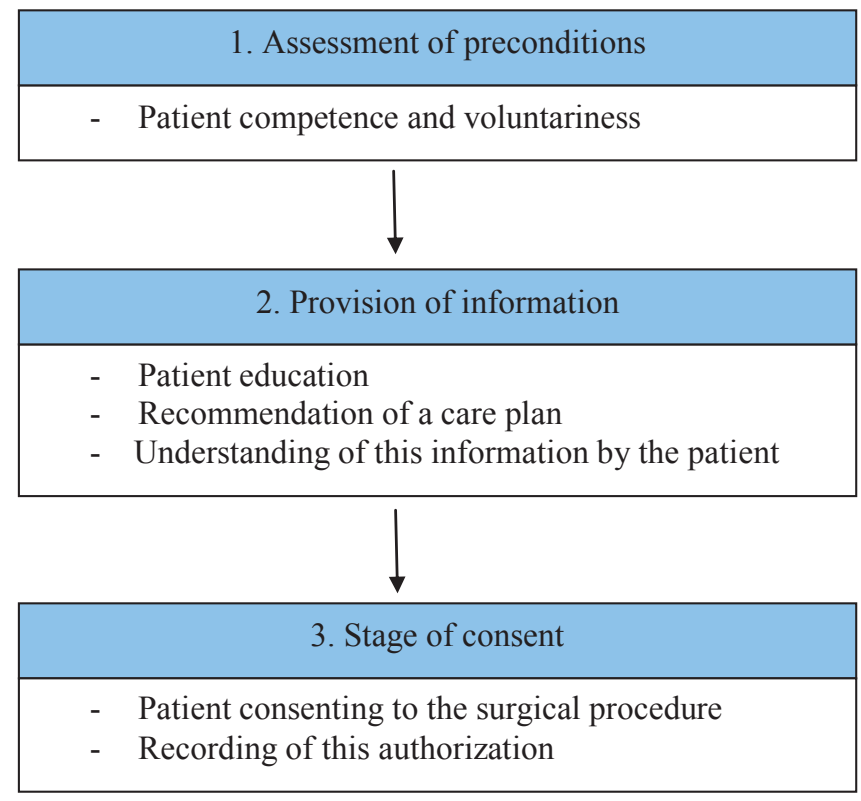

Figure 4.1 Elements of informed consent. 


\section{METHODS}

The study was performed between January 2011 and December 2011 in Máxima Medical Centre, a large teaching hospital in the southern part of the Netherlands. Orthopaedic surgical procedures were performed in all 94 public Dutch hospitals (8 university, 26 large teaching and 60 general hospitals). Plastic surgery is primarily offered in larger hospitals (approximately 50/94). Orthopaedic and plastic surgical care are also provided on a much smaller scale in a limited number of private clinics serving as day care facilities.

Details of the survey were published previously. ${ }^{9}$ In summary, an existing questionnaire that was used in a survey among general surgeons was modified and optimized by an OS (JVM) and a PS consultant (HW) (Appendix 4.1). All questions were multiple choice. General characteristics, knowledge and daily practice were asked. Endorsed and facilitated by both the Scientific Association of Orthopaedic Surgeons (NOV) and the Dutch Society for Plastic Surgery (NVPC), an e-mail linked to an online multiple-choice questionnaire was sent in February 2011 and October 2011 to all actively practicing OS and PS surgeons and residents in the Netherlands (Table 4.1). A reminder was sent to non-responders one month later, shortly followed by an official study closure towards the end of 2011. Participants were excluded from analysis if they did not recently work in the Netherlands.

Table 4.1 Population and response.

\begin{tabular}{cccc}
\hline & Total number & Response & Percent \\
\hline Total & 1177 & 335 & 28.5 \\
Surgeons & 879 & 265 & 30.1 \\
Residents & 298 & 70 & 23.5 \\
OS total & 843 & 253 & 30.0 \\
Surgeons & 624 & 206 & 33.0 \\
Residents & 219 & 45 & 20.5 \\
PS total & 334 & 84 & 25.1 \\
Surgeons & 255 & 59 & 23.1 \\
Residents & 79 & 25 & 31.6 \\
\hline
\end{tabular}

OS Orthopaedic Surgery, PS Plastic Surgery.

Ethics, consent and permissions

Ethical approval was obtained from the Institutional Review Board of Máxima Medical Centre. 
Statistical analysis

All data were collected in an online database, checked for duplicates, and immediately rendered anonymous. Descriptive statistics were used to analyze the data. $X^{2}$ or Fisher's Exact tests (in the case of small numbers) were used to compare OS with PS surgeons and surgeons with residents. A $\mathrm{P}<0.05$ was considered significant. Statistical analyses were performed using version 18 SPSS, Chicago, Illinois, USA. 


\section{RESULTS}

Representativeness of the study

Responses were received from 81 of the 94 OS departments (86\%) and 39 of the 50 PS departments (78\%). 335 individual answers (28\%, 335 of 1177$)$ from surgeons $(S, n=267)$ and residents $(R, n=70)$ were eligible for analysis (Table 4.1). General characteristics of both groups are presented in Table 4.2. Of course, age and experience differ between $S$ and $\mathrm{R}$, but there were also age and experience differences between OS and PS surgeons (Table 4.1).

Table 4.2 General characteristics.

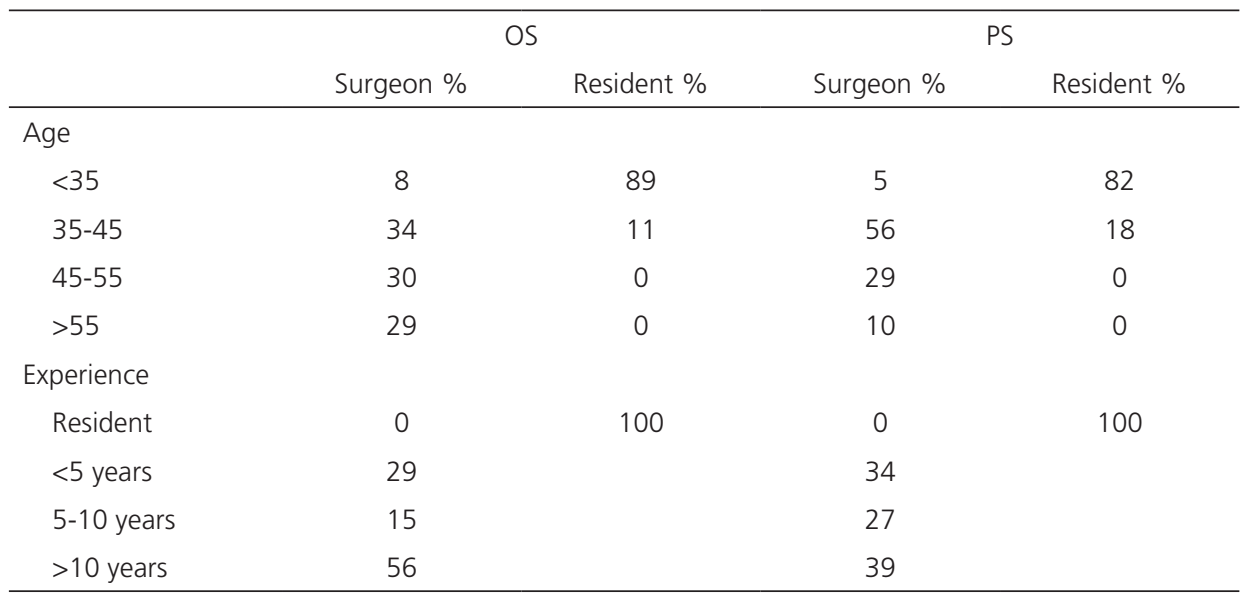

OS Orthopaedic Surgery, PS Plastic Surgery. Age: $n=312$ (missing value, $n=23$ ). Experience: $n=335$

Knowledge of SIC elements

Just over half (OS 51\%, PS 55\%, ns) of the respondents were aware that a competence check of the patient is part of the SIC process (Question 18, Table 3). Almost all responders (93\%) knew that providing information is the second obligatory aspect of SIC. Interestingly, the awareness on the third aspect of SIC ("recording") was significantly better in the OS group compared to the PS group ( $\mathrm{P}=0.002)$. Overall, one in four surgeons was not aware that recording of SIC is an essential step (S 74\%, R 91\%, P<0.002, not in table). Moreover, the PS group erroneously thought significantly more often than the OS group that a signature of either patient $(P=0.0001)$ or doctor $(P=0.0001)$ is necessary for adequately recording SIC (Table 4.3). 
SIC in daily practice

Only 37\% of the respondents informed their patients on the SIC process itself (Q14). 40 $\%$ considered the surgeon responsible for informing patients on SIC. The role for residents regarding this task was considered significantly different by surgeons as compared to residents ( $R$ 43\% vs. S 17\%, P<0.0001, not in table). Very few respondents relied on nursing staff or leaflets as a means to inform patients on SIC (Q18).

From a legal standpoint, patients have to give consent to any invasive or operative procedure. Just $37 \%$ of the respondents always asked for consent whereas the remaining did not. $31 \%$ asked for consent only in elective cases and $32 \%$ only in cases where consent was deemed crucial by the doctor (Q5).

Elements of SIC

Assessment of preconditions

Almost all respondents (98\%) checked patient competence. However, very few used questionnaires or checklists (3\%), so the majority relied on their own judgment $(95 \%)$ (Q7).

\section{Provision of information}

Sixty-six percent of the respondents claimed to have a standard operating procedure (SOP) regarding specifics of standard information that was communicated to the patient in the preoperative situation (Q8). There was a high consistency regarding the information given to the patients on diagnosis (99\%), operative procedure (97\%) and complications (98\%). There was no difference between OS and PS in informing their patients about alternative treatment options (OS 89\%, PS 89\%, ns). However, significantly more surgeons (92\%) claimed to inform their patients about alternatives compared to residents $(80 \%, \mathrm{P}<0.005$, not in table) (Q10).

An SOP regarding communication of potential complications associated with the procedure was significantly more present in the OS group compared to the PS group (OS $60 \%$ vs. PS $44 \%, P<0.01$, not in table). Surgeons were more aware of having a SOP on complication information than residents (S 59\% vs. R 44\%, P<0.025, not in table) (Q13).

One of three respondents (34\%) never specified the incidence of a complication, whereas $66 \%$ used complication rates from the literature. $31 \%$ of the surgeons used department rates, and $18 \%$ also provided personal complication rates. Compared to surgeons, residents were far less likely to provide complication rates from their departments (S 31\% vs. $\mathrm{R} 21 \%, \mathrm{P}=0.04$ ) or personal rates ( $18 \%$ vs. $\mathrm{R} 1 \%, \mathrm{P}<0.001$, not in table). 
Several methods may be used by a surgeon to verify whether information is understood by his patient. Merely asking if a patient has any questions or asking if everything is understood is not sufficient. The repeat back method is far more adequate, but this method is seldom used by either group (9\%) (Q11).

Stage of consent

Although SIC forms are not obligatory in the Netherlands, the PS group used them significantly more often compared to the OS group (OS $21 \%$ vs. PS $42 \%, P=0.001$ ) (Q6).

An important element of patient safety programs is a preoperative check on whether SIC was followed ${ }^{9,12}$ (Kuo CC and Robb WJ 3rd, 2012, Leclercq WK et al., 2013) $(9 ; 12)$ $(9 ; 12)(9 ; 12)(10 ; 13)$. However, just one of 3 respondents $(36 \%)$ claimed to check for an adequate preoperative consent (Q17).

\section{SIC support tools}

Various tools may aid surgeons and residents in facilitating the SIC process. Leaflets containing patient information were frequently used by all parties (98\%). However, other tools such as movies, software programs/websites and nursing staff for informing patients were more often used by the OS group (Q9). Significantly more surgeons than residents used modern tools such as websites to inform patients (OS surgeons $55 \%$ vs. OS residents $27 \%, \mathrm{P}<0.0001$; PS surgeons $39 \%$ vs. PS residents $16 \%, \mathrm{P}=0.04$, not in table).

Seventy-nine percent of the respondents claimed to have an interest in using interactive computer programs for SIC (Q22).

Medicolegal consequence of present day SIC practice Most respondents stated that they believed SIC was especially important for medical staff (89\%). In contrast, only 57\% thought that patients were aware of the importance of SIC (Q19). A total of 15\% (OS 12\%, PS 16\%, ns) of the surgeons and $7 \%$ (OS $4 \%$, PS $9 \%$, ns) of the residents had received one or more SIC-related official complaint in the preceding five years (Q21, not in table). 


\section{DISCUSSION}

A previous study demonstrated that SIC is poorly implemented in the daily practice of Dutch general surgeons. ${ }^{3}$ One explanation was a possible high percentage of (semi-) acute procedures in general practice. Conversely, as procedures in the orthopaedic and plastic surgical fields are mainly elective, it was hypothesized that the process of SIC would be better implemented in these two groups. However, the knowledge in the OS and PS groups were not better compared to GS (checking for competence OS 51\%, PS 55\%, GS $62 \%$; recording of consent OS 79\%, PS 75\%, GS $88 \%$ ). In daily practice this same observation can be made. To our surprise, the OS and PS asked less often for consent, even in elective cases, compared to GS (OS 38\%, PS 32\%, GS 49\%); moreover, a pre-operative check if consent was adequately provided by the patient was at least equally worse (OS $37 \%$, PS $32 \%$, GS $46 \%$ ). This same observation can be made in almost all questions asked. There was one exemption: Slightly more respondents in this study reported to have a standard operating procedure (SOP) for SIC in their department (OS 66\%, PS 69\%, GS $61 \%)$. Results of the present study generally indicate that knowledge and daily skills of SIC are also limited in both orthopaedic and plastic practices. Moreover, surgeons and residents performed equally poorly.

Most European law countries (including the Scandinavian) have strict laws on patient rights and SIC. Previous studies show low knowledge scores on most issues concerning SIC, and consequently, daily practice is suboptimal..$^{3,13}$ In many studies the use of SOPS, tools and standard forms enhances the quality of patient care. 5,6,14 In this study, knowledge was poor and the daily practice results were substandard. Improvement of the SIC process in the orthopaedic and plastic surgical field is required.

Solutions to improve the quality of the SIC process are available. Better training for medical staff should enhance the knowledge on SIC and should be implemented in surgical traineeships; introduction of best practice SOPs, adequate tools and standard SIC forms should enhance daily practice. SIC forms can aid medical staff during the SIC process if designed properly. ${ }^{15-17}$ In the PS group $42 \%$ already used SIC forms, compared to $21 \%$ of the OS group. The use of interactive online SIC programs might be the next leap forward. 3,9 Many respondents were interested in using interactive tools to aid the SIC process. We have developed an online SIC program for patients referred for several procedures such as blepharoplasty, basal cell carcinoma of the skin, breast reduction surgery and inguinal hernia repair. These programs will be tested in upcoming trials to test feasibility in daily practice. 
The strength of this study is the high response rate from many departments over the country and the opportunity to compare these results with our earlier study in the GS group. Some differences between the OS and PS groups are found, but on the majority of the questions, results are in concordance with this previous study. ${ }^{9}$

There are, however, also limitations to this study. SIC is not a very popular topic in the surgical field, and we had trouble getting respondents. The low individual response rate reflects this matter, and selection bias is therefore possible. But if present, this study is likely to provide too optimistic of a view of reality as the results of the respondents were not good, and they might even be lower in the rest of the population who did not respond. Many respondents asked for more training and better SOPs, forms and tools, and hopefully this article will help to improve awareness on this topic and enhance the quality of the SIC process in the future. 


\section{CONCLUSIONS}

In conclusion, informed consent in surgery is a rapidly developing area in medicine. ${ }^{8}$ The role of surgeons in SIC is truly important and determines its quality. The SIC process is, however, complex. Transmitting correct and adequate information to make the patient well informed is crucial. ${ }^{8}$ There are many tools to aid patients: Not solely to inform of surgical complication rates, but also to aid the patient in the decision making process and to reinforce the bond between surgeon and patient. ${ }^{8}$ Current developments in SIC are not implemented in daily practice, according to this study, but many opportunities are available to improve the SIC process as wanted by many patients and doctors. 


\section{REFERENCES}

1. Ajlouni KM. History of informed medical consent. Lancet. 1995;346:980.

2. Baron JH. History of informed medical consent. Lancet. 1996;347:410.

3. Leclercq WK, Keulers BJ, Scheltinga MR, Spauwen PH, van der Wilt GJ. A review of surgical informed consent: past, present, and future. A quest to help patients make better decisions. World J Surg. 2010;34:1406-15.

4. Sobel D, Popp PL. Informed consent and expectation management: a case study. J Healthc Risk Manag. 2006;26:21-6.

5. Farrell EH, Whistance RN, Phillips K, Morgan B, Savage K, Lewis V, et al. Systematic review and metaanalysis of audio-visual information aids for informed consent for invasive healthcare procedures in clinical practice. Patient Educ Couns. 2014;94:20-32.

6. Kinnersley P, Phillips K, Savage K, Kelly MJ, Farrell E, Morgan B, et al. Interventions to promote informed consent for patients undergoing surgical and other invasive healthcare procedures. Cochrane Database Syst Rev. 2013;7:CD009445.

7. Patient Rights in the EU. A General Overview of the national patient rights legislation in Europe. Katholieke Universiteit Leuven Centre for Biomedical Ethics and Law. http://europatientrights.eu/. 2008.

8. Cainzos MA, Gonzalez-Vinagre S. Informed consent in surgery. World J Surg. 2014;38:1587-93.

9. Leclercq WK, Keulers BJ, Houterman S, Veerman M, Legemaate J, Scheltinga MR. A survey of the current practice of the informed consent process in general surgery in the Netherlands. Patient Saf Surg. 2013;7:4.

10. KNMG. Consult informed consent. KNMG; 2001.

11. Centraal Beleids Orgaan C. Richtlijn het peroperatieve proces. 1-3-2010.

12. Kuo CC, Robb WJ 3rd. Critical roles of orthopaedic surgeon leadership in healthcare systems to improve orthopaedic surgical patient safety. Clin Orthop Relat Res. 2013;471(6):1792-800.

13. Cailliez J, Reina N, Molinier F, Chaminade B, Chiron P, Laffosse JM. Patient information ahead of anterior cruciate ligament reconstruction: Experience in a university hospital center. Orthop Traumatol Surg Res. 2012;98:491-8.

14. de Vries EN, Prins HA, Crolla RM, den Outer AJ, van Andel G, van Helden SH, et al. Effect of a comprehensive surgical safety system on patient outcomes. N Engl J Med. 2010;363:1928-37. doi:10.1056/NEJMsa0911535.

15. Bottrell MM, Alpert $H$, Fischbach RL, Emanuel LL. Hospital informed consent for procedure forms: facilitating quality patient-physician interaction. Arch Surg. 2000;135:26-33.

16. Paasche-Orlow MK, Taylor HA, Brancati FL. Readability standards for informed-consent forms as compared with actual readability. N Engl J Med. 2003;348:721-6.

17. Rahman L, Clamp J, Hutchinson J. Is consent for hip fracture surgery for older people adequate? The case for pre-printed consent forms. J Med Ethics. 2011;37:187-9. 


\section{APPENDIX 4.1. THE QUESTIONNAIRE}

1. Name

2. Type of surgical staff

3. Type of hospital

4. Does your department have a standard procedure describing the informed consent process?

5. For which surgical procedures is the informed consent process held?

6. In which way is the informed consent process recorded?

7. How do you verify if a patient is competent to make an informed consent about his / her surgical procedure?

8. Does your department have a standard, what information is being told to a patient in a pre-operative consult?

9. Are the following support tools used in informing your patients at your outpatient clinic?

10. Which of the following points are discussed with the patient in a pre-operative consult?

11. How do you verify if the patient has understood the information?

12. Which complications do you always discuss with your patient?

13. Which complication percentage do you use to inform your patient?

14. Is the patient being educated in what informed consent consists of?

15. If so, who is educating the patient?

16. Where is the informed consent form being stored?

17. Is there a check just before the surgical procedure if the informed consent process is being held correctly?

18. Of what elements consists the informed consent process according to you?

19. How important is the informed consent process in total patient care according to you?

20. How important is the informed consent process in total patient care according to the patient in your opinion?

21. Have you had any legal cases in which informed consent was part of the complaint?

22. Are you interested in software helping to inform patients about their surgical procedure and to fulfil the informed consent process?

23. Do you have any remarks? 

$\mathbb{x}$

0

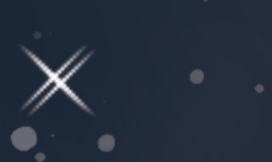

0

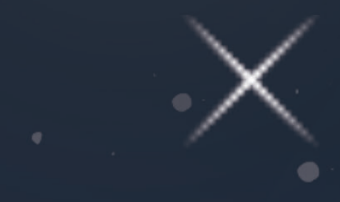

$x$

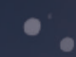
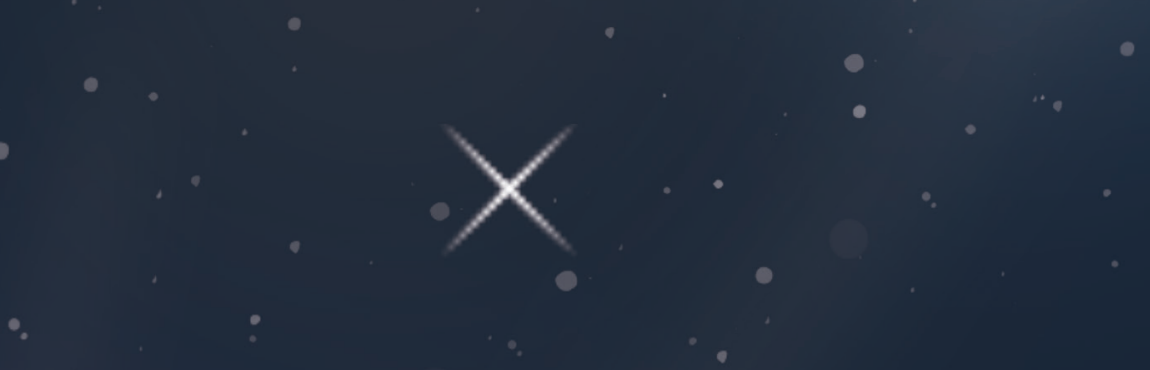

$$
\text { ๑. }
$$

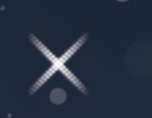

\section{$0 \times+2 \times 1 \times$}

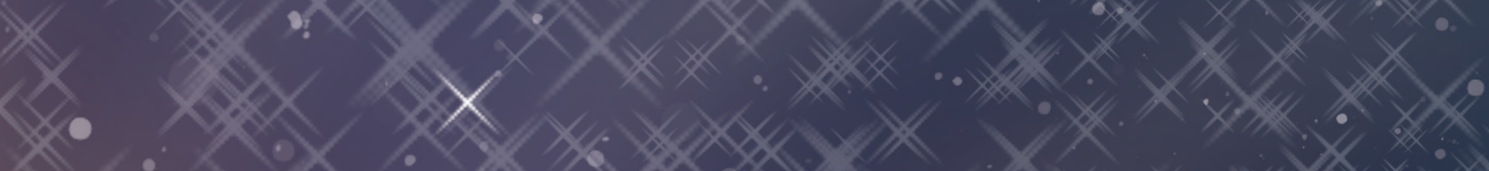

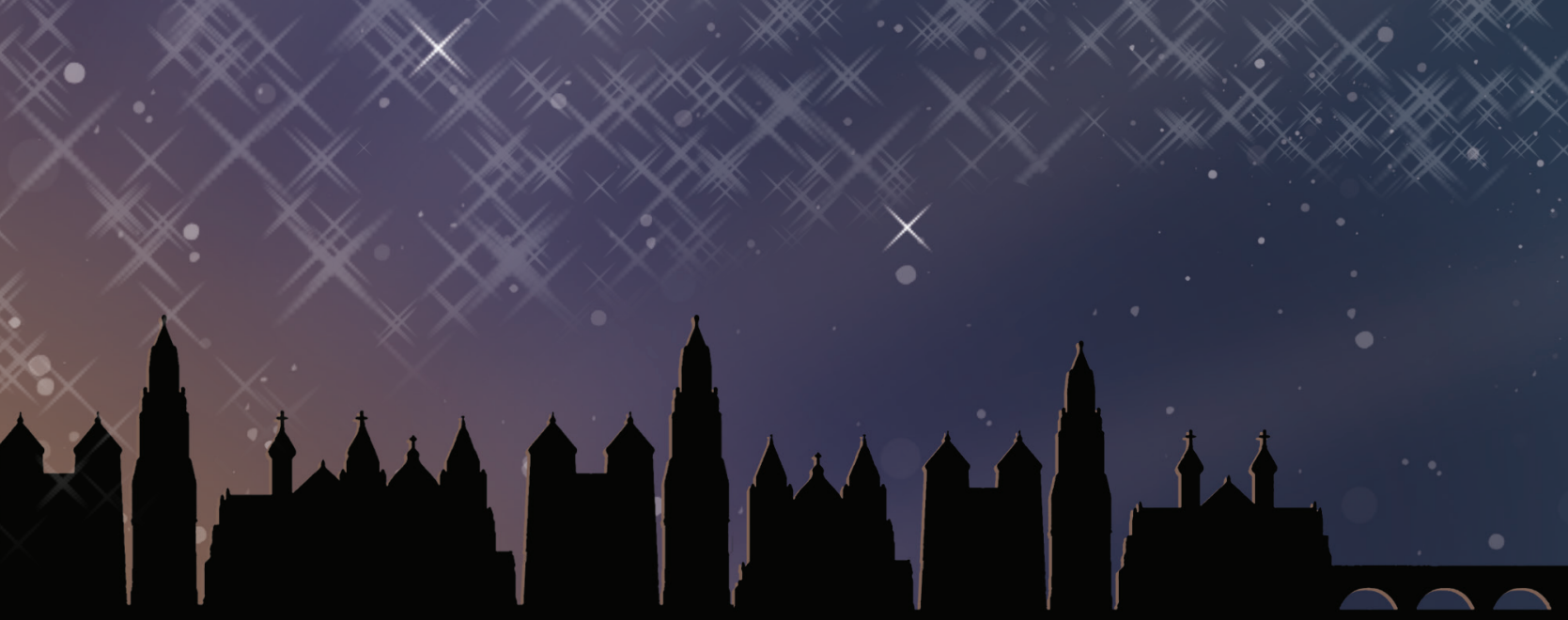




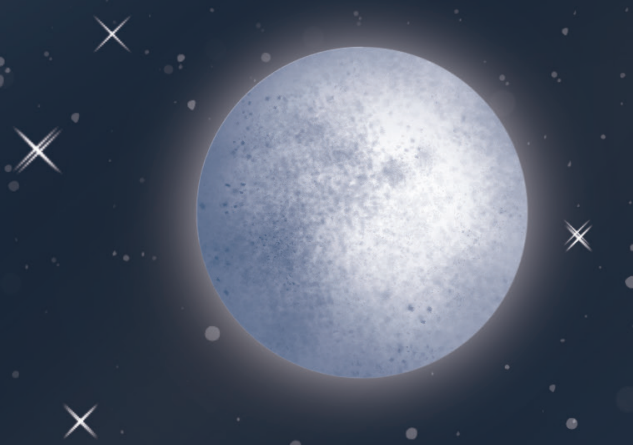

$$
\text { CHAPTER } 5
$$

Preoperative education and informed consent in young adults undergoing bariatric surgery: Patient perspectives on current practice

Wouter K.G. Leclercq, Danielle S. Bonouvrie, Charlotte E.J.M. Dohmen, Martine Uittenbogaart, Arijan A.P.M. Luijten, Johan Legemaate, Laurents P.S. Stassen, Francois M.H. van Dielen

Submitted .

\section{$\times$}

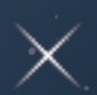

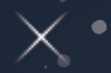




\section{ABSTRACT}

\section{Background}

Preoperative education is part of the informed consent process and should enable patients to make an informed decision. Information is lacking about the received quality of the education and informed consent process in bariatric surgery, especially for young adults. Aim of this study was to gain a more detailed insight in the perceptions and experiences of the informed consent process of young adults undergoing bariatric surgery.

\section{Methods}

Fifty-five young adults, aged 18-25 years, who underwent bariatric surgery at our center between 2012 and 2017, were invited to participate in a semi-structured interview. The interview covered 3 main topics: education of the specific informed consent domains; perioperative expectations and experiences; personal (un)certainties related to undergoing bariatric surgery.

\section{Results}

Twenty-seven patients participated in a semi-structured interview. Mean age was $23.1 \pm$ 1.6 years and mean body mass index was $43.9 \pm 7.2 \mathrm{~kg} / \mathrm{m}^{2}$. All the consent domains were remembered by the patients, but 24/27 patients could not recall 1 or more complications. Inadequate weight loss was not recalled by $6 / 27$ patients. Common remarks were that the preoperative education focused mainly on the positive results. Negative effects were inadequately educated.

\section{Conclusion}

The preoperative education and informed consent process for bariatric surgery is an essential step in the treatment process. This study provides new information on received quality of education and informed consent issues in young adults. Improved preoperative education including possible outcome scenarios after bariatric surgery to assess risks and lifetime consequences should be developed to improve informed consent in these patients. 


\section{INTRODUCTION}

With the increase of morbid obese adolescents and young adults, more bariatric procedures are performed on these patients. ${ }^{1-8}$ The positive effects of bariatric surgery on weight loss and remission of comorbidities in adolescents and young adults are comparable to adults. ${ }^{6-8}$ Furthermore, quality of life, confidence and self-esteem improve after bariatric surgery in adolescents and young adults. ${ }^{6-9}$ Colquitt et al. stated that young adults might have a greater benefit, because they have a longer period to obtain it, if weight loss and positive effects on comorbidity remain. ${ }^{10}$

For every surgical procedure a patient should give permission after being educated about the treatment, a process called surgical informed consent (SIC). ${ }^{11-12}$ This process consists of three separate elements with their specific items (Figure 5.1). ${ }^{12}$ A well-executed SIC increases the chance that a patient has realistic expectations of the effects of the treatment, sufficiently understands the reasons for treatment, will be able to deal with complications and might have a more effective participation in his/her own care. ${ }^{13-16}$

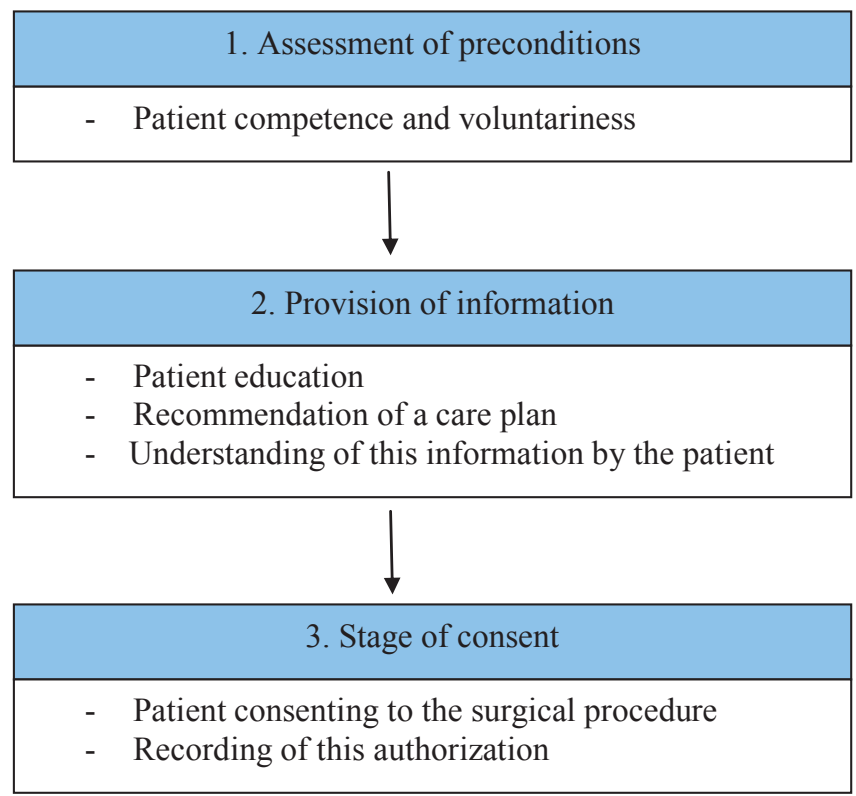

Figure 5.1 Items of informed consent. ${ }^{12}$ 
The preoperative education given by a multidisciplinary team helps patients to select the type of surgery and has an important input on psychological adaptation. ${ }^{17}$ As part of the bariatric SIC, preoperative education informs patients about the bariatric procedure, alternative treatment options, perioperative and postoperative risks, short and longterm results and effects on daily life and future health. Explaining the changes to be expected after bariatric surgery will help anticipate to negative feelings. ${ }^{15}$ Furthermore, the bariatric surgeon should inform the patient that the surgery itself does not guarantee a successful outcome but that the outcome is dependent on how well the lifestyle change is followed. ${ }^{9,13}$ A well conducted bariatric SIC process enables patients to make an informed decision to undergo a bariatric procedure and can improve patients' satisfaction.

The young adulthood is a stage with many changes: leaving parental care, starting a professional career, changes in peer relationships and starting a family. ${ }^{9}$ As young adults are in a different stage of life compared to adults, they may require other information and/or another approach, for example receiving information from other young bariatric patients and more involvement of his/her family in the SIC process. ${ }^{9}$

Following this perspective, the aim of this study is to gain a detailed understanding of the perceptions and experiences of young adults undergoing bariatric surgery regarding the SIC process and the preoperative education in bariatric surgery. 


\section{MATERIALS AND METHODS}

\section{Subjects}

A cohort of young adult patients (18 and 25 years old at the time of surgery) who had preoperative education and bariatric surgery in our bariatric center was selected from our hospital database and were invited to participate in the semi-structured interview. All patients were at least six months post-operative. Bariatric surgery included primary and revisional bariatric surgery. No specific exclusion criteria were applied for the study population.

\section{Medical Ethical Committee}

Approval of the local Medical Ethical Committee (MEC) was requested but deemed not formally necessary for this study by the MEC.

Local pre-operative education and informed consent process

Current practice involves multiple individual and group education sessions, combining presentations with didactic material (leaflets) (Figure 5.2). Bariatric nursing, psychology, dietetics and physiotherapy have specific education sessions. Additionally, a website and mobile application are available for patients containing more information regarding bariatric techniques, frequently asked questions, healthy recipes and more.
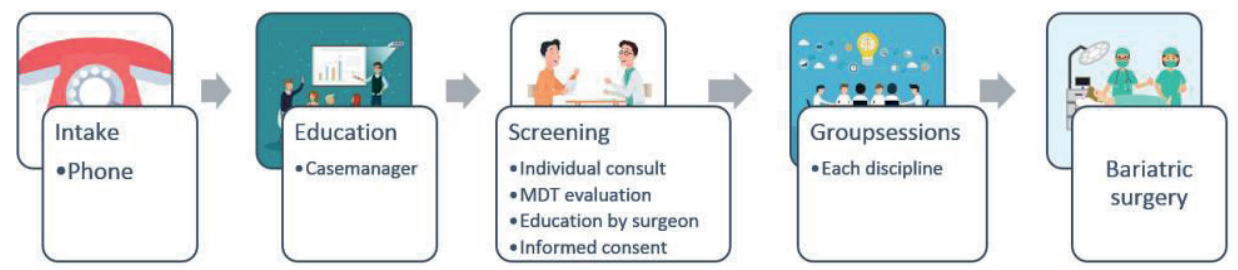

Figure 5.2 Current SIC procedure.

\section{Study design}

An oral survey which consisted of closed-ended questions and open-ended questions was executed in the form of a semi-structured interview. Therefore, a mixed methods design was applied. This semi-structured interview consisted of three parts of which the focus is described in the next paragraph.

\section{Semi-structured interview}

The knowledge was collected through the method of semi-structured interviewing. The interviews were performed individually to allow the gathering of detailed information. All interviews were conducted in Dutch and performed in the hospital or over the telephone. 
The interviews consisted of three main parts; 1 ) education in the specific informed consent domains; 2) perioperative expectations and experiences and 3) personal (un)certainties in undergoing bariatric surgery. The focus of this manuscript is solely on part 1 and part 3, regarding the preoperative education and the SIC process. Although in semi-structured interviewing the sequencing of questions is not the same for each participant, an interview guide [see Appendix 5.1] was used to ensure that the researcher would collect similar types of data from all participants. None of the interviews were recorded. The researcher made notes in the form of keywords during the performance of the interviews. If the researcher was of opinion that the participant made an interesting quote or statement, the whole quote/statement was literally noted. Directly after the interview all notes were transcribed.

\section{Setting}

This study was performed between October 2017 and April 2018 at a large teaching hospital with a bariatric surgery department certified as European Centre of Excellence. Patients were contacted by letter and telephone to participate in the study. Before the start of the semi-structured interviews, all patients had to sign a written informed consent form to participate in this study.

\section{Data}

Besides the gathering of information through semi-structured interviewing, preoperative and postoperative data (anthropometrics up to five years, postoperative complications and pre-operative comorbidities) were retrospectively collected from the electronic patient files.

Primary responder (i.e. weight loss success) was defined as the achievement of a percentage Excess Weight Loss (\%EWL) $>50 \%$ and primary non-responder (i.e. weight loss failure) was defined as the inability to achieve a $\% E W L>50 \%$ at eighteen months post-surgery. ${ }^{18}$

\section{Analysis and statistics}

All the gathered knowledge from the semi-structured interviews and the data from the electronic patient files were processed. The information gathered from the closedended questions was processed as quantitative data (comparable to a survey). The open conversations of part 1 and part 3 were of qualitative nature and were therefore addressed in a qualitative manner. Coding on the keywords was applied, including the identification of relevant "themes", to organize and group the information into "categories" (creating a single code to describe a large amount of text, for example: "missed information", "improvements"). Relevant information of these "categories" were then paralleled between the semi-structured interviews. Data processing and analysis in semi-structured interviews were on-going processes. As such, the data was collected until a point of data saturation was reached, namely when no new or relevant information emerged. 
Continuous variables were stated as mean with standard deviation. Quantitative outcomes of part 1 of the semi-structured interviews were stated as number. No specific statistical analyzes were performed. Percentages were not used as the number of patients was smaller than 100. 


\section{RESULTS}

\section{Patient characteristics}

The total cohort of young adults consisted of 55 patients. Mean age at surgery was 22.8 \pm 1.9 years and mean Body Mass Index (BMI) during screening was $43.3 \pm 6.1 \mathrm{~kg} / \mathrm{m}^{2}$. Mean BMI reduction was $11.7 \pm 3.1 \mathrm{~kg} / \mathrm{m}^{2}, 14.8 \pm 4.2 \mathrm{~kg} / \mathrm{m}^{2}$ and $15.2 \pm 5.1 \mathrm{~kg} / \mathrm{m}^{2}$ at 6 months, 1 and 2 years follow-up respectively.

Twenty-seven out of the 55 patients, mostly female, participated in a semi-structured interview (Figure 5.3). The baseline characteristics are stated in Table 5.1. Twenty-two patients received a primary Roux-en-Y Gastric Bypass (RYGB), 4 patients received a RYGB after gastric banding and 1 patient received an adjustable gastric band (primary). Mean BMI reduction was $11.1 \pm 2.2 \mathrm{~kg} / \mathrm{m}^{2}, 14.4 \pm 4.1 \mathrm{~kg} / \mathrm{m}^{2}$ and $15.4 \pm 5.0 \mathrm{~kg} / \mathrm{m}^{2}$ at 6 months, 1 and 2 years follow-up respectively. The mean time lapse between surgery and the interview was $2.9 \pm 1.7$ years after the bariatric surgery.

Education concerning weight loss and health benefits

The received education regarding the positive effects of bariatric surgery on weight loss was rated sufficient by the study cohort (Figure 5.4). Patients mentioned that the preoperative education focused primarily on the positive effects of bariatric surgery and that the negative effects were not given adequate attention. Some patients mentioned that they only remembered the positive effects, as this was what they wanted to hear. Other patients gave specific feedback on the education regarding the expectations of weight loss. Comments were that the formula to calculate their expected weight loss can be really informative but it also creates a certain expectation which cannot always be achieved. The latter should be explained more thoroughly.

All young adults knew about the positive effects on Type II Diabetes Mellitus (T2DM) and the majority $(23 / 27)$ also knew the positive effects on the cardiovascular risk profile. Four patients mentioned that the education about the health benefits emphasizes sleep apnea, joint pain and T2DM and that the education regarding the cardiovascular risk profile is inadequate.

\section{Education concerning complications}

Only 3 young adults could recall all the complications that were educated. In general, the most common complications were known, but there were some striking differences. For example, a wound infection was not known by 10 young adults and about half of the patients could not recall the complication anemia (Figure 5.5A-5.5B). 


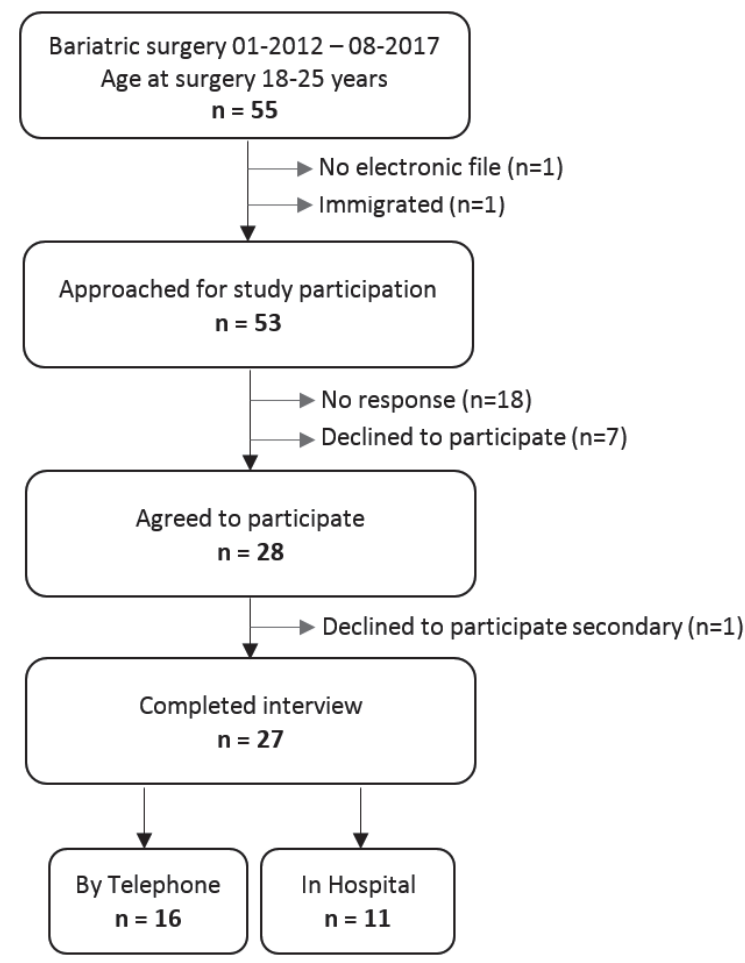

Figure 5.3 Inclusion flowchart.

Table 5.1 Patient characteristics of the 27 patients who participated in a semi-structured interview.

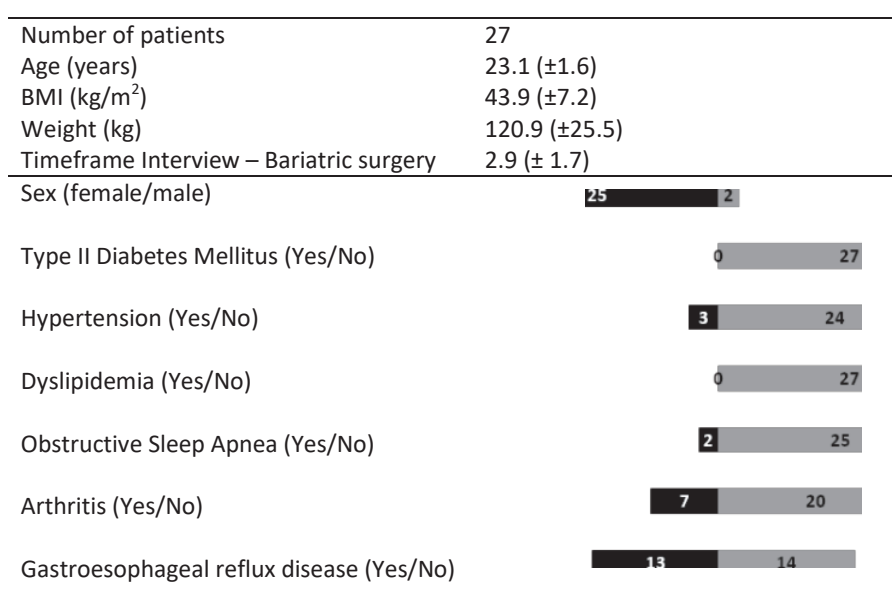

Scale variables are mentioned as mean $( \pm \mathrm{SD})$. Nominal variables are mentioned as absolute numbers. 


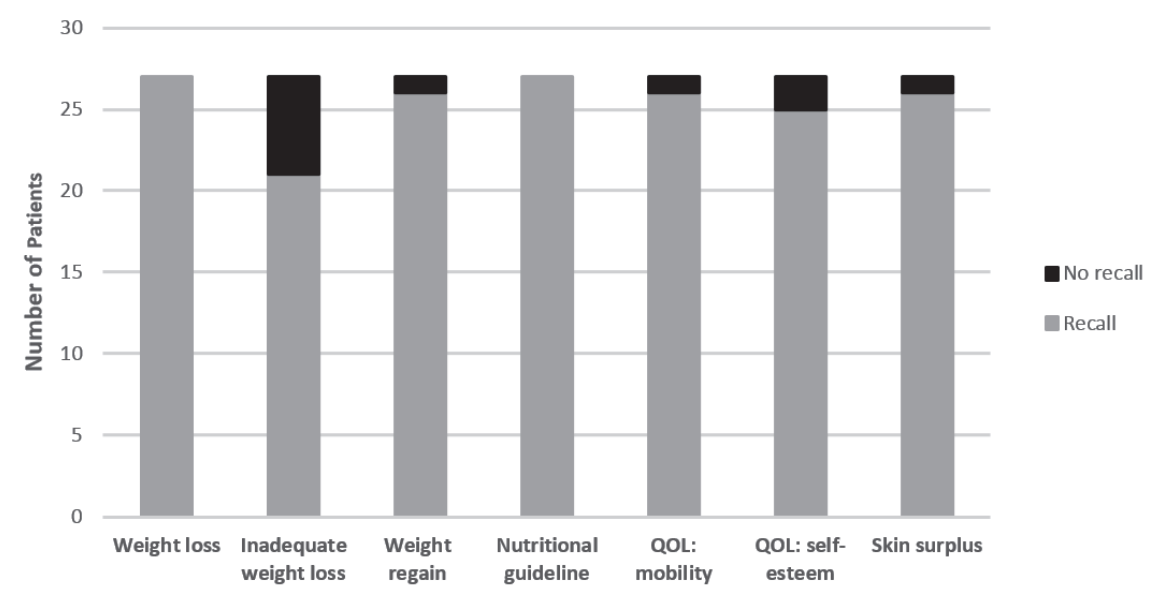

Figure 5.4 Recall of outcomes after bariatric surgery, that were addressed in the preoperative education.

In the long-term, 8 young adults had a more complicated course after the bariatric surgery. Six patients had abdominal pain of whom 5 patients received 1 or more diagnostic laparoscopic surgeries. Abdominal wall pain, gallstones, wound infection and anemia, all educated during the $\mathrm{SIC}$, were better recalled by patients with a complicated course compared to patients with a normal course (Figure 5.6).

One patient, who received a primary gastric banding, did not achieve a \%EWL $>50 \%$ (primary non-responder), all other patients were primary responders. The recall of complications and health risks by the primary non-responder was at least comparable to the rest of the cohort.

The patients who were interviewed within 1 year of their bariatric surgery (5/27) could better recall the complications, except for gallstones and osteoporosis, compared to the patients who were interviewed more than 1 year after the bariatric surgery.

\section{Surgical Informed Consent process}

More than one third of the patients found it very difficult to give consent for the bariatric surgery, despite the fact that they mentioned being informed sufficiently during the SIC process. About half of the patients missed some specific information prior to the surgery (Table 5.2). Some of them mentioned that, regardless of the information given, they were too young to make this decision on their own; they could not oversee all the effects, complications and lifestyle adjustments. There was a strong request to emphasize more on the effects of the bariatric surgery during a pregnancy on the mother and the fetus, on the menstrual problems and on the skin surplus in relation to the eligibility criteria for plastic surgery. 
A.

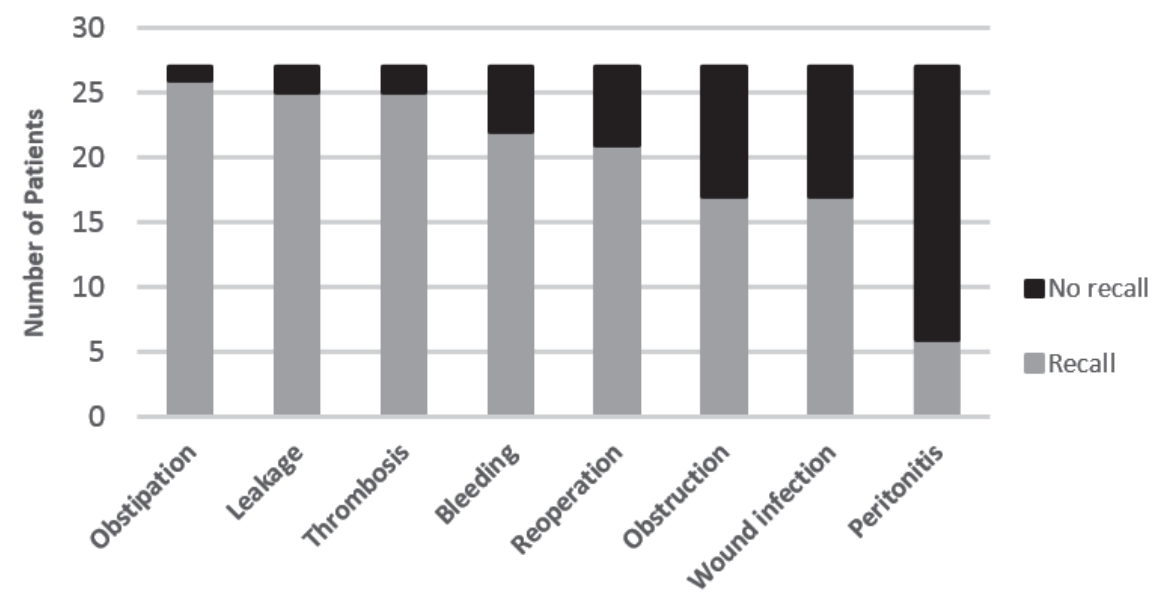

B.

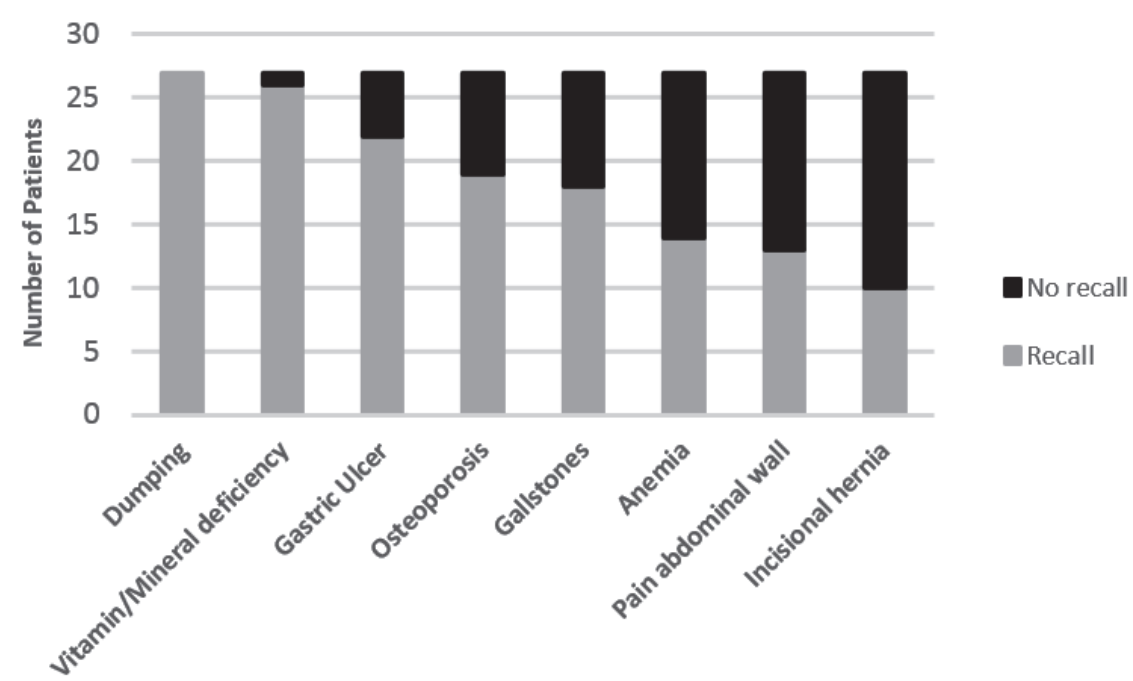

Figure 5.5 Recall of complications of bariatric surgery, that were addressed in the preoperative education. A. $\leq 30$ day-complications; $\mathbf{B}->30$-day complications

The online content and app were used by only a few young adults. More than one-third mentioned that social media should be included, but another one-third mentioned that social media would only give false expectations, good or bad.

A substantial part of the patients recommended that a specific SIC process for the age group of young adults be held. Being informed by a person that went through this process as a young adult would be really informative. 


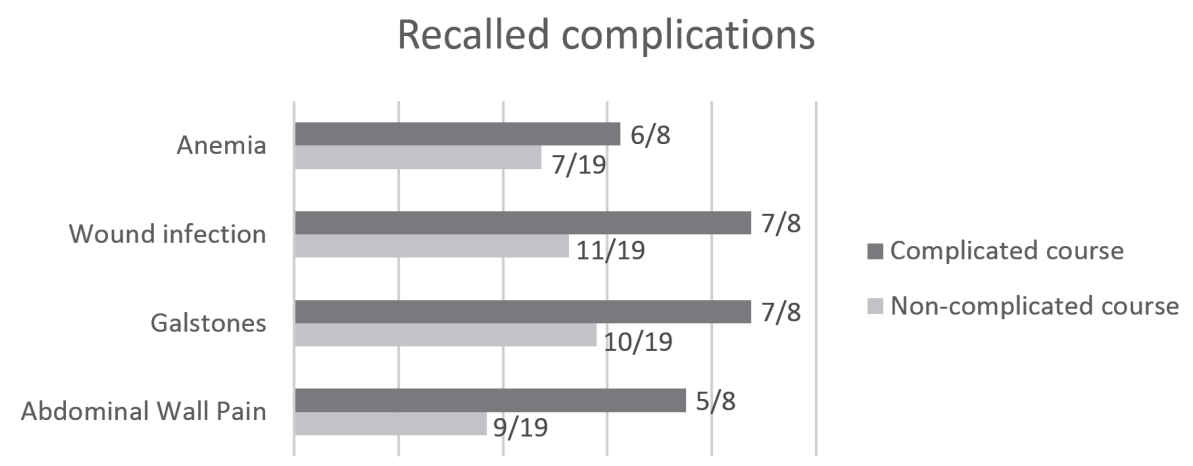

Figure 5.6 Complicated versus non-complicated course; recall of complications that were addressed in the preoperative education.

Table 5.2 Summary of inadequately educated topics

\begin{tabular}{lc}
\hline Topics & Number of patients \\
\hline Pregnancy - fertility - contraception - menstrual and vaginal disorders & $\mathrm{n}=11$ \\
Skin surplus - plastic surgery criteria & $\mathrm{n}=6$ \\
Dietary advise - Alcohol - Restaurant - lifestyle advise & $\mathrm{N}=6$ \\
Constipation - incontinence problems & $\mathrm{N}=3$ \\
Depression - happiness & $\mathrm{N}=2$ \\
Dumping & $\mathrm{N}=2$ \\
Vitamin deficiencies & $\mathrm{N}=2$ \\
Self-image & $\mathrm{N}=1$ \\
Chronic abdominal pain & $\mathrm{N}=1$ \\
The feeling of hunger & $\mathrm{N}=1$ \\
Fatigue & $\mathrm{N}=1$ \\
Surgery related information & $\mathrm{N}=1$ \\
Postoperative care; hospital admission, outpatient clinical care & $\mathrm{N}=1$ \\
Intolerance for specific products & $\mathrm{N}=1$ \\
\hline
\end{tabular}




\section{DISCUSSION}

Received preoperative counseling and recall of preoperative provided information were focus of the current study. The received education regarding positive effects of bariatric surgery was deemed sufficient. It is known that patients will forget several aspects about the SIC postoperatively. ${ }^{11}$ Madan et al. concluded that at $>1$ year postoperatively only $36 \%$ of the patients could answer all questions correctly regarding the preoperative information. ${ }^{19}$ Especially the negative aspects are easily forgotten, but also less emphasized, while patients express the need for education about these negative aspects. In our cohort, 24/27 patients could not recall one or more complications and the negative effects were less recalled. Physicians should educate patients more about the negative effects of a treatment.

Recollection of preoperative information might be biased by the occurrence of complications and/or by the participant's satisfaction on the surgery itself. Saigal et al. however found no significant difference between recall of specific complications experienced versus those not experienced in patients undergoing adult spinal deformity surgery. ${ }^{20}$ In our study, patients with a complicated course showed more knowledge of the postoperative complications abdominal (wall) pain and gallstones. More emphasis on postoperative complications in general and on specifically abdominal (wall) pain and gallstones is recommended.

The SIC process should be more age specific and personalized. Bariatric surgery requires a lifelong lifestyle adjustment. In a turbulent young adult stage of life, complying with all these adjustments might be challenging, especially in the long-term. Young people are known to show worse adherence to the postoperative outpatient hospital care and the postoperative behavioral adjustments. ${ }^{7}$ Taube-Schiff et al. reported the need to connect to other individuals that had gone through the surgical program and several participants also noted that having other young adults in the patient to patient support groups would have been beneficial. ${ }^{9}$ In this study a strong request was made by the young adults for more education regarding fertility, contraception and menstrual disorders and for more patient to patient support with other young adults. Next to this, over one third of the patients found it very difficult to give consent for the bariatric surgery, although the law considers a young adult capable of making independent decision, which indicates that there might be a need for a coach to make an informed consent decision.

The preoperative education and informed consent process is an essential step in the treatment process of bariatric surgery. Data from individual practice or larger published studies regarding outcomes after bariatric surgery helps physicians to optimally inform 
patients which can improve adherence to medical advice. ${ }^{13-14}$ However, there is a lack of literature regarding the optimal preoperative education and informed consent and the outcomes in young adults undergoing bariatric surgery. Our results show that more attention should be paid to the SIC process in these patients.

Further research should focus on the specific needs of young adults, in order to optimize the informed consent process for bariatric surgery and thereby allow patients to have more realistic expectations and improve satisfaction. Incorporating questionnaires on patient related outcome measures could provide this kind of information. In addition, further research should be performed regarding the recall of the SIC process.

Limitations to this study are the interval between surgery and interview $(2.9 \pm 1.7$ years), which can bias information considering that patients forgot information. ${ }^{19}$ In addition, one researcher (CD) did all the interviews and kept notes without audiotaping. All these factors could affect the reliability. ${ }^{22}$

This is the first study regarding the preoperative education and informed consent in young adults (aged 18-25 years) undergoing bariatric surgery from a patient's point of view. This study reveals that there is room for improvement of the SIC process in young adults undergoing bariatric surgery. More dedicated educational material on possible scenarios after bariatric surgery including risks and lifetime consequences should be developed. Preoperative education should focus more on specific age-related problems and social interactions. 


\section{REFERENCES}

1. Ng M, Fleming $\mathrm{T}$, Robinson $\mathrm{M}$, et al. Global, regional, and national prevalence of overweight and obesity in children and adults during 1980-2013: a systematic analysis for the Global Burden of Disease Study 2013. Lancet. 2014;384:766-81.

2. Shah AS, D'Alesso D, Ford-Adams ME, et al. Bariatric surgery: a potential treatment for type Il diabetes in youth. Diabetes Care. 2016 Jun;39(6): 934-940.

3. Pinhas-Hamiel $\mathrm{O}$, Zeitler P. The global spread of type 2 diabetes mellitus in children and adolescents. J Pediatr. 2005 May;146(5):693-700.

4. Gordon-Larsen P, The NS, Adair LS. Longitudinal trends in obesity in the United States from adolescence to the third decade of life. Obesity (Silver Spring). 2010 Sep;18(9):1801-a.

5. Serdula MK, Ivery D, Coates RJ, et al. Do obese children become obese adults? A review of the literature. Prev Med. 1993 Mar;22(2):167-77.

6. Olbers T, Beamish AJ, Gronowitz E, et al. Laparoscopic Roux-en-Y gastric bypass in adolescents with severe obesity (AMOS): a prospective, 5-year, Swedish nationwide study. Lancet Diabetes Endocrinol. 2017 Mar;5(3):174-183.

7. de Jong MMC, Hinnen C. Bariatric surgery in young adults: a multicenter study into weight loss, dietary adherence, and quality of life. Surg Obes Relat Dis. 2017 Jul;13(7):1204-1210.

8. Lennerz BS, Wabitsch $\mathrm{M}$, Lippert $\mathrm{H}$, et al. Bariatric surgery in adolescents and young adults--safety and effectiveness in a cohort of 345 patients. Int J Obes (Lond). 2014 Mar;38(3):334-40.

9. Taube-Schiff M, Yufe S, Kastanias P, et al. A Qualitative Study of Young Adult Experiences in the Bariatric Healthcare System: Psychosocial Challenges and Developmental Difficulties. Can J Diabetes. 2017 Aug;41(4):344-350.

10. Colquitt JL, Pickett K, Loveman E, et al. Surgery for weight loss in adults. Cochrane Database of Systematic Reviews 2014, Issue 8. Art. No.: CD003641.

11. Leclercq WK, Keulers BJ, Scheltinga MR, et al. A review of surgical informed consent: past, present, and future. A quest to help patients make better decisions. World J Surg. 2010 Jul;34(7):1406-15.

12. Leclercq WK, Keulers BJ, Houterman S, et al. A survey of the current practice of the informed consent process in general surgery in the Netherlands. Patient Saf Surg. 2013 Jan 21;7(1):4.

13. Raper SE, Sarwer DB. Informed consent issues in the conduct of bariatric surgery. Surg Obes Relat Dis. 2008 Jan-Feb;4(1):60-8.

14. Greenfield S, Kaplan S, Ware JE Jr. Expanding patient involvement in care. Effects on patient outcomes. Ann Intern Med. 1985 April; 102(4):520-8.

15. Kaplan RM. Health-related quality of life in patient decision making. J Soc Issues. 1991 Winter;47(4):69-90.

16. Roter DL, Hall JA. Studies of doctor-patient interaction. Annu Rev. Annu Rev Public Health. 1989; 10:163-80

17. Giusti V, De Lucia A, Di Vetta V, et al. Impact of Preoperative Teaching on Surgical Option of Patients Qualifying for Bariatric Surgery. Obes Surg. 2004 Oct;14(9):1241-6.

18. Bonouvrie DS, Uittenbogaart M, Luijten AAPM, et al. Lack of Standard Definitions of Primary and Secondary (Non)responders After Primary Gastric Bypass and Gastric Sleeve: a Systematic Review. Obes Surg. 2019 Feb;29(2):691-697.

19. Madan AK, Tichansky DS. Patients postoperatively forget aspects of preoperative patient education. Obes Surg. 2005 Aug;15(7):1066-9. 
20. Saigal R, Clark AJ, Scheer JK, et al. Adult Spinal Deformity Patients Recall Fewer Than $50 \%$ of the Risks Discussed in the Informed Consent Process Preoperatively and the Recall Rate Worsens Significantly in the Postoperative Period. (Spine (Phila Pa 1976). 2015 Jul 15;40(14):1079-85.

21. Van Nes $F, A b m a T$, Jonsson $H$, et al. Language differences in qualitative research: is meaning lost in translation? Eur J Ageing. 2010 Dec;7(4):313-316.

22. Saunders $M$, Lewis $P$, Thornhill A. Research methods for business students. Harlow: Pearson Education Limited; 2009. 


\section{APPENDIX 5.1.}

\section{Part 1 - SIC procedure}

Do you remember being informed about [domain]?

If so, how well was this domain discussed? $1=$ very bad, $2=$ bad, $3=$ average, $4=\operatorname{good}$ and $5=$ excellent.

These 2 questions were asked for the following domains

\begin{tabular}{lll}
\hline Outcomes & Short term complications & Long term complications \\
Weight loss & Wound infection & Vitamin/mineral deficiencies \\
Inadequate weight loss & Bleeding & Need to take vitamin pills \\
Weight regain & Leakage & Anaemia \\
Nutritional guideline & Obstruction & Gastric ulcer \\
Health benefits & Reoperation & Gallstones \\
Type II diabetes & Thrombosis & Dumping \\
Cardiovascular risk profile & Obstipation & Pain at/around scars \\
Quality of life & Peritonitis & Incisional hernia \\
Mobility & & Avoid pregnancy one year \\
Self-esteem & & postoperatively \\
Skin surplus & & \\
\hline
\end{tabular}

Did you miss information in the preoperative education?

Do you have experience with something which they should definitely say before surgery?

\section{Part 2 - Perioperative expectations and experiences}

What was your expectation when you started this journey?

When [the answer of last question] is reached, you call this treatment successful or would you describe this different?

Was your expectation fulfilled or did you change your expectation along the journey?

When would you describe your treatment as being bad?

Did you expect your study/work become easier after surgery?

Did you expect doing sports would be easier after your surgery?

Did you think your surgery would have impact on your partner relationship?

Did you think your surgery would have impact on your relationship with friends?

Do you think social media can stimulate to reach your goal?

If yes: in what way would it be useful?

Exchange personal stories?

Remind people to take their vitamins

\section{Part 3 - Personal (un)certainties to undergo bariatric surgery}

How (un)certain were you about your choice to undergo the bariatric surgery? 


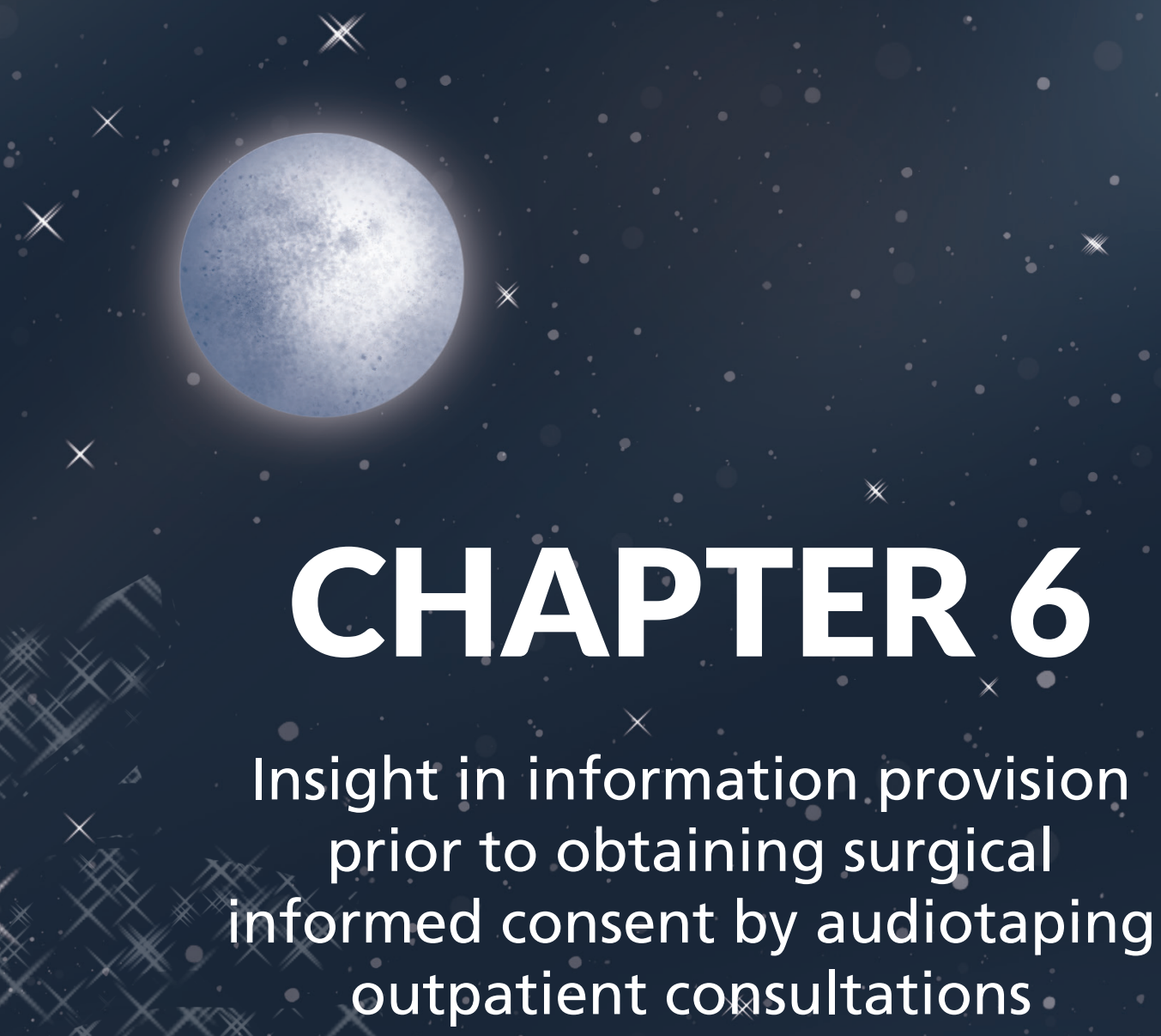




\section{ABSTRACT}

\section{Background}

Literature suggests that patient-informing process prior to obtaining surgical informed consent (SIC) does not function well. This study aimed to provide insight into the current practice of SIC in the Netherlands.

\section{Methods}

This is a prospective, observational, and multicenter study, conducted in one academic and two nonacademic teaching hospitals in the Netherlands. Audio recordings were made during outpatient consultations with patients presenting with Dupuytren Disease. The recorded informing process was scored according to a checklist. Written documentation of the SIC process in the patient's chart was compared to these scored checklists. Time spent on SIC during the consultations was also recorded.

\section{Results}

A total of 41 outpatient consultations were included in the study. Consultations were conducted by 25 plastic surgeons and their residents. Average time spent on SIC was $55.6 \%$ of the total consultation time. Considerable variation was observed concerning the amount and type of information given and discussed. In 59\% of the consultations, discrepancies were observed between written documentation of consultations and audio recordings. Information on treatment risks, the postoperative period, and the operating surgeon was addressed the least.

\section{Conclusion}

Despite a relatively large part of the consultation time being spent on SIC, patients received scarce information concerning treatment risks, postoperative period, and who their operating surgeon would be. Discrepancies were observed between the written documentation of SIC and information recorded on the audio recordings. This occurred predominantly in one hospital that used a pre-made list of 'discussed information' in its digital patient chart. 


\section{INTRODUCTION}

The term 'surgical informed consent' (SIC) refers to the patient's consent to a surgical treatment. The patient needs to comprehend all aspects of treatment which might influence his or her arrival at a well-considered decision. The responsibility for the patient's comprehension lies with the treating surgeon. ${ }^{1,2}$

In the Netherlands, SIC is regulated by law in the Dutch Medical Treatment Contracts Act (MTCA). Besides being legally required ${ }^{1,3}, \mathrm{SIC}$ is beneficial to patients. This is because patients with a proper understanding of their diagnosis, treatment, and their respective implications on lifestyle have been found to show lower levels of illness concerns, higher patient satisfaction, and better perceived control over the situation. ${ }^{4-6}$

Since SIC is an important part of medical treatment, it is surprising that most of the literature we have consulted suggests that SIC is not adequately conducted in current practice..$^{3,7}$ For example, surgeons seem not to be aware of every aspect of informed consent. Surgeons also underestimate the patient's desire to receive extensive information prior to a surgical procedure. ${ }^{8,9}$ Audio recordings of outpatient consultations show that patients are informed inconsistently. Only a minority of patients receives information on all aspects of treatment. ${ }^{10}$

Despite the issues that arise from these studies, there have only been a few studies that have aimed to analyze the actual practice of SIC today. Therefore, the purpose of the present study was to provide insight into the current practice of SIC in the Netherlands. We investigated the patient-informing process, the written documentation of the SIC process in the patient's chart, and time spent on SIC. 


\section{MATERIALS AND METHODS}

\section{Setting}

This prospective, observational study was conducted at the plastic surgery outpatient clinics of one academic and two non-academic teaching hospitals in the Netherlands. Audio recordings were made of consultations of patients referred with Dupuytren Disease. The consultations were carried out by plastic surgeons and their residents. The obtained recordings were analyzed after the consultation. The doctor and the patient were the only people present in the consultation room. A digital audio recorder was installed prior to the consultation. Participating doctors and patients were aware that SIC was the subject of the research and that they were being recorded. However, they had no knowledge about what specific content would be analyzed. We obtained written and verbal informed consent from both patients and doctors for participation in this study. The need for ethical approval of this study was waived by the local medical ethics committee.

Inclusion in this study was limited to patients that were both presenting with Dupuytren Disease and being counseled for the surgical treatment option of a limited fasciectomy. This treatment usually requires only a single preoperative consultation, in which the entire SIC information exchange takes place. Exclusion criteria were: (1) Consultations that did not directly lead to a scheduling for limited fasciectomy. (2) Consultations with patients who had an earlier healthcare consultation about Dupuytren Disease during the past one-and-a-half years and patients who had a surgical correction for Dupuytren Disease in the past 10 years. (3) Consultations with patients under 18 years of age. (4) Consultations with patients with a language barrier.

\section{Analysis}

The information discussed on the audiotapes was scored on a checklist by one of the investigators (BBB). This checklist contained a range of information items that might be addressed during the process of SIC. The items were sourced from the 2004 report by the Royal Dutch Medical Association (KNMG). This report stipulates how to perform the MTCA in practice. ${ }^{2}$ Information items on the list were specified to Dupuytren Disease using the Dutch guidelines on Dupuytren Disease established by the Dutch Society for Plastic Surgery in 2012."11 The checklist consisted of 33 different information items and divided into the following eight categories: diagnosis, treatment characteristics, purpose, risks, postoperative period, operating surgeon, alternatives, and prognosis. An overview of scored checklist results was made.

For every item on the checklist, we calculated the percentage of consultations in which the item was addressed. Per information category, the mean of these percentages was determined. 
The doctors' documentation of SIC in the patients' chart was examined and compared to the outcomes of the checklists. The total consultation time (TCT) and the time spent specifically on SIC [surgical informed consent time (SIT)] were recorded. The percentage SIT to TCT was calculated.

Internal validation

The reliability of the scoring process, performed by the first author (BBB), was tested by the second author (MMV), by re-scoring almost all of the consultations. The second researcher was blinded to the results of the first researcher. The inter-rater agreement was calculated using Cohen's kappa coefficient. 


\section{RESULTS}

Between March and October of 2015, a total of 41 consultations, conducted by 25 different plastic surgeons and residents, were included in the study (Table 6.1).

Table 6.1 Consultation characteristics.

\begin{tabular}{ll}
\hline Patient $(\mathrm{n}=41)$ & \\
\hline Median age in years (range) & $62(46-85)$ \\
Male & $29(71 \%)$ \\
Education level* & $1(2 \%)$ \\
Low & $28(68 \%)$ \\
Intermediate & $11(27 \%)$ \\
High & 41 \\
Competent in Dutch language & \\
\hline Doctors ( $n=25)$ & $34(30-61)$ \\
\hline Median age in years (range) & $14(56 \%)$ \\
Male** & \\
Function & $11(44 \%)$ \\
Plastic surgeon & $14(56 \%)$ \\
Resident & \\
\hline
\end{tabular}

*Educational levels included low (none or primary school), intermediate (completed high school or vocational education), and high (completed pre-university education or university). One patient refused to share his level of education, ${ }^{* *}$ Male doctors conducted a total of 24 consultations (59\%)

Within these consultations, an inconsistency was found concerning the number and choice of consultation items that were discussed. This inconsistency can be deduced from the irregular distribution of black rectangles in the overview of scored checklist items per consultation (Table 6.2).

The information categories that were less often discussed were treatment risks, postoperative period, and operating surgeon. These had the lowest mean percentage of the discussed information items, respectively: 44\%, 33\%, and 18\% (Table 6.2).

In $90 \%$ of the consultations, the patient chart contained documentation about the SIC. In $59 \%$ of consultations, the written documentation of SIC contained in the patient charts stated that certain information had been discussed, while the audio recordings of the verbal exchange did not confirm these claims. In six of these consultations, five or more information items were erroneously described as having been discussed (Table 6.2). 
Table 6.2 Overview of scored checklist items per consultation.

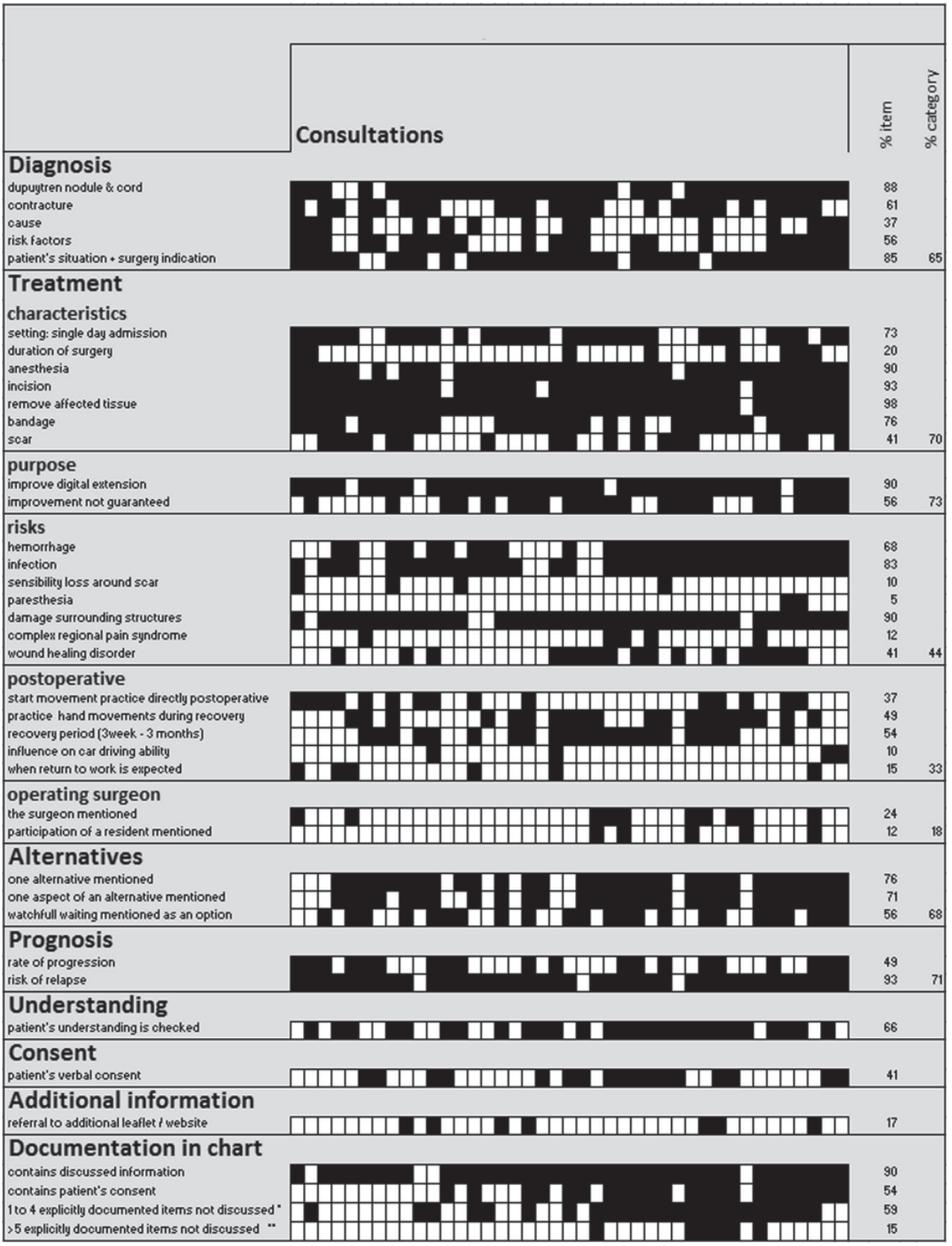

Overview of the results of the scored checklist items per consultation. The vertical columns represent the 41 different consultations. The horizontal rows display the different checklist items grouped by information category. Items mentioned and scored are marked as a black small rectangle. Items not mentioned and not scored are marked as a white small rectangle. The two columns on the right display the percentage of consultations in which a checklist item was addressed and the mean of these percentages per information category *Consultations in which 1-4 items were noted as being discussed while they actually were not, ${ }^{*}$ Consultations in which five or more items were noted as being discussed while they actually were not. 
This discrepancy between written record and the actual verbally discussed information was mainly observed in one specific hospital in which the list of items to be discussed was prelisted in the electronic patient file. Thirteen out of 23 consultations that contained this discrepancy and all six consultations that erroneously mentioned five or more information items in the patient chart were from this hospital. The mean TCT was $15.91 \mathrm{~min}(r=7.4$ $\mathrm{min})$, and the mean SIT was $8.85 \mathrm{~min}(\mathrm{r}=3.5 \mathrm{~min})$. The percentage of TCT that was spent on SIC was $55.6 \%$ (Figure 6.1).

Almost all consultations $(n=37)$ were retested by the second author. A kappa coefficient of $0.63(95 \% \mathrm{Cl}, 0.59-0.66)$ was calculated, which corresponds to the second best kappa coefficient category. This means that the scored results of both authors were similar to a high degree.

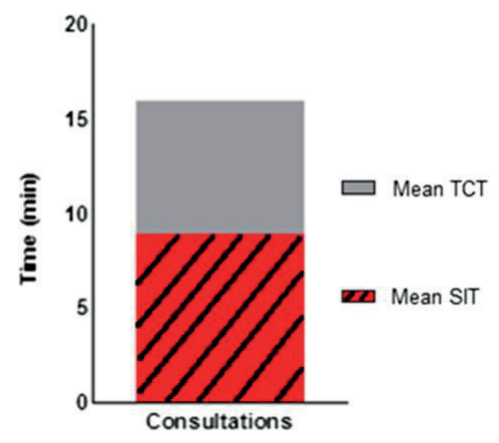

Figure 6.1 Graphical view of the mean SIT as a part of the mean TCT, which corresponds to $55.6 \%$. 


\section{DISCUSSION}

This study aimed to provide insight into the current practice of SIC in the Netherlands. The results show that, despite more than half of total consultation time being spent on SIC, several information categories were hardly mentioned. In many cases, the written documentation of the SIC process did not match the actual information discussed with the patient.

This is one of few studies that has analyzed what SIC information is actually discussed during patient consultations. Most of the previous studies that aimed to analyze the current practice of SIC either endeavored to describe the patient's understanding of discussed information or the surgeon's knowledge of SIC.8,12,13 From the few that studied the actual patient-informing process ${ }^{10,14,15}$, only Knops et al. focused on the surgical part of informed consent. As with our study, Knobs et al. used audiotapes and a checklist to analyze consultations. Our main findings are in line with their results, as they show a considerable variation concerning the information received by patients, as well as the neglect of certain information categories (treatment purpose, treatment risks, and alternative treatments). The combined results of these studies suggest that, in current practice, no unambiguous way of informing exists and certain information is less well covered.

The checklist items are unproven when it comes to their value for the patient's decisionmaking process concerning their consent to treatment. This is because we did not ask the patients about their opinion concerning the relevance of the items. Therefore, the relevance of the relatively less discussed categories is unclear. However, other studies suggest that, in general, patients seem to value extensive information on treatment risks and the postoperative period.9,16 Moreover, patients from a former study liked to know who would be their operating surgeon, and they have opined to be informed about the level of resident participation during surgery. This kind of information could have changed their decision for consent.9.17 This suggests that, despite the fact that these information categories are relatively less well covered, they might still be relevant to the patient's consent.

In the case of a malpractice claim or lawsuit, sufficient documentation of the discussed information aids the doctor in proving that certain information was given before the start of treatment. ${ }^{18,19}$ Not surprisingly, adequate documentation has been associated with a decreased indemnity risk. ${ }^{20}$ It is particularly remarkable that, since this documentation can be used as evidence in court, a discrepancy between documented and actually discussed information was found. This discrepancy was found in all of the three hospitals, but 
mainly seen in one hospital that used a pre-made list of possibly discussed information items in the digital patient chart. Doctors had to actively delete the items that they did not discuss before saving their final note. Probably, this kind of pre-made list contributes to these mistakes in the patient chart documentation.

One of the strengths of this study is that inclusion was limited to cases with only one preoperative consultation. Therefore, the entire SIC process took place in the consultation studied, allowing us to fully capture the discussed information. Still, a couple of limitations merit a mention. The plastic surgeons and their residents were aware of the audio recorder's presence and of the fact that SIC was the object of study. Though the doctors were not aware of the study's methods, the above limitations might have led to a considerable performance bias. It can be assumed that the doctors will have tried to conduct SIC more thoroughly than usual. In regular practice, less information is probably transferred. Besides that, this study solely focused on patients with Dupuytren Disease. Therefore, the results of this study only describe SIC concerning Dupuytren Disease and not SIC in general. Nevertheless, when interpreted with care, these results might be used as an indication for the current practice of SIC in the Netherlands in general.

Since this study and previous studies indicate that current SIC has several shortcomings, we believe that there is room for improvement. Digital and multimedia educative software might serve to aid the patient-informing process ${ }^{21,22}$, as it can facilitate the process of addressing all aspects of information. Perhaps, when used before or after the consultation, the system can free up time in the consultation room.

In conclusion, despite the fact that a rather large part of the consultation time was spent on SIC, patients were only partially informed about treatment risks, the postoperative period, and who will be their operating surgeon. A discrepancy exists between noted and actually discussed information. This discrepancy was mainly seen in one hospital that used a pre-made SIC information list in its digital patient chart. 


\section{REFERENCES}

1. Article 7:448 section 2 of Dutch Civil Code. http://wetten.overheid.nl/jci1.3:c:BWBR0005290\&boek= 7\&titeldeel=7\&afdeling=5\&artikel $=448 \& z=2011-02-23 \& g=2011-02-23$.

2. Royal Dutch Medical Association (KNMG) Department of Internal and External Communication. 2004 Report on implementation of the MTCA; from law to practice (part 2, information and consent). https://www.knmg.nl/web/file?uuid=efcf86c8-d0bc-438d-8ebc-d98ff1753831\&owner=5c945405d6ca-4debaa16-7af2088aa173\&contentid=532\&elementid=1890309.

3. Leclercq WK, Keulers BJ, Scheltinga MR et al. A review of surgical informed consent: past, present, and future. A quest to help patients make better decisions. World J Surg 2010;34(7):1406-1415.

4. Dennis KE. Patients' control and the information imperative: clarification and confirmation. Nurs Res 1990;39(3):162-166.

5. Brody DS, Miller SM, Lerman CE et al. Patient perception of involvement in medical care: relationship to illness attitudes and outcomes. J Gen Intern Med 1989;4(6):506-511.

6. Shabason JE, Mao JJ, Frankel ES et al. Shared decisionmaking and patient control in radiation oncology: implications for patient satisfaction. Cancer 2014;120(12):1863-1870.

7. Schenker $Y$, Meisel A. Informed consent in clinical care practical considerations in the effort to achieve ethical goals. JAMA 2011;305(11):1-1130.

8. Leclercq WK, Keulers BJ, Houterman S et al. A survey of the current practice of the informed consent process in general surgery in the Netherlands. Patient Saf Surg 2013;7(1):4.

9. Keulers BJ, Scheltinga MR, Houterman $S$ et al. Surgeons underestimate their patients' desire for preoperative information. World J Surg 2008;32(6):964-970.

10. Knops AM, Ubbink DT, Legemate DA et al. Information communicated with patients in decision making about their abdominal aortic aneurysm. Eur J Vasc Endovasc Surg 2010;39(6):708-713.

11. Dutch Society for Plastic Surgery (Nederlandse Vereniging voor Plastische Chirurgie). 2012 Guidelines on morbus dupuytren. https://www.nvpc.nl/uploads/stand/2015-04_Richtlijn_Ziekte_van_ Dupuytren148.pdf.

12. Weckbach S, Kocak T, Reichel H. A survey on patients' knowledge and expectations during informed consent for spinal surgery: can we improve the shared decision-making process? Patient Saf Surg 2016;10:15.

13. Saigal R, Clark AJ, Scheer JK. Adult spinal deformity patients recall fewer than $50 \%$ of the risks discussed in the informed consent process preoperatively and the recall rate worsens significantly in the postoperative period. Spine 2015;40(14):85-1079.

14. Kunneman M, Marijnen CA, Rozema $T$ et al. Decision consultations on preoperative radiotherapy for rectal cancer: large variation in benefits and harms that are addressed. Br J Cancer 2015;112(1): 39-43.

15. Koedoot CG, Oort FJ, De Haan RJ et al. The content and amount of information given by medical oncologists when telling patients with advanced cancer what their treatment options are: palliative chemotherapy and watchfull-waiting. Eur J Cancer 2004;40(2):35-225.

16. Bismark MM, Gogos AJ, Clark RB et al. Legal disputes over duties to disclose treatment risks to patients: a review of negligence claims and complaints in Australia. PLoS Med 2012;9(8):e1001283.

17. Porta CR, Sebesta JA, Brown TA et al. Training surgeons and the informed consent process: routine disclosure of trainee participation and its effect on patient willingness and consent rates. Arch Surg 2012;147(1):57-62. 
18. Patel PB, Gilchrist A, Cronan KM et al. Adequacy of informed consent for lumbar puncture in a pediatric emergency department. Pediatr Emerg Care 2010;26:739-741.

19. Fine A. Informed consent in California, latent liability without 'negligence'. West J Med $1977 ; 127(2): 158-163$.

20. Bhattacharyya T, Yeon $\mathrm{H}$, Harris MB. The medical-legal aspects of informed consent in orthopaedic surgery. J Bone Jt Surg Am 2005;87(11):2395-2400.

21. Tipotsch-Maca SM, Varsits RM, Ginzel C et al (2016) Effect of a multimedia-assisted informed consent procedure on the information gain, satisfaction, and anxiety of cataract surgery patients. J Cataract Refract Surg 42:110-116.

22. Heller L, Parker PA, Youssef A et al (2008) Interactive digital education aid in breast reconstruction. Plast Reconstr Surg 122(3):717-724. 

$\geqslant$

0

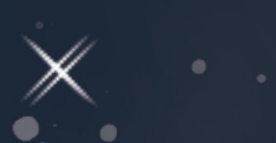

○.

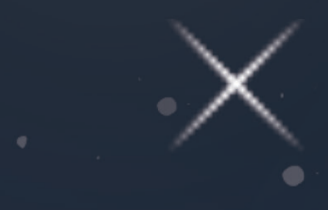

\section{$x$}

•。

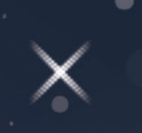

$x$

- \& $\times 3 \times x$ $x^{2}+2 \times$

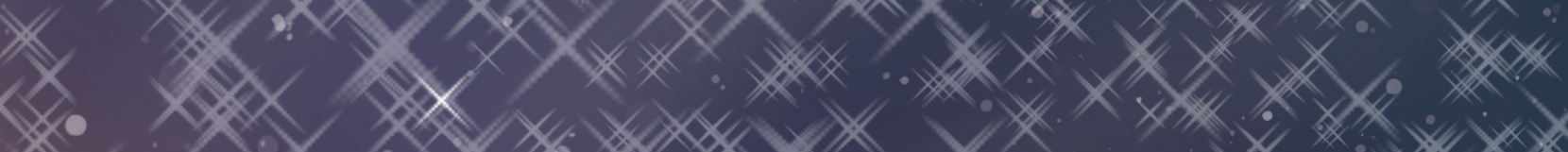

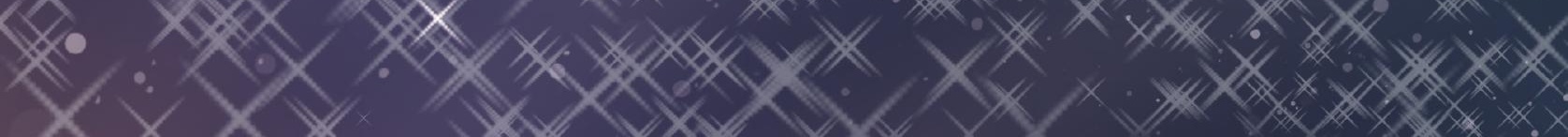
X. $\times x \times x \times x+x$

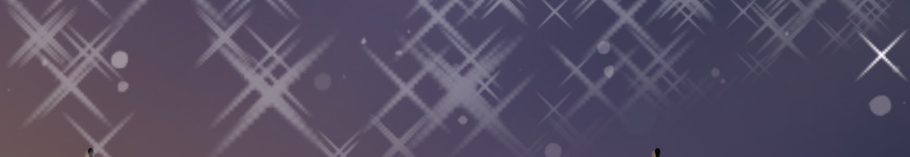

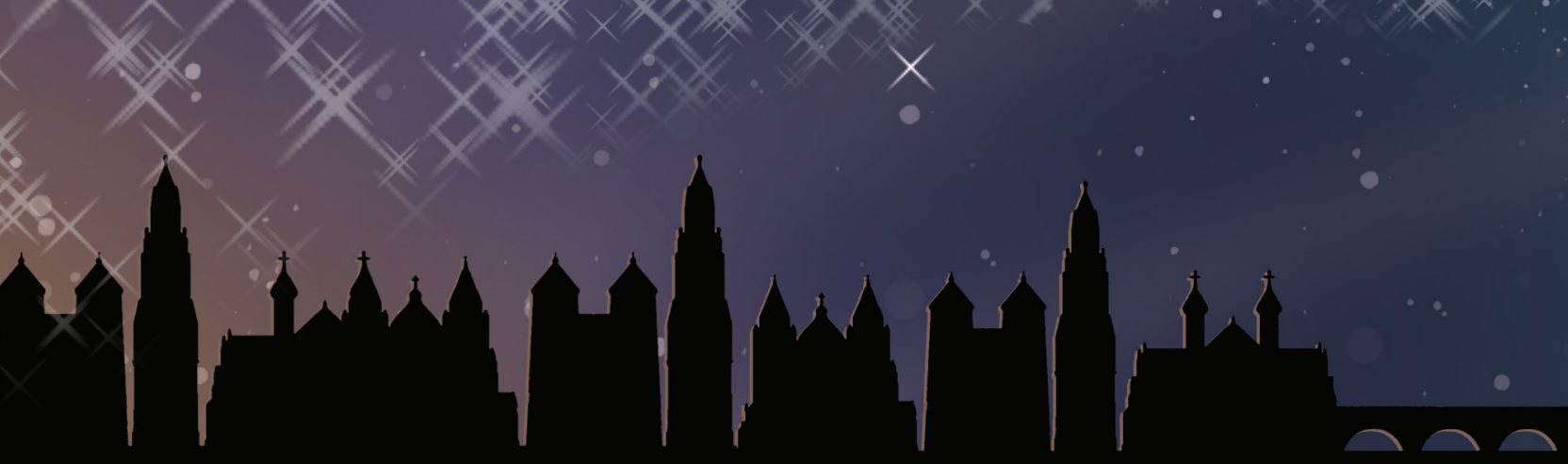




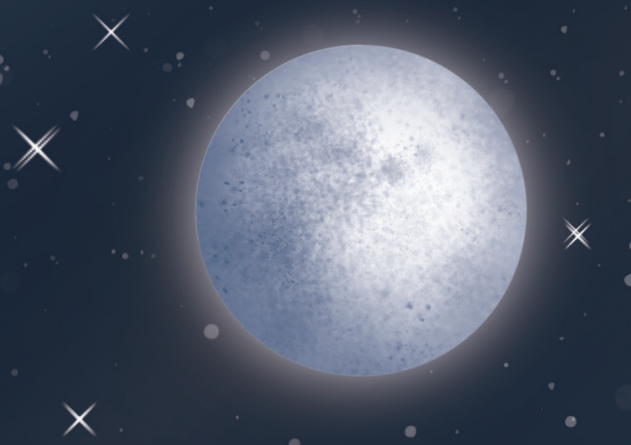

$$
\text { CHAPTER ? }
$$

Shared decision making and surgical informed consent in general surgery: A pilot study on differences in perspectives of physicians and patients

\section{Wouter K.G. Leclercq, Willem Zwaans, Loes Janssen,} Johan Legemaate, Laurents P.S. Stassen, Marc R. Scheltinga Submitted .

\section{$x$}




\section{ABSTRACT}

Introduction

Shared decision making (SDM) and surgical informed consent (SIC) are increasingly recognized as important aspects of preoperative consultation in general surgery. Different perspectives of physicians and patients may result in suboptimal levels of communication, expectations and knowledge exchange. Goal of this study is to assess the quality of, and relation between, SDM and SIC in a general surgery outpatient department.

\section{Methods}

Randomly selected surgical patients completed a questionnaire concerning SDM aspects of their preoperative consultation (SDM-Q-9). Their surgeons completed the doctor's version termed SDM-Q-Doc. SDM-Q-9 and SDM-Q-Doc scores (0-100), and SIC scores based upon the medical record (0-10) were calculated and analysed using standard statistical methods, including calculation of intraclass correlation coefficients (ICC).

\section{Results}

A total of 38 sets of both SDM-Q-9 and SDM-Q-Doc questionnaires were available for analysis. Median total SDM-Q-9 scores were higher than SDM-Q-Doc scores (90 vs. 79, $P<0.05)$. Significant differences were found in 3 of 9 items of the patient's and surgeon's

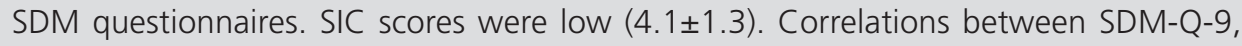
SDM-Q-Doc and SIC scores were low (all ICCs $<0.1)$.

\section{Discussion}

This pilot studying both shared decision making (SDM) and informed consent (SIC) in a surgical outpatient department indicates an imbalance in expectations between surgical patients, their surgeons and consent recordings. Future initiatives should be aimed at reducing this imbalance to optimize the physician-patient relationship with respect to legal standards. 


\section{INTRODUCTION}

In the past it was generally accepted 'standard of care' that a physician defined most (if not all) details of the client's treatment regimen. More recently, the patient's active role in this treatment process is increasingly acknowledged. In a physician-patient partnership, preferences and available treatment options should openly be discussed.1,2 'Shared decision making' (SDM) is a widely accepted concept that is considered pivotal for good clinical practice..$^{3-5}$ SDM is intuitively appealing and may possibly lead to an improved therapeutic outcome..$^{2-5}$

A smooth introduction of SDM in standard surgical patient care is challenging. ${ }^{4}$ Questionnaires may aid in evaluating the roles of both patient and care provider during a consultation. Recently, a nine-item SDM-Questionnaire (SDM-Q-9) assessing a patient's role demonstrated good psychometric characteristics including internal consistency, item discriminations, and face and factorial validity scores. ${ }^{1}$ A physician version (SDM-QDoc) followed in suit. ${ }^{5} \mathrm{~A}$ Dutch version of both questionnaires was found to have good acceptance and reliability in a study among general practitioners and medical specialists. ${ }^{3}$

The informed consent process in surgery is another aspect that is increasingly recognized as important in the physician-patient relationship (Figure 7.1). It is thought that a proper completion of all three stages (preconditions, information and consent) of a surgical informed consent (SIC) procedure also depends on SDM. In other words, SIC is destined to fail if both partners are unaware of the mechanisms that play a role in SDM. Both SIC and SDM processes share certain items. However, SIC has a legal focus whereas SDM is aimed at perspectives of the decision process. Physicians must monitor both processes during a consultation as neglecting either SDM or SIC may result in suboptimal treatment results and dissatisfied patients. A number of recent studies found that completion of the SIC process in general surgery, orthopaedic-, as well as plastic surgery was suboptimal. ${ }^{6,7}$ These findings suggest that improvement of SDM may also lead to improved quality of the SIC process.

Goal of this pilot study was to test the quality of, and relation between SDM and SIC in a Dutch general surgery outpatient department using the SDM-Q-9, SDM-Q-Doc questionnaires and a SIC rating scale. If there is a strong correlation between these SDM and SIC measures, SDM questionnaires might be used as a tool or outcome parameter in SIC studies. 


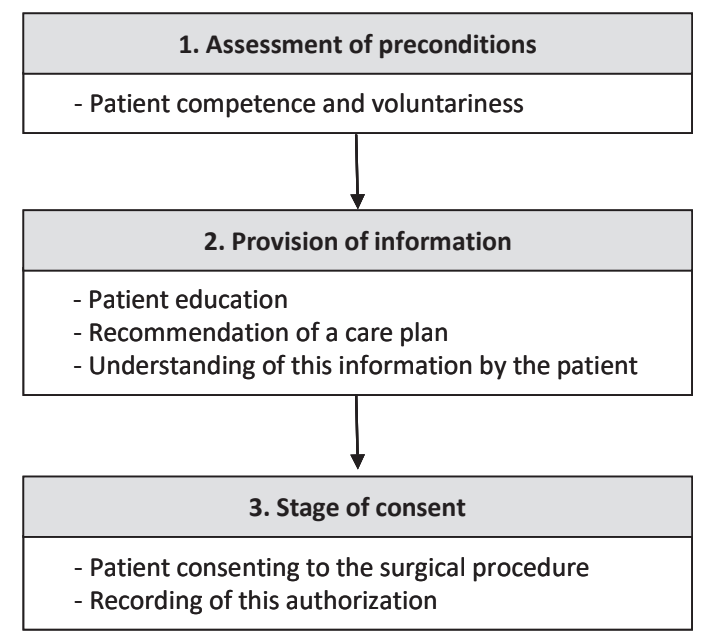

Figure 7.1 Three elements of informed consent (Leclercq). ${ }^{7}$ 


\section{METHODS}

\section{General study information}

This pilot study was performed between April and November 2014 at the surgical outpatient department of Máxima Medical Center (MMC), Veldhoven, the Netherlands. MMC is a 595-bed teaching hospital located in the south-eastern part of the country. Approval of the medical ethics board of MMC was requested but deemed unnecessary as it was judged by MMC's ethics board that the questionnaires only required a very limited amount of extra time and effort by the patients and did not interfere with daily practice.

\section{Outpatient consultation}

A random subset of MMC surgical surgeons (general, vascular, oncology, trauma; total $\mathrm{n}=13$ ) working in a team of 29 professionals (surgeons, $\mathrm{n}=15$; residents, $\mathrm{n}=14$ ) were asked to participate. If a surgeon agreed, he was asked to thoroughly read both the SDM-Q-9 and SDM-Q-Doc questionnaires but extra background information or additional teaching was not provided. He was instructed to inform a patient as usual on details of a pending operative procedure during an outpatient department consultation. He was also asked to complete the SIC process according to his professional standard. Details of the consultation were documented in the electronic patient dossier (EPD; EZIS Chipsoft, Amsterdam). A basic SIC module in this EPD allowed tabulation of notes on three aspects of SIC including the discussion of frequently occurring or major potential complications and alternative treatment options.

A nurse informed patients who were scheduled for preoperative consultation in the surgical outpatient department regarding specifics of the study and requested consent to participate. Once the consultation with the surgeon was finished and the patient had left the room, the surgeon completed a paper version of the SDM-Q-Doc. The patient completed a paper version of the SDM-Q-9 in a separate room. Both questionnaires usually required less than 5 minutes to finish.

\section{SDM-Q-Doc, SDM-Q-9 and SIC}

The SDM-Q-9 and SDM-Q-Doc questionnaires measure patient and physician perception of extent and quality of SDM during a physician-patient-consultation (Table 7.1). ${ }^{3}$ Both include two open questions ('what is the reason for consultation', 'which decision is made') and 9 multiple choice questions. Each of these 9 questions is scored on a sixpoint Likert scale (range, 0 totally disagree to 5, totally agree). As a consequence, a total questionnaire score ranges from 0 to 45 . Scores are converted into a 0 (low SDM) to 100 (excellent SDM) range as reported. ${ }^{1-5}$ 
The process of SIC was recorded in the EPD. For the purpose of the study, a total of ten items, deemed essential for SIC as previously described, were scored by the first author as listed in Table 7.2.2 As a consequence, SIC scores ranged from 0 (no item discussed) to 10 points (all items discussed).

Table 7.1 SDM-Q-9 and SDM-Q-Doc items (Santema4).

\begin{tabular}{ll}
\hline SDM & \\
\hline Item 1 & Clarifying a decision needs to be made \\
Item 2 & Eliciting the patients' preferred involvement \\
Item 3 & Stating there is more than one way to deal with the problem \\
Item 4 & Explaining pros and cons of the treatment options \\
Item 5 & Investigating if the patient understood all the information \\
Item 6 & Identifying the patients' preferred treatment option \\
Item 7 & Weighting the treatment options \\
Item 8 & Making a shared decision \\
Item 9 & Agreement on follow up arrangement \\
\hline
\end{tabular}

Apart from multiple Choice Questions, the SDM-Q-9 and -Doc consisted of two open questions: "What is the reason for consultation?" and "Which decision is made?". SDM = Shared Decision Making.

Table 7.2 Electronic Patient file SIC items and surgeon scores.

\begin{tabular}{llc}
\hline SIC & & $\%$ \\
\hline Item 1 & Patient competence is checked & 0 \\
Item 2 & Diagnosis is noted & 91 \\
Item 3 & Prognosis with or without surgery is noted & 19 \\
Item 4 & Advised treatment is noted & 100 \\
Item 5 & Alternative options are noted & 72 \\
Item 6 & Frequent complications are noted & 81 \\
Item 7 & Infrequent but serious complications are noted & 53 \\
Item 8 & Leaflet is provided & 3 \\
Item 9 & Operating surgeon is clearly appointed & 3 \\
Item 10 & Explicit consent patient is noted & 6 \\
\hline
\end{tabular}

$\%=$ Percentage of dossiers where the specific SIC item was scored.

Calculations and statistics

It was decided to obtain data sets of approximately 30 patient-surgeon-interactions as a pilot sample. A power analysis could not be performed as previous data on this issue were not available. Goal of the pilot was to obtain SDM-Q-9, SDM-Q-Doc and SIC scores for analysis. Primary focus was to collect baseline outcome data for these three scores and to identify a correlation between SDM and SIC scores. 
Descriptive statistics included means and standard deviation (SD), or median with range as appropriate. A Wilcoxon signed ranks test analysed significant differences between scores on the related individual items of the SDM-Q-9 and SDM-Q-Doc using the SPSS for Windows version 22 (SPSS Inc., Chicago, IL, US). A Bland-Altman plot was generated to graphically investigate the agreement between total SDM-Q-9 and SDM-Q-Doc scores. The mean differences between total SDM-Q-9 and SDM-Q-Doc scores were calculated and tested for significance by a paired samples t-test. Furthermore, intraclass correlation coefficients (ICC) quantified the degree of accordance between patient and surgeon in SDM and SIC, using the two-way random model for consistency. ${ }^{4}$ Acceptability was assessed as the percentage of participants who completed a minimum of 7 of the 9 questions of each questionnaire. ${ }^{1}$ According to the SDM-Q-9 and SDM-Q-Doc guideline, a mean score of the completed questions was used to score the 1 or 2 missing question(s). A questionnaire was not analysed if more than 2 items were missing. ${ }^{1}$ 


\section{RESULTS}

A total of 38 sets of both SDM-Q-9 and SDM-Q-Doc questionnaires were obtained during the 6 months study period and were available for analysis. As 6 SDM-Q-9 questionnaires missed more than 2 items, patient acceptability was 84\% (32/38). Similarly, surgeon acceptability was $97 \%$ (37/38). Therefore, study results are based on an analysis of 32 complete sets of consultations that were provided by 32 different patients and 13 individual general surgeons (range per surgeon 1-7). Mean patient age was $55 \pm 18$ years whereas the female/male ratio was $17 / 15$. Mean surgeon age was $47 \pm 11$ year with a $1 / 12$ female/male ratio. A wide range of pathologies was diagnosed during these consultations (Appendix 7.1).

SDM-Q-9 and SDM-Q-Doc

Mean total SDM-Q-9 score was $84.5 \pm 17.9$ with a median score per item ranging from 4.0 to 5.0 (Table 7.3). Twelve of the 32 patients scored the maximum score. Mean total SDM-Q-Doc score was $76.8 \pm 13.4$ with a median score per item ranging from 3.0 to 4.0. Three of the 32 consultations received a maximum score by the surgeon.

SDM-Q-9 compared to SDM-Q-Doc

Significant differences between surgeons and patients were found regarding item 4, 5 and 6 (Table 7.4). A Bland-Altman plot demonstrated higher mean SDM-Q-9 scores compared to SDM-Q-Doc scores, with an overall 7.8 difference ( $P=0.07$, Figure 7.2). A -0.12 [95\% CI -0.44-0.24] ICC between SDM-Q-9 and SDM-Q-Doc scores was calculated, indicating a negligible agreement.

\section{SIC scores}

The mean number of 10 possible SIC items that were scored was $4.1 \pm 1.3$ (Table 7.2). Basic information such as diagnosis and advised treatment were often documented. In contrast, patient competence, prognosis or consent were often not, or infrequently captured. Alternative treatment options $(72 \%)$ and frequent or serious complications $(81 \%)$ were often described, but only in $31 \%(10 / 32)$ all three of these items were documented. The ICC between SDM-Q-DOC and SIC was 0.01 [95\% CI -0.34-0.35]. Also, no correlation was found between SDM-Q-9 and SIC score, -0.02 [95\% CI-0.36-0.33]. 
Table 7.3 SDM-Q-9 and SDM-Q-Doc scores in various studies.

\begin{tabular}{|c|c|c|c|c|c|}
\hline & & & SDM-Q-9 & & \\
\hline Item & $\begin{array}{c}\text { MMC } \\
\text { (median) }\end{array}$ & $\begin{array}{l}\text { MMC } \\
\text { (mean) }\end{array}$ & $\begin{array}{l}\text { Rodenburg } \\
\text { (mean) }\end{array}$ & $\begin{array}{l}\text { Santema }^{4} \\
\text { (mean) }\end{array}$ & $\begin{array}{c}\text { Scholl//Kriston } \\
\text { (mean) }\end{array}$ \\
\hline 1 & 5.0 & 4.3 & 3.7 & 4.3 & 3.9 \\
\hline 2 & 4.0 & 4.1 & 3.5 & 4.5 & 3.4 \\
\hline 3 & 5.0 & 4.0 & 3.5 & 4.1 & 3.4 \\
\hline 4 & 5.0 & 4.4 & 3.7 & 4.6 & 3.4 \\
\hline 5 & 5.0 & 4.5 & 4.2 & 4.8 & 3.6 \\
\hline 6 & 5.0 & 4.3 & 3.6 & 4.1 & 3.3 \\
\hline 7 & 4.5 & 4.0 & 3.5 & 4.4 & 3.2 \\
\hline 8 & 5.0 & 4.2 & 3.7 & 4.2 & 3.4 \\
\hline 9 & 5.0 & 4.3 & 4.3 & 4.7 & 3.5 \\
\hline raw & 40.5 & 38.0 & 33.7 & 39.7 & 31.1 \\
\hline \multirow[t]{2}{*}{ total } & 90.0 & 84.5 & 74.9 & 88.3 & 69.0 \\
\hline & \multicolumn{5}{|c|}{ SDM-Q-Doc } \\
\hline 1 & 4.0 & 4.0 & 3.9 & 4.2 & 4.0 \\
\hline 2 & 3.0 & 3.6 & 3.3 & 3.9 & 3.5 \\
\hline 3 & 4.0 & 3.6 & 3.6 & 4.4 & 3.9 \\
\hline 4 & 4.0 & 3.9 & 3.6 & 4.2 & 3.9 \\
\hline 5 & 4.0 & 4.1 & 4.1 & 4.2 & 4.2 \\
\hline 6 & 4.0 & 3.8 & 3.6 & 4.0 & 3.7 \\
\hline 7 & 3.0 & 3.6 & 3.4 & 3.7 & 3.6 \\
\hline 8 & 4.0 & 4.0 & 3.6 & 3.5 & 3.8 \\
\hline 9 & 4.0 & 3.9 & 4.5 & 4.6 & 4.3 \\
\hline raw & 35.5 & 34.6 & 33.6 & 36.7 & 34.9 \\
\hline total & 78.9 & 76.8 & 74.6 & 81.5 & 77.5 \\
\hline
\end{tabular}

Table 7.4 A comparison of scores of SDM-Q-9 vs. SD-Q-Doc.

\begin{tabular}{lccc}
\hline Item & SDM-Q-9 & SDM-Q-Doc & P-value \\
\hline Q-1 & 5.0 & 4.0 & 0.054 \\
Q-2 & 4.0 & 3.0 & 0.053 \\
Q-3 & 5.0 & 4.0 & 0.252 \\
Q-4 & 5.0 & 4.0 & $\mathbf{0 . 0 2 4}$ \\
Q-5 & 5.0 & 4.0 & $\mathbf{0 . 0 4 6}$ \\
Q-6 & 5.0 & 4.0 & $\mathbf{0 . 0 2 6}$ \\
Q-7 & 4.5 & 3.0 & 0.113 \\
Q-8 & 5.0 & 4.0 & 0.422 \\
Q-9 & 5.0 & 4.0 & 0.214 \\
\hline
\end{tabular}




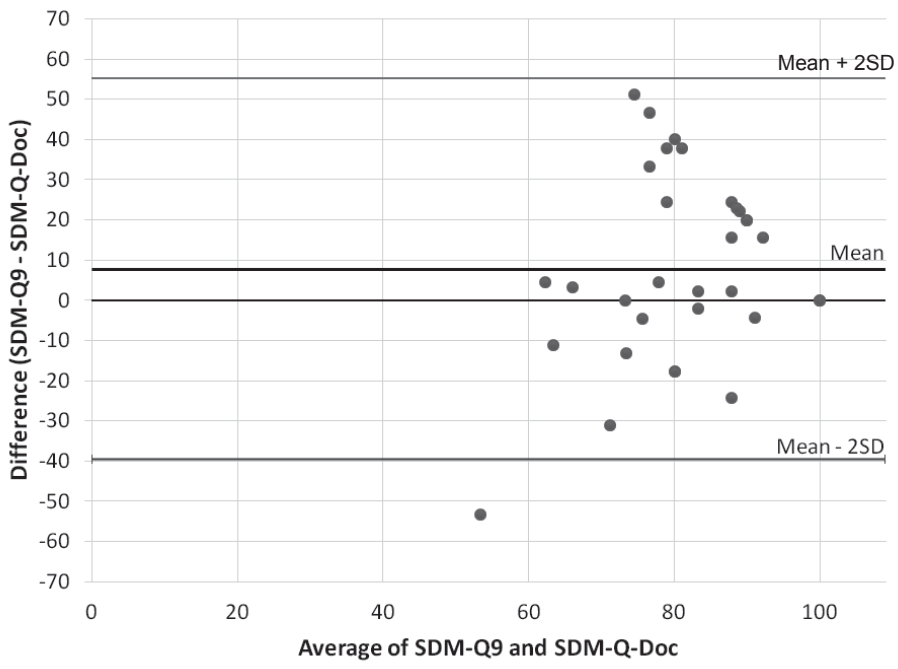

Figure 7.2 SDM-Q-9 versus SDM-Q-Doc scores. 


\section{DISCUSSION}

Shared decision making (SDM) and surgical informed consent (SIC) are increasingly recognized as important aspects of preoperative consultation in general surgery. Aim of this study was to assess the potential use of SDM-Q-9 and SDM-Q-Doc in SIC related research. Very few studies investigated the applicability of these tools in general surgery. To our knowledge this is the first study analysing SDM-Q-9, SDM-Q-DOC in relation to $\mathrm{SIC}$ recording in the EPD.

The current SDM-Q-9 scores were higher than expected. Based on a previous Dutch study, a SDM-Q-9/Doc score around 75 was anticipated in the present pilot. ${ }^{3}$ However, a mean SDM-Q-9 score of 85 was attained, a score that was also higher compared to the original study from Kriston and Scholl. Another recent study of Santema also reported a much higher score (Table 7.3). ${ }^{1,4-5} \mathrm{~A}$ possible explanation of these higher scores in the present study and that of Santema may be the clinical setting when compared to the general practice setting of the Kriston and Scholl studies. Surely, treatment options that were selected by these patients were in line with their expectation after the consultation in the general practice setting as a surgical procedure is necessary. As SDM-Q-9 scores were almost at maximum level in this and other clinical studies, this tool is not discriminative and is not recommended in clinical studies.

In the present study, surgeons scored their consultations at a lower SDM level compared to their patients (Table 7.4). In literature, scores of doctors and patients vary widely (Table 7.3). In this study, the items 'pros and cons of surgery', 'checking if provided information is understood by the patient', and 'reflecting on the patients' choice differed significantly between patients and physicians (Table 7.4). The lower scores of surgeons may reflect a basic uncertainty regarding these issues. A more recent study by Geessink showed a higher SDM level perceived by patients in comparison to that perceived by observers. ${ }^{8}$ They suggested that patients may have difficulties to distinguish between the constructs of involvement and satisfaction. In our study, this may have led to an overestimation of the level of involvement by the patients.

Interestingly, SDM items that differed between patients and surgeons are also key items in SIC (Table 7.1 and 7.2). Previous studies already showed high subjective SIC-scores but low objective SIC-scores. An equal observation recently was made in SDM. ${ }^{4}$ Therefore we speculate that enhancing focus on SDM will enhance the SIC process and vice versa and possibly may enhance satisfaction for patients and surgeons. 
Whereas SDM scores were generally good, quality of SIC recording as observed by evaluation of the EPD was poor. Previous studies also showed a low quality of SIC recording in general surgery. A number of items were not, or inadequately noted. Improved recording is required as surgeons are at risk for legal issues. This is even more true once patient satisfaction is altered when postoperative complications occur.

The present pilot study has limitations including a limited number of participants. Patient selection was at random whereas the SIC score was not validated. SDM-Q-9 and SDMQ-Doc scores were higher as expected reducing their discriminative ability.

SDM may be improved if surgeons receive adequate training. A pilot study by Geessink in which surgeons were trained in implementation of SDM and difficult conversations, showed an enhancement of their level of SDM in consultations with older cancer patients. ${ }^{9}$ One method of improving both SDM and SIC is the implementation of standard SIC modules in the EPD, addressing items that are considered essential in SDM and SIC. In this pilot study, the EPD could not be used as an adequate checklist for neither SDM nor SIC as only a restricted number of items were recorded. A standard, extensive SDM/SIC checklist may help surgeons and patients to improve the quality of their consultation. If this checklist is made available as a leaflet with personalised perioperative information and contact details for future questions, a patient may be optimally prepared prior to the surgical procedure.

In conclusion, focus on optimizing SDM and SIC may help patient and surgeons in their preoperative process. However, The potential use of SDM-Q-9 and SDM-Q-doc questionnaires seems limited as baseline scores are very high whereas a correlation with SIC scores was absent. 


\section{REFERENCES}

1. Kriston L, Scholl I, Holzel L, Simon D, Loh A, Harter M. The 9-item Shared Decision Making Questionnaire (SDM-Q-9). Development and psychometric properties in a primary care sample. Patient education and counseling 2010;80(1):94-99 doi: 10.1016/j.pec.2009.09.034[published Online First: Epub Date]|.

2. Leclercq WK, Sloot S, Keulers BJ, Legemaate J, Scheltinga MR. [Preoperative medical record-keeping can be improved: new informed consent form assists both physicians and patients]. Ned Tijdschr Geneeskd 2014;158:A7109

3. Rodenburg-Vandenbussche S, Pieterse AH, Kroonenberg PM, Scholl I, van der Weijden T, Luyten GP, Kruitwagen RF, den Ouden H, Carlier IV, van Vliet IM, Zitman FG, Stiggelbout AM. Dutch Translation and Psychometric Testing of the 9-Item Shared Decision Making Questionnaire (SDM-Q-9) and Shared Decision Making Questionnaire-Physician Version (SDM-Q-Doc) in Primary and Secondary Care. PloS one 2015;10(7):e0132158

4. Santema TB, Stubenrouch FE, Koelemay MJ, Vahl AC, Vermeulen CF, Visser MJ, Ubbink DT. Shared Decision Making in Vascular Surgery: An Exploratory Study. European journal of vascular and endovascular surgery : the official journal of the European Society for Vascular Surgery 2016 doi: 10.1016/j.ejvs.2015.12.010[published Online First: Epub Date]|.

5. Scholl I, Kriston L, Dirmaier J, Buchholz A, Harter M. Development and psychometric properties of the Shared Decision Making Questionnaire--physician version (SDM-Q-Doc). Patient education and counseling 2012;88(2):284-290 doi: 10.1016/j.pec.2012.03.005[published Online First: Epub Date]|.

6. Leclercq WK, Sloot S, Keulers BJ, Houterman S, Legemaate J, Veerman M, Thomas L, Scheltinga MR. Challenging the knowledge base and skillset for providing surgical consent by orthopedic and plastic surgeons in the Netherlands: an identified area of improvement in patient safety. Patient Saf Surg. 2016 Oct 22;10:21. eCollection 2016.

7. Leclercq WK, Keulers BJ, Houterman S, Veerman M, Legemaate J, Scheltinga MR. A survey of the current practice of the informed consent process in general surgery in the Netherlands. Patient Saf Surg. 2013 Jan 21;7(1):4.

8. Geessink NH, Ofstad EH, Olde Rikkert MGM, van Goor H, Kasper J, Schoon Y. Shared decisionmaking in older patients with colorectal or pancreatic cancer: Determinants of patients' and observers' perceptions. Patient Educ Couns. 2018 Oct;101(10):1767-1774.

9. Geessink NH, Schoon Y, Olde Rikkert MG, van Goor H. Training surgeons in shared decision-making with cancer patients aged 65 years and older: a pilot study. Cancer Manag Res. 2017 Nov 10;9:591600. 


\section{APPENDIX 7.1 \\ DIAGNOSIS DURING CONSULTATION}

\section{General}

(Recurrent) Inguinal/ umbilical hernia

Ventral incisional hernia

Cholecystolithiasis

Lipoma

Pilonidal sinus

Intestinal stenosis in inflammatory bowel disease

Accessory spleen

Adrenal (Pheochromocytoma)

Thyroid (struma, primary hyperparathyroidism)

Os Coccygodynia

Anterior Cutaneous Nerve Entrapment Syndrome

Oncology

Pulmonary lesion (suspicion of)

Adrenal carcinoma (suspicion of)

Lymphadenopathy (neck/throat area)

Vascular

Symptomatic Carotid artery stenosis

Arteriovenous fistula

Necrotic hallux

Chronic Exertional Compartment Syndrome

Trauma

Implant removal of after fracture healing 


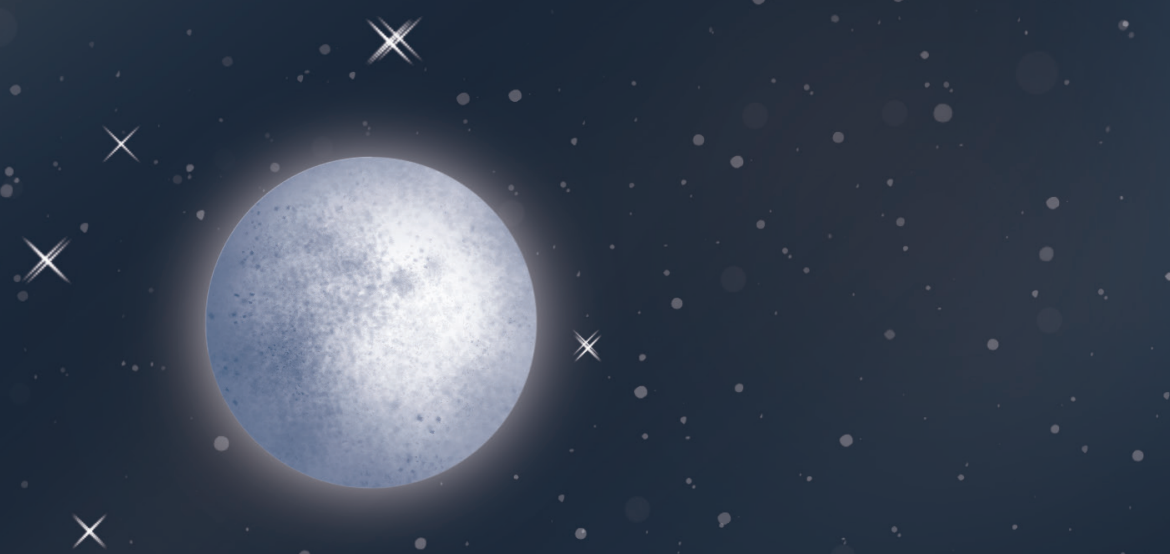

$$
\text { CHAPTER } 8
$$

\section{A decade of litigation regarding} surgical informed consent in the Netherlands

Margot M. Veerman, Laurả A. van der Woude, Michiel A. Tellier, Johan. Legemaate, Marc R. Scheltinga,

Laurents P.S. Stassen, Wouter K. G. Leclercq Patient Educ Couns. 2019;102(2):340-345
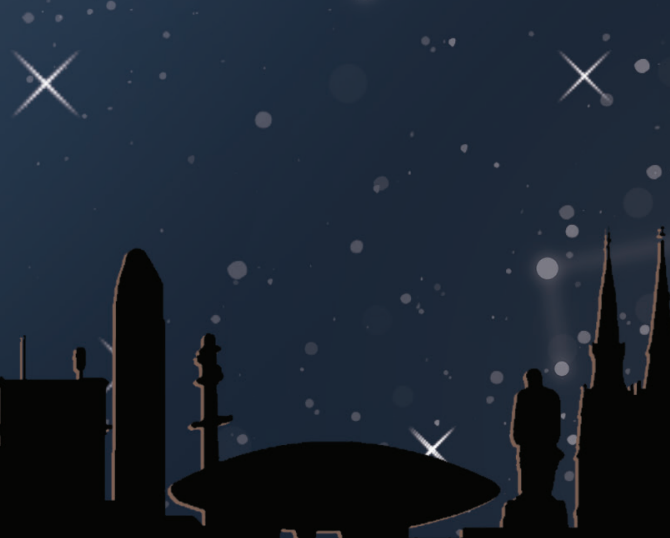


\section{ABSTRACT}

Objective

An inadequate surgical informed consent process (SIC) may result in a medical malpractice claim or medical disciplinary board (MDB) complaint. Aim of this study was to analyse characteristics of a decade of malpractice claims and MDB decisions regarding SIC in the Netherlands.

Methods

A retrospective analysis of malpractice claims and MDB decisions concerning SIC disputes in four major surgical specialties was conducted based on company data from the largest medical malpractice insurance company and two public available online MDB databases.

\section{Results}

A total of 11376 malpractice claims and 661 MDB complaints were filed between 20042013 and $676(6 \%)$ of these claims and $69(10 \%)$ of these complaints involved an alleged deficient SIC process. A random sample of 245(37\%) claims and all MDB decisions were analysed. Reasons for filing a claim or complaint were insufficient counselling or recording of SIC elements. In $20 \%$ of lawsuits and $25 \%$ of claims the case resulted in favour of the complainant.

\section{Conclusion}

A substantial portion of malpractice claims and MDB decisions is related to a deficient SIC process. 


\section{INTRODUCTION}

Medical claims and malpractice lawsuits are the final stage of a clinical process where a patient feels aggrieved, maltreated, disappointed, dissatisfied or had expectations that were not lived up to..$^{1-3}$ An important reason for patients to file a medical malpractice suit or complaint at a medical disciplinary board (MDB) is an inadequate surgical informed consent (SIC) process. ${ }^{4,5}$ Until now the frequency, characteristics, clinical circumstances and legal outcome of malpractice claims and MDB decisions concerning SIC (in the Netherlands) have not been systematically analysed and described. Informed consent is an evolving concept in history. The oldest document establishing rules for the conduct of medical professionals is the Hippocratic oath, stating that doctors should conceal most information from patients as they could not be trusted with making intelligent health decisions. ${ }^{6}$ Only in the 19th century this paternalistic approach shifted towards a patient-centred approach, in which a patient agrees to a health intervention based on an understanding of it. ${ }^{7}$ Patients should be educated by their physicians to make informed choices concerning their health. A properly conducted surgical informed consent process (SIC) allows patients to authorize an invasive procedure with full comprehension of relevant information including involved risks and benefits. ${ }^{8} \mathrm{~A}$ sound SIC process consists of three important elements: preconditions, information and consent. ${ }^{6}$ Preconditions include a determination of the cognitive competence of a patient to make a voluntary decision about his or her own body. ${ }^{9}$ The second element is SIC information consists of seven sub elements. ${ }^{9}$ In most common-law countries, patients must be 'reasonably' informed on the purpose, possible risks and complications of a treatment, alternative treatment options and prognosis, completed with a sound advice from the medical team involved. ${ }^{9}$ The last element of SIC is consent. ${ }^{9}$ The patient's decision and consent must be registered. Although a written consent in the patient's medical file is highly recommended, in the Netherlands a patient's signature is not legally obliged. ${ }^{10}$ An adequate SIC process serves a number of purposes. The patient's autonomy is respected and the patient is protected against potential harm. Better informed patients have more realistic expectations, higher satisfaction rates and become more compliant with their treatment objectives. ${ }^{11-19}$ Conversely, SIC violation undermines the patient's right of selfdetermination and jeopardizes the patient-doctor relationship resulting in an increased risk for disappointed or aggrieved patients filing a malpractice claim or a complaint at an MDB. ${ }^{20-23}$ According to annual reports of European, United States and Australian health services the number of malpractice claims and MDB complaints and the associated costs have risen in the past years. ${ }^{24-27}$ A substantial number of these claims and complaints is due to omissions during the informed consent process. ${ }^{28-32}$ In the Netherlands ${ }^{6}$, one in every six surgeons and one in seven orthopaedic or plastic surgeons was faced with an official SIC related complaint in the previous 5 years. ${ }^{33}$ The purpose of this study was 
to describe the frequency, characteristics, clinical circumstances and legal outcome of medical malpractice claims and MDB decisions concerning SIC from a patient's point of view, in order to provide information for future projects to improve the SIC process and to possibly prevent future malpractice litigation. 


\section{METHODS}

This study involves a retrospective analysis of malpractice claims and MDB decisions concerning SIC disputes. Definitions and information on Dutch law are established in Table 8.1. Medical malpractice claims were obtained from the company database of Medirisk, the Netherlands' largest provider of medical indemnity insurance. Medirisk, a non-profit organization, covers almost $70 \%$ of the country's registered general hospitals. MDB decisions were obtained from two online legal databases: www. tuchtrecht.nl and www. tuchtcollege-gezondheidszorg.nl. These databases comprise all medical MDB decisions in the Netherlands (Table 8.1).

Table 8.1 Definitions.

\section{Medical malpractice}

Professional negligence by act or omission by a health care provider in which the treatment provided falls below the accepted standard of medical practice and causes injury or death to the patient. In case of medical malpractice patients can file a medical claim to an insurance company and/or they can file a complaint at a medical disciplinary board (MDB). There is a significant difference between a medical claim and an MDB complaint. A medical claim does not involve the court system, whereas an MDB complaint is a court decision.

\section{Medical claim}

If monetary compensation is sought in professional negligence, patients can file a claim to a medical insurance company (Medirisk). The insurance company then researches that claim. The insurer will consult the accused doctor and ask for a reaction. A medical advisor (who is in the same field as the accused doctor) will analyze the case and give an expert opinion. Finally a lawyer of the insurance company will choose to pay all, some or nothing of the claim.

\section{MDB complaint}

If a patient is not satisfied with the settlement of a malpractice claim or wants to take legal action, a complaint with the MDB can be filed. The MDB consists of fellow professionals of the subject of the complaint. The MDB does not decide on any damages. The board can issue a caution or reprimand or impose a fine. Professionals may also be barred temporarily or permanently from practicing their profession. In the Netherlands, legal complaints are dealt with by regional MDBs primarily. If the patient or accused doctor disagrees with the verdict, an appeal can be made to the national MDB, which makes the final decision.

\section{Case identification}

The flowchart of our study sample is shown in Figure 8.1. All claims and MDB decisions concerning SIC, filed between 1 January 2004 and 31 December 2013 were included for analyses. Cases closed more than 10 years or still in progress at time of this study were excluded. Claims and lawsuits were labelled according to their main subject. Claims with an 'informed consent' label and lawsuits with an 'information' label were selected. Subsequently all cases within surgical specialties were selected and read completely. Cases 
in which the patient had a complaint about his or her IC procedure were included. A second reviewer re-reviewed some of the files to reduce the risk of bias. A random sample of claims and a total of MDB decisions concerning SIC were to be included for analysis. The study focused on four major surgical disciplines: general surgery, orthopaedic surgery, plastic surgery and gynaecology. Because our study was based on retrospective analysis of existing databases, the rules laid down in the Medical Research Involving Human Subjects Act do not apply to this study.

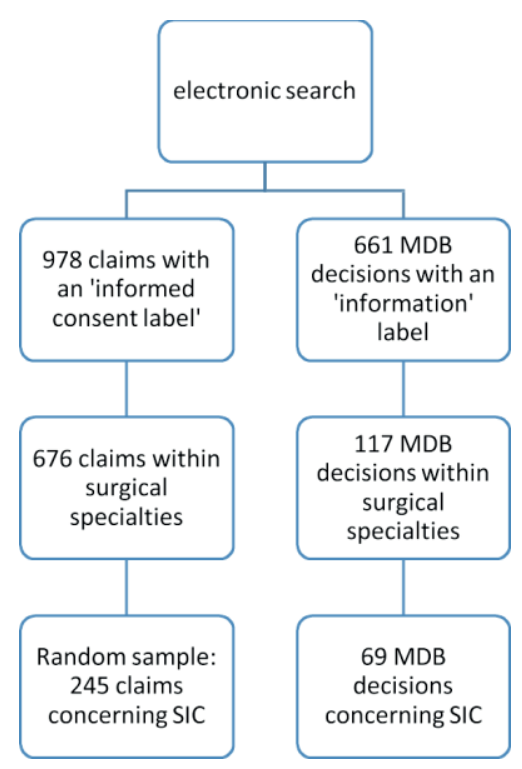

Figure 8.1 Flowchart of our study sample.

Data, variables and study instrument

All data were anonymized. Of all claims and MDB decisions, the following data were extracted: patient and doctor characteristics, the patient's allegations and the legal outcome of claims and MDB decisions (Table 8.2). The patient's allegations were coded into 9 predefined categories based on the description of informed consent in the Dutch law. ${ }^{8}$ The reasonableness or legitimacy of the patient's allegations was not evaluated in this study. The judicial outcome of claims was not specifically focused on SIC, therefore statistics were only performed on cases in which the lack of informed consent was the main issue ( $n=95$ ) In case of a MDB decision, two different sentences were imposed in our study: a caution or a reprimand. We analysed how often the accused doctors recognized the patient's complaint about SIC in comparison to medical advisors, lawyers of Medirisk or the MDB. 
Table 8.2 Variables of interest.

\begin{tabular}{ll}
\hline Patient characteristics & Gender, age, type of surgery \\
\hline Doctor characteristics & Medical specialty, specialist or trainee status \\
\hline Lead-time (in days) & Time between the incident and the actual complaint \\
\hline Informed consent is: & Main complaint / part of the complaint \\
\hline Association of SIC aspect & The doctor's behaviour and communication \\
\hline with & Insufficient documentation in the medical file \\
\hline Patient's allegations & Insufficient information about: \\
& - Diagnosis \\
& - Treatment \\
& - In general \\
& - Characteristics \\
& - Aims \\
& - Risks / complications \\
& - Alternatives \\
& - Health status / prognosis \\
& - No explicit consent was given \\
& Judgment (recognition, settlement, rejection) of SIC \\
& complaint by the: \\
& - Medical advisor \\
& - Accused doctor \\
& - Lawyer of Medirisk \\
& - MDB \\
\hline Case outcome &
\end{tabular}

$\mathrm{SIC}=$ surgical informed consent.

Statistical analysis

Due to a limited time frame to access the Medirisk database a random sample was taken of the medical claims about surgical informed consent. In order to have a balanced sample over the total time frame a random sample per year was taken. An employee of Medirisk who was not involved in the research, did this randomization with a computer. Analyses were descriptive and outcomes depicted as whole numbers and percentages. Continuous variables for group comparison were tested using Student's T-tests or Mann Whitney U tests. Significance of categorical variables and proportions were analysed using a twosided Fisher's exact test. The sign test, which can be used to identify differences between paired observations on an ordinal scale, was used to identify differences between the judgment of the doctor, the medical advisor, the lawyer or the medical court. ${ }^{14}$ P-values (two-tailed) of $<0.05$ were considered as statistically significant. Data analysis was performed using SPSS statistics data 22. 


\section{RESULTS}

A total of 11376 malpractice claims were filed between 1 January 2004 and 31 December 2013 (Figure 8.1). 978 (8.6\%) of these cases involved allegations of deficiencies in the informed consent process. Nearly $70 \%$ (676/978) concerned surgical specialties. $15 \%$ of the files were re-reviewed by the second reviewer and conflicting results were discussed until consensus was reached (kappa $=0.57$ ). A random sample of 245 claims $(37 \%)$ was eligible for analysis. From the online databases 661 MDB decisions were retrieved: 117 concerned surgical specialties of whom 69 MDB decisions met the inclusion criteria and were analysed.

General characteristics

In more than sixty percent of the malpractice claims and MDB complaints the complainant was female (Table 8.3). Most claims and complaints were filed against medical specialists. In $39 \%$ of claims and $28 \%$ of MDB decisions, informed consent was the main subject. Most patients complained about the lack of informed consent in relation to the occurrence of a postsurgical complication. More than $10 \%$ of patients were (also) dissatisfied by the doctor's behaviour and communication. In addition to the information complaint, there were often allegations about the insufficient documentation of the SIC process in the medical file.

Cases per medical specialty

In our study, four surgical specialties accounted for $82 \%$ of all claims and lawsuits concerning SIC (Table 8.4). This was representative for the overall group of 676 malpractice claims in which these specialties accounted for $84 \%$. Relatively, most malpractice claims were against orthopaedic surgeons. Plastic surgeons had the highest rates of informed consent disputes.

\section{Patient's allegations}

In $67 \%$ of claims and MDB decisions the primary allegation concerned a particular risk or complication of the treatment that had not been disclosed by the physician (Table 8.5). The second most common allegation involved insufficient information about the characteristics of the treatment, especially about the medical technical aspects, which doctor performed the procedure or which alternative treatment options were available. In 15\% of claims and MDB decisions the treatment was ruled to have been performed without the patient's (full) consent. When a resident was involved in the treatment process, patients claimed significantly more about which doctor performed the treatment $(\mathrm{P}<0.001)$. 
Table 8.3 Characteristics of SIC claims and MDB decisions $(n=314)$.

\begin{tabular}{lcc}
\hline & $\begin{array}{c}\text { No (\%) } \\
\text { Claims }(\mathrm{n}=245)\end{array}$ & $\begin{array}{c}\text { MDB decisions } \\
(\mathrm{n}=69)\end{array}$ \\
\hline Patient & $158(64 \%)$ & $42(61 \%)$ \\
Female & $87(36 \%)$ & $27(39 \%)$ \\
Male & $209(82 \%)$ & $64(93 \%)$ \\
Doctor & $36(18 \%)$ & $3(7 \%)$ \\
$\quad$ Resident & & $19(28 \%)$ \\
Medical specialist & $95(39 \%)$ & $50(72 \%)$ \\
Role of IC in the complaint & $150(61 \%)$ & $8(12 \%)$ \\
Main subject & & $14(20 \%)$ \\
Minor subject & $27(11 \%)$ & \\
Role of other aspects in the SIC process & $38(15 \%)$ & 895 days* \\
Unpleasant attitude of the doctor & & 15 days \\
Insufficient documentation of SIC & 614 days* & 3505 days \\
Lead time & 22 days & 3553 days \\
Mean &
\end{tabular}

$\mathrm{SIC}=$ surgical informed consent. * There is a significant difference $(P=0.003)$ between the mean leadtime of claims and lawsuits.

Legal outcome of malpractice claims and MDB decisions

An overview of the legal outcome of claims and lawsuits concerning SIC is shown in Tables 8.6 and 8.7. In 25\% (24/95) of the malpractice claims and 20\% (14/69) of the MDB decisions the patient's allegations were recognized. Our study shows that the accused doctors rarely agree that something went wrong with their SIC procedure. This difference in recognition of the patient's complaint on SIC was significant between doctors and medical advisors ( $P=0.002)$ and between doctors and the MDB ( $P=0.013)$. In addition, the judgment of the medical advisors often differed from the final judgment of the lawyer of Medirisk ( $P=0.027)$. When the patient's allegations involved insufficient documentation of SIC, the complaint on SIC was more often recognized as significant. This applied to both claims ( $P=0.001)$ and MDB decisions ( $P=0.005)$. 


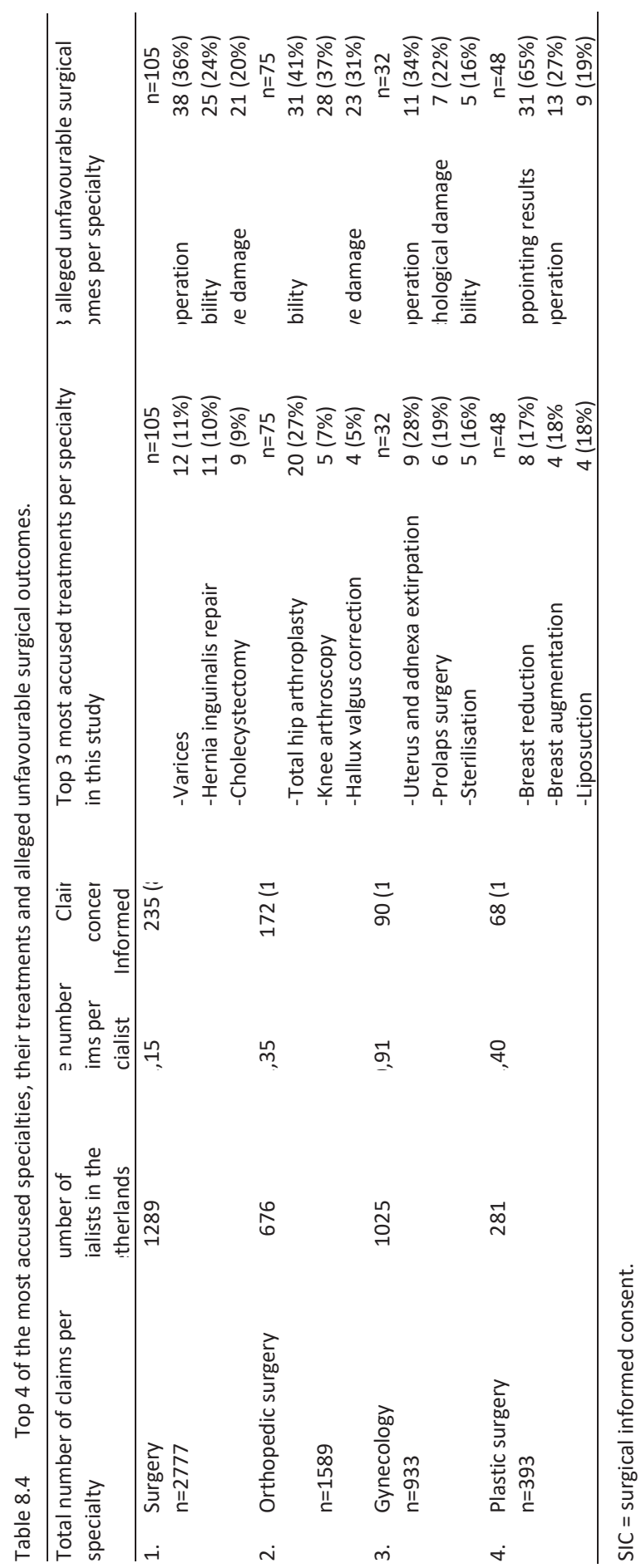


Table 8.5 Patient's allegations concerning SIC.

\begin{tabular}{lcccc}
\hline Patient's allegations & $\begin{array}{c}\text { Malpractice } \\
\text { claims } \\
(n=245)\end{array}$ & \multicolumn{2}{c}{$\begin{array}{c}\text { MDB } \\
\text { decisions } \\
(\mathrm{n}=69)\end{array}$} \\
\cline { 2 - 5 } & $\mathrm{n}$ & $\%$ & $\mathrm{n}$ & $\%$ \\
\hline Diagnosis & 4 & $2 \%$ & 2 & $3 \%$ \\
Treatment: & 245 & $100 \%$ & 69 & $100 \%$ \\
- Insufficient information in general & 14 & $6 \%$ & 10 & $28 \%$ \\
- Characteristics of treatment: & 78 & $32 \%$ & 19 & $28 \%$ \\
* Medical technical aspects & 41 & $17 \%$ & 12 & $17 \%$ \\
$*$ Duration & 4 & $2 \%$ & 2 & $3 \%$ \\
$*$ Preparation & 2 & $1 \%$ & 0 & - \\
$\quad$ * Follow up & 18 & $7 \%$ & 1 & $1 \%$ \\
* Time of treatment & 1 & $0,5 \%$ & 1 & $1 \%$ \\
* Which doctor performs the treatment & 19 & $8 \%$ & 7 & $10 \%$ \\
* Other & 4 & $2 \%$ & 1 & $1 \%$ \\
- Aim of treatment & 3 & $1 \%$ & 0 & - \\
- Risks or complications of treatment & 164 & $67 \%$ & 46 & $67 \%$ \\
- Alternative treatment options & 33 & $13 \%$ & 10 & $14 \%$ \\
- Current health status or prognosis & 9 & $4 \%$ & 4 & $6 \%$ \\
- No explicit permission was given for performing the treatment & 43 & $18 \%$ & 8 & $12 \%$ \\
- Other & 1 & $0,5 \%$ & 0 & - \\
\hline
\end{tabular}

Table 8.6 Legal outcome of malpractice claims regarding SIC ( $n=95)$.

\begin{tabular}{llll}
\hline Judgment & Doctor & Medical advisor & Judicial outcome \\
\hline - Recognition & $10(11 \%)$ & $27(28 \%)$ & $24(25 \%)$ \\
- Settlement & $12(13 \%)$ & $12(13 \%)$ & $8(8 \%)$ \\
- Rejection & $63(66 \%)$ & $39(41 \%)$ & $54(57 \%)$ \\
- N/A* & 0 & $4(4 \%)$ & 0 \\
- Unknown & $10(11 \%)$ & $13(14 \%)$ & $9(10 \%)$ \\
\hline
\end{tabular}

$\mathrm{SIC}=$ surgical informed consent. Not applicable.

Table 8.7 MDB decisions regarding SIC ( $n=69)$.

\begin{tabular}{llll}
\hline Judgment & Doctor & Regional MDB & National MDB \\
\hline - Recognition & $1(1 \%)$ & $14(20 \%)$ & $3(4 \%)$ \\
- Settlement & $2(3 \%)$ & - & - \\
- Rejection & $61(88 \%)$ & $55(80 \%)$ & $22(32 \%)$ \\
- N/A* & - & 0 & $44(64 \%)$ \\
- Unknown & $5(7 \%)$ & 0 & 0 \\
\hline
\end{tabular}

$\mathrm{SIC}=$ surgical informed consent. Not applicable. 


\section{DISCUSSION}

To the best of our knowledge, this is the first study in the Netherlands that analysed the deficiencies in the SIC process in malpractice claims and MDB decisions from a patient's point of view. This analysis might be helpful in future projects enhancing the SIC process. In the current study most files involved information elements of SIC. Improved understanding of patient's preferences and expectations regarding preoperative information contributes to a better adjustment of the information and thereby the quality of care. ${ }^{15-17,34}$ There is, however, a gap between the information doctors usually share before surgery and the information patients actually want to receive. Surgeons think patients desire more extensive information on the cause, effect and prognosis of the disease, while patients actually wanted more information on the operation characteristics and risk or complication rates of a specific surgery. ${ }^{35}$ Our study affirms this, as $67 \%$ of the patients felt not properly informed about a particular risk or complication of an operation and $30 \%$ felt not adequately informed about the (technical) characteristics of the surgery. The predominance of cases alleging undisclosed risks in $\mathrm{SIC}$ is striking. The most accusations in this study involve frequently performed elective or aesthetic surgical procedures ${ }^{29,36,37}$, This seems plausible, as extensive risk disclosure tends to matter more for patients undergoing elective surgery. Next to patient's expectations, good communication plays a major role in the perception of care. This is confirmed by the fact that the majority of legal cases is caused by failures in communication, rather than failures in treatment. ${ }^{1,30,38-41}$ In our study at least $10 \%$ of patients were dissatisfied by the doctor's behaviour and communication. They felt their problems were not taken seriously or the doctor did not have enough time. According to recent studies, Dutch orthopaedic, plastic and general surgeons have poor knowledge and skills regarding SIC.., 32 If staff is well trained, adequate information provision and consent recording is less at risk. Our study had some shortcomings. Our results were based upon a random sample of Medirisk cases and our analysis did not include the claims which were not covered by Medirisk. Not all malpractice and MDB cases from this period were fully completed and publicised. This might had some unknown selection bias effects. It was also impossible to specify the lawyer's judgment on SIC. We tried to compromise this by only analysing the complaints in which SIC was the main complaint. Nevertheless this study provides clues to enhance the SIC process. Doctors should discuss all relevant risks, that prioritize patient's preferences. ${ }^{6}$ In the Netherlands, $39 \%$ of the surgeons claimed that there was no institutional standard operating procedure (SOP) on quality or quantity of preoperative information. ${ }^{6}$ It appears useful to standardize the SIC process and specify factual risks for different treatments. Moreover, it is important to enhance patient's understanding, as recall of informed consent information is poor. ${ }^{42-49}$ Improving information transfer to patients with currently popular interventions as shared decision making (SDM) and e-health projects might be beneficial and should be further 
explored in surgical practice. Good communication requires substantial training and is often offset in practice by lack of consultation time. Improving doctor's skills and knowledge in these specific aspects also appears to be necessary to improve the SIC process and patient care in general. Modern tools as e-health or multimedia programs could be a useful adjunct to the current SIC process. Different studies investigated the use of multimedia in informed consent and found significant improvement of patient satisfaction and understanding. ${ }^{21,27,50,51}$ Although the patient-doctor relationship remains crucial for the SIC process, multimedia is a promising contribution. Further work is required to establish standardized SIC information within guidelines and determine which type of modern intervention is the best practice in clinical informed consent. In conclusion, this study presents new information on patient's perspectives of malpractice claims and MDB decisions regarding SIC in the Netherlands between 2004-2013. The majority of SIC related claims and complaints were focused on postoperative complications. Future effort should focus on better transfer of SIC information by improving doctor-patient communication, standardize SIC information within guidelines and use modern tools to enhance shared decision making. 


\section{REFERENCES}

1. Vincent C, Young M, Phillips A. Why do people sue doctors? A study of patients and relatives taking legal action, Lancet 1994;343:1609-1613.

2. Beckman HB, Markakis KM, Suchman AL, Frankel RM. The doctor-patient relationship and malpractice. Lessons from plaintiff depositions, Arch. Intern. Med. 1994;154:1365-1370.

3. Fisher TL. Medical malpractice in the United States: a review, Can. Med. Assoc. J. 1974;110:102-103.

4. Hamasaki T, Hagihara A. Physicians' explanatory behaviours and legal liability in decided medical malpractice litigation cases in Japan, BMC Med. Ethics 2011;21(12):7.

5. Gittler GJ, Goldstein EJ. The elements of medical malpractice: an overview, Clin. Infect. Dis. 1996;23: 1152-1155.

6. Faden RR, Beauchamp TL, King NMP. A History and Theory of Informed Consent, Oxford University press, New York, 1986.

7. Leclercq WKG, Keulers BJ, Scheltinga MR, Spauwen PH, van der Wilt GJ. A review of surgical informed consent: past, present and future. A quest to help patients make better decisions, World J. Surg. 2010;34(7):1406-1415.

8. Leclercq WKG, Keulers BJ, Houterman S, Veerman M, Legemaate J, Scheltinga MR. A survey of the current practice of the informed consent process in general surgery in the Netherlands, Patient Saf. Surg. 2013;7(1):4.

9. Leclercq WK, Sloot S, Keulers BJ, Legemaate J, Scheltinga MR. [Preoperative medical record-keeping can be improved: new informed consent form assists both physicians and patients], Ned Tijdschr Geneeskd 2014;158:A7109.

10. Verbogt S. Hoofdstukken over gezondheidsrecht, 9th edn., Wolters- Noordhoff, Groningen, 2003.

11. Kessler TM, Nachbur BH, Kessler W. Patients' perception of preoperative information by interactive computer program—exemplified by cholecystectomy, Patient Educ. Couns. 2005;59(2):135-140.

12. Grueninger UJ, Goldstein MG, Duffy FD. A conceptual framework for interactive patient education in practice and clinic settings, J. Hum. Hypertens. 1990;4(Suppl. 1):21-31.

13. Breemhaar B, Van den Borne HW. Effects of education and support for surgical patients: the role of perceived control, Patient Educ. Couns. 1991;18:199-210.

14. Conover WJ. Chapter 3.4: the sign test, Practical Nonparametric Statistics, third ed., Wiley, 1999: 157-176 ISBN 0-471-16068-7.

15. Brody DS. The patient's role in clinical decision-making, Ann. Intern. Med. 1980;93:718-722.

16. Cassileth BR, Zupkis RV, Sutton-Smith K, et al. Information and participation preferences among cancer patients, Ann. Intern. Med. 1980;92:832-836.

17. Ende J, Kazis L, Ash A, et al. Measuring patients' desire for autonomy: decision making and information-seeking preferences among medical patients, J. Gen. Intern. Med. 1989;4:23-30.

18. McIntosh J. Processes of communication, information seeking and control associated with cancer: a selective review of the literature, Soc. Sci. Med. 1974;8:167-187.

19. Temple WJ, Temple WJ, Russell ML, et al. Conservation surgery for breast cancer as the preferred choice: a prospective analysis, J. Clin. Oncol. 2006;24:3367-3373.

20. Baum N. Informed consent - more than a form, J. Med. Pract. Manage. 2006;22(3):145-148.

21. Waitzkin H. Doctor-patient communication. Clinical implications of social scientific research, JAMA 1984;252:2441-2446. 
22. Schenker $Y$, Fernandez $A$, Sudore $R$, Schillinger $D$. Interventions to improve patient comprehension in informed consent for medical and surgical procedures: a systematic review, Med. Decis. Mak. 2011; 31:151-173.

23. Chassin MR, Becher EC. The wrong patient, Ann. Intern. Med. 2002;136:826-833.

24. Mello MM, Chandra A, Gawande AA, Studdert DM. National costs of the medical liability system, Health Aff. (Project Hope) 2010;29(9):1569-1577.

25. http://www.nhsla.nhs.uk/AboutUs/Documents/NHS\%20LA\%20Annual\%20Review\%20201314\%20 and\%20Forward\%20Look\%20for\%202014-17.pdf.

26. http://www.health.vic.gov.au/hsc/resources/annualrep.htm.

27. www.medirisk.nl.

28. Bismark MM, Gogos AJ, Clark RB, Gruen RL, Gawande AA, Studdert DM. Legal disputes over duties to disclose treatment risks to patients: a review of negligence claims and complaints in Australia, PLoS Med. 2012;9(8):e1001283.

29. Mehta S, Farhadi J, Atrey A. A review of litigation in plastic surgery in England. Lessons learned, J. Plast. Reconstr. Aesthet. Surg. 2010;63:1747-1748.

30. Bismark MM, Gogos AJ, McCombe D, Clark RB, Gruen RL, Studdert DM. Legal disputes over informed consent for cosmetic procedures: a descriptive study of negligence claims and complaints in Australia, J. Plast. Reconstr. Aesthet. Surg. 2012;65(11):1506-1512.

31. Gogos AJ, Clark RB, Bismark MM, Gruen RL, Studdert DM. When informed consent goes poorly: a descriptive study of medical negligence claims and patient complaints, Med. J. Aust. 2011;195(6): 340-344.

32. Patel AJK, Morrison CM. Opportunities to reduce plastic surgery claims through an analysis of complaints data, J. Plast. Reconstr. Aesthet. Surg. 2013;66(4):455-459.

33. Leclercq WK, Sloot S, Keulers BJ, Houterman S, Legemaate J, Veerman M, Thomas L, Scheltinga MR. Challenging the knowledge base and skillset for providing surgical consent by orthopedic and plastic surgeons in the Netherlands: an identified area of improvement in patient safety, Patient Saf. Surg. 2016;22:21.

34. Waitzkin H. Doctor-patient communication. Clinical implications of social scientific research, JAMA 1984;252:2441-2446.

35. Keulers BJ, Scheltinga MRM, Houterman S, Van der Wilt GJ, Spauwen PHM. Surgeons underestimate their patients' desire for preoperative information, World J. Surg. 2008;32(6):964-970.

36. http://statline.cbs.n//StatWeb/publication/? VW=T\&DM=SLNL\&PA=80386NED\&LA=NL.

37. Studdert DM, Mello MM, Gawande AA, Gandhi TK, Kachalia A, Yoon C, et al. Claims, errors, and compensation payments in medical malpractice litigation, N. Engl. J. Med. 2006;354:2024-2033.

38. Beisecker AE, Beisecker TD. Patient information-seeking behaviors when communicating with doctors, Med. Care 1990;28(1):19-28.

39. Burkle CM, Pasternak JJ, Armstrong MH, Keegan MT. Patient perspectives on informed consent for anaesthesia and surgery: american attitudes, Acta Anaesthesiol. Scand. 2013;57(3):342-349.

40. Krause HR, Bremerich A, Rustemeyer J. Reasons for patients' discontent and litigation, J. Craniomaxillofac. Surg. 2001;29(3):181-183.

41. Huntington B, Kuhn N. Communication gaffes: a root cause of malpractice claims, Proc. (Bayl. Univ. Med. Cent.) 2003;16(2):157-161.

42. Falagas ME, Korbila IP, Giannopolou KP, Kondilis BK, Peppas G. Informed consent: how much and what do patients understand? Am. J. Surg. 2009;198(3):420-435.

43. Brezis M, Israel S, Weinstein-Birenshtock A, Pogoda P, Sharon A, Tauber R. Quality of Informed consent for invasive procedures, Int. J. Qual. Health Care 2008;20(5):352-357. 
44. Krupp W, Spanehl O, Laubach W, et al. Informed consent in neurosurgery: patients' recall of preoperative discussion, Acta Neurochir. (Wien) 2000;142(3):233-238.

45. Turner $P$, Williams $C$. Informed consent: patients listen and read, but what information do they retain? N. Z. Med. J. 2002;115(1164):U218.

46. Brown TF, Massoud E, Bance M. Informed consent in otologic surgery: prospective study of risk recall by patients and impact of written summaries of risk, J. Otolaryngol. 2003;32:368-372.

47. Shurnas PS, Coughlin MJ. Recall of the risks of forefoot surgery after informed consent, Foot Ankle Int. 2003;24:904-908.

48. Thorevska N, Tilluckdharry L, Ticko S, et al. Informed consent for invasive medical procedures from the patient's perspective, Conn. Med. 2004;68:101-105.

49. Pesudovs K, Luscombe CK, Coster DJ. Recall from informed consent counselling for cataract surgery, J. Law Med. 2006;13:496-504.

50. Nishimura A, Carey J, Erwin PJ, Tilburt JC, Hassan Murad M, McCormick JB. Improving understanding in the research informed consent process: a systematic review of 54 interventions tested in randomized control trials, BMC Med. Ethics 2013;14:28.

51. Keulers BJ, Welters CFM, Spauwen PHM, Houpt P. Can face-to-face patient education be replaced by computer-based patient education? A randomized trial, Patient Educ. Couns. 2007;67(1-2):176-182. 



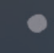

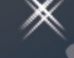

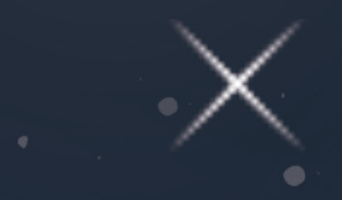

$\times \cdots$

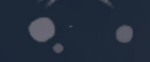

$x$

$\bullet$

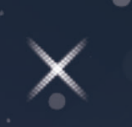

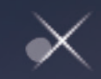
.

$x$ $x \times x$ $\times$ $x^{x}$

… : $x^{x} \times 2 \times x \times x \times x$ $\times \times \times \times$

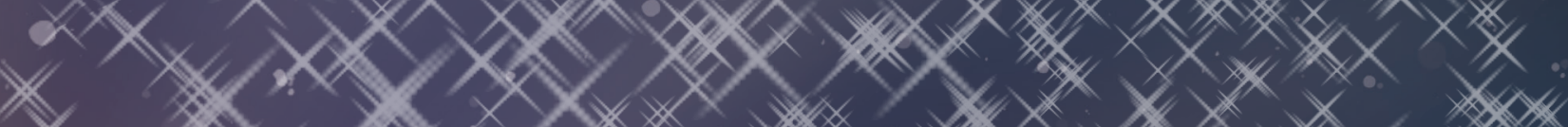
* $\times x^{*} \times$ - $x^{*} \times x^{*} \times x^{*} \times$

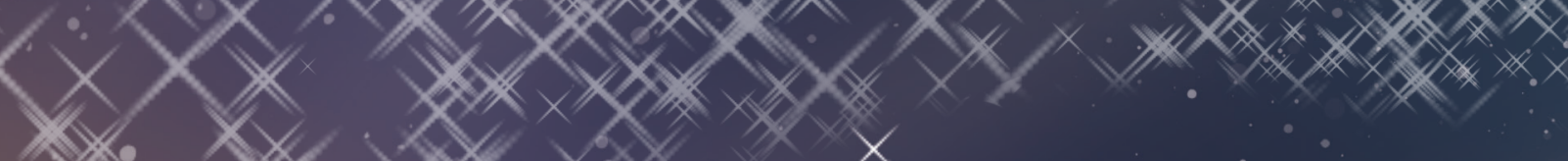
1. $\times 1 \times 1 \times$

$x \times x+2$ $x$ SWM
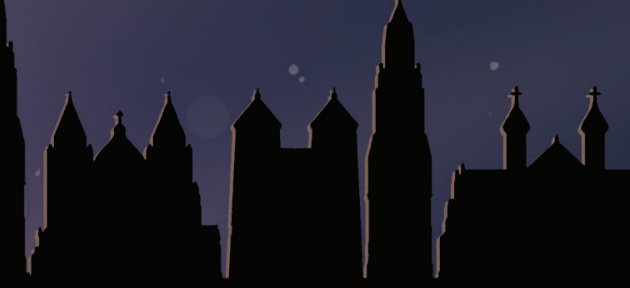


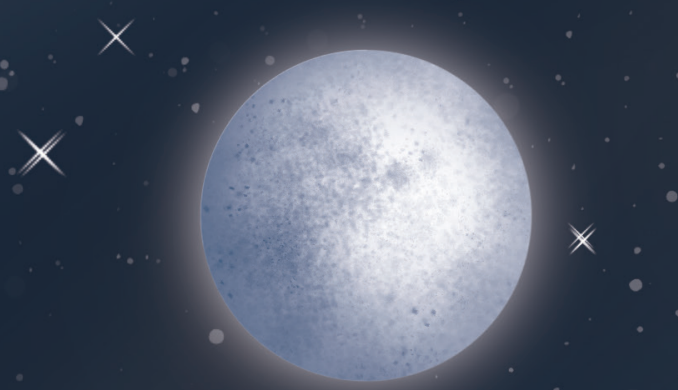

$x$

$$
\text { CHAPTER ? }
$$

\section{Preoperative medical}

$x$ record-keeping can be improved:

New informed consent form assists both physicians and patients

Wouter K.G. Leclercq, Sarà Sloot, Bram J. Keulers, Johan Legemaate, Mär R. Scheltinga

Ned Tijdschr Geneeskd. 2014;158:A7109.
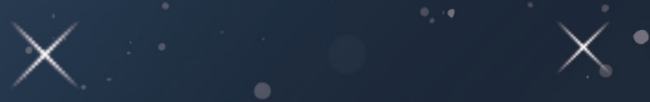


\section{ABSTRACT}

Adequate record-keeping is an important part of the surgical informed consent (IC) process. Standardization can enhance the quality of this process but is incomplete and qualitatively insufficiently implemented in current surgical practice. The introduction of well-designed tools would improve daily practice. We inventoried preoperative reporting at all 91 Dutch departments of General Surgery. Thirty-nine of the 73 departments that provided information on their IC process used a standard form. Twenty-nine of these forms were sent for analysis using a checklist based on legislation, recent case law and specialist literature. The mean number of items per form was 37 , but not a single form was complete. Based on these results in combination with relevant legislation, guidelines and expert opinions, an adequate, user-friendly and straightforward preoperative IC form was designed. This IC form can serve as a checklist and report for the physician and as an information leaflet for the patient. 


\section{INTRODUCTION}

Good file management is an important part of the preoperative informed consent process. Standardisation could improve the quality of this process, but currently it is incomplete and inadequately implemented. The introduction of good, practical tools could improve daily practice. We have inventoried the preoperative recording for the 91 surgical departments in the Netherlands. Of the 73 departments that responded, 39 indicated they used a standard form. 29 of these forms were sent in for analysis. These documents were assessed using a checklist based on legislation, recent case law and professional literature. On average, the forms listed 37 different data. However, none of the forms was complete. On the basis of this inventory and taking into account legislation, literature and expertise in the field, we designed a standard form that records preoperative informed consent in a legally adequate, user-friendly and clear manner. This form can serve both as a checklist and reporting tool for the physician, and as a 'leaflet' for the patient.

All physicians must keep their records up to date. ${ }^{1}$ In the case of major events such as surgery, the need for adequate reporting may be even greater. ${ }^{2}$ The report should reflect what has been discussed with the patient and which choices the patient has made. ${ }^{1-3}$ This is the summary of the preoperative surgical informed consent process (SIC) that the physician and patient have discussed together. ${ }^{1-4}$ This process guarantees the autonomy of a patient who has to undergo invasive surgery and helps the patient to make an informed decision about the treatment.

To date, there are no generally accepted standard forms for recording the preoperative consultation in the Netherlands. We believe that a legally adequate, user-friendly and above all practical standard form for preoperative informed consent would be a major step forward. 


\section{FOCAL POINTS FOR INFORMED CONSENT}

The NTVG earlier published an article about the basic rules of preoperative informed consent and the current limitations and focal points in this respect. ${ }^{5,6}$ The basic rules include: reach agreement within the department about the information that is given during common interventions; make sure that leaflets and websites are up-to-date; avoid jargon and check whether the core message has been conveyed and understood; repeat information if necessary, emphasize that the patient can always ask additional questions, and explain how this works in practice. ${ }^{5}$

There have been regular reports in both the scientific press and the mainstream media indicating that this process needs to be improved. . $^{4-72}$ Physicians and patients appear to have different opinions, and not just about the content and scope of the information that is provided preoperatively. ${ }^{13}$ There also appears to be a big difference between what physicians think they do and what actually happens in practice. ${ }^{7,8}$ 


\section{THE LEGAL BASIS OF INFORMED CONSENT}

In the Netherlands, the Medical Treatment Contracts Act (WGBO) has been in force since $1995 .{ }^{14}$ The WGBO also includes the rules for informed consent. Physicians must clearly inform the patient about a proposed examination or treatment and, if requested, record this in writing. ${ }^{14,15}$ Informed consent consists of 3 components: 'basic conditions', 'providing information' and 'consent section' (Table 9.1).

Table 9.1 Components of the preoperative informed consent.

\begin{tabular}{l}
\hline Preoperative informed consent \\
\hline basic conditions \\
voluntary competence \\
\hline providing information \\
diagnosis \\
prognosis \\
treatment options \\
complications \\
checking whether the information was understood \\
consent section \\
record of consent
\end{tabular}

The basic conditions component consists of checking whether the patient is physically and mentally capable of making a well-considered and voluntary decision about their treatment (competence), without pressure from others (voluntary). The 'providing information' component assumes that the information is adequate, comprehensible and complete, and has also been understood by the patient. In the case of elective procedures, information about a procedure must be provided in good time, enabling the patient to process the information and, if necessary, further discuss it. The decision taken by the patient is recorded in the consent section. . $2,14^{4}$ 


\section{RECORDING}

The preoperative consultation can be recorded in various ways. In some countries, SIC standard forms, whether or not signed by the patient, are legally required (US) or highly recommended (UK and Australia). ${ }^{4,9,16-18}$ In the Netherlands, the oral consent of the patient is usually sufficient, although the physician would do well to make a note of this consent in the file. ${ }^{15,19,20}$ The more drastic the procedure, the more guidelines recommend that the consent be recorded in writing by making adequate notes.,3,14 SIC forms can serve as a checklist for the completeness of the provided information and as a reporting tool in the file. The patient receives a copy as a 'patient leaflet' for the operation.

Earlier research showed that $26 \%$ of Dutch surgeons used SIC forms. ${ }^{7}$ The quality of these forms often proved insufficient, due to their incompleteness, illegibility or lack of user-friendliness; studies in other Western countries showed a similar picture. 4,18,21,22 Moreover, the forms were used inconsistently, filled in incorrectly, or not checked before the intervention. $4,18,21$ 


\section{CURRENT PRACTICE}

In April and May 2011, we conducted a survey by e-mail and telephone, asking surgeons and surgical residents from all 91 general surgery departments in the Netherlands whether they used a standard pre-operative form. If such a form was available, they were asked to send a copy - hardcopy or digital. Forms for specific procedures or emergency surgery were excluded. In the absence of a reaction, repeated requests were sent. We finalised the data collection at the end of 2011. A checklist was drawn up on the basis of the WGBO and the guideline 'The preoperative process' of the Quality Institute for Healthcare CBO. Based on this checklist, the submitted reports were assessed for quality.

Of the 91 surgical departments, 73 (80\%) responded; 18 departments refused to cooperate or did not respond. A small majority (39 out of 73,53\%) used a standardised SIC report. 29 departments sent us an example of their preoperative report (see the supplement to this article). The forms were very diverse and often incomplete. The average number of data recorded was 37 (extremes: 3-205). Basic data such as date (83\%), hospital (66\%), patient $(86 \%)$ and physician (72\%) were usually present, but remarkably few forms mentioned items such as indication (52\%), prognosis (21\%) or other possible treatment options (7\%). $69 \%$ of the forms stated that consent for surgery had been obtained. $28 \%$ required a signature by the physician and/or patient. 


\section{DEVELOPING A STANDARD FORM}

In our opinion, none of the forms in our inventory was satisfactory. That is why we looked for available case law and literature as the basis for a SIC standard form. The starting point was that the form should be legally adequate, user-friendly and practically applicable. The form must be easily interpretable for physician and patient, clear and printable. And, not unimportantly, we wanted the possibility to integrate it into an electronic patient file (EPF), to limit the administrative burden by offering semi-automatic completion.

Based on these principles, we drew up a draft form and presented it to experts in health law and patient information, to an insurance company (Medirisk) - with a view to assess medical liability - and to the Dutch Patients and Consumers Federation (NPCF). Following the feedback from these parties, the concept was modified until consensus was reached on the content of the form. Linguistically and literally, it was adapted to a suitable language level for this purpose. 


\section{NEW SIC STANDARD FORM}

Based on the obtained practical examples, the literature and the case law, as well as the feedback from the experts and organisations consulted, we drew up a list of data deemed necessary for a SIC form. First of all, the form must establish the hospital, main physician and patient involved. In addition, the 3 domains of the SIC must be specifically named: basic conditions, information and consent (see the Table 9.1). In total, this form records 19 items. In addition, there is the possibility to document additional information (supervisor, witnesses). Figure 9.1 shows an example of the standard form for preoperative informed consent that we have developed using this method. In some of the hospitals involved, the EPF was redesigned (Figure 9.2) to test this form in practice.

For the physician, the process is the following. The physician clicks on 'Surgery' at the bottom of the outpatient clinic file, which opens a checklist called 'Informed Consent'; the physician then completes the various items (see Figure 9.2). The hospital information system automatically fills in data about the hospital, the department, the treating physician, the patient and the date on the form. The physician assesses the patient's competence and can systematically review all the information discussed. After this, the physician is prompted to check whether the patient has actually understood all the information. The file should also contain information about additional sources of information that have been mentioned or provided, such as leaflets, websites or information programmes. Finally, the patient's consent is recorded. The SIC form is then approved and printed for the patient with the press of a button. The patient will also receive a brief description of the purpose of this form, and is given contact information in case of further questions, providing the patient with a 'leaflet' for the surgery. 


\section{CONSIDERATION}

We had to make choices when creating our form. We were looking for a balance between perfection and practical feasibility. This has led to a general form that is easy to implement. At a later stage, operation-specific forms could be created, adding additional characteristic elements. The selection of a digital form is logical, given the progressive digitisation of healthcare. Digital data is easy to store and trace. The ability to print a form and have it checked by the patient can increase patient involvement and safety.

The signing of a SIC form by the patient is not necessary and should only be done in exceptional cases, to avoid unnecessary formalisation of the patient-doctor relationship. Oral consent from the patient, along with a detailed medical record documented by the physician, is usually sufficient. 7,15 An exception can be made for very drastic or experimental treatments.

A more important aspect is clearly defining who the surgeon will be. Uncertainty about this can contribute to patient dissatisfaction. ${ }^{23}$ We want to emphasize that the proposed $\mathrm{SIC}$ form is a tool. This may be insufficient for certain patients or conditions. A SIC form never releases the physician from their obligation to monitor the quality of the entire SIC process and, if necessary, to adapt it to the circumstances of the individual patient.

Our research of the current use of forms for preoperative informed consent has limitations. Not all departments cooperated, and due to a lack of clarity of the submitted forms, these were sometimes difficult to assess. The SIC form presented here has not yet been tested with an effect measurement either. The form is intended as a well-reasoned and substantiated suggestion for practice. We suggest that several hospitals implement this form, after which an evaluation can take place. 


\begin{tabular}{|l|l|}
\hline Date: $x x-x x-20 x x$ & $\begin{array}{l}\text { Hospital Name and Logo } \\
\text { Hospital location } \\
\text { Department (e.g. surgery) }\end{array}$ \\
\hline
\end{tabular}

Standard Preoperative Informed Consent Form Print version

\begin{tabular}{|l|l|}
\hline \multicolumn{1}{|c|}{ Patient data } & \multicolumn{1}{c|}{ Treating physician } \\
Name: & Name: \\
Date of birth: & Function: \\
Patient number: & Supervisor*: \\
\hline
\end{tabular}

\section{General}

The patient demonstrates free will and

gives consent without pressure from others:

Yes $\square \quad$ No $\square$

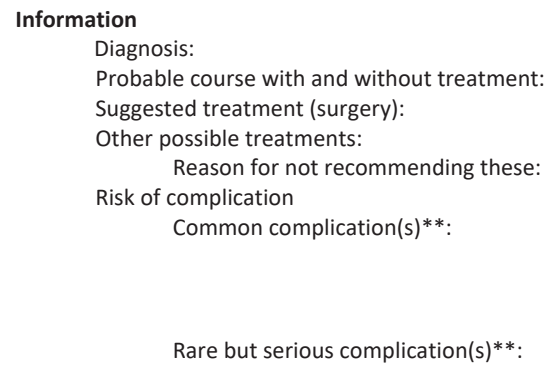

Probable course with and without treatment:

Suggested treatment (surgery):

Other possible treatments:

Reason for not recommending these:

Risk of complication

Common complication(s)**:

Rare but serious complication(s)**:

The patient has understood the information well and is able to name the main elements: Yes $\square$ No $\square$

\section{Additional information provided via:}

Leaflet $\square$

Website $\square$

Computer application

Other $\square$ :

\section{Surgeon}

The surgery is performed by:

The treating physician

$\square$

A surgeon from the department

No preference

$\square$

$\square$

Consent

Based on the information provided, the patient consents to the treatment described above

Oral consent by patient

$\square$

Witnesses:

* If no: additional meeting or consultation with another physician

*** If possible based on percentages

Version 2.1201312

Figure 9.1A Example of a standard form for preoperative informed consent as it is printed for the patient (A: front), (See separate file for translation of informed consent form). 


\section{What is Informed Consent?}

Informed consent means that you have been well informed and are consenting to surgery.

\section{What does informed consent mean for me?}

If you need to undergo surgery, it is important that you agree to it and know what to expect. You should discuss all your questions and concerns with your physician and/or surgeon before surgery.

The physician will try to inform you as completely as possible about your condition, the possible treatments and the consequences for your health.

Your physician and/or surgeon will regularly ask you if you have sufficiently understood the course of events surrounding the surgery. Ask yourself whether the information you have received about the surgery has been sufficient. Only after this has been completed have you been fully informed and can you consent to the surgery.

\section{What do I need to know?}

Not everyone wants to know all the specific details of the surgery. Nevertheless, it is wise to be well informed, so that you know what is going to happen and what to expect. The more extensive the intervention is, the more important it is for you and your loved ones to receive good information.

No physician and/or surgeon can fully guarantee the outcome of the surgery. There are many factors that can play a role. However, your physician and/or surgeon will do everything possible to give you the best possible information about what you can expect from the surgery.

\section{What should I do if I still have questions?}

If you have questions about this form, please contact your physician's outpatient clinic.

Figure 9.1B Example of a standard form for preoperative informed consent as it is printed for the patient (B: back) 


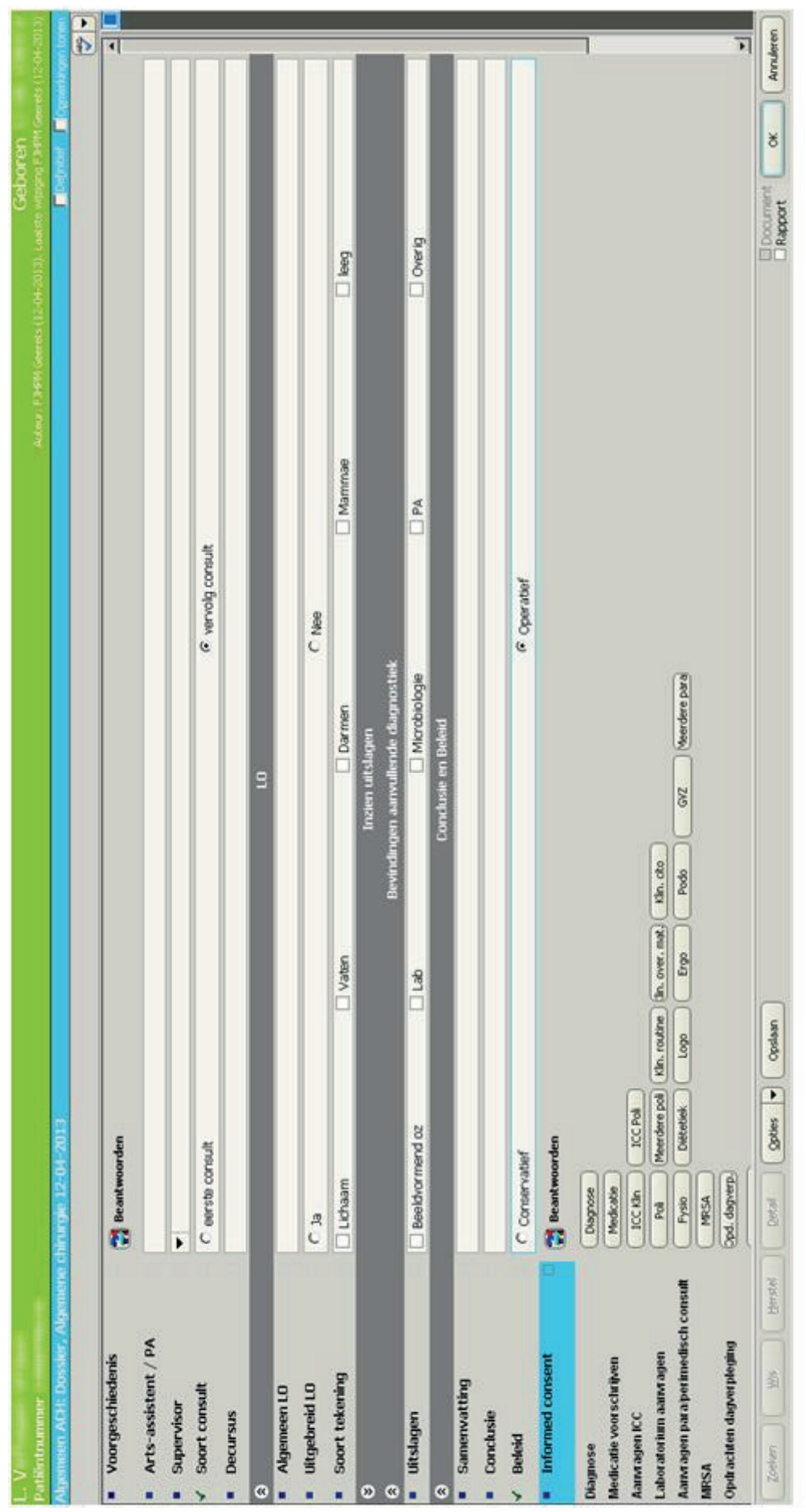

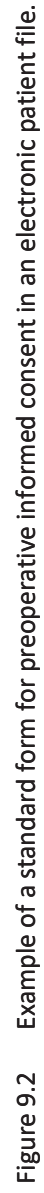




\section{REFERENCES}

1. Modelregeling arts-patiënt V.01. Utrecht: KNMG; 1998.

2. Richtlijn Informed Consent. Utrecht: KNMG; 2001.

3. Richtlijn Het preoperatieve traject. Utrecht: Kwaliteitsinstituut voor de Gezondheidszorg CBO; 2010.

4. Leclercq WK, Keulers BJ, Scheltinga MR, Spauwen PH, van der Wilt GJ. A review of surgical informed consent: past, present, and future. A quest to help patients make better decisions. World J Surg. 2010;34:1406-15.

5. Legemate DA, Legemaate J. Het preoperatief informed consent. Ned Tijdschr Geneeskd. 2010;154:A2492.

6. Van Staveren R. Gezamenlijke besluitvorming in de praktijk. Ned Tijdschr Geneeskd. 2011;155:A3777.

7. Leclercq WK, Keulers BJ, Houterman S, Veerman M, Legemaate J, Scheltinga MR. A survey of the current practice of the informed consent process in general surgery in the Netherlands. Patient Saf Surg. 2013;7:4.

8. Snijders HS, Kunneman M, Bonsing BA, et al. Preoperative risk information and patient involvement in surgical treatment for rectal and sigmoid cancer. Colorectal Dis. 2014;16:043-9.

9. Kinnersley P, Phillips K, Savage K, et al. Interventions to promote informed consent for patients undergoing surgical and other invasive healthcare procedures. Cochrane Database Syst Rev. 2013;7:CD009445.

10. TROS Radar. Burgerinitiatief: 'Bijsluiter' bij operaties. 4 January 2013. https://forum.www. trosradar.nl/ viewtopic.php?t=127675, consulted on 9 April 2014.

11. Consumentenbond. Minigids 'Ken uw rechten als patiënt'. The Hague: Consumentenbond; 2011.

12. Legemaate J. De informatierechten van de patiënt: te weinig en te veel. Magazine Gezondheidsrecht. 2011;35:478-86.

13. Keulers BJ, Scheltinga MR, Houterman S, van der Wilt GJ, Spauwen PH. Surgeons Underestimate Their Patients' Desire for Preoperative Information. World I Surg. 2008;32:964-70.

14. Wet op de geneeskundige behandelingsovereenkomst (WGBO). http://wetten.overheid.nl/ BWBR0005290/Boek7/Titel7/Afdeling5/Artikel446/geldigheidsdatum_09-04-2014.

15. Leenen HJJ, Geevers JKM, Legemaate J. Handboek Gezondheidsrecht Deel 1 - Rechten van mensen in de gezondheidszorg. The Hague: Boom Legal Publishers; 2011:189-209.

16. Anderson OA, Wearne IM. Informed consent for elective surgery--what is best practice? J R Soc Med. 2007:100:97-100.

17. Royal Australasian College of Surgeons. Informed Consent Policy. www.surgeons.org/media/ 8329/ FES_PST_2032_P_Informed_Consent_Policy.pdf, consulted on 9 April 2014.

18. Jefford M, Moore R. Improvement of informed consent and the quality of consent documents. Lancet Oncol. 2008;9:485-93.

19. Bulstra G, Wiggers T, Hubben H. Chirurg en tuchtrecht 1996-2007. The Hague: Sdu Uitgevers BV; 2008.

20. Heineman M, Hubben H. De chirurg in de medische tuchtrechtspraak 1986-1995. Lelystad: Koninklijke Vermande; 1996.

21. Paasche-Orlow MK, Taylor HA, Brancati FL. Readability standards for informed-consent forms as compared with actual readability. N Engl J Med. 2003;348:721-6.

22. Fick TE, Bijlsma K, Postuma HS, Van Velthoven PCM. Het medisch dossier en de WGBO. Ned Tijdschr Heelkunde. 1998;7:92-4.

23. Knifed E, Taylor B, Bernstein M. What surgeons tell their patients about the intraoperative role of residents: a qualitative study. Am J Surg. 2008;196:788-94. 



\section{x}

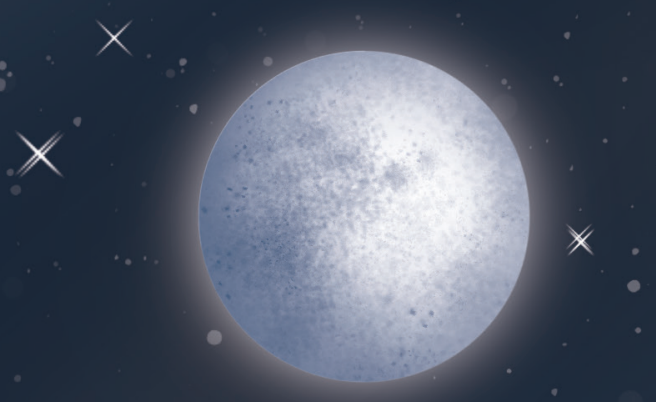

$x$

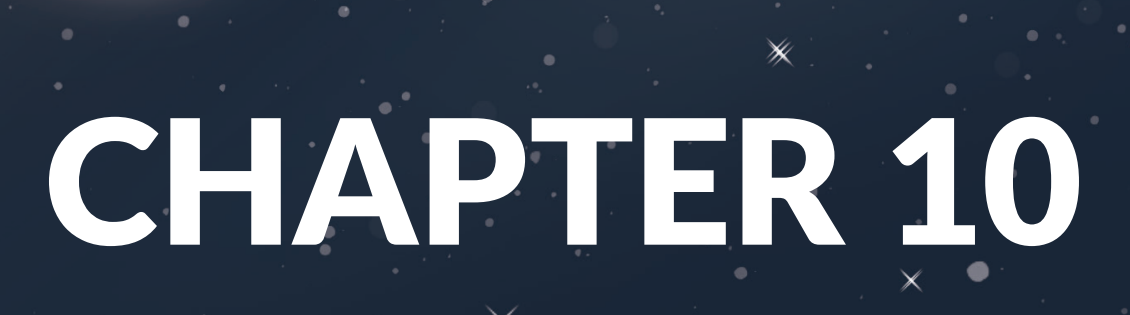

Personalised perioperative care by e-health after intermediate-grade abolominal surgery: A multicentre, single-blind, randomised, placebo: controlled trial.

Eva van der Meidi Johannes R. Anema, Wouter K.G. Leclercq, Marlies Y. Bongers, Esther C.J. Consten, Steven E. Schraffordt Koops, Peter M. van de Ven, Caroline B. Terwee, Johanna M. van Dongen, Frederieke G: Schaạfsma,Wilhelmus J.H.J. Meijerink, - Hendrik j. Bonjer, Judith A.F. Huirne Lancet. 2018,392(1014.1):51-59

$x$

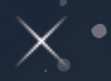




\section{ABSTRACT}

\section{Background}

Instructing and guiding patients after surgery is essential for successful recovery. However, the time that health-care professionals can spend with their patients postoperatively has been reduced because of efficiency-driven, shortened hospital stays. We evaluated the effect of a personalised e-health-care programme on return to normal activities after surgery.

\section{Methods}

A multicentre, single-blind, randomised controlled trial was done at seven teaching hospitals in the Netherlands. Patients aged 18-75 years who were scheduled for laparoscopic cholecystectomy, inguinal hernia surgery, or laparoscopic adnexal surgery for a benign indication were recruited. An independent researcher randomly allocated participants to either the intervention or control group using computer-based randomisation lists, with stratification by sex, type of surgery, and hospital. Participants in the intervention group had access to a perioperative, personalised, e-health-care programme, which managed recovery expectations and provided postoperative guidance tailored to the patient. The control group received usual care and access to a placebo website containing standard general recovery advice. Participants were unaware of the study hypothesis and were asked to complete questionnaires at five timepoints during the 6-month period after surgery. The primary outcome was time between surgery and return to normal activities, measured using personalised patient-reported outcome measures. Intention-to-treat and per-protocol analyses were done. This trial is registered in the Netherlands National Trial Register, number NTR4699.

\section{Findings}

Between Aug 24, 2015, and Aug 12, 2016, 344 participants were enrolled and randomly allocated to either the intervention $(n=173)$ or control $(n=171)$ group. 14 participants (4\%) were lost to follow-up, with 330 participants included in the primary outcome analysis. Median time until return to normal activities was 21 days (95\% Cl 17-25) in the intervention group and 26 days (20-32) in the control group (hazard ratio $1.38,95 \% \mathrm{Cl}$ 1.09-1.73; $P=0.007)$. Complications did not differ between groups.

\section{Interpretation}

A personalised e-health intervention after abdominal surgery speeds up the return to normal activities compared with usual care. Implementation of this e-health programme is recommended in patients undergoing intermediate-grade abdominal, gynaecological, or general surgical procedures. 


\section{INTRODUCTION}

The length of hospital stay after intermediate-grade abdominal surgery has reduced significantly during past decades because minimally invasive surgical procedures are now typically used. ${ }^{1}$ Implementation of rapid-recovery protocols after surgery, and economic pressures to lower the cost of a hospital stay, have also contributed to shortening of time in hospital. ${ }^{2}$ These changes of clinical practice have restricted the opportunity for health-care professionals to spend time with their patients before and after surgery, thus affecting negatively the provision of information and postoperative instructions tailored to the individual. ${ }^{3}$ High-quality patients' counselling improves postoperative recovery, ${ }^{4,5}$ and as a result of the changes in practice, recovery after minimally invasive surgery is slower than expected. ${ }^{6,7}$ Hence, patients will not take full advantage of minimally invasive surgery until optimum guidance and information is provided in the perioperative period. In view of the increase in surgical procedures over past decades, this problem is urgent and should be addressed in an efficient way. ${ }^{8}$

We have developed an interactive e-health programme that offers patients personalised care during the perioperative period. Patients receive customised recovery advice and day-to-day feedback tailored to their personal situation by an activity tracker, while an e-consult function enables patients to chat with the health-care provider. ${ }^{9}$ Here, we report the findings of a randomised controlled trial of this interactive e-health programme versus standard care in patients undergoing intermediate-grade abdominal general surgical or gynaecological procedures. We postulated that using the e-health programme will lead to quicker patients' recovery in terms of return to normal activities. Because normal activities vary considerably between participants, we used personalised patient-reported outcome measures to assess the effect of the e-health intervention. 


\section{METHODS}

Study design and participants

We did a multicentre, single-blind, randomised controlled trial at seven teaching hospitals in the Netherlands. We recruited potential study participants from the surgical waiting lists of these teaching hospitals. We judged patients eligible for the study if they were aged 18-75 years and scheduled for laparoscopic adnexal surgery, laparoscopic or open hernia inguinal surgery, or laparoscopic cholecystectomy. Exclusion criteria included surgery without curative intent or with additional radiotherapy or chemotherapy, deep infiltrating endo metriosis, (ectopic) pregnancy, adnexal surgery because of pelvic inflammatory disease or tubal ovarian abscess, a combination of several surgical procedures, and severe comorbidity that might complicate the postoperative course. We defined these exclusion criteria because the intervention would not be applicable for these patients. ${ }^{10,11}$ Two further exclusion criteria were an inability to understand information about the research and insufficient understanding or ability to fill in (Dutch) questionnaires. We defined these two exclusion criteria because patients meeting these criteria would not be able to participate in the study.

We obtained written informed consent from all patients who met the inclusion criteria and were willing to participate. The study was approved by the local medical ethics committee of the VU University Medical Centre (registration number 2014.301) and by the institutional review boards of all participating hospitals. The quality committee of the Amsterdam Public Health research institute reviewed and approved the study. The study protocol has been published. ${ }^{9}$

\section{Randomisation and masking}

After informed consent had been signed we asked participants to complete a baseline questionnaire (TO) in the 4-week period before surgery. Randomisation to either the intervention or control group took place directly after the baseline questionnaire had been completed. Randomisation was done in a 1:1 ratio using computer-generated lists and was stratified by hospital, sex, and surgical procedure using a block size of two. A researcher who was independent from the recruitment process and data analyses did the randomisation process. Immediately after randomisation, participants received an email that was generated automatically, containing a link to one of the two care programmes (intervention or control). Participants were unaware of the study hypothesis: they knew they were allocated to one of two care programmes, but they did not know that one programme was developed as an intervention and the other as a control. The researcher who did the analyses was masked to the random allocation throughout. Health-care providers were not masked to the allocation. 


\section{Procedures}

The intervention care programme comprised three parts: a website, an app, and an activity tracker. The aim of the different parts of the intervention was to prepare participants in the best way for surgery and to support them during the postoperative period. ${ }^{12}$ With the intervention programme, participants had the option to develop a personalised convalescence plan, could access information about the perioperative period by text and video animations, could use a monitor providing personal feedback on the recovery process, and had use of an e-consult function. By using an activity tracker, participants assigned the intervention programme were provided on a day-to-day basis with their current recovery status, based on a baseline measurement from the week before surgery. Figure 10.1 shows the different aspects of the intervention, and these are described in detail elsewhere. ${ }^{9}$

The control programme consisted of usual care and access to a placebo website, consisting of a patient information leaflet with information about the surgical procedure, general recovery advice provided by the hospital, and telephone numbers of their hospital. The reason for giving patients access to this placebo website was to minimise bias in estimation of the intervention effect (Figure 10.1).

In addition to the baseline questionnaire completed in the 4-week period before surgery (T0), participants received electronic questionnaires by email 1 week (T1), 3 weeks (T2), 6 weeks (T3), 3 months (T4), and 6 months (T5) after surgery. We used responses to these questionnaires for outcome assessment.

\section{Outcomes}

The primary outcome measure was time elapsing between surgery and return to normal activities after surgery. We used the Dutch-Flemish Patient-Reported Outcomes Measurement Information System (PROMIS) Physical Function (PROMIS-PF) item bank version 1.2 to assess return to normal activities after surgery. ${ }^{13-15}$

The PROMIS-PF item bank includes 121 items, covering a wide range of activities from selfcare (everyday activities) to more complex activities requiring a combination of skills. Every item contains five response categories. The PROMIS-PF item bank was developed using Item Response Theory (IRT) analyses and has been validated extensively in diverse populations and countries, including our own population. ${ }^{13,14,16,17}$ The items included in IRT-based item banks are all manifestations of the same underlying construct, and after calibration and validation of an item bank, subsets of items can be administered, giving valid and reliable scores that can be compared on the same scale with scores obtained from answering the whole item bank. ${ }^{13,14,18}$ PROMIS scores are expressed as T-scores, where a T-score of 50 
represents the average score of the general US population, with an SD of 10. We preselected 29 items from this item bank that were relevant activities for our study population. On the baseline (T0) electronic questionnaire, we asked participants from both groups to select eight activities from this list of 29 that-in their view-would most reflect their day-today activities. Participants, thus, created their personalised physical function short form. Based on the underlying IRT model of the item bank, individual T-scores are comparable, even though participants completed different items. ${ }^{18}$ In questionnaires administered after surgery (T1 to T5), we asked participants if they had already resumed these activities, and if so, since when they had done so. Every participant, therefore, had eight resumption dates for their personalised activities. We converted these dates into periods by subtracting the date of surgery from these dates. The moment on which the last activity was resumed was the return to normal activities moment and, thus, the primary outcome.

\begin{tabular}{|c|c|c|c|c|c|}
\hline & \multicolumn{5}{|c|}{ Aim } \\
\hline & & $\begin{array}{l}\text { Creating } \\
\text { recovery } \\
\text { expectations }\end{array}$ & \begin{tabular}{|c|} 
Reducing \\
uncertainties \\
during the \\
recovery \\
period \\
\end{tabular} & \begin{tabular}{|} 
Increasing \\
access to care, \\
reducing \\
workload
\end{tabular} & \begin{tabular}{|c} 
Minimise bias \\
in estimation \\
of the \\
intervention \\
effect
\end{tabular} \\
\hline \multirow{7}{*}{ 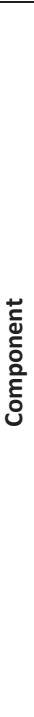 } & Intervention group & & & & \\
\hline & $\begin{array}{l}\text { Recovery advice based on a } \\
\text { personalised convalescence plan } \\
\text { Available on: intervention website and } \\
\text { app }\end{array}$ & $V$ & $V$ & & \\
\hline & $\begin{array}{l}\text { Information about the perioperative } \\
\text { period } \\
\text { Available on: intervention website and } \\
\text { app }\end{array}$ & $V$ & $V$ & & \\
\hline & $\begin{array}{l}\text { Monitoring and giving feedback on } \\
\text { recovery } \\
\text { Available on: intervention website, app, } \\
\text { and activity tracker }\end{array}$ & & $V$ & & \\
\hline & $\begin{array}{l}\text { E-consult } \\
\text { Available on: intervention website }\end{array}$ & & $V$ & $V$ & \\
\hline & \multicolumn{5}{|l|}{ Control group } \\
\hline & $\begin{array}{l}\text { Standard patient information leaflet } \\
\text { with information about the } \\
\text { perioperative period } \\
\text { Available on: placebo website }\end{array}$ & & & & $V$ \\
\hline
\end{tabular}

Figure 10.1 Description of the intervention and control.

If one or more activities had not been resumed when completing the last questionnaire (6 months after surgery [T5]), we censored the dates of resumption of these activities on 6 months. When the resumption dates of one or two activities were missing, we calculated the return to normal activities moment based on six or seven activities, respectively. 
For participants with missing resumption dates for more than two activities, we could not ascertain accurately the return to normal activities moment, because five-item short forms have little reliability for patients with more extreme scores. ${ }^{14}$ We censored these participants at the latest follow-up moment for which we knew return to normal activities was not yet resumed.

To check that participants assigned to the control group did not select so-called easier activities than participants allocated to the intervention group, we calculated for each participant the mean first threshold of the IRT item characteristic curve of the eight selected items. In IRT analyses, every item with five response options has four thresholds, indicating the level of physical function at which the highest probability of giving a certain response changes from one response category to the next (also called item difficulty).

Secondary outcome measures were: first return to normal activities after surgery (i.e., the moment on which the first activity was resumed); $75 \%$ return to normal activities after surgery (i.e., the moment on which $75 \%$ of the activities were resumed); physical function (T-score of PROMIS-PF personalised short form); social participation (T-score of PROMIS Ability to Participate in Social Roles and Activities version 2.0 short form $8 \mathrm{a}$ [PROMIS-APS]); ${ }^{19}$ self-rated health (measured with EuroQol five dimensions three levels [EQ-5D-3L]); ${ }^{20}$ time until the first day of return to work; time until full resumption of work activities; physical activity (calculated as total hours of walking, moderate, and vigorous activities per week and measured with the International Physical Activity Questionnaire [IPAQ]); ${ }^{21}$ length of recovery (mean score of the Recovery Index short version form [RI5]);22 pain intensity (measured on a visual analogue scale) ${ }^{23}$ and satisfaction with perioperative care and with the care programme (measured with a satisfaction questionnaire on a scale from 1 [low] to 10 [high]).

We assessed major complications during and after surgery by reviewing surgical reports and postoperative notes. For the calculation of costs, we included intervention costs (bottom-up approach), health-care costs (primary health-care costs, secondary health-care costs, medication costs, and home care costs [ascertained with a cost questionnaire]), and costs related to productivity loss. ${ }^{9}$ To calculate quality-adjusted life-years (QALYs), we used the EQ-5D-3L. Further, we did a process evaluation in which the implementation process of the intervention was evaluated. Results of this study are published elsewhere. ${ }^{24}$ A detailed description of the outcome measures in the study, including how and when they were assessed, is in the study protocol. $^{9}$ 
Statistical analysis

We calculated the sample size needed for our study using the following procedure. Based on a previous study, we expected a hazard ratio (HR) of 1.4 for the difference in return to normal activities between both groups. ${ }^{25}$ Using a two-sided log-rank test at a significance level of $5 \%$, we needed to observe 285 events (participants returning to normal activities) to achieve a power of $80 \%$. We aimed for a total of 308 participants (154 in both groups), allowing for an expected proportion of $2.5 \%$ of participants not returning to normal activities within the 6-month follow-up period and a dropout rate of $5 \%$.

We did analyses in SPSS version 22. We did statistical analyses according to the intentionto-treat (ITT) principle. We also did per-protocol analyses, which included only participants who used the intervention as intended (i.e., those from the intervention group who at least generated a convalescence plan on the website, and all patients in the control group). We used Kaplan-Meier curves to describe differences between study groups in time to return to normal activities after surgery and time to return to work, and we compared these outcomes between groups using Cox regression. For the primary analysis, we included study group as an independent variable and adjusted for covariates used for stratification (i.e., sex, hospital, surgical procedure). Moreover, we did a sensitivity analysis in which baseline factors that might affect the length of the recovery period after surgery (i.e., RI5 score, recovery expectations at baseline, and employment status) were added to the model with study group and stratification factors. ${ }^{5}$ We did a final sensitivity analysis in which we defined return to normal activities after surgery as time elapsing between randomisation and return to normal activities. We analysed differences in continuous outcomes between groups over time by mixed models, with time as a categorical independent variable. We included an interaction between group and time in these models, to compare the course of the mean outcome over time between the groups. When the interaction was found not to be significant we removed it from the model, and the main effect for group was considered to establish whether means when averaged over follow-up differed between groups.

We did an economic evaluation from a health-care and societal perspective for the primary outcome measure (return to normal activities) and QALYs. ${ }^{9}$ Cost differences were-in line with the primary outcome analysis - adjusted for factors for which stratification took place. We used bivariate regression analyses to estimate total cost and effect differences. ${ }^{26} \mathrm{We}$ used bias-corrected accelerated bootstrapping (5000 replications) to estimate statistical uncertainty. Cost-effectiveness acceptability curves were estimated. A detailed description of methods and results of the cost-effectiveness analysis are reported in the appendix. This trial is registered in the Netherlands National Trial Register, number NTR4699. 
Role of the funding source

The funder had no role in study design, data collection, data analysis, data interpretation, or writing of the report. The corresponding author had full access to all the data in the study and had final responsibility for the decision to submit for publication. 


\section{RESULTS}

Between Aug 24, 2015, and Aug 12, 2016, 896 potential participants were assessed for study participation. Of these, 344 (38\%) gave their consent to participate (Figure 10.2). A comparison of participants and nonparticipants according to age, sex, and type of surgical procedure revealed no clinically relevant or significant differences between both groups (data not shown). 173 participants were randomly allocated to the intervention group and 171 to the control group. One participant allocated to the intervention did not receive an account for the intervention website, because of logistical problems. 138 participants used the intervention as intended (i.e., they at least generated a convalescence plan on the website) and were included in per-protocol analyses. Follow-up ended on March 14, 2017. Median length of follow-up was 26 weeks (IQR 26-26).

$344(100 \%)$ participants completed the baseline questionnaire (T0), and questionnaires at 1 week (T1), 3 weeks (T2), 6 weeks (T3), 3 months (T4), and 6 months (T5) after surgery were completed by, respectively, 327 (95\%), 323 (94\%), 310 (90\%), 304 (88\%), and $300(87 \%)$ study participants. Data for the primary outcome measure (return to normal activities after surgery) were available for 330 (96\%) study participants (Figure 10.2). For four participants, the date for return to normal activities after surgery was based on seven instead of eight activities ( $n=1$ in the intervention group and $n=3$ in the control group).

Baseline characteristics of study participants are groups, except participants in the control group expected to return to work earlier than did participants in the intervention group. The mean difficulty scores of the short forms (personalised by participants) were comparable between the intervention and the control group, which means that the activities selected by participants were comparable in item difficulty. Complications during and after surgery were low in both groups (Table 10.1).

Median time until return to normal activities was 21 days (IQR 17-25) for participants in the intervention group and 26 days (20-32) for participants in the control group (adjusted HR 1.38, 95\% Cl 1.09-1.73; P=0.007; Table 10.2, Figure 10.3). Comparable results were noted in sensitivity analyses when adjustments were made for factors that might affect the length of the recovery period (adjusted HR 1.36, 95\% Cl 1.08-1.72; $P=0.008$; Table 10.2), and when return to normal activities was measured from the moment of randomisation instead of from the moment of surgery (median 32 days [IQR 22-52] in the intervention group and 40 days [24-69] in the control group; $H R$ 1.38, 95\% Cl 1.10-1.73; P=0.006). Perprotocol analyses had no substantial effect on the results (Table 10.2). 


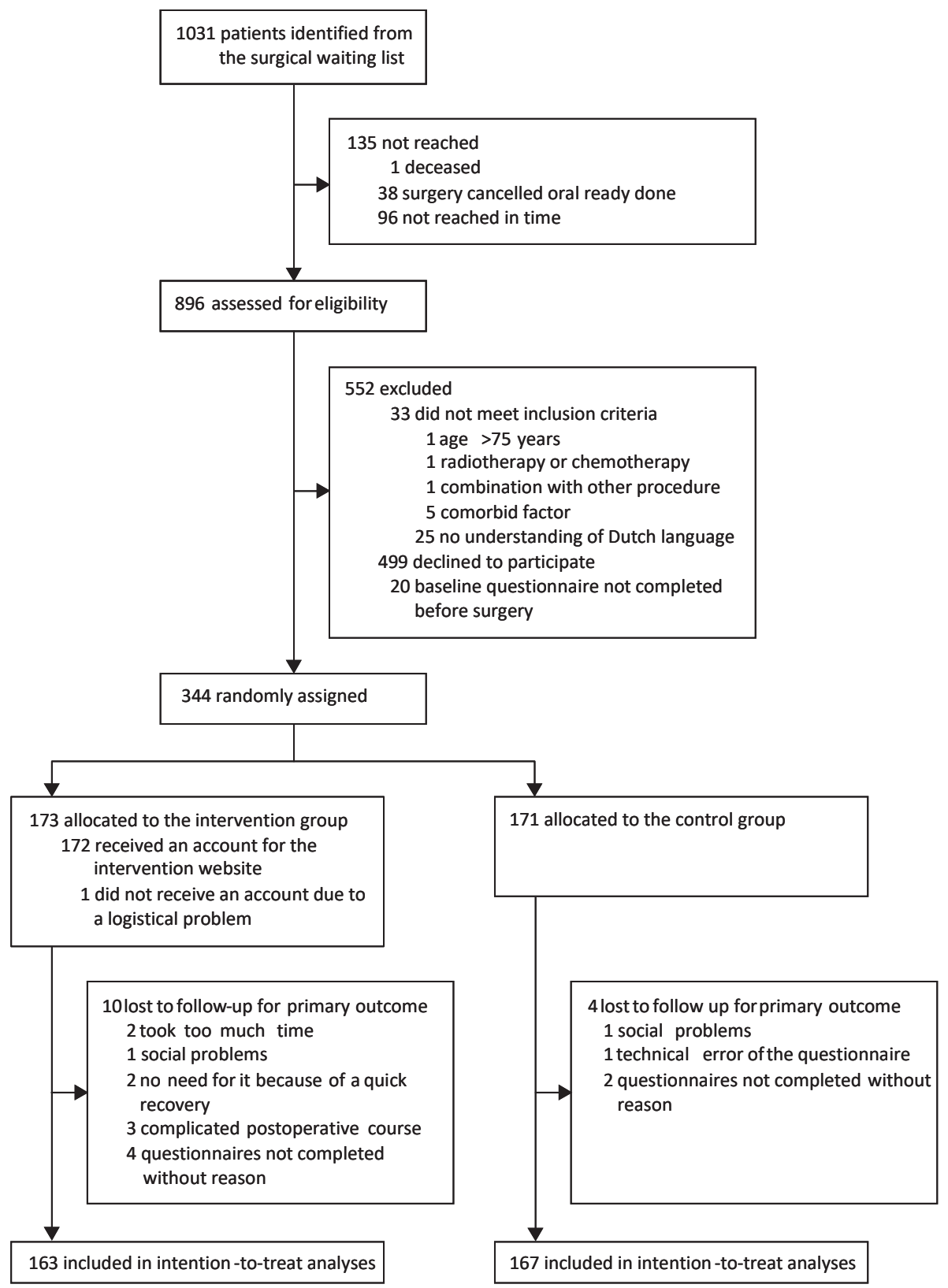

Figure 10.2 Trial profile. 
Table 10.1 Baseline characteristics.

\begin{tabular}{|c|c|c|}
\hline & $\begin{array}{c}\text { Intervention group } \\
(n=173)\end{array}$ & $\begin{array}{c}\text { Control group } \\
(n=171)\end{array}$ \\
\hline Men & $78(45 \%)$ & $79(46 \%)$ \\
\hline Women & $95(55 \%)$ & $92(54 \%)$ \\
\hline Age (years) & $52(42-61)$ & $51(41-58)$ \\
\hline \multicolumn{3}{|l|}{ Nationality } \\
\hline Dutch & $171(99 \%)$ & $168(98 \%)$ \\
\hline Other & $2(1 \%)$ & $3(2 \%)$ \\
\hline \multicolumn{3}{|l|}{ Level of education } \\
\hline Low & $31(18 \%)$ & $31(18 \%)$ \\
\hline Medium & $50(29 \%)$ & $58(34 \%)$ \\
\hline High & $92(53 \%)$ & $82(48 \%)$ \\
\hline Employed & $132(76 \%)$ & $123(72 \%)$ \\
\hline Salaried employment & 106 & 95 \\
\hline Self-employed & 25 & 26 \\
\hline Volunteer work & 1 & 2 \\
\hline Not employed & $41(24 \%)$ & $48(28 \%)$ \\
\hline Domestic work & 8 & 7 \\
\hline Student & 3 & 1 \\
\hline Incapacitated for work & 5 & 4 \\
\hline Unemployed & 2 & 9 \\
\hline Retired & 23 & 27 \\
\hline \multicolumn{3}{|l|}{ Type of work* } \\
\hline Light or medium intensity level & $98(74 \%)$ & $90(73 \%)$ \\
\hline Heavy intensity level & $34(26 \%)$ & $33(27 \%)$ \\
\hline \multicolumn{3}{|l|}{ Type of surgery } \\
\hline Gynaecological & $54(31 \%)$ & $49(29 \%)$ \\
\hline Hernia inguinal surgery (laparoscopic) & 67 & 63 \\
\hline Hernia inguinal surgery (open) & 1 & 2 \\
\hline Cholecystectomy (laparoscopic) & 51 & 57 \\
\hline Return to work expectation (days) $\dagger$ & $14(7-14)$ & $10(5-14)$ \\
\hline Return to normal activities expectation (days) $\neq$ & $14(14-28)$ & $14(10-28)$ \\
\hline Baseline PROMIS-PF score§ & $52(8)$ & $51(8)$ \\
\hline Difficulty of the selected PROMIS-PF items & $-0.6(0.6)$ & $-0.6(0.8)$ \\
\hline Complications during surgery & $3(2 \%)$ & $4(3 \%)$ \\
\hline Complications after surgery & $3(2 \%)$ & $2(1 \%)$ \\
\hline
\end{tabular}

Data are number of patients (\%), median (IQR), or mean (SD). PROMIS-PF=Dutch-Flemish PatientReported Outcomes Measurement Information System Physical Function. * Only applicable to employed participants; light or medium intensity level defined as sedentary work, no heavy lifting required; heavy intensity level defined as lifting and carrying loads required. † Number of days participants expect that they will return to work after surgery. ₹ Number of days participants expect that they will return to normal activities after surgery. $\S$ T-score of physical function short form (a T-score of 50 represents the average score of the general US population). ๆ Mean first threshold of the Item Response Theory item characteristic curve of the eight selected items on baseline. 
Median time until first return to normal activities was 3 days (IQR 1-5) in the intervention group and 3 days (1-6) in the control group (HR 1.14, 95\% Cl 0.92-1.42; $\mathrm{P}=0.229$ ). Median time until $75 \%$ of normal activities were resumed differed significantly between study groups (median 13 days [IQR 6-22] in the intervention group vs. 16 days [7-25] in the control group; HR 1.25, 95\% Cl 1.01-1.56; $\mathrm{P}=0.046$ ). In the subsample of participants who were employed, time until first resumption of work did not differ between groups (median 14 days [IQR 7-21] in the intervention group vs. 13 days [7-23] in the control group; HR 1.00, 95\% Cl 0.77-1.29; P=0.983), but time until full resumption of work did differ significantly (median 18 days [IQR 10-27] in the intervention group vs. 19 days [1133 in the control group; HR $1.3195 \% \mathrm{Cl} 1.01-1.70 ; \mathrm{P}=0.045)$.

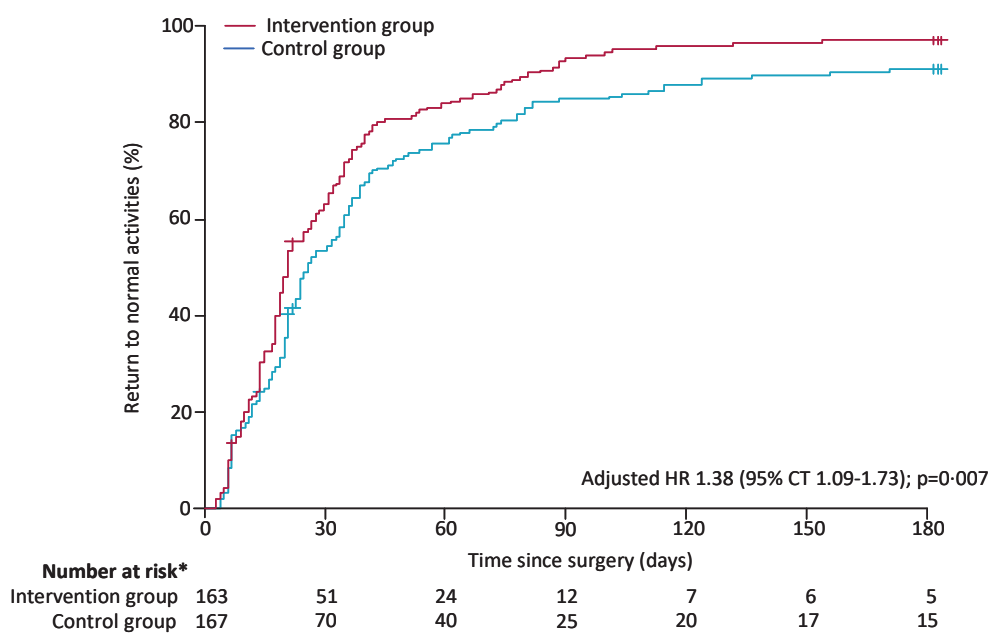

Figure 10.3 Time to return to normal activities after surgery. HR=hazard ratio. *Number at risk is the number of participants allocated to the group, minus the number who dropped out, minus the number who already reached the outcome event (return to normal activities).

Correcting these analyses for return to work expectations, which differed between groups at baseline, did not change the results by much (data not shown). Other secondary outcomes are presented in Table 10.3. None of the outcome measures showed a significant interaction with time, so the presented differences represent the mean differences averaged over the follow-up period. Social participation scores and physical function scores were significantly higher during follow-up in the intervention group compared with the control group. Other outcome measures did not differ between groups. 


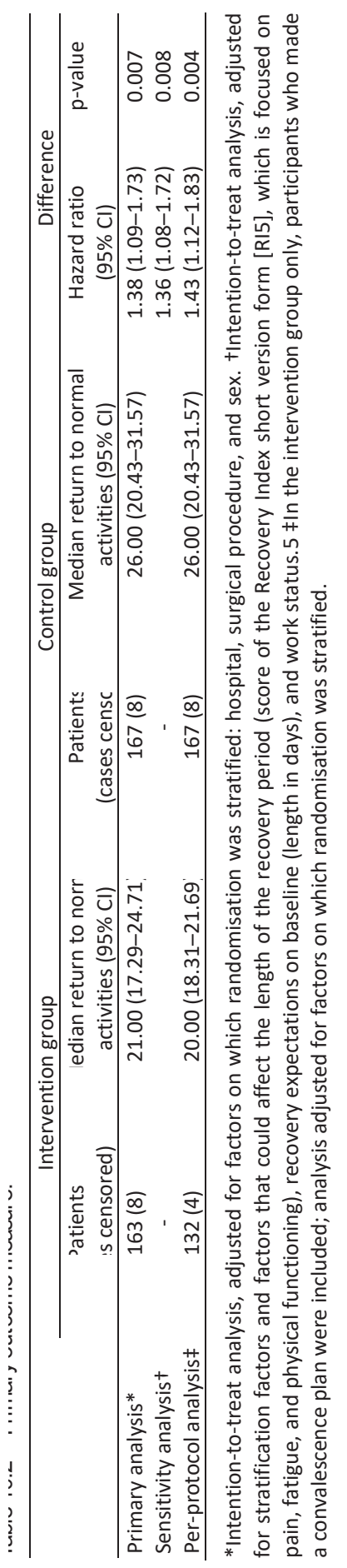


Table 10.3 Secondary outcome measures.

\begin{tabular}{llcc}
\hline & $\begin{array}{l}\text { Outcome measure } \\
\text { timepoint }\end{array}$ & $\beta^{*}(95 \% \mathrm{Cl})$ & p-value \\
\hline Physical function (PROMIS-PF) & $\mathrm{T} 1, \mathrm{~T} 2, \mathrm{~T} 3, \mathrm{~T} 4, \mathrm{~T} 5$ & $1.22(0.16$ to 2.27$)$ & 0.024 \\
Social participation (PROMIS-APS) & $\mathrm{T} 1, \mathrm{~T} 2, \mathrm{~T} 3, \mathrm{~T} 5$ & $1.44(0.15$ to 2.72$)$ & 0.038 \\
Self-rated health (EQ-5D-3L) & $\mathrm{T} 2, \mathrm{~T} 3, \mathrm{~T} 4, \mathrm{~T} 5$ & $1.62(-3.33$ to 6.57$)$ & 0.520 \\
Physical activities (IPAQ) & $\mathrm{T} 1, \mathrm{~T} 2, \mathrm{~T} 3$ & $5.87(-13.12$ to 24.87$)$ & 0.543 \\
Recovery (RI5) & $\mathrm{T} 1, \mathrm{~T} 2, \mathrm{~T} 3, \mathrm{~T} 4, \mathrm{~T} 5$ & $0.17(-0.41$ to 0.76$)$ & 0.559 \\
Pain intensity (VAS) & $\mathrm{T} 1, \mathrm{~T} 2, \mathrm{~T} 3$ & $-0.49(-1.59$ to 0.61$)$ & 0.379 \\
\hline
\end{tabular}

Mixed-model analyses using all outcome measure timepoints after surgery on which outcomes were assessed. Corrected for baseline scores measured the month before surgery, except pain variables because they were not measured at baseline. PROMIS=Dutch-Flemish Patient-Reported Outcomes Measurement Information System. PROMIS-PF=PROMIS Physical Function personalised short form. PROMIS-APS=PROMIS Ability to Participate in Social Roles and Activities short form. EQ-5D-3L=EuroQol five dimensions three levels. IPAQ=International Physical Activity Questionnaire. RI5=Recovery Index short version form. VAS=visual analogue scale. $\mathrm{T} 1=1$ week after surgery. $\mathrm{T} 2=3$ weeks after surgery. T3 $=6$ weeks after surgery. T4=3 months after surgery. T5=6 months after surgery. *Intervention relative to control group. Interactions between group and time were not significant and $\beta$ values for the main effect for the group after removing the interaction from the model are presented.

Participants in the intervention group gave a higher rating to the care programme they had access to than did participants in the control group (mean satisfaction score 7.2 [SD 1.7] vs. 6.3 [2.4]; $P=0.001$ ). Satisfaction with overall received care did not differ between study groups (mean score 7.5 [SD 1.7] for the intervention group vs. 7.1 [2.3] for the control group; $P=0.169)$. Total healthcare costs were $€ 202$ higher in the intervention group (€926 [SEM 124] for the intervention care programme vs. €721 [90] for the control programme), but this difference was not significant (95\% Cl -58 to 486; Table 10.4). The difference in QALYs between both groups was small (mean 0.46 [SEM 0.004] in the intervention group vs. 0.45 [0.004] in the control group; difference $0.01,95 \% \mathrm{CI}$ $0.0003-0.02)$. 
Table 10.4 Mean cost differences.

\begin{tabular}{lccc}
\hline & $\begin{array}{c}\text { Intervention group } \\
(\mathrm{n}=173)\end{array}$ & $\begin{array}{c}\text { Control group } \\
(\mathrm{n}=171)\end{array}$ & $\begin{array}{c}\text { Mean cost difference } \\
(95 \% \mathrm{Cl})^{*}\end{array}$ \\
\hline Hospital admission costs $(€)$ & $674(104)$ & $514(79)$ & $164(-67$ to 399) \\
Primary care costs $(€)$ & $32(7)$ & $67(14)$ & $-35(-70$ to -10$)$ \\
Secondary care costs $(€)$ & $106(18)$ & $119(15)$ & $-15(-54$ to 24$)$ \\
Medication costs $(€)$ & $12(5)$ & $11(6)$ & $-0.2(-23$ to 10$)$ \\
Home care costs $(€)$ & $57(30)$ & $10(4)$ & $44(10$ to 117$)$ \\
Intervention costs $(€)$ & 45 & 0 & 45 \\
Total health-care costs $(€)$ & $926(124)$ & $721(90)$ & $202(-58$ to 486) \\
\hline
\end{tabular}

Data are mean (SEM), unless otherwise stated. * Uncertainty estimated using bootstrapping, corrected for characteristics for which stratification took place (hospital, sex, and type of surgery). Including visits to the family doctor, occupational therapist, social worker, or physiotherapist. ₹ Excludes hospital admission costs. 


\section{DISCUSSION}

The findings of our study show that delivering personalised care via an e-health intervention programme is effective with respect to the time taken to return to normal activities after intermediate-grade abdominal surgery (as assessed with a personalised patient-reported outcome measure). Furthermore, the intervention care programme had a positive effect on social participation and physical function. No negative effects of the e-health intervention were noted, and complications before and after surgery were low.

As far as we know, our study is the first to assess the effect of an e-health intervention on the time to return to normal activities after intermediate-grade abdominal surgery. In a systematic review about the effects of e-health in perioperative care, 11 studies were identified in which educational e-health interventions were evaluated. ${ }^{27}$ However, only one study was done in patients undergoing abdominal surgery. ${ }^{25}$ This paucity of studies is remarkable considering the increasing popularity of minimally invasive techniques done in day-care settings in this area and the associated lack of postoperative guidance in the postoperative course, which creates an urgent need for e-health solutions. In that study, ${ }^{25}$ an educational perioperative e-health intervention was evaluated in patients undergoing gynaecological surgery. Participants in the intervention group returned to work (full resumption) 9 days earlier than participants in the control group. Our intervention was based on that study, ${ }^{25}$ thus, we expected comparable results. In our study, we noted a significant difference in time to full resumption of work, in favour of the intervention group; however, the difference between groups was only 1 day. The reason for this discrepancy between studies could be because the intervention in our study focused mainly on resumption of normal activities, and return to work was only assessed in employed participants (74\%). A second explanation could be that return to work was assessed in a less extensive way in our study (first day of work resumption and day of complete work resumption) by comparison with the earlier study, ${ }^{25}$ in which sickness absence calendars were assessed prospectively. Finally, the type of surgical procedures included in our study were, overall, less invasive in character compared with the earlier study, which might have caused the smaller difference between groups in return to work time because of the overall shorter duration of sickness absence after these types of surgical procedures.

A major strength of our study was the use of a personalised patient-reported outcome measure for assessment of the primary outcome. In several studies assessing the effects of an intervention on recovery after surgery, instruments or outcome measures were used that were not sensitive to measure effects or were not relevant in the context of the research question. ${ }^{22,28,29} \mathrm{~A}$ patient-reported outcome measure has the potential to 
quantify patients' subjective perceptions of the effect that treatment has on their daily lives, in a standardised manner. Furthermore, collection of patient-reported outcome data in clinical settings has been proven to help inform clinical decision making and can be helpful in reflecting the quality of health care. ${ }^{30}$ Above all, a patientreported outcome measure has the potential to personalise the outcome, making it possible to measure the effect on each individual patient, which is essential since normal activities are different for every participant. In our study, participants selected the activities that were most relevant for them in daily life; thus, the primary outcome of return to normal activities was specific to outcomes that mattered to participants. Moreover, the measurement process and the main part of the e-health intervention (the possibility to make a convalescence plan) were strongly related to each other, because activities that could be selected for the convalescence plan were (for the greater part) derived from the PROMIS-PF item bank. Therefore, the effect of the intervention could be measured very specifically. Further strengths of our study are the low proportion of dropouts $(4 \%)$ and the fact we could mask participants to the study hypothesis. This type of masking is unique in the area of e-health research and is the best possible option, because complete masking of participants is not possible since treatments compared are inherently different. ${ }^{31}$

All analyses regarding the primary outcome measure, including the per-protocol analysis, showed a significant effect in favour of the intervention group, which shows the consistency of our findings. One might argue that the criterion for including participants in the perprotocol analysis (i.e., creating a convalescence plan) might not be sufficient because we do not know if participants used the plan they created. However, this objectively measurable outcome acts as a proxy to create a clear cutoff. Selection bias is likely to play a part in the per-protocol analysis because a selected subgroup of participants from the intervention group was compared with all participants randomly allocated to the control group. Care should, therefore, be taken when interpreting the results of the per-protocol analysis, which in principle concerns a nonrandomised comparison.

Our study has other limitations. First, the proportion of participants included in the study after assessment for eligibility was low (38\%). Although we could compare participants and non-participants with respect to age, sex, and surgical procedure, selection bias cannot be ruled out completely. Further, we did not register the reason for non-participation in patients who were not willing to participate. Was the inclusion percentage low because of the study setting and the burden of completing questionnaires during a 6-month period after surgery, or because patients prefer not to use an e-health intervention at all? A survey study in a comparable population showed that $78 \%$ would prefer to use e-health in perioperative care; ${ }^{12}$ thus, the most 
obvious explanation would be the additional burden of the research setting. Second, we defined our outcome measures — return to normal activities and return to work-as time elapsing between surgery and reaching the event. Preferably, we would define these outcomes as time elapsing between randomisation and reaching the event. However, from a clinical perspective, this definition would be irrelevant because the event could not be reached before surgery. Doing the randomisation procedure at the time of surgery was also not possible for logistical reasons. To address this issue, we did an extra sensitivity analysis in which return to normal activities was measured from the date of randomisation. This analysis showed comparable results to the main analysis. Moreover, median lead times between randomisation and surgery were the same (8 days) in both groups. This finding, together with the comparable results between both analyses, reduce the likelihood of bias. Finally, we were not able to mask healthcare providers to the random allocation, but because these workers had no function in the data collection or analysis process, we are confident that the amount of bias is scant.

We postulated that patients who had surgery and used a personalised e-health intervention would return to normal activities sooner after the surgical procedure than patients who received usual care. Our hypothesis was based on the idea that informing patients about the surgical procedure and the recovery process before surgery and during the recovery process (management of expectations) would improve the recovery process. ${ }^{4,5}$ This hypothesis was confirmed by our study findings and, moreover, we showed that the e-health intervention improved postoperative recovery with little effort for health-care providers. However, the effect on return to normal activities was not reflected in the difference in QALYs between the study groups, which was small and not clinically relevant. Total health-care costs were higher in the intervention group than in the control group, but this difference was not significant. Primary health-care costs were lower and home care costs were higher in the intervention group compared with the control group. A possible explanation for this discrepancy between primary and home care costs is that the extra information and guidance that patients received by using the intervention reduced the demand for primary care. However, extra information about the expected recovery period might have resulted in a larger anticipated need for extra help after discharge, which might have induced the increase in home care costs.

Future research should focus on the needs and motivation of different stakeholders to invest in these types of interventions and the logistical facilitators and barriers for implementation. This knowledge, together with results of the cost-effectiveness analysis of this intervention (appendix), will provide important information with a view to the implementation process of this e-health intervention. Moreover, future studies of the e-health intervention should be done in patients undergoing major abdominal surgical 
procedures, because the findings of our study cannot be generalised to these procedures, although it is likely that this population would also benefit from this intervention, since shortening of hospital stay and the related reduced level of postoperative guidance also apply to this population. 2,5

The findings of our study showed a perioperative e-health-care programme was effective to shorten the time until normal activities were resumed after intermediate-grade abdominal surgery. This improvement in recovery time, in combination with a shortened hospital stay, an increase in surgical volume, and the growing popularity of technology in this area, suggests that a personalised, perioperative, e-health programme should be considered for implementation in standard perioperative care. 


\section{REFERENCES}

1 McIntyre RC Jr, Zoeter MA, Weil KC, Cohen MM. A comparison of outcome and cost of open vs laparoscopic cholecystectomy. J Laparoendosc Surg 1992;2:143-48.

2 Spanjersberg WR, Reurings J, Keus F, van Laarhoven CJ. Fast track surgery versus conventional recovery strategies for colorectal surgery. Cochrane Database Syst Rev 2011;2:CD007635.

3 Mitchell M. Home recovery following day surgery: a patient perspective. J Clin Nurs 2015;24:415-27.

4 Jones KR, Burney RE, Peterson M, Christy B. Return to work after inguinal hernia repair. Surgery 2001; 129:128-35.

5 Vonk Noordegraaf A, Anema JR, Louwerse MD, et al. Prediction of time to return to work after gynaecological surgery: a prospective cohort study in the Netherlands. BJOG 2014;121:487-97.

6 Brolmann HA, Vonk Noordegraaf A, Bruinvels DJ, de Vet RH, Dirksz AA, Huirne JA. Can prolonged sick leave after gynecologic surgery be predicted? An observational study in The Netherlands. Surg Endosc 2009;23:2237-41.

7 Tran TT, Kaneva P, Mayo NE, Fried GM, Feldman LS. Short-stay surgery: what really happens after discharge? Surgery 2014;156:20-27.

8 Rose J, Weiser TG, Hider P, Wilson L, Gruen RL, Bickler SW. Estimated need for surgery worldwide based on prevalence of diseases: a modelling strategy for the WHO Global Health Estimate. Lancet Glob Health 2015;3 (suppl 2):S13-20.

9 van der Meij E, Huirne JA, Bouwsma EV, et al. Substitution of usual perioperative care by ehealth to enhance postoperative recovery in patients undergoing general surgical or gynecological procedures: study protocol of a randomized controlled trial. JMIR Res Protoc 2016;5:e245.

10 van Vliet DC, van der Meij E, Bouwsma EV, et al. A modified Delphi method toward multidisciplinary consensus on functional convalescence recommendations after abdominal surgery. Surg Endosc 2016;30:5583-95.

11 Vonk NA, Huirne JA, Brolmann HA, van Mechelen W, Anema JR. Multidisciplinary convalescence recommendations after gynaecological surgery: a modified Delphi method among experts. BJOG 2011;118:1557-67.

12 van der Meij E, Bouwsma EVA, van den Heuvel B, Bonjer HJ, Anema JR, Huirne JAF. Using e-health in perioperative care: a survey study investigating shortcomings in current perioperative care and possible future solutions. BMC Surg 2017;17:61.

13 Crins MHP, Terwee CB, Klausch T, et al. The Dutch-Flemish PROMIS Physical Function item bank exhibited strong psychometric properties in patients with chronic pain. J Clin Epidemiol 2017;87: 47-58.

14 Rose M, Bjorner JB, Gandek B, Bruce B, Fries JF, Ware JE Jr. The PROMIS Physical Function item bank was calibrated to a standardized metric and shown to improve measurement efficiency. J Clin Epidemiol 2014;67:516-26.

15 Terwee CB, Roorda LD, de Vet HC, et al. Dutch-Flemish translation of 17 item banks from the patientreported outcomes measurement information system (PROMIS). Qual Life Res 2014;23:1733-41.

16 Cella D, Riley W, Stone A, et al. The Patient-Reported Outcomes Measurement Information System (PROMIS) developed and tested its first wave of adult self-reported health outcome item banks: 2005-2008. J Clin Epidemiol 2010;63:1179-94.

17 van der Meij E, Anema JR, Huirne JA, Terwee CB. Using PROMIS for measuring recovery after abdominal surgery: a pilot study. BMC Health Serv Res 2018;18:128. 
18 Cella D, Gershon R, Lai JS, Choi S. The future of outcomes measurement: item banking, tailored short-forms, and computerized adaptive assessment. Qual Life Res 2007;16:133-41.

19 Bode RK, Hahn EA, DeVellis R, Cella D. Measuring participation: the Patient-Reported Outcomes Measurement Information System experience. Arch Phys Med Rehabil 2010;91:S60-65.

20 Dolan P. Modeling valuations for EuroQol health states. Med Care 1997;35:1095-108.

21 Craig CL, Marshall AL, Sjostrom M, et al. International physical activity questionnaire: 12-country reliability and validity. Med Sci Sports Exerc 2003;35:1381-95.

22 Kluivers KB, Hendriks JC, Mol BW, et al. Clinimetric properties of 3 instruments measuring postoperative recovery in a gynecologic surgical population. Surgery 2008;144:12-21.

23 Von Korff M, Ormel J, Keefe FJ, Dworkin SF. Grading the severity of chronic pain. Pain 1992;50: 133-49.

24 van der Meij E, Huirne JA, Ten Cate AD, et al. A perioperative ehealth program to enhance postoperative recovery after abdominal surgery: process evaluation of a randomized controlled trial. J Med Internet Res 2018;20:e1.

25 Vonk Noordegraaf A, Anema JR, van Mechelen W, et al. A personalised ehealth programme reduces the duration until return to work after gynaecological surgery: results of a multicentre randomised trial. BJOG 2014;121:1127-35.

26 Willan AR, Briggs AH, Hoch JS. Regression methods for covariate adjustment and subgroup analysis for non-censored cost-effectiveness data. Health Econ 2004;13:461-75.

27 van der Meij E, Anema JR, Otten RH, Huirne JA, Schaafsma FG. The effect of perioperative e-health interventions on the postoperative course: a systematic review of randomised and non-randomised controlled trials. PLoS One 2016;11:e0158612.

28 Aspinen S, Karkkainen J, Harju J, Juvonen P, Kokki H, Eskelinen M. Improvement in the quality of life following cholecystectomy: a randomized multicenter study of health status (RAND-36) in patients with laparoscopic cholecystectomy versus minilaparotomy cholecystectomy. Qual Life Res 2017;26: 665-71.

29 King PM, Blazeby JM, Ewings P, Kennedy RH. Detailed evaluation of functional recovery following laparoscopic or open surgery for colorectal cancer within an enhanced recovery programme. Int J Colorectal Dis 2008;23:795-800.

30 Chen J, Ou L, Hollis SJ. A systematic review of the impact of routine collection of patient reported outcome measures on patients, providers and health organisations in an oncologic setting. BMC Health Serv Res 2013;13:211.

31 Shcherbatykh I, Holbrook A, Thabane L, Dolovich L. Methodologic issues in health informatics trials: the complexities of complex interventions. J Am Med Inform Assoc 2008;15:575-80. 



\section{x}

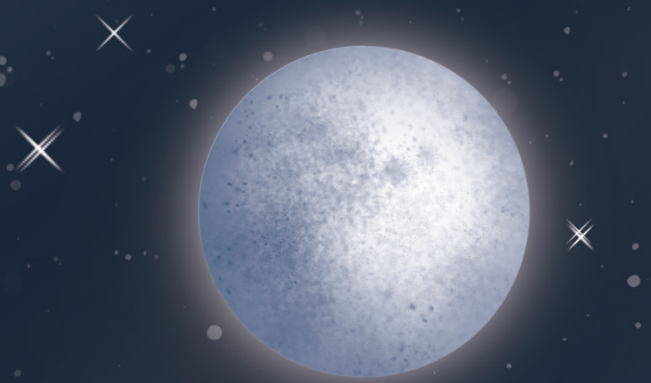

$x$

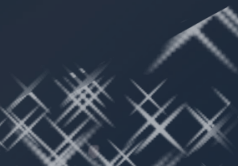

$$
\text { CHAPTER } 11
$$

s Summarizing discussion and $x \ldots$
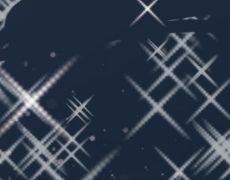
conclusions

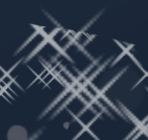

(x)

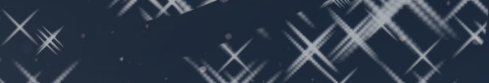

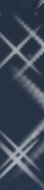

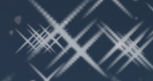





\section{SUMMARIZING DISCUSSION}

This thesis focuses on several aspects of preoperative surgical informed consent (SIC) and postoperative e-health counselling. As discussed in the introduction of this thesis, an optimally informed patient will likely have more realistic expectations regarding a surgical procedure and its associated risks, as well as demonstrate a faster recovery. Wellinformed patients are more satisfied, even in the event of complications or difficulties during their recovery period. Patients who are extensively counselled are known to file fewer complaints or legal claims.

The concept of SIC is over a century old. In chapter $\mathbf{2}$ we reported on the historical background of SIC, the current status and future perspectives to improve this process. A surgeon must have knowledge regarding the various elements of SIC (patient competence, information, consent). In addition, a surgeon should convince a patient that not the physician but the patient should be in control. A surgeon has the obligation to professionalize and structure SIC, and he should focus on all operations, not just the most invasive ones. Lastly, he should not be afraid to use tools such as interactive software for facilitating these aims.

Which specific strategies may be utilized to optimize these three different SIC elements? Regarding patient competence, clinical judgement of the care provider is just not reliable enough. Therefore, objective measures that are deemed valid in determining a patient's competence such as the Mini-Mental State Examination, MacArthur Competence Assessment Tool, Decision Evaluation Scales (DES), or MacCaT-T are indicated. When it comes to the second element of SIC, information, it is essential for a doctor to adapt information that is derived from (inter)national guidelines to the local setting and to the personal risk profile of a patient. Patients should fully understand the plan of operation, e.g. should be able to repeat essential information when interviewed and must explain, on demand, all relevant risks and alternative treatment options. The third element of SIC, consent, requires a succinct but complete registration. The SIC process should be recorded in detail using an adequate SIC form. This form has to be completed correctly and retrievably stored in a specific part of the EPD or medical record. It must be appreciated that all of these three items of the SIC process are dynamic. Therefore, regular updates must be critically evaluated and possibly incorporated in future versions of SIC.

In chapter $\mathbf{3}$ and $\mathbf{4}$, questionnaire studies supported by the Dutch Society of Surgery and the Orthopaedic and Plastic Surgical Societies evaluated the knowledge base, skillset and daily practice of general, orthopaedic and plastic surgeons regarding SIC. Chapter 3 focused on Dutch general surgeons and trainees. It appeared that the quality of the current 
SIC process was far from optimal. Surgical residents require (more) training to improve awareness and skills in SIC. The use of modern tools including web-based interactive programs is advised in order to enhance the quality of the SIC process.

A second questionnaire study that was presented in chapter $\mathbf{4}$ evaluated similar issues but now in Dutch orthopaedic and plastic surgery practices. Although improved adherence to SIC in these more elective subspecialisms was hypothesized (as compared to general surgeons), orthopaedic and plastic surgeons also demonstrated poor knowledge, skills and suboptimal practice regarding SIC. It was concluded that more elective and patient orientated surgical subspecialisms do not necessarily perform better regarding the elements of SIC. There is also an urgent need to optimize SIC management in the orthopaedic and plastic surgery arena.

In chapter 5, the preoperative education and informed consent process regarding bariatric surgery in young adults were explored with an emphasis on patient perspective. Young adults (18-25 years) who underwent bariatric surgery more than half a year previously at our centre participated in a semi-structured interview. The results indicated that they were able to recall all consent domains. In contrast, just a portion remembered all of the potential surgical complications. They judged that the current preoperative education mainly focused on positive results, whereas untoward effects were discussed inadequately. The study results clearly indicate that preoperative education including possible scenarios that address surgical risks and lifetime consequences should be improved to help young bariatric patients in making a more well-informed decision.

The study in chapter 6 aimed to obtain insight into the current practice of SIC in the Netherlands by audio recording outpatient consultations for Dupuytren disease. Written documentation of the SIC process in the patient's chart was compared to the recorded informing process that was scored using a checklist. Despite the finding that a relatively large part of the consultation time was spent on SIC, patients received scarce information concerning treatment risks, the postoperative period or the identity of their operating surgeon. Substantial discrepancies in information were observed between the written documentation of SIC and the audio recordings. The use of pre-made lists of 'discussed information' in the EPD had a negative impact on the real world discussion emphasizing the need for adequate testing tools before standard incorporation in clinical practice.

The lack of generally accepted and clinically relevant outcome parameters in SIC research is a major drawback that influenced all projects in this thesis. Aim of the study in chapter 7 therefore was to test characteristics of a shared decision making (SDM) questionnaire for the purpose of SIC research. The results indicated that a clear imbalance 
in expectations between surgical patients, their consultants and consent recordings was present. However, discriminative characteristics of the tested SDM questionnaires were suboptimal indicating that the use of these SDM questionnaires is not advised in future studies in the SIC domain.

Once a patient is (or feels) injured, ill-treated, disappointed or dissatisfied, medical disciplinary complaints and legal claims may be filed. Aim of the study that is reported in chapter $\mathbf{8}$ was to analyse characteristics of a decade of malpractice claims and medical disciplinary board (MDB) decisions regarding SIC in the Netherlands. It was concluded that a substantial portion of malpractice claims and MDB decisions were related to missing items in an overall deficient SIC process. Conversely, focusing on crucial SIC elements may improve patient satisfaction and expectations and may subsequently result in a lower risk of malpractice claims and MDB complaints.

In Chapter 9, an analysis of all SIC forms that are currently used in the Netherlands revealed substantial deficits in most. A practical best-practice guide for documenting SIC is proposed that may help doctors to optimally guide their patients and themselves through the SIC process and may help to provide an EPD with adequate SIC records. These SIC records can be made available to patients as a preoperative SIC leaflet.

The efficacy of modern tools using e-health options as a surrogate caregiver aiding patients during their recovery phase were analysed in chapter 10. Results of this study demonstrated that personalised e-health intervention after abdominal surgery accelerated the return to normal activities compared with usual care. Implementation of this e-health programme was recommended in patients undergoing intermediate-grade abdominal, gynaecological, or general surgical procedures. 


\section{CONCLUSIONS}

1. Adequate implementation of the elements of the SIC process will contribute to optimal patient care. Training both patient and surgeon supported by e-health tools may improve the SIC process in daily practice.

2. Overall knowledge of Dutch general, orthopaedic and plastic surgeons regarding SIC is far from optimal. Education, dedication and the use of innovative tools are needed to improve SIC in daily practice in the Netherlands.

3. The SIC process in young adults undergoing bariatric surgery requires improvement. Educational material on possible scenarios after bariatric surgery including risks and lifetime consequences should be developed.

4. Shared decision making (SDM) and SIC share certain aspects but SDM-Q-9 and SDMQ-Doc questionnaires are inadequate for SIC related research.

5. A substantial portion of malpractice claims and MDB decisions are related to missing items of an overall deficient SIC process. Optimizing SIC may improve patient satisfaction and expectations and may subsequently result in a lower risk on malpractice claims and MDB complaints.

6. Currently used SIC forms in general surgery have insufficient quality. A format for a best-practice SIC form for both surgeon and patient is proposed.

7. Personalised e-health interventions after abdominal surgery accelerate 'return to normal activities' compared to usual care. Implementation of an e-health programme is recommended for certain surgical procedures. 



\section{X}

○.

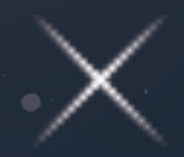

$x$

○。

$x$

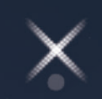

x

x

$\times$

(1)

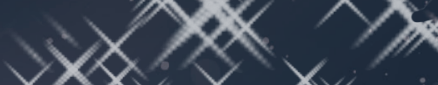
$x \times x$ . (x)

- $80 \times 1 \times \times \times \times \times$

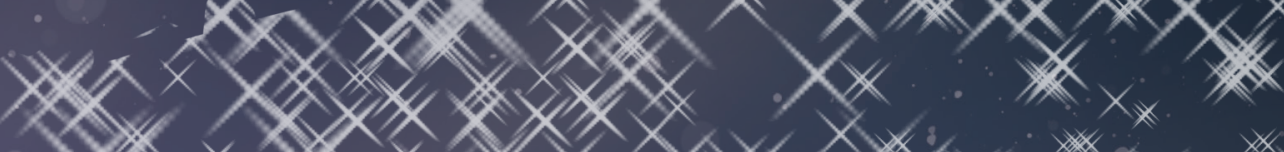
- Ox $\times 1 \times \times \times$

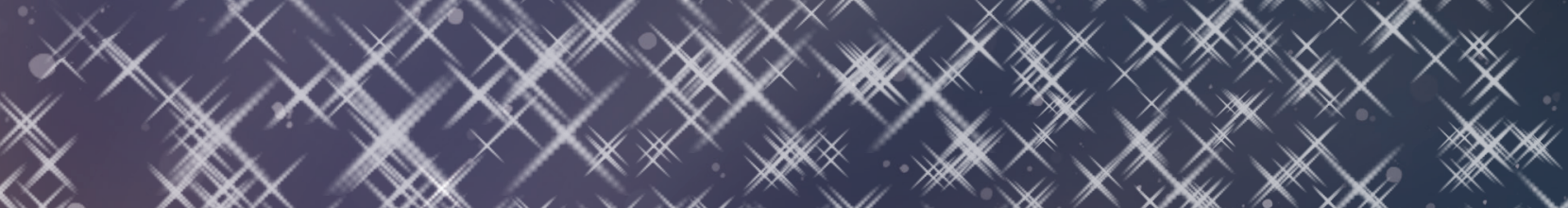

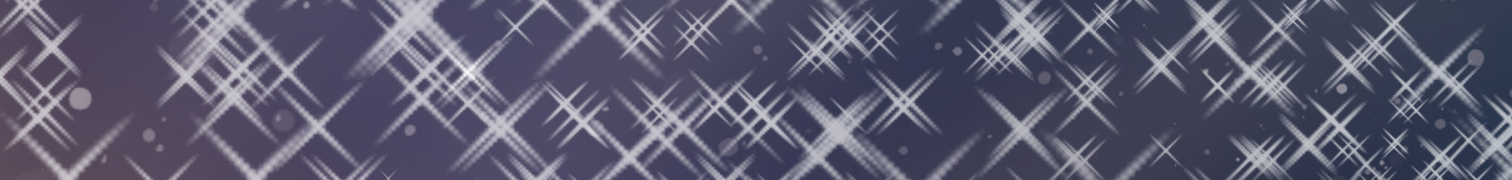
$\times \times \times \times \times x \times x \times 1 \times$ $x \times x \times x$
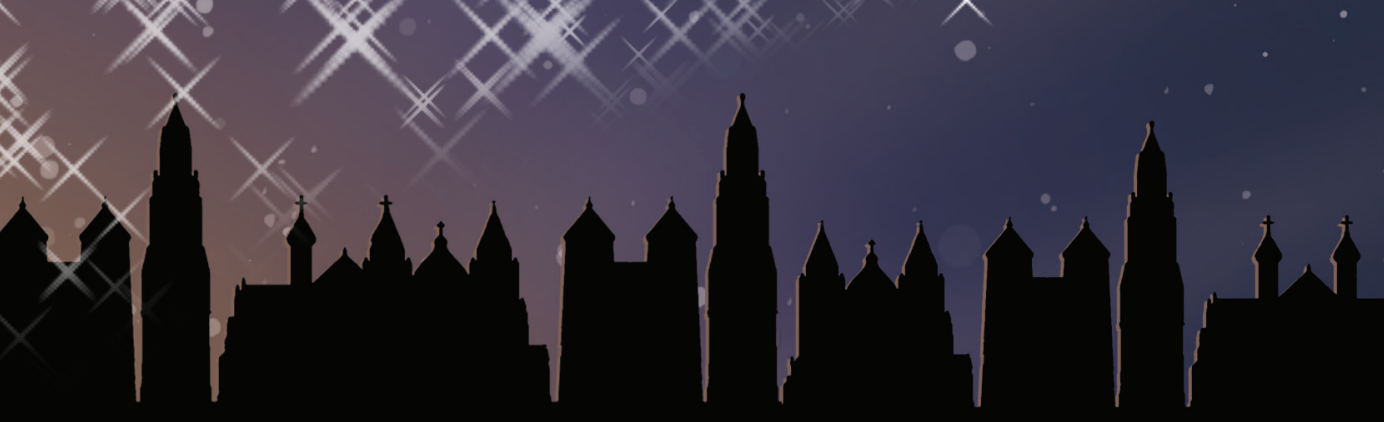


\section{x}

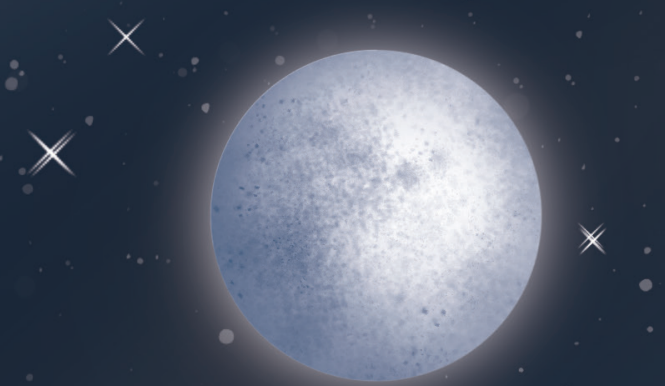

$x$

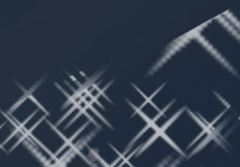

$x_{\ldots}$

$x^{-s}$

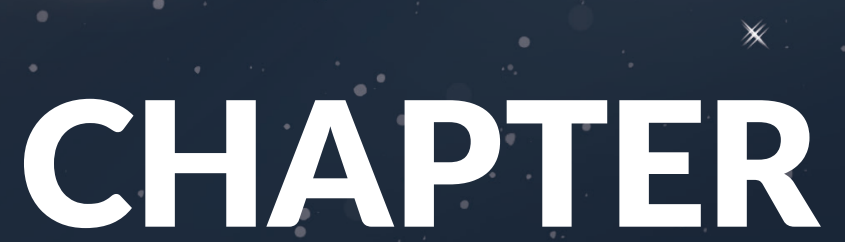

$x$

X

Future perspectives

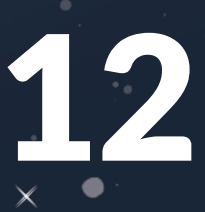

这

$x$

.

对 $\times$.

$\frac{x \times x \times x \times x}{x \times x} \times x$

$x$

$x+x$

$x^{\circ}$

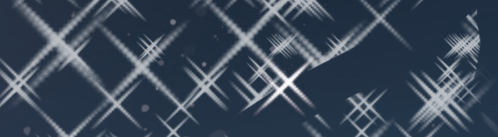

$3 \times x$

$x \times x$

ix

X
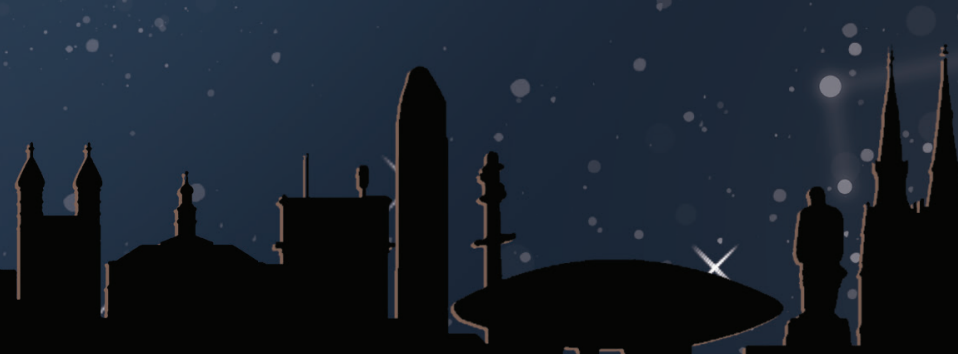

x 



\section{FUTURE PERSPECTIVES}

This thesis attempted to supply information to improve a variety of aspects of perioperative patient counselling. Some hurdles for implementing theoretical and scientific knowledge on surgical informed consent (SIC) and postoperative counselling by e-health may seem easy to overcome. Other aspects however are harder to tackle and need more research in the future.

\section{Patient perspectives}

The evolution to empower a patient's perspective in SIC is ongoing. In recent years, Shared Decision Making (SDM), Value Based Health Care (VHBC) and Patient Related Outcome Measures (PROM) have become important aspects of patient care. Future research should focus on implementing SDM, VHBC and PROM into the domain of SIC and post-operative recovery. This future research should focus on enhancing the awareness of patients for the topic "SIC" and the use of e-health incorporated with the knowledge from SDM, VBHC and quality guaranteed by PROM's.

In recent years, "Prehabilitation" and "Enhanced Recovery After Surgery (ERAS)" focus on the physical and mental preparation of patients before surgery and recovery after surgery. Research should also focus on preparation of the preceding phase: the SIC-process / the decision-making process. Future research should focus on how to prepare patients on the SIC process in order to help patients to discuss their situation with a care provider and to help them to make an informed decision. In the same way future research should focus on making e-tools more patient friendly. Developing optimal e-tools is a quest itself and more research is needed in the future with a focus on user-friendly personalised tools.

\section{Surgeon perspectives}

Optimizing the whole SIC process is only possible by increasing knowledge in SIC, SDM and post-operative recovery training for surgeons, physician-assistants and trainees. Future research should focus on methods to train surgeons and trainees in the field of SIC, and on the use of E-tools. At present however, such a course for surgical residents is lacking. Ideally, this should be developed, tested and preferably periodically evaluated to incorporate new insights in this fast developing field of patient education and counselling. Numerous questions arise. Which topics need training? What sort of initial training is required? Is repetitive training necessary? Do we need E-tool courses for surgeons?

\section{Daily practice perspectives}

Our daily practice is filled with guidelines, Standard Operating Procedures (SOPs) and using Electronic Patient Files (EPD, electronic patient dossier). Future guidelines and SOP's should have a specific focus on SIC, SDM and post-operative recovery counselling of patients. At 
present however, no specific chapter on SIC is included in most guidelines or SOPs. An EPD is an ideal environment for implementing SOP's in SIC, for instance by the use of a checklist concept. Nevertheless, a "Checklist-mentality" should be avoided as this may hamper instead of improve SIC as discussed in this thesis. Future research should focus on developing adequate, user-friendly software while avoiding checklist-feelings. We have made SIC notes available for patients but future research will determine whether this is appreciated by patients.

\section{E-health}

Improvements in e-health regarding all aspects of SIC are feasible. Patients have ample methods for improving their own situation. For instance, they can prepare for upcoming hospital visits, ask questions, test knowledge and receive upfront advice regarding recovery, or may want to compare their recovery with fellow patients. The potential downside of e-health is the availability of an immense amount of general as well as detailed information. In addition, most information is standardized whereas patients are different with respect to education, age or social-economic background. New software programs should provide concise and personalized and interactive information themes. This modern software is also useful as a monitoring board for professionals and can provide real-time status updates of their patients. Software of e-health programs needs to be as variable as the ever changing patient care. 



\section{x}

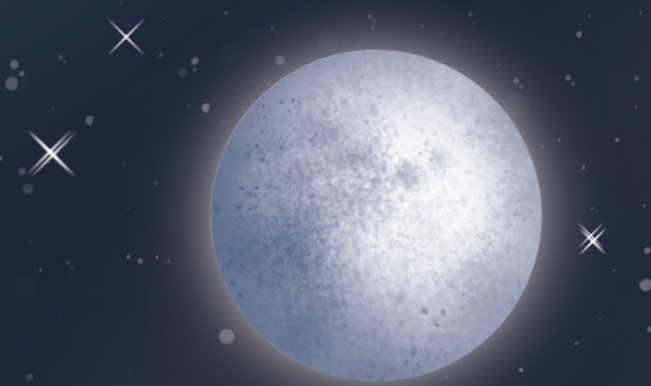

$x$

$\times$

(1). s

$X \ldots$

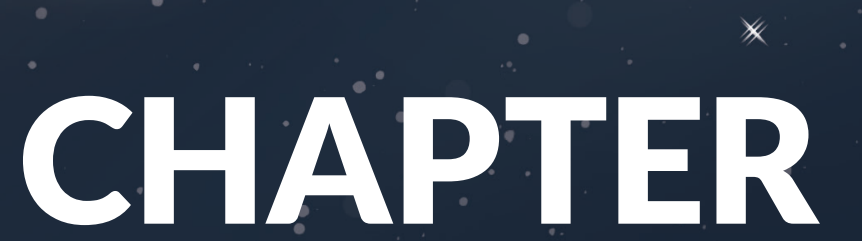

$\times$

X

\section{Samenvatting}

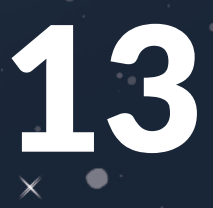

X

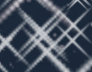

文

$\frac{x}{x}$

$x \times x$

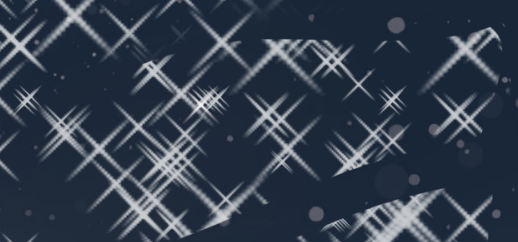

$x$

$x_{x}$

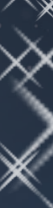

$\times$

$\times x \times x$

ix

x
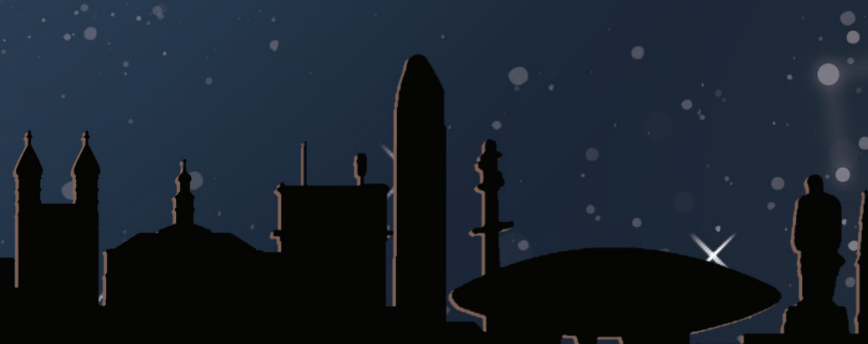

$x \cdot$ 



\section{SAMENVATTING}

Dit proefschrift richt zich op verschillende aspecten van het preoperatieve informed consent (Surgical Informed Consent, SIC) en postoperatieve begeleiding via e-health. Zoals besproken in de introductie van dit proefschrift zal een optimaal geïnformeerde patiënt waarschijnlijk realistischere verwachtingen hebben van zijn of haar operatie, de daarbij behorende risico's en zal het herstel sneller zijn. Goed geïnformeerde patiënten zijn tevredener, zelfs als er complicaties of problemen zich voordoen tijdens het herstel na een operatie. Patiënten die intensief begeleid zijn, zullen ook minder snel een civiele of tuchtrechtelijke klacht indienen.

Het concept van SIC is al meer dan een eeuw oud. In hoofdstuk $\mathbf{2}$ wordt de historische achtergrond, de huidige situatie en ontwikkelingen in het SIC proces beschreven. Een chirurg moet kennis en ervaring hebben met de verschillende onderdelen van het SIC proces: competentie, informatie en toestemming. Het is belangrijk dat de chirurg aan de patiënt duidelijk maakt dat niet de arts, maar de patiënt uiteindelijk de beslissende stem heeft. Een chirurg heeft de plicht om het SIC proces professioneel en gestructureerd aan te bieden bij iedere operatie ongeacht complex of eenvoudig. Tenslotte zou er geen terughoudendheid moeten zijn om hulpmiddelen zoals interactieve software in te zetten om bovenstaande doelen te bereiken.

Welke specifieke strategieën zouden kunnen worden toegepast om de drie onderdelen van het SIC proces te verbeteren? Ten aanzien van de inschatting of een patiënt competent is om over zichzelf een oordeel te vormen is de klinische blik niet voldoende. Er zijn een aantal hulpmiddelen hiervoor ontwikkeld zoals de Mini-Mental State Examination (MMSE), de MacArthur Competence Assessment Tool, de Decision Evaluation Scales (DES), of de MacCaT-Test. Ten aanzien van het onderdeel informatie is het cruciaal dat de informatie die wordt gegeven aangepast wordt van de (inter)nationale richtlijnen en literatuur naar de lokale setting en persoonlijke omstandigheden van de patiënt. Patiënten zouden het volledige proces rondom en tijdens de operatie moeten begrijpen, waardoor ze essentiële elementen zelf kunnen uitleggen aan een ander. Hieronder vallen nadrukkelijk operatieve risico's maar ook andere behandelopties dan degene die zij hebben gekozen optie. Het derde onderdeel van het SIC proces, de toestemming, vraagt om een nauwkeurige verslaglegging. Het SIC proces dient goed gedocumenteerd te worden waarbij een standaard formulier erg nuttig kan zijn. Dit formulier moet volledig worden ingevuld en moet zodanig bewaard worden dat het onderdeel is van het patiëntendossier. Belangrijk is te realiseren dat alle drie de hoofd onderdelen van het SIC proces dynamisch zijn en regelmatig geëvalueerd en aangepast moeten worden. 
In hoofdstuk 3 en 4, evalueerden we, met hulp van de Nederlandse Vereniging voor Heelkunde, voor Orthopedie en voor Plastische chirurgie, de kennis en kunde van algemeen, orthopedisch en plastisch chirurgen over SIC in de dagelijkse praktijk door middel van enquêtestudies.

Hoofdstuk 3 richtte zich op Nederlandse algemeen chirurgen en chirurgen in opleiding. De kwaliteit van het huidige SIC proces bleek verre van optimaal. Chirurgen in opleiding hebben (meer) training nodig om bewustzijn en vaardigheden t.a.v. het SIC proces te ontwikkelen. Het gebruik van moderne e-health hulpmiddelen wordt geadviseerd om dit SIC proces verder te ondersteunen.

Een tweede enquête studie in hoofdstuk 4 evalueerde deze zelfde thema's bij Nederlandse orthopedisch en plastisch chirurgen. De hypothese was dat in deze meer op electieve chirurgie gerichte specialismen SIC beter zou verlopen. Echter ook in deze groepen bleken kennis en vaardigheden rondom SIC en daardoor de dagelijkse praktijk suboptimaal te zijn. Conclusie van deze studie was dat ook meer patiënt en functioneel gerichte specialismen niet per se betere begeleiding geven aan hun patiënten rondom een operatie. De noodzaak om het SIC te proces te verbeteren lijkt dan ook breed van toepassing.

In hoofdstuk 5, werd vanuit patiënten perspectief het proces van preoperatieve voorlichting en informed consent in de bariatrische chirurgie bij jongvolwassenen bekeken. Jongvolwassenen (18-25 jaar) die meer dan half jaar geleden een bariatrische ingreep hadden ondergaan in ons ziekenhuis werden op semigestructureerde manier geïnterviewd. De resultaten lieten zien dat deze patiënten in staat waren om alle domeinen van het SIC te reproduceren. Echter, slechts een gedeelte herinnerde zich welke belangrijke complicaties zich konden voordoen. Patiënten oordeelden dat de huidige voorlichting teveel op de positieve resultaten van de behandeling was gericht en dat juist de negatieve aspecten onderbelicht bleven. Deze studie toont duidelijk dat patiënten een verdieping zoeken in de preoperatieve voorlichting inclusief scenario voorbeeld die operatieve risico's en lange termijn effecten benoemen om zodoende jongvolwassenen een echt weloverwogen beslissing te kunnen laten nemen.

De studie in hoofdstuk 6 richtte zich op het verkrijgen van diepgaand inzicht in de dagelijkse praktijk van het SIC proces door opnames te maken van patiënten die op het spreekuur kwamen vanwege klachten passend bij de ziekte van Dupytren. De schriftelijke verslaglegging werd vergeleken met de opgenomen gesprekken door middel van een score systeem. Ondanks de bevinding dat een relatief groot deel van het consult het SIC proces betrof, ontvingen de patiënten weinig informatie over risico's, de postoperatieve 
periode of wie hen zou opereren. Aanzienlijke verschillen werden bovendien aangetroffen tussen het dossier en de audio opnames. Het gebruik van kant en klare invulmemo's in het dossier had een negatief effect op het daadwerkelijk gevoerde gesprek, wat de noodzaak van het testen van dit soort hulpmiddelen in de praktijk voor algemene in gebruik name benadrukt.

Het gebrek aan algemeen geaccepteerde en klinisch relevante uitkomstparameters is een ernstige zwakte in het doen naar onderzoek naar het SIC proces, zo ook voor dit proefschrift.

Doel van de studie in hoofdstuk 7 was het testen van een Shared Decision Making vragenlijst voor het gebruik in SIC onderzoek. De resultaten toonden een duidelijke verschil in de verwachtingen van patiënten, hun chirurgen tegenover de SIC verslaglegging. Echter bleken de vragenlijsten te weinig onderscheidend vermogen te bezitten om een geadviseerd te worden in toekomstig onderzoek naar SIC.

Indien een patiënt zich rondom een operatie beschadigd of slecht behandeld voelt, teleurgesteld of ontevreden is dan kan een tuchtrechtelijke klacht of civiele zaak worden aangespannen. Doel van de studie in hoofdstuk 8 was om tien jaar civiele en tuchtrechtelijke zaken aangaande het SIC proces in Nederland te beschrijven. Een belangrijk deel van alle civiele en tuchtrechtelijke klachten bleek gebaseerd te zijn op missende onderdelen van een onvolledig uitgevoerd SIC proces. Om dit te voorkomen is het nodig extra aandacht te besteden aan het SIC proces waardoor de tevredenheid en verwachtingen van patiënten op een hoger niveau komen.

In hoofdstuk 9 werd een studie beschreven waarbij SIC formulieren uit de dagelijkse praktijk in Nederland aanzienlijke gebreken vertoonden. Een leidraad voor een standaard format SIC formulier werd in dit manuscript voorgesteld om chirurgen en hun patiënten op een ideale manier door het SIC proces te leiden en te zorgen voor een nauwkeurige notities in het dossier. Deze notities konden dan meteen aan de patiënt worden uitgereikt als een soort preoperatieve bijsluiter.

De effectiviteit van e-health, als surrogaat hulpverlener, om patiënten te ondersteunen tijdens hun postoperatieve herstel werd geanalyseerd in hoofdstuk 10. De resultaten van deze studie tonen aan dat gepersonaliseerde e-health interventies na abdominale chirurgie het herstel naar alledaagse activiteiten versnelden in vergelijking met reguliere nazorg. Implementatie in de dagelijkse praktijk werd geadviseerd voor patiënten die dit type gynaecologische of chirurgische buikoperaties ondergaan. 


\section{CONCLUSIES}

1. Adequate implementatie van de verschillende onderdelen van het preoperatieve informed consent (Surgical Informed Consent, SIC) proces leidt tot betere patiëntenzorg. Training van zowel patiënt als chirurg, ondersteund door e-health programma's zou het SIC proces verder kunnen verbeteren in de dagelijkse praktijk.

2. In het algemeen is de kennis van Nederlandse algemeen, orthopedisch en plastisch chirurgen over SIC verre van optimaal. Scholing, hogere prioritering en de inzet van innovatieve ondersteunende producten is nodig om de kwaliteit van het SIC proces in de dagelijkse praktijk in Nederland te verbeteren.

3. Het SIC proces bij jongvolwassenen, die zich oriënteren op bariatrische chirurgie, moet verbeterd worden. Educatie materiaal en scenario voorbeelden ter illustratie van perioperatieve risico's en lange termijn effecten zouden ontwikkeld moeten worden.

4. "Gezamenlijke besluitvorming" (Shared decision making, SDM) en het SIC proces bevatten gemeenschappelijke onderdelen maar de SDM-Q9 en SDM-Q-Doc vragenlijsten zijn niet geschikt om SIC georiënteerd onderzoek te verrichten.

5. Een belangrijk deel van alle civiele zaken en tuchtrechtelijke klachten zijn gerelateerd aan ontbrekende onderdelen van een onvolledig doorlopen SIC proces. Het verbeteren van het SIC proces zou de algemene tevredenheid en de verwachtingen van patiënten kunnen verbeteren en zo het aantal zaken en klachten kunnen verminderen.

6. De momenteel in gebruik zijnde SIC formulieren binnen de algemene chirurgie zijn van onvoldoende kwaliteit. Een leidraad ter ondersteuning van het SIC proces kan zowel arts als patiënt helpen.

7. Gepersonaliseerde e-health programma's na buikoperaties zorgen voor een snellere hervatting van alledaagse activiteiten in vergelijking met reguliere nazorg. Invoering van e-health wordt voor dit type operaties geadviseerd. 

$\mathbb{X}$

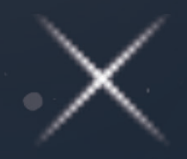

$x$
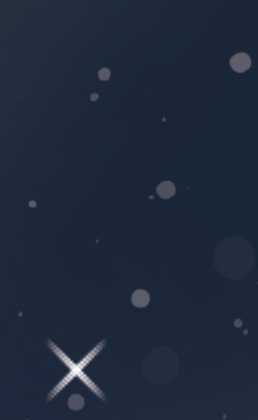

$x$

$\therefore$ $+x$ $x$ $x \times x$ $\therefore \times x \times x$ x $x \cdots>$

- $\times x \times$

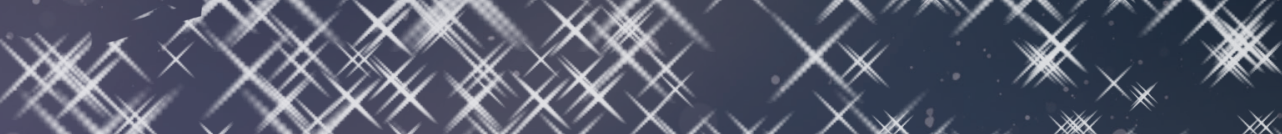
: N 201 . $\times 1 \times 1 \times$ . $\times x^{*} \times x^{\times}$

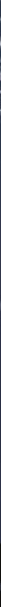





\section{IMPACT PARAGRAPH}

In this paragraph a reflection in layman's language is presented on the achieved or expected scientific and social impact of the results of the research described in this thesis. By answering four questions the impact of this thesis is explained.

Research

What is the main aim of the research described in the thesis and what are the main results and conclusions?

In chapter 1 the general aim of this thesis is stated as: to study methods of improving patient counselling before and after an operation. More specifically

1. To study history as well as the current and future status of the surgical informed consent (SIC) process.

2. To evaluate various characteristics of SIC of general, orthopaedic and plastic surgeons in daily practice

3. To report on perceptions and experiences of young adults undergoing bariatric surgery regarding the SIC process.

4. To assess the relation between SIC and Shared Decision Making (SDM) in general surgery.

5. To analyse characteristics of malpractice claims and Medical Disciplinary Board (MDB) decisions regarding SIC in the Netherlands.

6. To evaluate currently used SIC forms in general surgery in the Netherlands and to provide a best-practice SIC form for surgeon and patient.

7. To evaluate the effect of a personalised e-health-care programme on 'return to normal activities' after surgery.

In chapter 9 we concluded that:

1. An adequate implementation of the elements of the SIC process will contribute to an optimal patient care. Training both patient and surgeon supported by e-health tools may improve the SIC process in daily practice.

2. Overall knowledge of Dutch general, orthopaedic and plastic surgeons regarding SIC is far from optimal. Education, dedication and the use of innovative tools are needed to improve SIC in daily practice in the Netherlands.

3. The SIC process in young adults undergoing bariatric surgery requires improvement Educational material on possible scenarios after bariatric surgery including risks and lifetime consequences should be developed.

4. Shared decision making (SDM) and SIC share certain aspects but SDM-Q-9 and SDMQ-Doc questionnaires are inadequate for SIC related research. 
5. A substantial portion of malpractice claims and MDB decisions are related to missing items of an overall deficient SIC process. Optimizing SIC may improve patient satisfaction and expectations and may subsequently result in a lower risk on malpractice claims and MDB complaints.

6. Currently used SIC forms in general surgery have insufficient quality. A format for a best-practice SIC form for both surgeon and patient is proposed.

7. Personalised e-health interventions after abdominal surgery accelerate 'return to normal activities' compared to usual care. Implementation of an e-health programme is recommended for certain surgical procedures.

\section{Relevance}

What is the (potential) contribution of the results of this research to science, and if applicable to social sectors and societal challenges?

The scientific relevance of this thesis can be found in the publication of all (but one) chapter in a peer reviewed journal indexed on Pubmed®. The publications are cited over 300 times according to Google Scolar $®$ and contributed to the expanding knowledge of SIC and post-operative counselling of surgical patients.

Next to the scientific value, this thesis has a social and economic value. The quest to improve SIC for patients and surgeons is of social relevance. The general view of SIC is modulated by the timeframe, social circumstances and has developed intensively over the last century and the last decades (chapter 2). The role of the paternalistic surgeon has changed to a more patient orientated perspective. This thesis is an example of patient orientated research and provides new insights in several aspects, such as the difficulties of SIC in daily practice (chapter 3-6), the challenge to enhance SIC, diminish complaints and claims (chapter 7-9), or the implementation of E-health during recovery (chapter 10). The economic value can be found in faster recovery, higher satisfaction, enhanced compliance and fewer legal cases, which all lead to economic value for patients, hospitals and society.

\section{Target audience}

For whom are the research results interesting and / or relevant? And why? In this thesis some patient groups were included but the conclusions of this thesis are more widely applicable to all patients. The more patients are in the lead and optimally guided by professionals during the SIC and postoperative process, the better their outcome. Patients are willing to spend more time and energy on becoming experts of their own situation. Focussing on patient empowerment will result in higher patient satisfaction and compliance. 
In this thesis specific surgical specialties were included. But the conclusions for general, orthopaedic and orthopaedic surgeons are relevant for all surgeons. Apart from surgical subspecialties, introduction of this concept may also be worthwhile in other specialities including gastroenterology, (interventional) radiology or pulmonology and others.

\section{Activity}

How can these target groups be involved in and informed about the research results, so that the acquired knowledge can be used in the future?

From the patients' point of view reinforcing the patient empowerment by involving patients and patient perspectives in all domains of the surgical field is needed to optimize SIC and postoperative counselling. In the last decade the patient participation is on the rise and this thesis emphasizes the need and usefulness of this process.

From the surgeons' point of view adequate training regarding SIC issues is required. Formal incorporation in the Dutch basic training program for surgeons (including orthopaedic, plastics surgeons and urologists) is currently still lacking and needs implementation. 



\section{DANKWOORD}

Aan alle patiënten, waarbij ik in een deel van hun behandeling mocht acteren. Dank voor alle levenslessen en reflectiemomenten op het leven. Dit proefschrift is er door en voor jullie.

Dank aan mezelf. Dit project heb ik volbracht! Dank aan mijn kritische ik, mijn doorzettende $i k$, mijn volhardende ik, mijn nieuwsgierige ik, mijn innovatieve ik, mijn reflectieve ik, mijn steunende ik, mijn coachende ik, maar bovenal mijn blije kind dat nu luid zingend een dansje op tafel doet van puur plezier omdat uiteindelijk de zon schijnt over dit proces: uiteindelijk komt alles goed.

Mijn Promotoren:

Professor Stassen, beste Laurents. Dank voor je open blik op dit proefschrift en je inzet om deze vrijbuiter binnen de academische lijntjes te laten kleuren.

Professor Legemaate, beste Johan. Dank voor je initiële enthousiasme, je vele bondige adviezen en opmerkingen die me maanden achtervolgden, je lef om duidelijke adviezen te geven, je hartelijkheid als ik het weer eens niet zag zitten en je begrip toonde voor mijn uitdagingen buiten dit proefschrift.

Mijn co-promotor, dr. Scheltinga, beste Marc. Had je ooit verwacht dat het toch nog zou lukken? Wat heb jij ongelooflijk veel tijd en energie in dit proefschrift zitten. Van de eerste schets tot de laatste punt en komma, je was erbij. Ik was niet je makkelijkste promovendus, niet je beste, niet je liefste, misschien wel je langstlopende... maar het is goed zo, de laatste opmerking is gezet, het laatste rood van een verandering geplaatst, de laatste SLET gevormd. Super dank voor alles.

Beste leden van de beoordelingscommissie, prof. dr. I.H.J.T. de Hingh, prof. dr. C.H.C. Dejong, dr. J.H. Zwaveling, mr. dr. E. Pans. Hartelijk dank voor het beoordelen van dit proefschrift en deelname aan de promotiecommissie.

Mijn paranimfen, William van Dijk, chirurg Máxima MC, en Tamara Henken, klinisch psycholoog Máxima MC. William, zie deze promotie als een stimulans om vol overgave ook te promoveren of keihard er nooit aan te beginnen. Tamara, al jaren ben je een van mijn beste vriendinnen. Je kent mijn lief en leed en staat altijd met een kritiekloze knuffel klaar. Het is een eer dat jullie mijn paranimfen willen zijn. Mocht een van jullie beiden promotie aspiraties krijgen dan kunnen jullie op mij rekenen. 
Wim Zwiers, (voormalig) uroloog Máxima MC en advocaat. Wim, je bent niet meer in ons midden, maar je hebt een onuitwisbare indruk op mijn leven gemaakt door je eigenzinnige, scherpe en kritische maar vooral medico-legaal geschoolde blik op de geneeskunde. Je inspireerde me tot het thema van dit proefschrift. Dit proefschrift draag ik met trots aan je op.

Mijn mede-onderzoekers, Sarah Sloot, Margot Veerman, Eva van de Meij en Bram Keulers. Tsjonge jonge jonge wat een thema hadden we te pakken om onderzoek in te doen. Wat hebben we gezwoegd en gestreden (om een artikel gepubliceerd te krijgen). Inmiddels is iedereen haar of zijn paadje verder gaan lopen en zien of horen we elkaar zelden meer, maar zonder jullie inbreng was dit proefschrift er nooit gekomen. Dank daarvoor.

De medewerkers van de polikliniek chirurgie in het Máxima MC en met name Ellis Lavrijsen; Marion Schonewille van afdeling kwaliteit en veiligheid; de MMC academie. Dank voor jullie inzet in alle losse projecten. Van enquêtes sturen, tot patiënten includeren tot review artikelen controleren, niets was te lastig of te gek. Dank daarvoor.

Mijn maatjes, de vakgroep chirurgie Máxima MC inclusief fellows, inmiddels pensionadochirurgen en natuurlijk Miranda. Als wij werken voor de groep dan zijn we onoverwinnelijk, kunnen we de grootste stormen trotseren, de meeste bizarre (covid)tijden aan, de mooiste momenten delen, de waardigste manier vinden om afscheid te nemen als iemand ons toch verlaat. Dank voor alle steun, die jullie me hebben gegeven, dank voor mijn rol in onze groep.

Mijn mini-maatjes, (oud) arts-assistenten chirurgie Máxima MC en Radboud UMC. Teveel om bij naam te noemen, maar wat heb ik afgelopen 15 jaar veel geluk gehad met mijn collega arts-assistenten. Vroeger als echte collega, nu als plaatsvervangend opleider is en blijft het zo waardevol om in zo'n leergierig klimaat te mogen werken. Naast waardevol, natuurlijk ook de gezelligheid buiten het ziekenhuis, van borrel tot "academisch weekend". Hartelijk dank voor alles inclusief de laatste plons in het water van Aquabest.

The next generation onderzoekers in Máxima MC. Martine Uittenbogaart, Danielle Bonouvrie, Marleen Romeijn, Bart Corten, Willem Zwaans, Kelly van de Pas. Naast mijn promotie heb ik met jullie al veel onderzoek mogen verrichten. Van galblaas tot definities in onderzoek, van pijn tot zwangeren, van gewichtstoename tot bonuspunten. Dank voor alle leerzame en heerlijke "promotie ontwijkende onderzoeken". 
De rekenknobbels, Saskia Houterman en Loes Janssen. Saskia en later Loes, jullie hebben mijn zwakste kant in onderzoek gevonden, ondersteund en soms ook simpelweg overgenomen. Ik en statistiek zullen nooit vrienden worden, maar dankzij jullie vertaalslag begrijpen statistiek en ik elkaar met een bepaalde mate van begrip van mijn zijde. Dank daarvoor.

De ruïnisten van onafhankelijk heerendispuut Perikles, Maastricht. Eenheid door diversiteit. Studeren met jullie was een feest. Studentje spelen blijft een topper. Lustrum-reizen, wintersport of zomaar een borrel of bbq, zolang er politiebusjes rijden zijn ze niet veilig... Dank voor alle schitterende herinneringen en hilarische verhalen.

Tom en Tam, Ro en Marys, Oz en Tan. Al meer dan 20 jaar vriendschap. Als het weer mooi is, als het grijs is, maar vooral als het stormt dan waren jullie er voor mij. Niet alleen door dit proefschrift maar ook door mijn carrière(drang) was ik er niet altijd genoeg tijd voor jullie. Dank dat jullie in onze vriendschap zijn blijven geloven.

Mijn peut, Judith. Je leerde me kennen toen ik psychologisch gezien wakker werd. Je hebt me met een psychologisch mes gefileerd, uitgebeend tot het bot totdat alles helder en duidelijk in beeld was. Je hebt me vervolgens mezelf laten reconstrueren; van kleurenblind naar kleurenliefhebber zien veranderen; van puberaal tot psychisch volwassen zien groeien. Je hebt me mezelf laten herkennen, erkennen, omarmen en leren los laten. Dank daarvoor.

Mijn Guilty-pleasure friends (Basje, Franzle, Han, Jets, Joyce, Lieke, Lies, Maris, Miran, Nicoline, Ollie, Sab, Soes, Tim, Wendy, Yvonne, Woutje en ik ben vast wel iemand vergeten). Latte macchiato met hazelnut of zonder smaakje, of zonder koffie maar dan met thee, ijs of cola of een Redbull. De praatjes met jullie, het reflecteren op het leven, open en kwetsbaar als mens op mens. Over vreugde, verdriet, rouw of leed: het maakt niet uit. Soms vijf minuten, soms eindeloos. Jullie verrijk(t)en mijn leven. Dank daarvoor.

Ouders, stief- en schoonfamilie. Mam, pap, Adri, Gea, Tony en Jacqueline, Anne en Rob, Anouk en Richard en alle anderen. Dank voor jullie interesse en steun voor mijn onderzoek. Bedankt voor alle hulp, liefde en zorg voor Marjolein, de kids en mij, zodat ik tussen gezin, werk en onderzoek, dat laatste ook tijd kon geven en dit proefschrift er kon komen. 
Marjolein. Dank voor alle hulp, steun, snoep, chips en cola, de eindeloze moppersessies aanhorend, het gevloek als weer iets niet lukte, de ontreddering, maar soms de sprankjes vreugde of sensatie als iets wel liep zoals gehoopt. Onze relatie was pril toen dit project begon, nu het proefschrift eindigt, gaan ook wij een eigen route. Ik dank je voor alles, wat je voor me hebt gedaan en wens je alle goeds in de toekomst.

Eva en Stijn, mijn dotjes, mijn kadootjes. Wat ben ik vol liefde voor jullie. In alles wat ik doe, probeer ik er voor jullie te zijn, niet perfect, maar wel vol overgave, energie en aandacht. Ik hoop dat we nog heel vaak zullen dansen, zingen, feesten, wandelen, fietsen, lezen, puzzelen, tekenen, klauteren, gymen, skeeleren, hockeyen, voetballen, zwemmen, kano varen, muziek maken, hangmat-teren, knuffelen en elkaar laten voelen en zeggen dat we van elkaar houden. Ik heb jullie lief. 




\section{LIST OF PUBLICATIONS}

Pubmed

Vermeulen M, Kruimer JWH, Farid WRR, Dercksen MW, Buijsen J, Meijerink MR, Leclercq WKG.

Fatal Venous Thrombosis-Associated Liver Failure due to Microwave Ablation for Recurrent Liver Metastases After Prior Liver Surgery and Radiation.

Cardiovasc Intervent Radiol. 2021 Jul 6. doi: 10.1007/s00270-021-02910-5. Epub ahead of print. PMID: 34231003.

\section{COVIDSurg Collaborative Co-authors.}

Machine learning risk prediction of mortality for patients undergoing surgery with perioperative SARS-CoV-2: the COVIDSurg mortality score. Br J Surg. 2021 Jul 6:znab183. doi: 10.1093/bjs/znab183. Epub ahead of print. PMID: 34227657.

Görgec B, Fichtinger RS, Ratti F, Aghayan D, Van der Poel MJ, Al-Jarrah R, Armstrong T, Cipriani F, Fretland ÅA, Suhool A, Bemelmans M, Bosscha K, Braat AE, De Boer MT, Dejong CHC, Doornebosch PG, Draaisma WA, Gerhards MF, Gobardhan PD, Hagendoorn J, Kazemier G, Klaase J, Leclercq WKG, Liem MS, Lips DJ, Marsman HA, Mieog JSD, Molenaar QI, Nieuwenhuijs VB, Nota CL, Patijn GA, Rijken AM, Slooter GD, Stommel MWJ, Swijnenburg RJ, Tanis PJ, Te Riele WW, Terkivatan T, Van den Tol PMP, Van den Boezem PB, Van der Hoeven JA, Vermaas M, Edwin B, Aldrighetti LA, Van Dam RM, Abu Hilal M, Besselink MG; Dutch Liver Collaborative Group.

Comparing practice and outcome of laparoscopic liver resection between high-volume expert centres and nationwide low-to-medium volume centres.

Br J Surg. 2021 Jul 1:znab096. doi: 10.1093/bjs/znab096. PMID: 34195799

Elfrink AKE, Olthof PB, Swijnenburg RJ, den Dulk M, de Boer MT, Mieog JSD, Hagendoorn J, Kazemier G, van den Boezem PB, Rijken AM, Liem MSL, Leclercq WKG, Kuhlmann KFD, Marsman HA, ljzermans JNM, van Duijvendijk P, Erdmann Jl, Kok NFM, Grünhagen DJ, Klaase JM; Dutch Hepato Biliary Audit Group, Collaborators, Te Riele WW, Buis Cl, Patijn GA, Braat AE, Dejong CHC, Hoogwater FJH, Molenaar IQ, Besselink MGH, Verhoef C; Collaborators. Factors associated with failure to rescue after liver resection and impact on hospital variation: a nationwide population-based study.

HPB (Oxford). 2021 Apr 30:S1365-182X(21)00120-9. doi: 10.1016/j.hpb.2021.04.020. PMID: 34090804

Romeijn MM, Schellekens J, Bonouvrie DS, Janssen L, van Dielen FMH, Leclercq WKG, van de Wal M. 
Emotional eating as predictor of weight loss 2 years after Roux-en-Y gastric bypass.

Clin Obes. 2021 May 30:e12458. doi: 10.1111/cob.12458. PMID: 34053188

Kolen AM, Romeijn MM, Holthuijsen DDB, Janssen L, Greve JWM, Leclercq WKG, van Dielen FMH.

Current preoperative strategies applied in the Dutch bariatric centers: A national survey. Clin Obes. 2021 May 24:e12461. doi: 10.1111/cob.12461. PMID: 34028197

Romeijn MM, Bongers M, Holthuijsen DDB, Janssen L, van Dielen FMH, Anema HJR, Leclercq WKG. Place Work on a Scale: What Do We Know About the Association Between Employment Status and Weight Loss Outcomes After Bariatric Surgery? Obes Surg. 2021 May 21. doi: 10.1007/s11695-021-05388-9. PMID: 34018099

Romeijn MM, van Hoef S, Janssen $L$, van de Pas $K G H$, van Dielen FMH, Luijten AAPM, Göttgens KWA, Greve JWM, Leclercq WKG.

Correction to: Comparison of Linear Versus Circular-Stapled Gastroenterostomy in Rouxen-Y Gastric Bypass: a Nationwide Population-Based Cohort Study.

Obes Surg. 2021 May 14. doi: 10.1007/s11695-021-05474-y.

Erratum for: Obes Surg. 2021 Apr 27;: PMID: 33990850

Elfrink AKE, Kok NFM, den Dulk M, Buis Cl, Kazemier G, ljzermans JNM, Lam HD, Hagendoorn J, van den Boezem PB, Ayez N, Zonderhuis BM, Lips DJ, Leclercq WKG, Kuhlmann KFD, Marsman HA, Verhoef C, Patijn GA, Grünhagen DJ, Klaase JM; Collaborators; Dutch Hepato Biliary Audit Group.

Short-term postoperative outcomes after liver resection in the elderly patient: a nationwide population- based study.

HPB (Oxford). 2021 Mar 19:S1365-182X(21)00067-8. doi: 10.1016/j.hpb.2021.03.002.

PMID: 33926842

Romeijn MM, van Hoef $S$, Janssen $L$, van de Pas $K G H$, van Dielen FMH, Luijten AAPM, Göttgens KWA, Greve JWM, Leclercq WKG.

Comparison of Linear versus Circular-Stapled Gastroenterostomy in Roux-en-Y Gastric Bypass: A Nationwide Population-Based Cohort Study.

Obes Surg. 2021 Apr 27. doi: 10.1007/s11695-021-05436-4.

Erratum in: Obes Surg. 2021 May 14;: PMID: 33905068

Sharma A, Minh Duc NT, Luu Lam Thang T, Nam NH, Ng SJ, Abbas KS, Huy NT, Marušić A, Paul CL, Kwok J, Karbwang J, de Waure C, Drummond FJ, Kizawa Y, Taal E, Vermeulen J, Lee GHM, Gyedu A, To KG, Verra ML, Jacqz-Aigrain ÉM, Leclercq WKG, Salminen ST, 
Sherbourne CD, Mintzes B, Lozano S, Tran US, Matsui M, Karamouzian M.

A Consensus-Based Checklist for Reporting of Survey Studies (CROSS).

J Gen Intern Med. 2021 Apr 22. doi: 10.1007/s11606-021-06737-1. PMID: 33886027

Corten BJGA, de Savornin Lohman EAJ, Leclercq WKG, Roumen RMH, Verhoeven R, van Zwam PH, de Reuver PR, Dejong CHC, Slooter GD.

Should all gallbladders be examined routinely or selectively by microscopy after cholecystectomy? Population-based Dutch study over a decade.

Br J Surg. 2021 Apr 5;108(3):e131-e132. doi: 10.1093/bjs/znaa161. PMID: 33793735

\section{COVIDSurg Collaborative, GlobalSurg Collaborative.}

SARS-CoV-2 vaccination modelling for safe surgery to save lives: data from an international prospective cohort study.

Br J Surg. 2021 Mar 24:znab101. doi: 10.1093/bjs/znab101. PMID: 33761533

Romeijn MM, Holthuijsen DDB, Kolen AM, Janssen L, Schep G, van Dielen FMH, Leclercq WKG.

The effect of additional protein on lean body mass preservation in post-bariatric surgery patients: a systematic review.

Nutr J. 2021 Mar 14;20(1):27. doi: 10.1186/s12937-021-00688-3. PMID: 33715633

\section{COVIDSurg Collaborative; GlobalSurg Collaborative.}

Timing of surgery following SARS-CoV-2 infection: an international prospective cohort study. Anaesthesia. 2021 Jun;76(6):748-758. doi: 10.1111/anae.15458. Epub 2021 Mar 9. PMID: 33690889

Romeijn MM, Uittenbogaart M, Janssen L, van Dielen FMH, Leclercq WKG. Gewichtstoename na bariatrische chirurgie Ned Tijdschr Geneeskd. 2020 Oct 29;164:D5339. Dutch. PMID: 33331734

Elfrink AKE, Haring MPD, de Meijer VE, ljzermans JNM, Swijnenburg RJ, Braat AE, Erdmann Jl, Terkivatan T, Te Riele WW, van den Boezem PB, Coolsen MME, Leclercq WKG, Lips DJ, de Wilde RF, Kok NFM, Grünhagen DJ, Klaase JM; Dutch Hepato Biliary Audit Group. Surgical outcomes of laparoscopic and open resection of benign liver tumours in the Netherlands: a nationwide analysis.

HPB (Oxford). 2020 Dec 29:S1365-182X(20)32399-6. doi:10.1016/j.hpb.2020.12.003. PMID: 33478819 
Bonouvrie DS, Boerma EJ, van Dielen FMH, Leclercq WKG.

Internal herniation during pregnancy after banded Roux-en-Y gastric bypass: a unique location.

BMJ Case Rep. 2020 Dec 9;13(12):e236798. doi: 10.1136/bcr-2020-236798. PMID: 33298482

\section{Singhal R, Tahrani AA, Ludwig C, Mahawar K; GENEVA collaborators.}

Global 30-day outcomes after bariatric surgery during the COVID-19 pandemic (GENEVA): an international cohort study.

Lancet Diabetes Endocrinol. 2021 Jan;9(1):7-9. doi: 10.1016/\$2213-8587(20)30375-2. Epub 2020 Nov 27. PMID: 33253631

Elfrink AKE, Nieuwenhuizen S, van den Tol MP, Burgmans MC, Prevoo W, Coolsen MME, van den Boezem PB, van Delden OM, Hagendoorn J, Patijn GA, Leclercq WKG, Liem MSL, Rijken AM, Verhoef C, Kuhlmann KFD, Ruiter SJS, Grünhagen DJ, Klaase JM, Kok NFM, Meijerink MR, Swijnenburg RJ; Dutch Hepato Biliary Audit Group; Collaborators. Hospital variation in combined liver resection and thermal ablation for colorectal liver metastases and impact on short-term postoperative outcomes: a nationwide populationbased study.

HPB (Oxford). 2021 Jun;23(6):827-839. doi: 10.1016/j.hpb.2020.10.003. Epub 2020 Nov 18. PMID: 33218949

Elfrink AKE, van Zwet EW, Swijnenburg RJ, den Dulk M, van den Boezem PB, Mieog JSD, Te Riele WW, Patijn GA, Leclercq WKG, Lips DJ, Rijken AM, Verhoef C, Kuhlmann KFD, Buis Cl, Bosscha K, Belt EJT, Vermaas M, van Heek NT, Oosterling SJ, Torrenga H, Eker $\mathrm{HH}$, Consten ECJ, Marsman HA, Wouters MWJM, Kok NFM, Grünhagen DJ, Klaase JM; Dutch Hepato Biliary Audit Group.

Case-mix adjustment to compare nationwide hospital performances after resection of colorectal liver metastases.

Eur J Surg Oncol. 2021 Mar;47(3 Pt B):649-659. doi: 10.1016/j.ejso.2020.10.016. Epub 2020 Oct 16. PMID: 33183927

Jonker PKC, van der Plas WY, Steinkamp PJ, Poelstra R, Emous M, van der Meij W, Thunnissen F, Bierman WFW, Struys MMRF, de Reuver PR, de Vries JPM, Kruijff S; Dutch

\section{Surgical COVID-19 Research Collaborative.}

Perioperative SARS-CoV-2 infections increase mortality, pulmonary complications, and thromboembolic events: A Dutch, multicenter, matched-cohort clinical study.

Surgery. 2021 Feb;169(2):264-274. doi: 10.1016/j.surg.2020.09.022. Epub 2020 Sep 24. PMID: 33158548 
Romeijn MM, Kolen AM, Holthuijsen DDB, Janssen L, Schep G, Leclercq WKG, van Dielen FMH. Effectiveness of a Low-Calorie Diet for Liver Volume Reduction Prior to Bariatric Surgery: a Systematic Review.

Obes Surg. 2021 Jan;31(1):350-356. doi: 10.1007/s11695-020-05070-6. Epub 2020 Nov 2. PMID: 33140292

Bellato V, Konishi T, Pellino G, An Y, Piciocchi A, Sensi B, Siragusa L, Khanna K, Pirozzi BM, Franceschilli M, Campanelli M, Efetov S, Sica GS; S-COVID Collaborative Group. Screening policies, preventive measures and in-hospital infection of COVID-19 in global surgical practices.

J Glob Health. 2020 Dec;10(2):020507. doi: 10.7189/jogh.10.020507. PMID: 33110590

An Y, Bellato V, Konishi T, Pellino G, Sensi B, Siragusa L, Franceschilli M, Sica GS; S-COVID Collaborative Group.

Surgeons' fear of getting infected by COVID19: A global survey.

Br J Surg. 2020 Oct;107(11):e543-e544. doi: 10.1002/bjs.11833. Epub 2020 Aug 18. PMID: 32808678

Bellato V, Konishi T, Pellino G, An Y, Piciocchi A, Sensi B, Siragusa L, Khanna K, Pirozzi BM, Franceschilli M, Campanelli M, Efetov S, Sica GS; S-COVID Collaborative Group. Impact of asymptomatic COVID-19 patients in global surgical practice during the COVID-19 pandemic.

Br J Surg. 2020 Sep;107(10):e364-e365. doi: 10.1002/bjs.11800. Epub 2020 Aug 6. PMID: 32767367

Bonouvrie DS, Janssen L, Niemarkt HJ, van Laar JOEH, Leclercq WKG, van Dielen FMH. Small bowel intussusception in pregnant women with a history of a Roux-en-Y gastric bypass: a case series and a systematic review of the literature.

Surg Obes Relat Dis. 2020 Oct;16(10):1603-1613. doi: 10.1016/j.soard.2020.05.019. Epub 2020 Jun 1. PMID: 32737008

Corten BJGA, Leclercq WKG, van Zwam PH, Roumen RMH, Dejong CH, Slooter GD. Method for adequate macroscopic gallbladder examination after cholecystectomy. Acta Chir Belg. 2020 Dec;120(6):442-450. doi: 10.1080/00015458.2020.1785219. Epub 2020 Jul 23. PMID: 32701051 
Bonouvrie DS, van der Woude DAA, Uittenbogaart M, Luijten AAPM, van Dielen FMH, Niemarkt HJ, van Laar JOEH, Leclercq WKG.

The Acute Abdomen in Pregnant Women After Roux-en-Y Gastric Bypass: Encouraging Results from a National Referral Centre.

Obes Surg. 2020 Oct;30(10):4029-4037. doi: 10.1007/s11695-020-04833-5. Epub 2020 Jul 15. PMID: 32671725

Nieuwenhuizen S, Puijk RS, van den Bemd B, Aldrighetti L, Arntz M, van den Boezem PB, Bruynzeel AME, Burgmans MC, de Cobelli F, Coolsen MME, Dejong CHC, Derks S, Diederik A, van Duijvendijk P, Eker HH, Engelsman AF, Erdmann JI, Fütterer JJ, Geboers B, Groot G, Haasbeek CJA, Janssen JJ, de Jong KP, Kater GM, Kazemier G, Kruimer JWH, Leclercq WKG, van der Leij C, Manusama ER, Meier MAJ, van der Meijs BB, Melenhorst MCAM, Nielsen K, Nijkamp MW, Potters FH, Prevoo W, Rietema FJ, Ruarus AH, Ruiter SJS, Schouten EAC, Serafino GP, Sietses C, Swijnenburg RJ, Timmer FEF, Versteeg KS, Vink T, de Vries JJ, de Wilt JHW, Zonderhuis BM, Scheffer HJ, van den Tol PMP, Meijerink MR. Resectability and Ablatability Criteria for the Treatment of Liver Only Colorectal Metastases: Multidisciplinary Consensus Document from the COLLISION Trial Group.

Cancers (Basel). 2020 Jul 3;12(7):1779. doi: 10.3390/cancers12071779. PMID: 32635230

Romeijn MM, Leclercq WKG, Luijten AAPM, Janssen L, van Dielen FMH.

Banded Roux-en-Y gastric bypass in patients with super morbid obesity (BRandY-study): protocol of a cohort study with 10 year follow-up.

BMC Surg. 2020 Jun 5;20(1):122. doi: 10.1186/s12893-020-00784-x. PMID: 32503510

Bonouvrie DS, Beamish AJ, Leclercq WKG, van Mil EGAH, Luijten AAPM, Hazebroek EJ, Vreugdenhil ACE, Olbers T, van Dielen FMH.

Laparoscopic roux-en-Y gastric bypass versus sleeve gastrectomy for teenagers with severe obesity - TEEN-BEST: study protocol of a multicenter randomized controlled trial.

BMC Surg. 2020 Jun 3;20(1):117. doi: 10.1186/s12893-020-00778-9. PMID: 32493359

\section{COVIDSurg Collaborative.}

Mortality and pulmonary complications in patients undergoing surgery with perioperative SARS-CoV-2 infection: an international cohort study.

Lancet. 2020 Jul 4;396(10243):27-38. doi: 10.1016/S0140-6736(20)31182-X. Epub 2020

May 29. Erratum in: Lancet. 2020 Jun 9;: PMID: 32479829 
Elfrink AKE, Pool M, van der Werf LR, Marra E, Burgmans MC, Meijerink MR, den Dulk $M$, van den Boezem PB, Te Riele WW, Patijn GA, Wouters MWJM, Leclercq WKG, Liem MSL, Gobardhan PD, Buis Cl, Kuhlmann KFD, Verhoef C, Besselink MG, Grünhagen DJ, Klaase JM, Kok NFM; the Dutch Hepato-Biliary Audit Group.

Preoperative imaging for colorectal liver metastases: a nationwide population- based study.

BJS Open. 2020 Aug;4(4):605-621. doi: 10.1002/bjs5.50291. Epub 2020 May 6. PMID: 32374497

Jansen CMAH, Bonouvrie DS, Jacobs MLYE, Janssen N, Leclercq WKG, Scheltinga MRM, Roumen RMH. Chronic Abdominal Pain After Previous Bariatric Surgery: Consider the Abdominal Wall.

Obes Surg. 2020 Aug;30(8):2942-2948. doi: 10.1007/s11695-020-04629-7. PMID: 32337643

Elfrink AKE, Kok NFM, van der Werf LR, Krul MF, Marra E, Wouters MWJM, Verhoef C, Kuhlmann KFD, den Dulk M, Swijnenburg RJ, Te Riele WW, van den Boezem PB, Leclercq WKG, Lips DJ, Nieuwenhuijs VB, Gobardhan PD, Hartgrink HH, Buis Cl, Grünhagen DJ, Klaase JM; Dutch Hepato Biliary Audit Group; Collaborators.

Population-based study on practice variation regarding preoperative systemic chemotherapy in patients with colorectal liver metastases and impact on short- term outcomes.

Eur J Surg Oncol. 2020 Sep;46(9):1742-1755. doi: 10.1016/j.ejso.2020.03.221. Epub 2020 Apr 5. PMID: 32303416

Uittenbogaart M, de Witte $\mathrm{E}$, Romeijn MM, Luijten AAPM, van Dielen FMH, Leclercq WKG.

Primary and Secondary Nonresponse Following Bariatric Surgery: a Survey Study in Current Bariatric Practice in the Netherlands and Belgium.

Obes Surg. 2020 Sep;30(9):3394-3401. doi: 10.1007/s11695-020-04574-5. PMID: 32236909.

Olthof PB, Elfrink AKE, Marra E, Belt EJT, van den Boezem PB, Bosscha K, Consten ECJ, den Dulk M, Gobardhan PD, Hagendoorn J, van Heek TNT, IJzermans JNM, Klaase JM, Kuhlmann KFD, Leclercq WKG, Liem MSL, Manusama ER, Marsman HA, Mieog JSD, Oosterling SJ, Patijn GA, Te Riele W, Swijnenburg RJ, Torrenga H, van Duijvendijk P, Vermaas M, Kok NFM, Grünhagen DJ; Dutch Hepato Biliary Audit Group.

Volume-outcome relationship of liver surgery: a nationwide analysis.

Br J Surg. 2020 Jun;107(7):917-926. doi: 10.1002/bjs.11586. Epub 2020 Mar 24. PMID: 32207856 
Kalkdijk-Dijkstra AJ, van der Heijden JAG, van Westreenen HL, Broens PMA, Trzpis M, Pierie JPEN, Klarenbeek BR; FORCE Trial Group.

Pelvic floor rehabilitation to improve functional outcome and quality of life after surgery for rectal cancer: study protocol for a randomized controlled trial (FORCE trial).

Trials. 2020 Jan 28;21(1):112. doi: 10.1186/s13063-019-4043-7. PMID: 31992358

Taverne SB, Bonouvrie DS, Uittenbogaart M, Luijten AA, Niemarkt HJ, van Laar JO, van Dielen FM, Leclercq WK.

Guidelines Regarding Management of a Surgical Emergency During Pregnancy After Bariatric Surgery. Obes Surg. 2020 Mar;30(3):1126-1127. doi: 10.1007/s11695-01904325-1. PMID: 31848985.

Corten BJGA, Leclercq WKG, Roumen RMH, van Zwam PH, Dejong CH, Slooter GD. Histological examination of the gallbladder following routine cholecystectomy? A selective analysis is justified.

Eur J Surg Oncol. 2020 Apr;46(4 Pt A):572-576. doi: 10.1016/j.ejso.2019.11.497. Epub 2019 Nov 14. PMID: 31753427.

Corten BJGA, Leclercq WKG, Dercksen MW, van den Broek WT, van Zwam PH, Dejong $\mathrm{CH}$, Slooter GD. Paraganglion, a pitfall in diagnosis after regular cholecystectomy. Int J Surg Case Rep. 2019;65:205-208. doi: 10.1016/j.ijscr.2019.10.042. Epub 2019 Oct 28. PMID: 31731083

Leclercq WK, Uittenbogaart M, Niemarkt HJ, van Laar JO.

Pregnant patient with acute abdominal pain and previous bariatric surgery.

BMJ Case Rep. 2019 Aug 21;12(8):e228962. doi: 10.1136/bcr-2018-228962. PMID: 31439565

Corten BJGA, Leclercq WKG, Dejong CH, Roumen RMH, Slooter GD.

Selective Histological Examination After Cholecystectomy: An Analysis of Current Daily Practice in The Netherlands.

World J Surg. 2019 Oct;43(10):2561-2570. doi: 10.1007/s00268-019-05077-w. PMID: 31286186.

van der Poel MJ, Fichtinger RS, Bemelmans M, Bosscha K, Braat AE, de Boer MT, Dejong CHC, Doornebosch PG, Draaisma WA, Gerhards MF, Gobardhan PD, Gorgec B, Hagendoorn J, Kazemier G, Klaase J, Leclercq WKG, Liem MS, Lips DJ, Marsman HA, Mieog JSD, Molenaar QI, Nieuwenhuijs VB, Nota CL, Patijn GA, Rijken AM, Slooter GD, Stommel MWJ, Swijnenburg RJ, Tanis PJ, Te Riele WW, Terkivatan T, van den Tol PM, van 
den Boezem PB, van der Hoeven JA, Vermaas M, Abu Hilal M, van Dam RM, Besselink MG; Dutch Liver Collaborative Group.

Implementation and outcome of minor and major minimally invasive liver surgery in the Netherlands. HPB (Oxford). 2019 Dec;21(12):1734-1743. doi: 10.1016/j.hpb.2019.05.002. Epub 2019 Jun 21. PMID: 31235430.

Uittenbogaart M, Leclercq WK, Bonouvrie D, Romeijn MM, Luijten AA, Olde Damink SW, van Dielen FM, Rensen SS.

Diet-Induced Alteration of Microbiota and Development of Obesity, Nonalcoholic Fatty Liver Disease, and Diabetes: Study Protocol of a Prospective Study.

JMIR Res Protoc. 2019 Jun 19;8(6):e11553. doi: 10.2196/11553. PMID: 31219051

Uittenbogaart M, Leclercq WKG, Smeele P, van der Linden AN, Luijten AAPM, van Dielen $\mathrm{FMH}$.

Reliability and usefulness of upper gastro intestinal contrast studies to assess pouch size in patients with weight loss failure after Roux- en-Y gastric bypass.

Acta Chir Belg. 2020 Oct;120(5):329-333. doi: 10.1080/00015458.2019.1631625. Epub 2019 Jun 27. PMID: 31203729

den Bakker CM, Schaafsma FG, van der Meij E, Meijerink WJ, van den Heuvel B, Baan AH, Davids PH, Scholten PC, van der Meij S, van Baal WM, van Dalsen AD, Lips DJ, van der Steeg JW, Leclercq WK, Geomini PM, Consten EC, Schraffordt Koops SE, de Castro SM, van Kesteren PJ, Cense HA, Stockmann HB, Ten Cate AD, Bonjer HJ, Huirne JA, Anema JR. Electronic Health Program to Empower Patients in Returning to Normal Activities After General Surgical and Gynecological Procedures: Intervention Mapping as a Useful Method for Further Development.

J Med Internet Res. 2019 Feb 6;21(2):e9938. doi: 10.2196/jmir.9938. PMID: 30724740

Bonouvrie DS, Uittenbogaart M, Luijten AAPM, van Dielen FMH, Leclercq WKG.

Reply to Letter to the Editor: Measuring and Defining Response and Non-response After Bariatric Surgery.

Obes Surg. 2019 May;29(5):1651-1652. doi: 10.1007/s11695-019-03747-1. PMID: 30707353

Bonouvrie DS, Uittenbogaart M, Luijten AAPM, van Dielen FMH, Leclercq WKG.

Lack of Standard Definitions of Primary and Secondary (Non)responders After Primary Gastric Bypass and Gastric Sleeve: a Systematic Review.

Obes Surg. 2019 Feb;29(2):691-697. doi: 10.1007/s11695-018-3610-4. PMID: 30554304 
Abel EEDH, Cup EHC, Lanser A, Leclercq WKG, Raaphorst J, Padberg GW, Satink T, Voermans NC.

Experiences with bariatric surgery in patients with facioscapulohumeral dystrophy and myotonic dystrophy type 1: A qualitative study.

Neuromuscul Disord. 2018 Nov;28(11):938-946. doi: 10.1016/j.nmd.2018.09.003. Epub 2018 Sep 19. PMID: 30342904

Ponten JEH, Leclercq WKG, Lettinga T, Heemskerk J, Konsten JLM, Bouvy ND, Nienhuijs SW.

Mesh OR Patch for Hernia on Epigastric and Umbilical Sites (MORPHEUS-Trial): The Complete Two-year Follow-up.

Ann Surg. 2019 Jul;270(1):33-37. doi: 10.1097/SLA.0000000000003086. PMID: 30339623

Burger BB, Veerman MM, Tellier MA, Leclercq WKG, Mouës-Vink CM, Werker PMN. Insight in Information Provision Prior to Obtaining Surgical Informed Consent-by Audiotaping Outpatient Consultations.

World J Surg. 2019 Feb;43(2):425-430. doi: 10.1007/s00268-018-4804-6. PMID: 30267290

Leclercq WKG, van Sambeek A, Uittenbogaart M, Niemarkt HJ, Bongers MY, van Laar JOEH.

Buikpijn bij een zwangere die een maagverkleining heeft gehad

Ned Tijdschr Geneeskd. 2018 Jul 27;162:D2616. Dutch. PMID: 30182623

Veerman MM, van der Woude LA, Tellier MA, Legemaate J, Scheltinga MR, Stassen LPS,

\section{Leclercq WKG.}

A decade of litigation regarding surgical informed consent in the Netherlands.

Patient Educ Couns. 2019 Feb;102(2):340-345. doi: 10.1016/j.pec.2018.08.031. Epub 2018 Aug 29. PMID: 30173877

Corten BJGA, Alexander S, van Zwam PH, Leclercq WKG, Roumen RMH, Slooter GD. Outcome of Surgical Inspection of the Gallbladder in Relation to Final Pathology. J Gastrointest Surg. 2019 Jun;23(6):1130-1134. doi: 10.1007/s11605-018-3921-8. Epub 2018 Aug 21. PMID: 30132295

van der Meij E, Anema JR, Leclercq WKG, Bongers MY, Consten ECJ, Schraffordt Koops SE, van de Ven PM, Terwee CB, van Dongen JM, Schaafsma FG, Meijerink WJHJ, Bonjer HJ, Huirne JAF. 
Personalised perioperative care by e-health after intermediate-grade abdominal surgery: a multicentre, single-blind, randomised, placebo-controlled trial.

Lancet. 2018 Jul 7;392(10141):51-59. doi: 10.1016/S0140-6736(18)31113-9. Epub 2018 Jun 21. PMID: 29937195

Peters EG, Smeets BJJ, Nors J, Back CM, Funder JA, Sommer T, Laurberg S, Løve US, Leclercq WKG, Slooter GD, de Vries Reilingh TS, Wegdam JA, Nieuwenhuijzen GAP, Hiligsmann M, Buise MP, Buurman WA, de Jonge WJ, Rutten HJT, Luyer MDP.

Perioperative lipid-enriched enteral nutrition versus standard care in patients undergoing elective colorectal surgery (SANICS II): a multicentre, double-blind, randomised controlled trial. Lancet Gastroenterol Hepatol. 2018 Apr;3(4):242-251. doi: 10.1016/S2468-1253(18)300311. Epub 2018 Feb 14. PMID: 29426699

Ponten JEH, Leenders BJM, Leclercq WKG, Lettinga T, Heemskerk J, Konsten JLM, Castelijns PSS, Nienhuijs SW.

Mesh Versus Patch Repair for Epigastric and Umbilical Hernia (MORPHEUS Trial); One-Year Results of a Randomized Controlled Trial.

World J Surg. 2018 May;42(5):1312-1320. doi: 10.1007/s00268-017-4297-8. PMID: 29026977

Mommers EHH, Leenders BJM, Leclercq WKG, de Vries Reilingh TS, Charbon JA.

A modified Chevrel technique for ventral hernia repair: long-term results of a single centre cohort.

Hernia. 2017 Aug;21(4):591-600. doi: 10.1007/s10029-017-1602-2. Epub 2017 Apr 13. PMID: 28409277

Uittenbogaart M, Luijten AAPM, van Dielen FMH, Leclercq WKG.

Long-Term Results of Laparoscopic Sleeve Gastrectomy for Morbid Obesity: 5 to 8-Year Results. Obes Surg. 2017 Jun;27(6):1624. doi: 10.1007/s11695-017-2655-0. PMID: 28357618

van der Meij E, Huirne JA, Bouwsma EV, van Dongen JM, Terwee CB, van de Ven PM, den Bakker CM, van der Meij S, van Baal WM, Leclercq WK, Geomini PM, Consten EC, Schraffordt Koops SE, van Kesteren PJ, Stockmann HB, Ten Cate AD, Davids PH, Scholten PC, van den Heuvel B, Schaafsma FG, Meijerink WJ, Bonjer HJ, Anema JR.

Substitution of Usual Perioperative Care by eHealth to Enhance Postoperative Recovery in Patients Undergoing General Surgical or Gynecological Procedures: Study Protocol of a Randomized Controlled Trial.

JMIR Res Protoc. 2016 Dec 21;5(4):e245. doi: 10.2196/resprot.6580. PMID: 28003177 
Leclercq WK, Sloot S, Keulers BJ, Houterman S, Legemaate J, Veerman M, Thomas L, Scheltinga MR.

Challenging the knowledge base and skillset for providing surgical consent by orthopedic and plastic surgeons in the Netherlands: an identified area of improvement in patient safety.

Patient Saf Surg. 2016 Oct 22;10:21. doi: 10.1186/s13037-016-0110-0. PMID: 27790289

Uittenbogaart M, van Dielen F, Leclercq W.

Assessment of pouch and stoma size in weight loss failure after Roux-en-Y gastric bypass. Surg Obes Relat Dis. 2016 Jan;12(1):210. doi: 10.1016/j.soard.2015.08.513. Epub 2015 Aug 29. PMID: 26439840

Uittenbogaart M, Leclercq WK, Luijten AA, van Dielen FM.

Laparoscopic Adjustable Gastric Banding After Failed Roux-En-Y Gastric Bypass.

Obes Surg. 2017 Feb;27(2):381-386. doi: 10.1007/s1 1695-016-2283-0. PMID: 27412671

Leclercq WK, Sloot S, Keulers BJ, Legemaate J, Scheltinga MR.

Preoperatieve dossiervoering kan beter: nieuw informed-consentformulier helpt arts én patiënt

Ned Tijdschr Geneeskd. 2014;158:A7109. Dutch. PMID: 24823852

\section{Leclercq WK.}

An innovative technique in colorectal surgery.

Eur J Surg Oncol. 2013 Jun;39(6):666. doi: 10.1016/j.ejso.2013.03.016. Epub 2013 Apr

8. PMID: 23579174

Leclercq WK, Keulers BJ, Houterman S, Veerman M, Legemaate J, Scheltinga MR.

A survey of the current practice of the informed consent process in general surgery in the Netherlands. Patient Saf Surg. 2013 Jan 21;7(1):4. doi: 10.1186/1754-9493-7-4. PMID: 23336609

Leclercq WK, Keulers BJ, Scheltinga MR, Spauwen PH, van der Wilt GJ.

A review of surgical informed consent: past, present, and future. A quest to help patients make better decisions.

World J Surg. 2010 Jul;34(7):1406-15. doi: 10.1007/s00268-010-0542-0. PMID: 20372902 
Leclercq WK, Roumen RM.

Een vrouw met acute pijn in de kuit. Achillespeesruptuur [A woman with acute pain in the calf. Achilles tendon rupture].

Ned Tijdschr Geneeskd. 2009 Jan 10;153(1-2):44. Dutch. PMID: 19198212

de Vries B, Köhl J, Leclercq WK, Wolfs TG, van Bijnen AA, Heeringa P, Buurman WA. Complement factor $\mathrm{C} 5$ a mediates renal ischemia-reperfusion injury independent from neutrophils.

J Immunol. 2003 Apr 1;170(7):3883-9. doi: 10.4049/jimmunol.170.7.3883. PMID: 12646657

Non- Pubmed

Leclercq WKG, Bonouvrie DS, Dohmen CEJM, Uittenbogaart M, Luijten AAPM, Legemaate J, Stassen LPS, van Dielen FMH.

Preoperative education and informed consent in young adults undergoing bariatric surgery: Patient perspectives on current practice

Bariatric Surgical Practice and Patient Care 2021 Mar 15; 16(1)41-47

M. Uittenbogaart, W. Leclercq, A. Luijten, F. van Dielen.

Secundair plaatsen van een maagband bij patiënten met gewichtstoename na een Rouxen-Y gastric bypass.

Medisch Journaal, jaargang 2015,3 - 124.

Keulers BJ, Veerman M, Leclercq WKG, Winters H.

Kostenbesparing en kwaliteitswinst door een online interactief patiëntenvoorlichtingsprogramma.

Ned Tijdschr Plastische Chirurgie 2010 (1):10-11

Leclercq WKG, Braam PFCM, Rasenberg E, Roumen RMH.

Beeldspraak: Een mannelijke vagina?

Medisch Journaal 2006; 35(2): 86-87.

Re-publicatie "Operationeel" tijdschrift landelijke vereniging voor operatieassistenten 2007

Leclercq WKG, Nanlohy-Manuhutu E, Levens W, Zwiers W, Braam P.

Veranderende inzichten in de operatieve behandeling van beperkt niercelcarcinoom.

Medisch Journaal 2005; 34(2): 55-58.

Re-publicatie "Operationeel" tijdschrift landelijke vereniging voor operatieassistenten 2005 



\section{CURRICULUM VITAE}

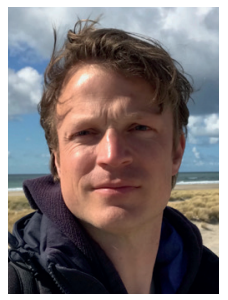

Wouter Leclercq werd geboren op 13 oktober 1978 in Gouda. Hij groeide met zijn uit Vlaanderen afkomstige ouders op in Boskoop, Asten en Roosendaal.

Met zijn gymnasium diploma op zak begon hij in 1997 in Maastricht aan de studie Gezondheidswetenschappen. Gelukkig kon hij na een jaar met propedeuse de overstap maken richting geneeskunde. Wouter was vooral student en zeer actief op sociaal vlak binnen zijn dispuut Perikles; als werkpaard in de bevoorrading van en bediening in kroegen en ook nog medische werkzaamheden binnen het transplantatieteam van de afdeling heelkunde als student-assistent multi-orgaan donatie (Kidneyracer) waarvoor hij vele reizen in binnen- en buitenland mocht maken.

Studeren deed hij in de beperkte tijd die overbleef, waarbij hij studie en sociale activiteiten bleef combineren. Zo maakte hij een reis rond de wereld door een stage kinderchirurgie in Brisbane Australië te volbrengen. Terug in Nederland was de teleurstelling echter groot toen kinderchirurgie in Australië niet te vergelijken bleek met de Nederlandse situatie.

Na zijn coschappen kreeg Wouter de kans om in het Máxima MC te starten als ANIO urologie en binnen 1 jaar werd hij aangenomen voor de opleiding urologie waarbij hij mocht starten met de vooropleiding in het Máxima MC.

De vooropleiding heelkunde beviel zeer goed. Zo zeer dat Wouter zijn hoofd op het hakblok legde en de overstap maakte naar de chirurgie. Na 5 jaar Máxima MC en 1 jaar academische vorming in het Radboud in Nijmegen bij o.a. professor van Laarhoven werd hij in 2012 algemeen chirurg, gecertificeerd chirurg-oncoloog en gastro-intestinaal chirurg onder eindverantwoording van Rudi Roumen en Marc Scheltinga. Na 2 jaar hard werken als fellow en Europees erkend chirurg-oncoloog, werd hij in december 2014 opgenomen in de maatschap, later MSB de Medici van het Máxima MC. Onderzoek kwam tussen alle bedrijven èn het gewone leven door.

Momenteel is Wouter gefocust op lever-, bijnier- en neuroendocriene en colontumoren, bariatrische en buikwand pathologie. Hij is plaatsvervangend opleider, lid van het bestuur Máxima Oncologisch Centrum (MOC), gastoperateur in het pancreasteam van het Catharina Ziekenhuis Eindhoven, begeleidt meerdere promovendi en publiceert met enige regelmaat op diverse terreinen binnen de chirurgie.

Hij is bovenal de trotse papa van Eva (2014) en Stijn (2016). 


